Prepared in cooperation with the U.S. Bureau of Reclamation

\title{
One-Water Hydrologic Flow Model (MODFLOW-OWHM)
}

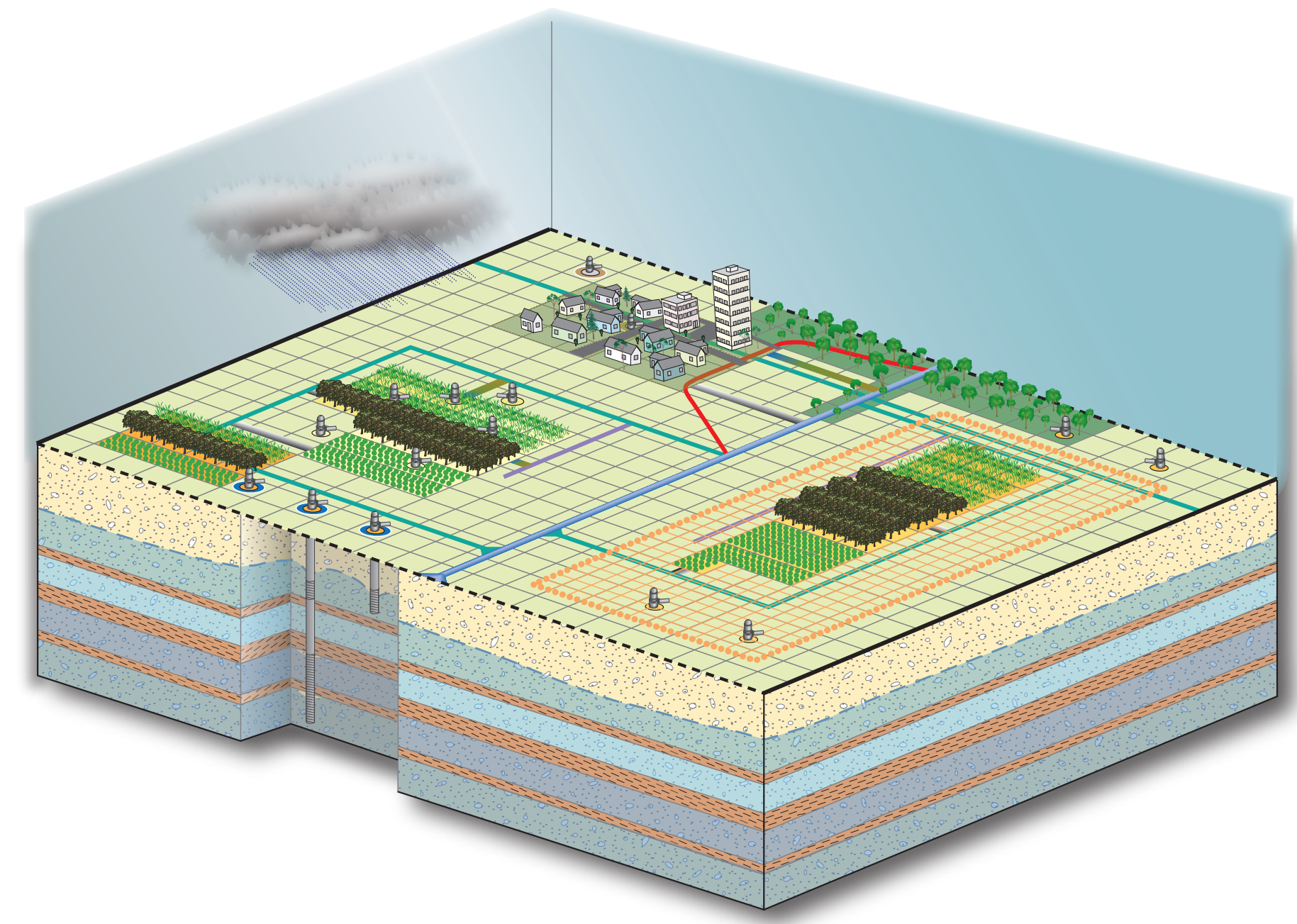

Chapter 51 of

Section A, Groundwater

Book 6, Modeling Techniques

Techniques and Methods 6-A51

U.S. Department of the Interior

U.S. Geological Survey 
Cover. Generalized view of the model domain. 


\section{One-Water Hydrologic Flow Model (MODFLOW-OWHM)}

By R.T. Hanson', Scott E. Boyce', Wolfgang Schmid",3, Joseph D. Hughes', Steffen M. Mehl ${ }^{1,4}$, Stanley A. Leake ${ }^{1}$, Thomas Maddock III ${ }^{2}$, and Richard G. Niswonger ${ }^{1}$

${ }^{1}$ U.S. Geological Survey

${ }^{2}$ University of Arizona

${ }^{3}$ Commonwealth Scientific and Industrial Research Organization

${ }^{4}$ California State University at Chico

In cooperation with the U.S. Bureau of Reclamation

Techniques and Methods 6-A51 


\title{
U.S. Department of the Interior SALLY JEWELL, Secretary
}

\section{U.S. Geological Survey Suzette M. Kimball, Acting Director}

\author{
U.S. Geological Survey, Reston, Virginia: 2014
}

For more information on the USGS - the Federal source for science about the Earth, its natural and living resources, natural hazards, and the environment, visit http://www.usgs.gov or call 1-888-ASK-USGS.

For an overview of USGS information products, including maps, imagery, and publications, visit http://www.usgs.gov/pubprod

To order this and other USGS information products, visit http://store.usgs.gov

Any use of trade, firm, or product names is for descriptive purposes only and does not imply endorsement by the U.S. Government.

Although this information product, for the most part, is in the public domain, it also may contain copyrighted materials as noted in the text. Permission to reproduce copyrighted items must be secured from the copyright owner.

Suggested citation:

Hanson, R.T., Boyce, S.E., Schmid, Wolfgang, Hughes, J.D., Mehl, S.M., Leake, S.A., Maddock, Thomas, III, and Niswonger, R.G., 2014, One-Water Hydrologic Flow Model (MODFLOW-OWHM): U.S. Geological Survey Techniques and Methods 6-A51, 120 p., http://dx.doi.org/10.3133/tm6A51.

ISSN 2328-7055 (online) 


\section{Preface}

This report presents a computer program for simulating the conjunctive movement and use of surface water and groundwater in the U.S. Geological Survey (USGS) hydrologic model, MODFLOW-One-Water Hydrologic Flow Model (MF-OWHM).

All MODFLOW code developed by the U.S. Geological Survey is available for downloading over the internet from a U.S. Geological Survey software repository. The repository is accessible on the world wide web from the U.S. Geological Survey Water Resources Information web page at http://water.usgs.gov/ogw/modflow-owhm/

Although this program has been used by the USGS, no warranty, expressed or implied, is made by the authors, the USGS, or the United States Government as to the accuracy and functioning of the program and related program material. Nor shall the fact of distribution constitute any such warranty, and no responsibility is assumed by the authors or the USGS in connection therewith. Future applications, however, might reveal errors that were not detected in the test simulations. Users are requested to notify the U.S. Geological Survey of any errors found in this document or the computer program using the email address available on the website mentioned above. When any significant updates are made to either the MF-OWHM program or the documentation, these updates will be uploaded to the USGS website. Users are encouraged to check the website periodically and read the OWHM_ChangeLog.txt document. If you would like to be added to the MF-OWHM email list for software update notifications, please send an email to MF.OWHM@gmail.com

The computer program described herein consists, in part, of copyrighted scientific methodologies originally obtained from the copyright holder (Schmid, 2004). The copyright holder has granted full permission to quote, copy, and use these methods to the USGS and to the public. Requests for modification of copyrighted methods and for publication of such can be made to the copyright holder or to the address listed below. Whereas MF-OWHM (revision [rev.] 1.00) includes all of the features of MF-2005 (rev. 1.11), MF-LGR (rev 2.0), MF-NWT (rev 1.0.9), MF-SWR (rev 1.3), MF-SWI (rev 2.0)., we request that if you use this software that you also include proper citation to this document in any related reports, articles, or presentations. For a complete reference to all input features from all packages and processes

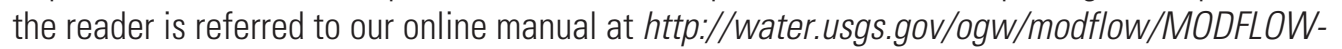
2005-Guide/or http://water.usgs.gov/ogw/modflow-owhm/Guide/index.html.

Correspondence regarding the report or program should be sent to:

U.S. Geological Survey

Water Resources Discipline

4165 Spruance Road, Suite 200

San Diego, CA 92101

Attention: Randall T. Hanson for MF-OWHM 


\section{Acknowledgments}

The development of MF-OWHM was supported by the San Joaquin River Restoration Project of the U.S. Bureau of Reclamation, the U.S. Geological Survey National Water Quality Assessment (NAWQA), the Delta Mendota Water Authority, and by various stakeholders participating with the USGS Cooperative Water Program Studies such as Pajaro Valley Water Management Agency. The authors also thank Larry Schneider of the USGS for illustrator work on the scientific illustrations. 


\section{Conversions Factors}

SI to Inch/Pound

\begin{tabular}{lll}
\hline \multicolumn{1}{c}{ Multiply } & \multicolumn{1}{c}{ By } & \multicolumn{1}{c}{ To obtain } \\
\hline centimeter $(\mathrm{m})$ & Length & \\
meter $(\mathrm{m})$ & 0.3937 & inch (in.) \\
\hline & 3.281 & foot $(\mathrm{ft})$ \\
\hline cubic meter per second $\left(\mathrm{m}^{3} / \mathrm{day}\right)$ & Flow rate & \\
\hline
\end{tabular}

Elevation, as used in this report, refers to distance above the vertical datum.

\section{Abbreviations}

Abbreviations, acronyms, and variables are defined as follows unless already defined in the FMP1 or FMP2 user's guides (Schmid and others, 2006; Schmid and Hanson, 2009) and in user input instructions summarized in the appendixes.

\begin{tabular}{|c|c|}
\hline ASCII & American Standard Code for Information Interchange \\
\hline CIMIS & California Irrigation Management Information System \\
\hline ETR or $\mathrm{ET}_{\text {ref }}$ & Reference evapotranspiration flux [L/T] \\
\hline HYDMOD & Computer program for calculating hydgraph time series data for MODFLOW \\
\hline $\mathrm{K}_{\mathrm{c}}$ & Crop coefficient [-] \\
\hline MF2005 & MODFLOW-2005 \\
\hline MF2005-FMP2 & MODFLOW-2005 version 1.6 with the Farm Process version 2 \\
\hline MF-OWHM & MODFLOW-One Water Hydrologic Flow Model \\
\hline MNW1 & Multi-Node Well Package MNW1 \\
\hline MNW2 & Multi-Node Well Package MNW2 \\
\hline MULT & Multiplier Package \\
\hline SFR & $\begin{array}{l}\text { Streamflow Routing Package (SFR2 refers to the most recent published } \\
\text { version 2; note: current code GWF1SFR7.F refers to code version 7) }\end{array}$ \\
\hline SUB & Subsidence Package \\
\hline UZF & Unsaturated Zone Flow Package \\
\hline ZONEBUDGET & Computer program for calculating subregional water budgets for MODFLOW \\
\hline
\end{tabular}




\section{Contents}

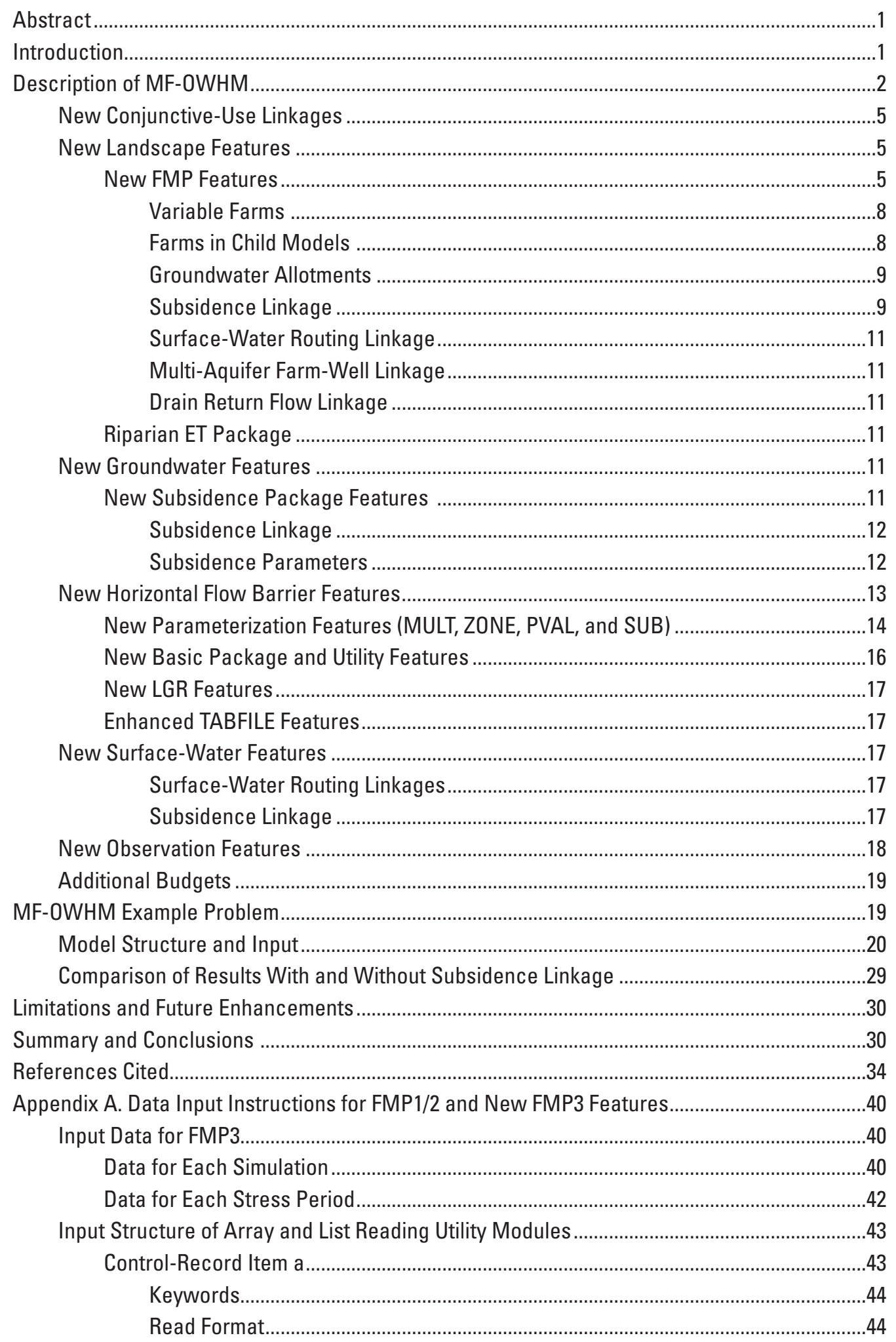




\section{Contents-Continued}

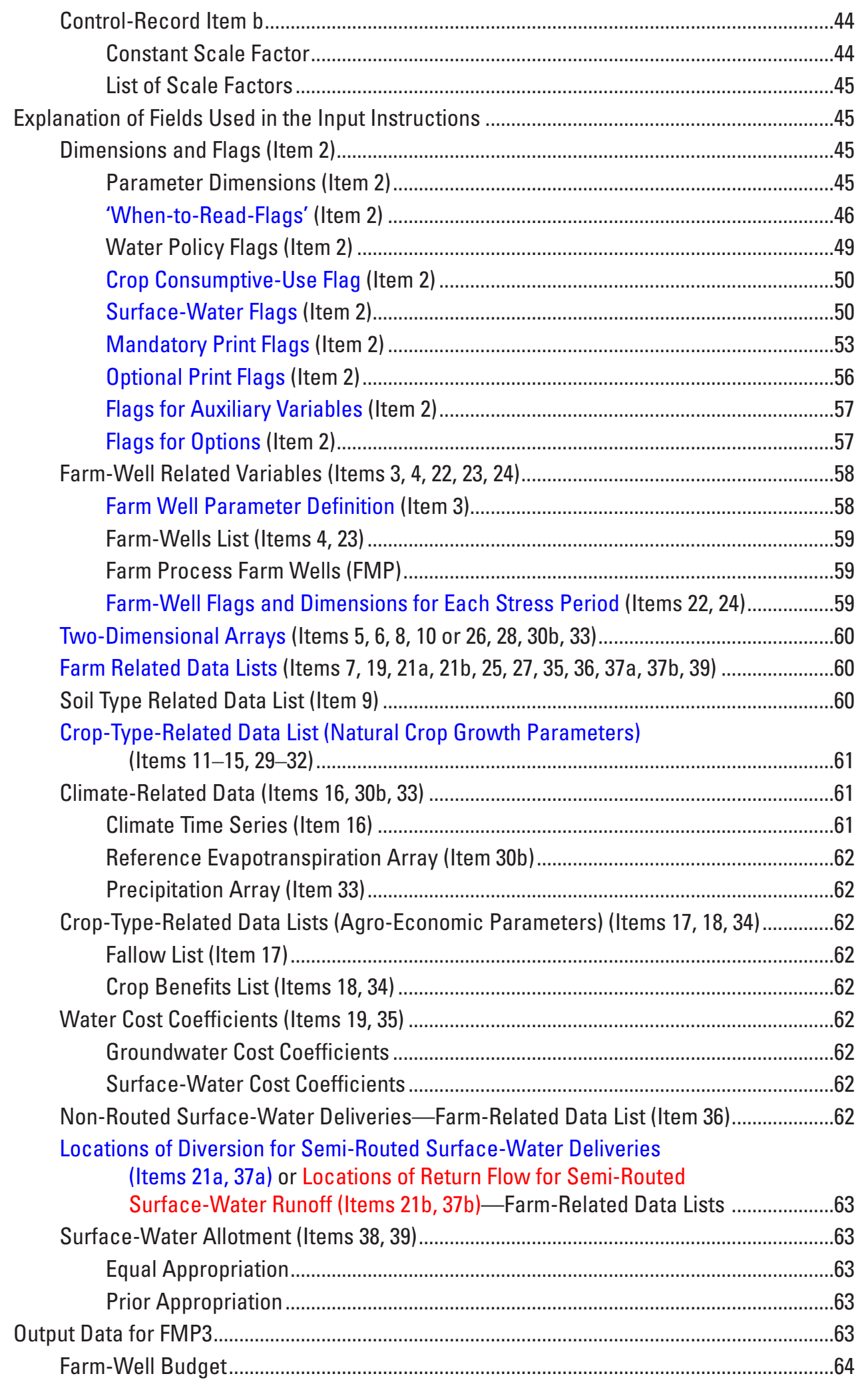




\section{Contents-Continued}

Farm Net-Recharge Budget......................................................................................64

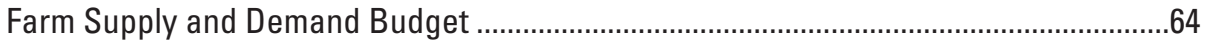

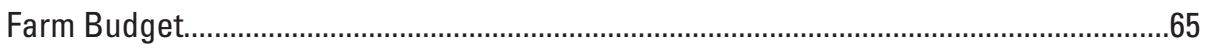

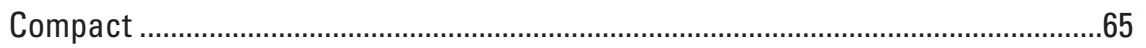

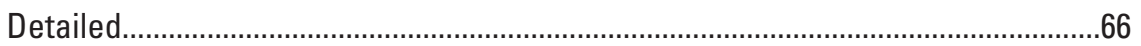

Routing Information for Farm Deliveries and Runoff Returnflows .................................67

Optimized Flow Rates and Optimized Acreage of Farms ................................................68

Budgets at Points of Diversion from the River and Farm Diversion ................................69

Appendix B. Subsidence Package Linkages and Parameters (SUB) ............................................70

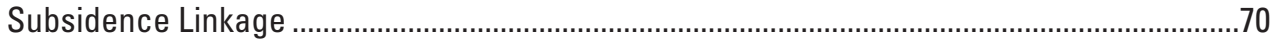

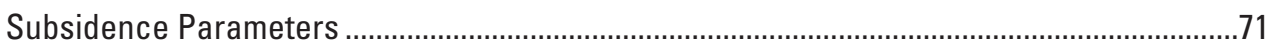

Explanation of Parameter Fields Used in Input Instructions ....................................................73

Appendix C. Enhancements to the Horizontal Flow Barrier Package (HFB2) ...................................74

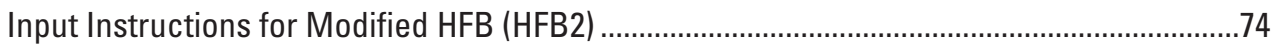

Explanation of Fields Used in HFB Package Input Instructions ................................................74

Appendix D: Multiplier Array (MULT) and Zone (ZONE) Enhancements ........................................77

Programmer Documentation for ExpressionParser...........................................................

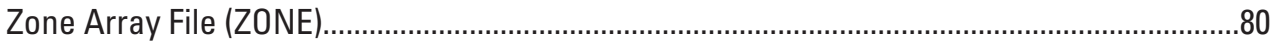

Appendix E. Summary of Upgrades to Other MODFLOW-OWHM Packages ..................................81

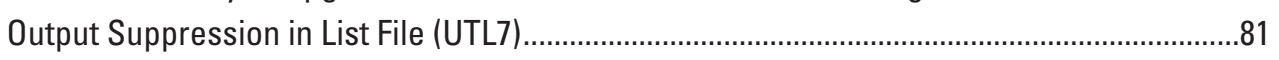

Groundwater Budget Summary Output (OC) .................................................................. 81

Maximum Number of Parameter, Instance, and Cluster Specification (BAS) ........................81

Parameter Values Output Arrays (PVAL/LPF/UPW) ............................................................

Rate Balance Percent Error Printing (BAS) ………........................................................

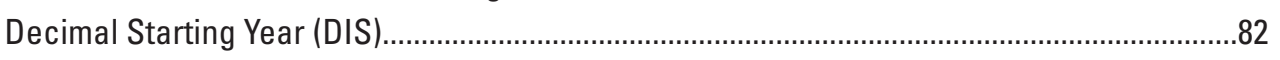

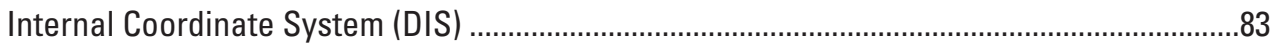

Drains with Return Flow Connections (DRT) ....................................................................83

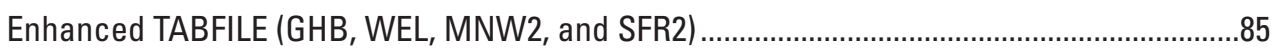

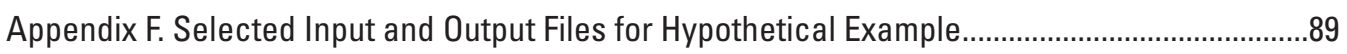




\section{Figures}

1. Diagram showing the types of interdependencies within MF2005-FMP2 and the related constraints on the supply and demand components............................................3

2. Diagram showing the interdependencies of flows within a hydrologic system simulated by MF-OWHM

3. Diagram showing the interdependencies within MF-OWHM for head, flow, and deformation-dependent supply-and-demand components of flow ...

4. Diagram showing fundamental connections for various components of a hydrologic model with effects of displacement on surface and subsurface features

5. Diagram showing the relation between surface and subsurface processes with linkage to land subsidence

6. Diagram showing groundwater-flow equation across an adjacent model cell face by using Darcy's Law

7. Diagram showing groundwater flow equation across a non-adjacent model cell face by using Darcy's Law

8. Graph showing an example of relationship between hydraulic conductivity and the percentage of coarse-grained deposits based on hydraulic conductivity end members and the exponent of the power mean, with selected values from aquifer tests or specific capacity tests in Pajaro Valley, California ...

9. Map showing the example model structure and features with $A$, plan view of model domain, grid resolution, boundary conditions, distribution of farms and farm wells, and streamflow routing network with points of diversion to farms and points of return flow from farms and surface-water canal traversing an urban area, $B$, block view of model layering, and $C$, simulated land subsidence

10. Grid showing $A$, crop and other vegetation distribution, and $B$, distribution of soils for MF-OWHM example model

11. Graphs showing $A$, crop coefficients, $B$, fractions of transpiration, $C$, fractions of evaporation related to precipitation, and $D$, fractions of evaporation related to irrigation through time for the 6 virtual crop types in the MF-OWHM example problem

12. Graph showing relation between the land surface and the water table with an unsaturated zone for the MF-OWHM example.

13. Graph showing differences in groundwater storage, interbed storage, and net flow into the model domain between using SUBLink and using SUB with no linkage

14. Graphs showing differences in streamflow $A$, diversions and $B$, return flows between using SUBLink and using SUB with no linkage

15. Graph showing differences in streamflow between using SUBLink and using just SUB with no linkage..

16. Diagram showing differences in stage, top, and bottom of canal using SUBLink and using just SUB with no linkage

B1. Generalized flow chart illustrating major components of the linkage between SUB, SFR, FMP, RIP, DRN, and LPF/UPW and the integration into MF-OWHM

C1. Flowchart of key subroutines in MF-OWHM used when HFB has transient faults and layer routing.

E1. Diagram showing potential rotation representations of a 10 row, 20 column model grid in the DIS file. 


\section{Tables}

A1. Summary of FMP3 input for data required for the entire period of simulation ................40

A2. Summary of FMP3 input for data required for each stress period during the entire

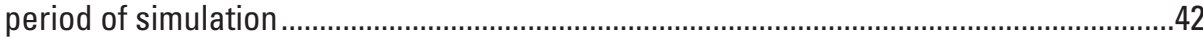




\title{
One-Water Hydrologic Flow Model (MODFLOW-OWHM)
}

\author{
By R.T. Hanson, Scott E. Boyce, Wolfgang Schmid, Joseph D. Hughes, Steffen M. Mehl, Stanley A. Leake, \\ Thomas Maddock III, and Richard G. Niswonger
}

\section{Abstract}

The One-Water Hydrologic Flow Model (MF-OWHM) is a MODFLOW-based integrated hydrologic flow model (IHM) that is the most complete version, to date, of the MODFLOW family of hydrologic simulators needed for the analysis of a broad range of conjunctive-use issues. Conjunctive use is the combined use of groundwater and surface water. MF-OWHM allows the simulation, analysis, and management of nearly all components of human and natural water movement and use in a physically-based supply-and-demand framework. MF-OWHM is based on the Farm Process for MODFLOW-2005 (MF-FMP2) combined with Local Grid Refinement (LGR) for embedded models to allow use of the Farm Process (FMP) and Streamflow Routing (SFR) within embedded grids. MF-OWHM also includes new features such as the Surface-water Routing Process (SWR), Seawater Intrusion (SWI), and Riparian Evapotrasnpiration (RIP-ET), and new solvers such as Newton-Raphson (NWT) and nonlinear preconditioned conjugate gradient (PCGN). This IHM also includes new connectivities to expand the linkages for deformation-, flow-, and head-dependent flows. Deformationdependent flows are simulated through the optional linkage to simulated land subsidence with a vertically deforming mesh. Flow-dependent flows now include linkages between the new SWR with SFR and FMP, as well as connectivity with embedded models for SFR and FMP through LGR. Head-dependent flows now include a modified Hydrologic Flow Barrier Package (HFB) that allows optional transient HFB capabilities, and the flow between any two layers that are adjacent along a depositional or erosional boundary or displaced along a fault. MF-OWHM represents a complete operational hydrologic model that fully links the movement and use of groundwater, surface water, and imported water for consumption by irrigated agriculture, but also of water used in urban areas and by natural vegetation. Supply and demand components of water use are analyzed under demand-driven and supply-constrained conditions. From large- to small-scale settings, MF-OWHM has the unique set of capabilities to simulate and analyze historical, present, and future conjunctive-use conditions. MF-OWHM is especially useful for the analysis of agricultural water use where few data are available for pumpage, land use, or agricultural information. The features presented in this IHM include additional linkages with SFR, SWR, Drain-Return (DRT), Multi-Node Wells (MNW1 and MNW2), and Unsaturated-Zone Flow (UZF). Thus, MF-OWHM helps to reduce the loss of water during simulation of the hydrosphere and helps to account for "all of the water everywhere and all of the time."

In addition to groundwater, surface-water, and landscape budgets, MF-OWHM provides more options for observations of land subsidence, hydraulic properties, and evapotranspiration (ET) than previous models. Detailed landscape budgets combined with output of estimates of actual evapotranspiration facilitates linkage to remotely sensed observations as input or as additional observations for parameter estimation or water-use analysis. The features of FMP have been extended to allow for temporally variable wateraccounting units (farms) that can be linked to land-use models and the specification of both surface-water and groundwater allotments to facilitate sustainability analysis and connectivity to the Groundwater Management Process (GWM).

An example model described in this report demonstrates the application of MF-OWHM with the addition of land subsidence and a vertically deforming mesh, delayed recharge through an unsaturated zone, rejected infiltration in a riparian area, changes in demand caused by deficiency in supply, and changes in multi-aquifer pumpage caused by constraints imposed through the Farm Process and the MNW2 Package, and changes in surface water such as runoff, streamflow, and canal flows through SFR and SWR linkages.

\section{Introduction}

The management of conjunctive use of water resources requires extending the capabilities to analyze the movement and use of water throughout the hydrologic cycle in a process-based context within applications of hydrologic simulation code MODFLOW-2005 (MF) (Harbaugh, 2005). This required the transformation of MF to a fully-coupled, integrated hydrologic model (IHM) that can simulate the complete movement and use of water across the land surface and within the surface-water and groundwater systems. This was first attempted by the development of two extensions of 
MF in GSFLOW (Markstrom and others, 2008) and MFFMP (Schmid and Hanson, 2009; Schmid and others, 2006; Schmid, 2004). While GSFLOW connects MODFLOW to the precipitation-runoff model PRMS (Leavesley and others, 1983) to simulate the coupling between groundwater flow and surface flows, it lacks a connection to human infrastructure and related landscape processes and a supply-and-demand structure needed for conjunctive-use analysis. This required the development of MF-FMP that provided a connection to both natural and anthropogenic uses of all the water all of the time throughout the simulated hydrosphere in the context of a supply-and-demand framework of movement and use. An additional comparison to other IHMs including MF-FMP was completed by Hanson and others (2010).

The simulation of all water use includes the application, consumption, and movement of water for natural vegetation, agriculture, and urban settings on the land surface (the uppermost surface of the hydrologic model, hereinafter referred to as the "landscape"). The movement and use of inflows and outflows derived from precipitation, surface water, and groundwater are facilitated within a fully coupled, processbased hydrologic simulation model through the integration of the Farm Process within MODFLOW-2005 (MF-FMP2).

The evolution of many specialized versions of MODFLOW has enhanced our capability to analyze a broader class of hydrologic settings and related water-resource issues. However, many hydrologic and environmental problems require a more complete version of MODFLOW in the context of an IHM that can address all of these components within one code. Typical problems related to conjunctive use not only include the movement and use of all of the water everywhere that are needed for a more complete accounting of water in the hydrosphere, but also the need to simulate coupling to many of the secondary effects that may become the controlling factors to resource development and sustainable management. These include groundwater-dependent ecosystems (GDEs), the combination of seawater intrusion and land subsidence throughout most alluvial coastal aquifers, salt and nutrient transport related to agricultural best management practices, as well as subgrid models maintained by local purveyors or within adjacent regions. Although multiple versions of MODFLOW are currently available, the analysis of conjunctive-use issues is prohibitive without running multiple models that contained some of the features needed to resolve the common problems related to conjunctive use. To overcome this deficiency, a more complete version of MODFLOW was developed that not only includes the new features of FMP3, but is extended to include the features of MF-LGR (Mehl and Hill, 2005), MF-NWT (Niswonger and others, 2011), MF-SWR (Hughes and others, 2012), and MF-SWI (Bakker and others, 2013). This new version, MF-OWHM, also includes new features such as the Riparian ET Package, RIP-ET (Maddock and others, 2012), a complete set of solvers that include GMG (Wilson and Naff, 2004) and PCGN (Naff and Banta, 2008), and new observation and parameter features for more complete parameter-estimation capability. MODFLOW-USG (Panday and others, 2013) is an alternative replacement to some of these MODFLOW versions, but it still lacks some of the nessecary features of an IHM to simulate and analyze issues related to conjunctive use and environmental issues and a supply-and-demand framework needed for sustainability and other forms of resource analysis that are difficult to preestimate input for beforehand. Similarly, GS-FLOW remains limited in its ability to include new features or connections to human infrastructure and connectivity to other models or a supply-and-demand framework that is essential for IHM analysis. Thus, MF-OWHM is a more complete version of MODFLOW that is a fully coupled integrated hydrologic model (IHM), which can address any combination of head-, flow-, and deformation-dependent flows needed to assess conjunctive use of all the water.

This report describes the new features and potential applications of the most complete version of MODFLOW (MF-OWHM) currently (version 1.0, August 2014) available from the USGS. Improvements made to the Farm Process and other key features are summarized in this report. In addition to instructions for use of the model, selected descriptions of the broader class of problems, issues, and analysis that can be addressed are provided. The examples and previous uses are used to demonstrate how conjunctive use analysis is facilitated through the integration of additional packages and processes in one code and the connections with the supply-and-demand structure unique to MF-OWHM. Additional modifications of selected packages within MF-OWHM required to align their functionality from MODFLOW-2005 to MF-OWHM are also described. For an online description of MF-OWHM input files please refer to http://water.usgs.gov/ogw/modflow-owhm/ Guide/index.html and contact MF.OWHM@gmail.com with an add request to be notified of updates.

\section{Description of MF-OWHM}

The modifications to MODFLOW and integration of most of the versions of MODFLOW into one code, MF-OWHM, results in a wide variety of upgrades that facilitate the use of head-dependent flows (traditional MODFLOW), flow-dependent flows, and deformation-dependent flows. These couplings collectively affect the movement and use of water across a landscape that is connected to the climate, surface-water, and groundwater components of the hydrosphere. The descriptions of the upgrades, updates, and integrations are summarized in the following sections of conjunctive-use linkages, new groundwater features, new surface-water features, new observation features, and new landscape features. Selected features, such as the Newton Solver Formulation (NWT), streamflow routing (SFR), and the landscape processes (FMP3), are now useable together within a modeling structure that includes local grid refinement (LGR) for a combination of regional (parent) and embedded subgridded (child) models. Selected packages and processes were modified to be compiler and operating system independent through the use of complier preprocessor macros and conditional compilation source files. The detailed description of new input instructions are summarized in the appendixes. 


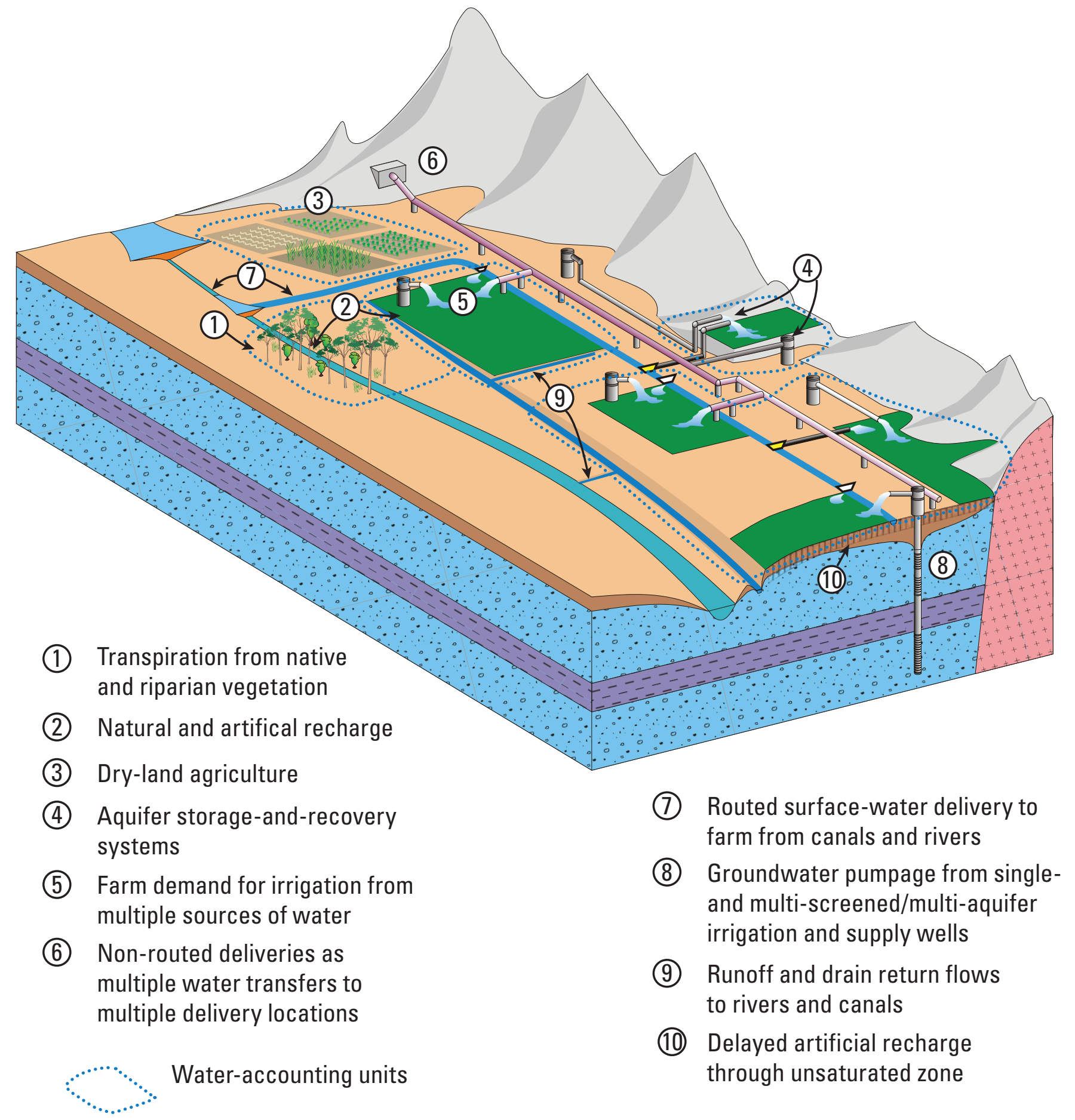

Figure 1. Diagram showing the types of interdependencies within MF-OWHM and the related constraints on the supply and demand components (modified from Schmid and Hanson, 2009). 


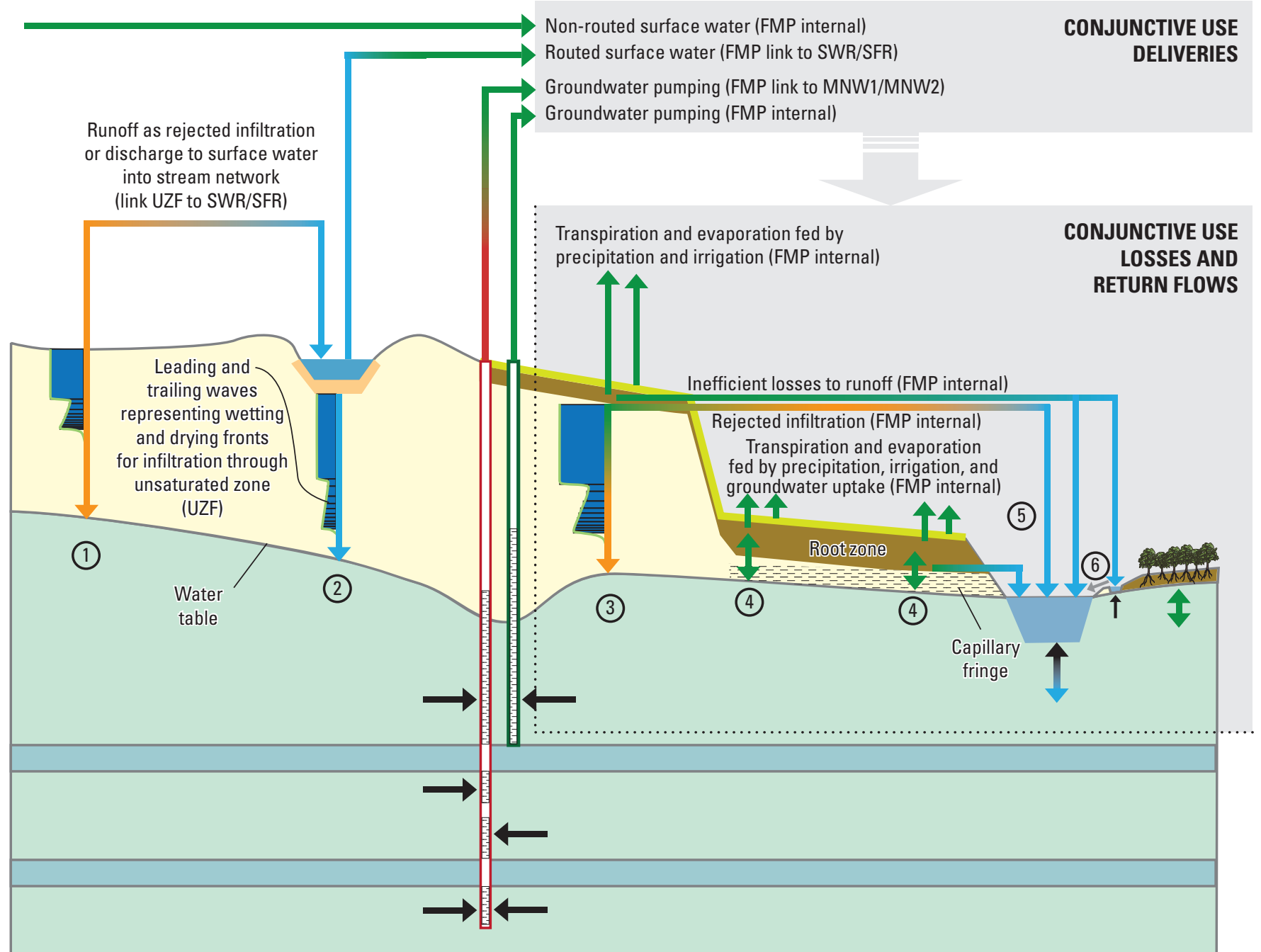

(Modified from Schmid and Hanson, 2009)

(1) Vertical unsaturated flow through deep unsaturated zones equals delayed recharge (UZF internal)

(2) Vertical unsaturated flow beneath streams (SFR internal) and canals (SWR)

(3) Inefficient losses to percolation equals infiltration into deeper unsaturated zones and simulation of delayed recharge (Link to UZF package)

(4) Inefficient losses to percolation equals instant recharge (FMP internal)

(5) Runoff (by FMP or UZF) discharge into stream network (by linking FMP to SFR or UZF to SFR)

(6) Drain returnflows (from DRT) link from discharge into SFR from FMP or directly to SWR

Figure 2. Diagram showing the interdependencies of flows within a hydrologic system simulated by MF-OWHM (modified from Schmid and Hanson, 2009). 


\section{New Conjunctive-Use Linkages}

New conjunctive-use linkages include the options for coupling flow-dependent and deformation-dependent flows. Connections to the landscape process (FMP3) include new connectivities to Streamflow Routing Package (SFR2)

(Niswonger and Prudic, 2005), Surface-Water Routing Process (SWR) (Hughes and others 2012), the Unsaturated-Flow Package (UZF) (Niswonger and others, 2006), the Drainreturnflow Package (DRT) (Harbaugh, 2005), the Subsidence Package (SUB) (Hoffmann and others, 2003), and Local-Grid Refinement (LGR) (Mehl and Hill, 2005, 2007). The framework of optional linkages for demand-driven and supplyconstrained flow shows how the feedback of head, flow, and deformation-dependent flows help control the movement and use of water for conjunctive use (fig. 3).

Conjunctive use is the combined use of groundwater and surface water (UNESCO, 2010). The evolution of management of conjunctive water use (conjunctive use) has come to include both the natural and anthropogenic framework of water resources (Schmid and others, 2014). The engineered components of supply and demand have become more sophisticated and ubiquitous in the urban and agricultural landscape (fig. 4). Many of these components, such as canals, multiple-aquifer wells, aquifer storage and recovery of artificial recharge, and reuse have an effect on conjunctive use. The connection to potential land subsidence has not been systemically linked to other processes and hydraulic properties of groundwater flow to assess conjunctive use. The feedback from these components and the operation of other components that are linked to these activities may require combined assessment within a physically-based, supply-anddemand modeling structure. This type of supply-and-demand analysis helps to identify the capacity and limits that these components can bring to conjunctive use that cannot be directly identified through water-allocation models. One of the current issues for regions that transport large amounts of surface water through canal systems is the potential effects on this infrastructure from land subsidence. In particular, reduced surface-water supplies caused by dry climate and environmental constraints are being supplanted by increased groundwater pumpage that can cause increased land subsidence. An unintended feedback in the conjunctive use from this cause-and-effect linkage is impairment of the conveyance and integrity of the canal systems as well as related streamflows and runoff. Land subsidence and differential land subsidence can affect the elevation and slopes across the landscape. For canals, these changes manifest themselves with potential reduction in freeboard transmission capacity and structure discharge capacity (conveyance), reduced or reversed slopes, and even fractures in the canals. Similarly, the natural streamflow system is affected and the ability to deliver water for irrigation and return to streams or reuse water is directly and indirectly affected by land subsidence. Finally, land subsidence affects the subsurface, where compaction is providing additional water to the groundwater flow system. Aquifer systems also have reduced storage and transmission properties associated with the dewatering-induced compaction (Schmid and others, 2014). The option to allow deformation-dependent flows within MF-OWHM affects several of the features of FMP (Schmid and others, 2014) that depend on groundsurface elevations that may change as a result of subsidence or uplift. In those situations, MF-OWHM updates land-surface elevations at the end of each time step. Unlike previous versions of MODFLOW, MF-OWHM programmatically links land-subsidence processes to other processes and hydraulic properties of groundwater flow to assess how conjunctive use may be affected by changes in flows, supply, and demand from deformation (fig. 4). The potential changes in movement of water before and after the linked effects of subsidence result in redirected runoff, reduced streamflow and canal flows, reduced canal freeboard, additional connection of root zone to capillary fringe above water table, and reduced hydraulic properties (fig. 4).

\section{New Landscape Features}

New landscape features include upgrades to the Farm Process (now FMP3) and the inclusion of the Riparian Evapotranspiration Package (RIP). Both simulate evapotranspiration but have slightly different features that may make them better suited for selected applications. For example, both FMP and RIP simulate riparian vegetation, including submerged vegetation, but FMP separates the $\mathrm{E}$ and $\mathrm{T}$ components while RIP does not. Conversely, RIP allows the simulation of overlapping or mixed vegetation cover within a model cell, but FMP will simulate only one vegetation or land-cover type in each cell.

\section{New FMP Features}

The Farm Process (FMP) simulates the use and movement of water across the landscape and is linked to the surface-water movement (SFR2) and groundwater flow within MODFLOW (Schmid and others, 2006; Schmid and Hanson, 2009). FMP estimates the use of water from natural, urban, and agricultural vegetation in a demand-driven and supplyconstrained model structure that estimates surface-water deliveries and groundwater pumpage needed for irrigation. Returnflows from irrigation or precipitation are also simulated as overland flow or specific-point deliveries back to the streamflow network. These returnflows can be based on slopes for automated returnflows or specified as point returnflows for engineered returnflows. FMP also simulates the direct uptake of water for evaporation and transpiration separately and is connected to the Unsaturated Zone Flow Package (UZF) to simulate unsaturated zone processes and to facilitate delayed recharge beneath the root zone.

Additional features and improvements made to the Farm Process are described in the order in which they affect the FMP input data set. Although most of the new or amended features simply require a change in user-specified options (hereinafter referred to as "flag settings" that control input options through user specification in the FMP input file) in 


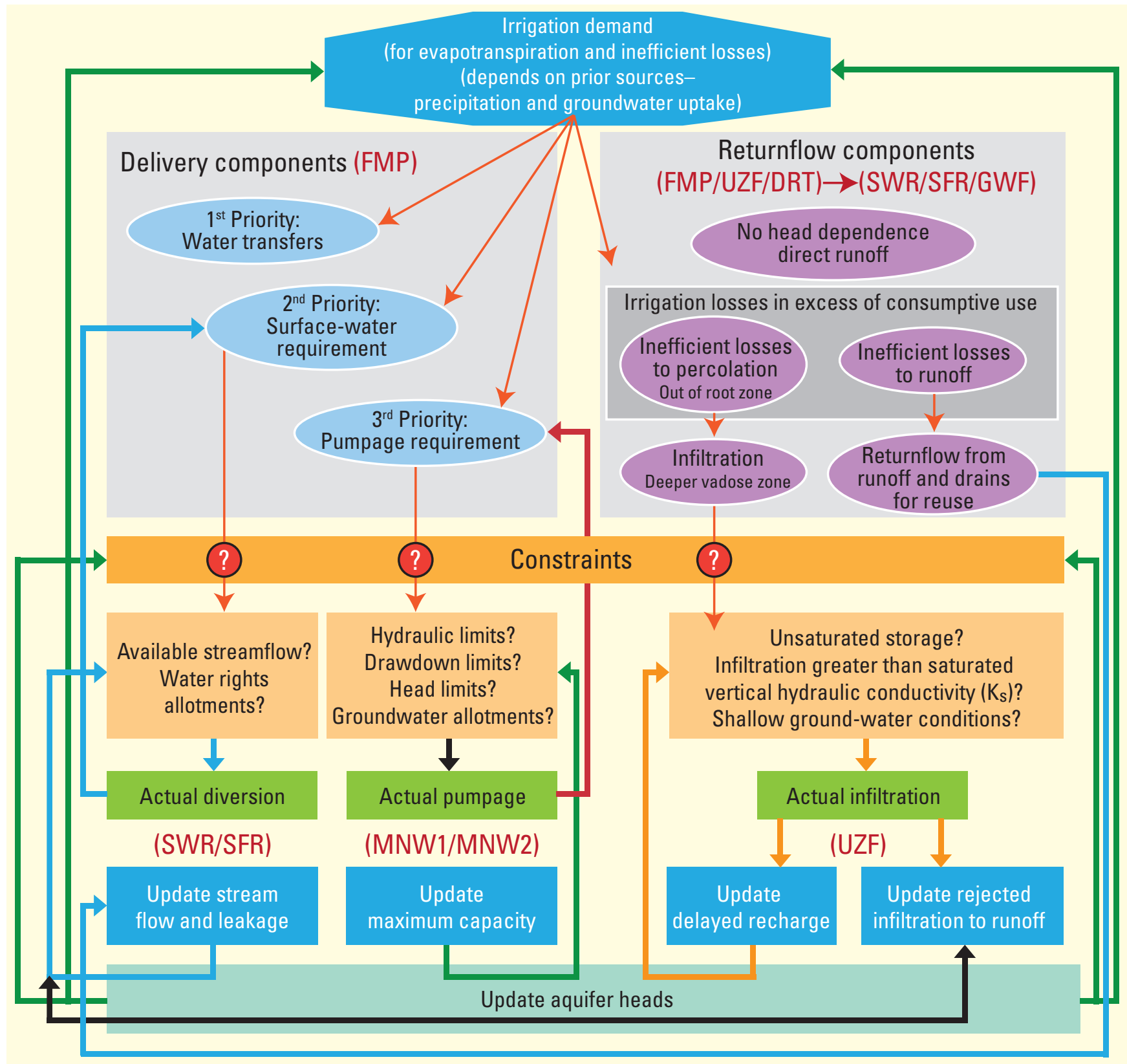

\begin{tabular}{|l}
$\longrightarrow$ Farm Process (FMP) \\
Multi-Node Well Package (MNW1/MNW2) \\
Streamflow Routing Package (SFR) \\
Surface-water Routing Process (SWR) \\
Drain Returnflow Package (DRT) \\
$\rightarrow$ Unsaturated-Zone Flow Package (UZF) \\
$\longrightarrow$ Groundwater Flow Process (GWF) \\
? Inflow constraints
\end{tabular}

Figure 3. Diagram showing the interdependencies within MF-OWHM for head, flow, and deformation-dependent supply-and-demand components of flow (modified from Schmid and Hanson, 2009). 


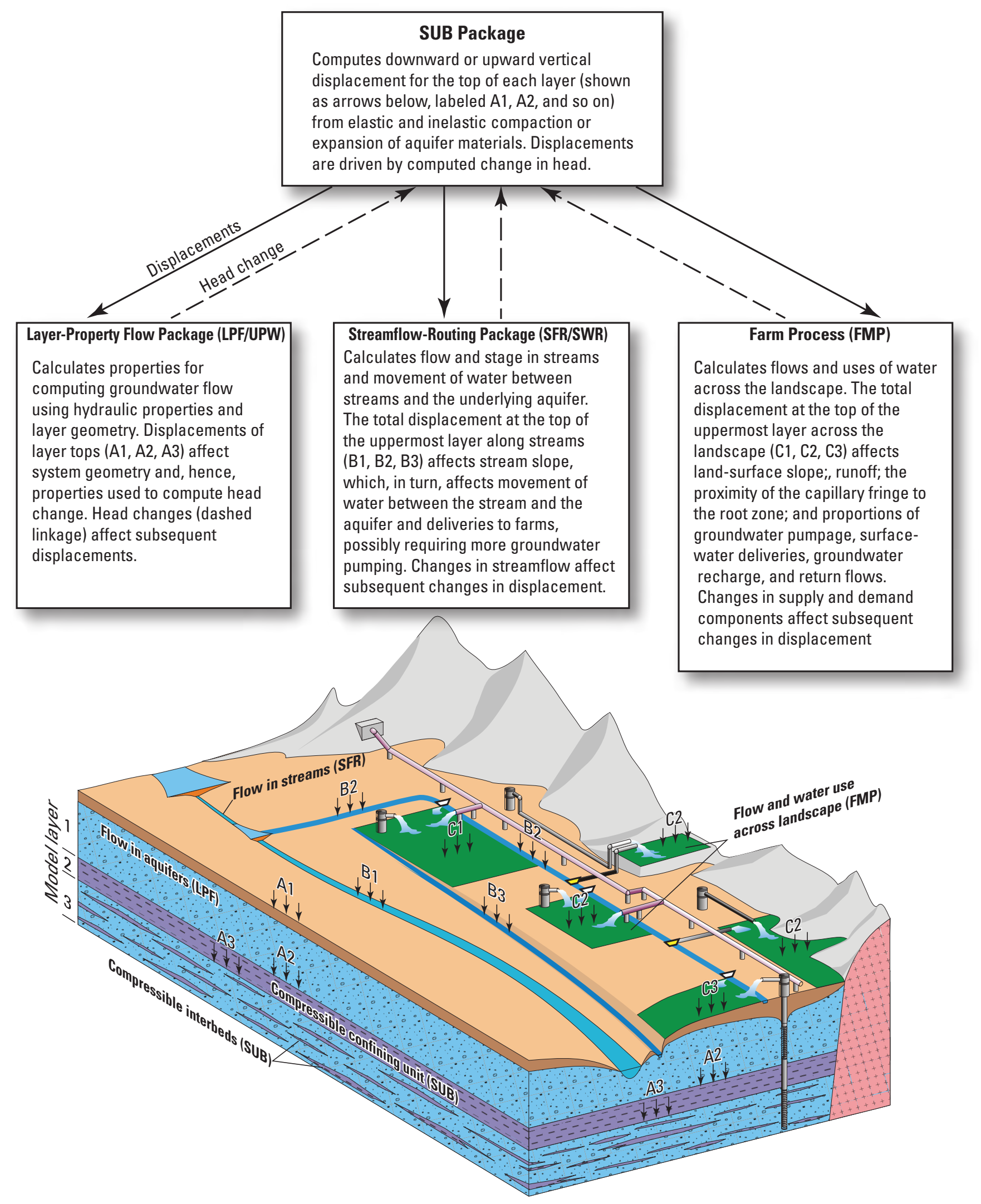

Figure 4. Diagram showing fundamental connections for various components of a hydrologic model with effects of displacement on surface and subsurface features in MF-OWHM (Schmid and others, 2014). 
Item 2 of the FMP input data set, some features do not require changes to the flags, but rather involve direct changes to the data sets that are read for the entire simulation or for every stress period. Hence, the order in which the new and amended features are described in this report are not related to the level of significance of each feature. For instance, the ability to simulate water-accounting units within a regional (parent) and within embedded (child) models is probably the most extensive improvement of MF-OWHM, but is described intermittently with each parameter that can be set for "farms" within a parent or child model in appendix A.

The additional features and improvements made to the Farm Process include the following:

1. Variable Farms - Simulation of variable water-accounting units that can either remain fixed through time or change with every stress period with changing land use, ownership, or delivery of water.

2. Farms in Child Models-FMP can now be used in embedded child models.

3. Groundwater Allotments - Additional restriction of farmwell pumping through simulation of a groundwater allotment for each water accounting unit for the assessment of limits of groundwater supply such as groundwater rights or sustainability analysis limits to supply.

4. Subsidence Linkage-Connections of FMP to the effects of land subsidence to allow deformation-dependent flows through an optional update of the land surface used by FMP.

5. Surface-Water Routing Linkage-Indirect connections through SFR to SWR canals or other surface-water bodies or structures simulated with SFR as points of diversion for semi-routed deliveries and semi-routed returnflows that can then be connected to SWR.

6. MNW2 Farm Wells - Connection of FMP farm wells as either MNW1 or MNW2 multi-aquifer wells.

7. Drain Returnflows - Connection of Drain Returnflows Package (DRT) to FMP semi-routed returnflows or directly or indirectly to SFR from an SWR reach.

8. Additional Observations - Output of the simulated actual ET for direct comparisons with remotely sensed or weather-station based estimates of actual ET.

9. Additional Budgets-Farm budgets for parent and child models.

The new features generally are downwardly compatible with FMP2 data sets, except for the new optional flag settings and full specification of input data sets such as On-Farm Efficiency arrays. The input data options and specifications for each of these new or altered features are fully described in the new input data descriptions listed in appendix A. The following discussions provide brief summaries of the new features.
The new concepts and general data requirements of new FMP3 features that are add-on options to existing FMP1/2 features are described in the order of their occurrence within the input instructions in appendix A, "Data Input Instructions for FMP1/2 and new FMP3 Features." For new FMP3 features, the parameter and input item number of the FMP1/2 input instructions are referenced in parentheses after the respective section titles. The summary of input parameters (tables A1 and A2) includes the previous features, previous features changed from FMP1 to FMP2, newly changed features from FMP2 to FMP3, and new FMP3 input items and is listed accordingly in appendix A.

\section{Variable Farms}

One of the new features of MF-OWHM is the ability to simulate water-accounting units that can remain fixed through time or change at the stress period level with changing land use and ownership. While a few other IHM codes, such as PARFLOW (Maxwell and Miller, 2005), have had some capability to link to a common land-use model, the ability to change through time both the land use and the water-accounting units, which control the relation of supply and demand, is unique to MF-OWHM. This feature is needed to allow continuous, long-term simulations in which changes in both vegetation and land ownership can collectively affect governance of the delivery and use of water and changes in the relations of water accounting such as Aquifer-Storage-andRecovery (ASR) projects, new habitat, division of agricultural lands into multiple farms, or expansion of urban areas. This new feature also allows the user to add or change the "ownership" relation of surface water and groundwater pumpage as deliveries. The distribution of water-accounting units (farms) within MF-OWHM can now remain constant for the entire period of simulation or can change for each new stress period. Thus, changes with each stress period can easily repeat blocks of time in which the ownership of land that affects water accounting is believed to remain the same or change one or more accounting units in any time period.

\section{Farms in Child Models}

FMP can now be used, along with SFR, in embedded child models through the application of LGR. In many situations, existing subregional models need to take advantage of regional models for boundary conditions, yet still need the detail of local-scale modeling that can be either autonomously or fully coupled to the regional model. The new linkages between FMP and LGR allow local embedded models to have most of the features of FMP, including farm wells both within and outside of the embedded child model, semi-routed deliveries and returnflows, and all of the vegetation and landscape properties of FMP. 


\section{Groundwater Allotments}

While in some settings of governance there are groundwater rights and state or national ownership of groundwater, in other settings little governance or restrictions exist in the extractions of groundwater. In parts of the United States, many settings contain a large number of wells that collectively have the pumping capacity to drive overdraft and deplete the groundwater resources beyond sustainable limits. Thus, it was recognized that in order to simulate and analyze the components and limits of sustainability, additional restrictions of farm-well pumping needed to be specified, such as in simulations that are used for sustainability analysis. This is now achieved through the simulation of a groundwater allotment for each water-accounting unit. Each water-accounting unit is given a volumetric-rate constraint that is the portion of the unit that can be derived from groundwater sources. Each allotment can represent any kind of physical or governance limit, such as a groundwater right or a transboundary operating agreement. Such limits on groundwater extractions are useful for the assessment of limits of groundwater supply such as those imposed by development of a basin management plan or sustainability analysis that are subject to other limits to groundwater supply from secondary effects, such as land subsidence, seawater intrusion, streamflow capture, maintenance of groundwater-dependent ecosystems, or adaptation schemes for climate change and climate variability. The groundwater allotments complement the existing surface-water allotments in FMP which, when combined with non-routed deliveries, can provide constraints on the total amount of water available for conjunctive use for an entire watershed or for individual water-accounting units within the watershed. These features also collectively provide potential constraints for watermanagement analysis and optimization through linkages to the Groundwater Management Process (GWM) (Ahlfeld and others, 2005, 2009, 2011, 2013; Ahlfeld and Barlow, 2013; Banta and Ahlfeld, 2013) for systematic sustainability analysis by using changes in storage, secondary effects, or pumping limits on specific groups of wells, as well as using with FMP prior appropriation schemes for surface-water allotments (Schmid and Hanson, 2007).

\section{Subsidence Linkage}

The option to allow deformation-dependent flows within MF-OWHM affects several of the features of FMP that depend on ground-surface elevations that can change due to land subsidence or uplift (Schmid and others, 2014). When linked to the SUB Package, the incremental displacements are used to update the land surface in FMP at the end of each time step. Changes in the land surface not only affect runoff, surface-water deliveries, and focused returnflows, but also can affect the direct uptake of groundwater for evaporation or transpiration by altering the proximity of the capillary fringe and root zone to the water table. Therefore, changes in slope and elevation can alter the proportions of water that are delivered from the simulated conveyance of surface water for irrigation or from direct uptake of groundwater, which in turn affects the amount of water that may be required for irrigation from groundwater pumpage. If FMP options for automatically determining delivery and return-flow locations are used, the deformation-related changes in the land surface can also result in movement of the points of delivery and returnflow.

Connections of FMP to the effects of land subsidence not only affect the consumption of water through evapotranspiration (ET) but also can affect the distribution and timing of the supply-and-demand components that interact with the surfacewater and groundwater systems (fig. 5). For example, the proximity of the root zone to the water table or capillary fringe can affect the rate and distribution of direct uptake of water through ET. This changing consumption can, in turn, affect the demand from other supply components and the related losses due to inefficiencies from those externally derived components that become runoff to surface water or groundwater recharge. Similarly, the actual timing, distribution, and amounts of deliveries and returnflows can be affected through this linkage. For example, the indirect effects of the deformation on surface flows, conveyance, and leakage to groundwater can affect the distribution of surface supplies available from diversions from streams and canals. This can result in requiring more or less supplemental groundwater pumpage. Thus, the deformation-dependent flows indirectly affect the head- and flow-dependent flows. The deformation linkage can also affect the distribution of pumpage from multi-aquifer wells or the amount of drawdown in farm wells that supply water for irrigation, as deformation can affect the aquifer hydraulic properties and groundwater flow to these wells. Finally, the amounts and directions of surface runoff and returnflows also can be affected through this linkage (Schmid and others, 2014).

Additional features that are potentially affected by changes in the land surface include drains and simulation of riparian evapotranspiration, RIP-ET (Maddock and others, 2012). Changing elevation of the land surface can effect the simulation of drain flows [with the Drain Package (DRN); Harbaugh, 2005] that represent discharge of water from features on the land surface, such as springs, when the head in the aquifer exceeds the elevation of the land surface. When linked to the SUB Package, the incremental displacements are used to update the land surface in DRN or DRT and can affect the discharge of water from these cells. For DRT, this can also affect the simulation of returnflows from these discharges that were used to approximate return-flow infiltration prior to the use of FMP. 


\section{Before subsidence}

Native vegetation (FMP)
Landscape processes

Farm Process (FMP)

Streamflow Routing Package (SFR)

Surface-Water Routing Process (SWR)

\section{Subsurface processes}

Layer-Property Flow Package (LPF)

Subsidence Package (SUB)

Multi-Node Well Package (MNW)
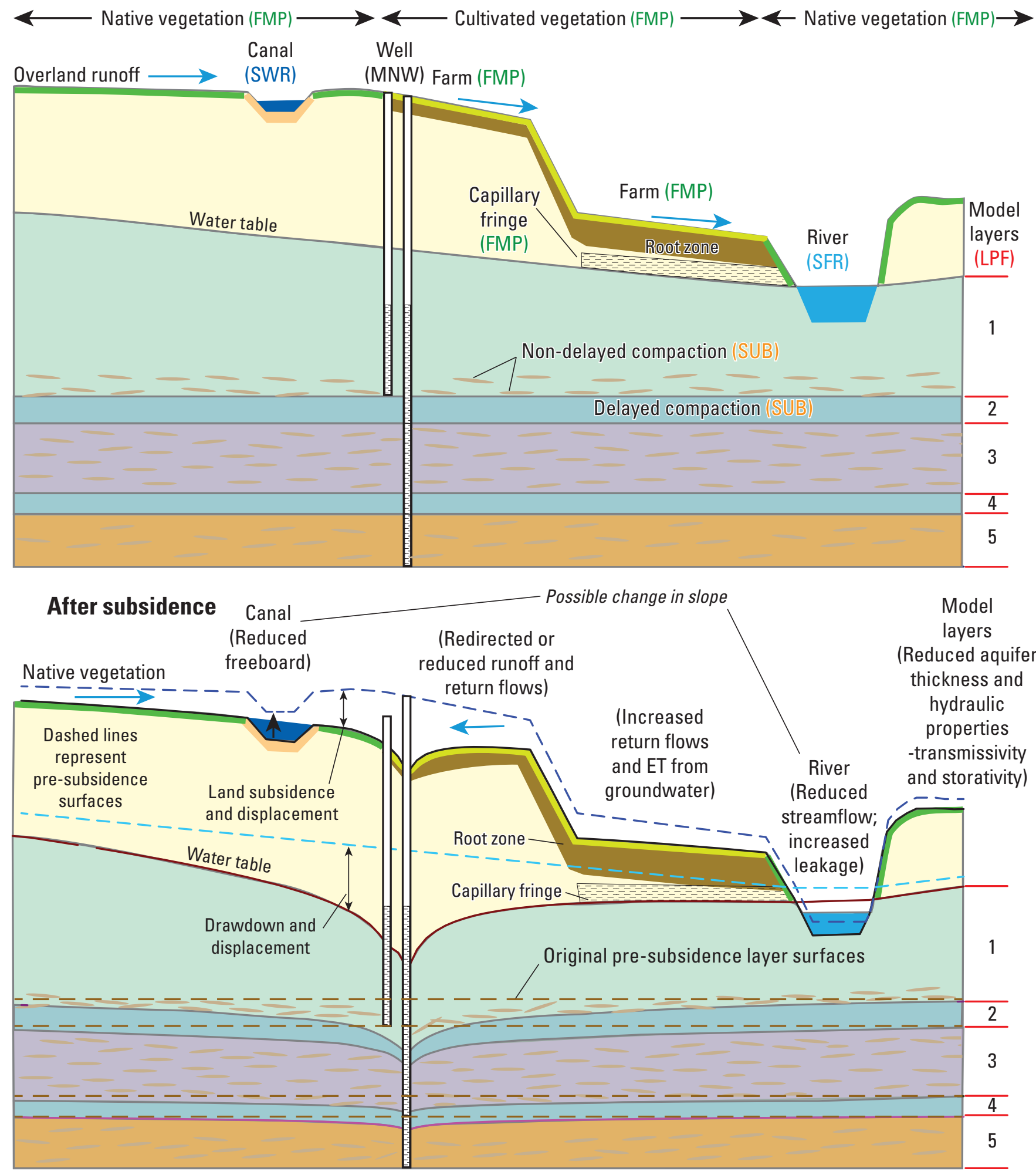

Figure 5. Diagram showing the relation between surface and subsurface processes with linkage to land subsidence (Schmid and others, 2014). 


\section{Surface-Water Routing Linkage}

Semi-routed surface water is defined as surface water routed through a "river-to-canal" network to a point of diversion from where water is delivered in a nonrouted form (for example, by pipeline) to a remote farm not adjacent to the canal (Schmid and others, 2006). Semi-routed water deliveries in FMP can now make connections to canals or other surfacewater bodies or structures simulated with SWR as points of diversion indirectly through SFR streamflow segments. Thus, SWR canals can be used to deliver water to SFR diversion segments that can be used to withdraw water for irrigation through semi-routed deliveries to FMP.

\section{Multi-Aquifer Farm-Well Linkage}

The connectivity to multi-aquifer wells has also been extended to MNW2 (Konikow and others, 2009). Connection of FMP farm wells as either MNW1 or MNW2 multi-aquifer wells is now available, which allows for simulation of farm wells that are subject to other conditions, such as partial penetration of the aquifer. While the first versions of FMP provided a linkage to MNW1 (Halford and Hanson, 2002), it was not possible to have more than one MNW farm well in a model cell, easily identify the FMP-MNW wells, or use the advanced features of MNW2 for farm wells with special conditions, such as partial penetration of aquifer layers by farm wells. For FMP3, the farm-well names are now connected to the MNW2 names, so there can now be multiple farm wells in one model cell if necessary. Additional discussion of the MNW2 linkage is described in appendix A description of FMP3 input instructions and new features.

\section{Drain Returnflow Linkage}

Drain returnflows with the DRT Package also can now be redirected to either to FMP through semi-routed returnflows or directly to SWR to keep flows from tile drains, springs, or tail waters moving within the simulated hydrosphere. Connection of Drain Returnflows Package (DRT) to FMP semi-routed returnflows or directly to SWR structures allows water to stay in the model and potentially be available for reuse by other processes within the model or movement to other features within the model. Drain returnflows to SWR can also be indirectly routed from SWR to SFR reaches. Additional discussion and input instructions for these new connections are described in appendix $\mathrm{B}$.

\section{Riparian ET Package}

While all ET from natural, urban, and agricultural settings can be simulated with FMP3, in some landscape settings it can be advantageous to simulate the riparian ET separately. MF-OWHM allows this through the inclusion of the new Riparian-ET Package (Maddock and others, 2012), which includes the ability to have a time-varying multi-polygon definition of Riparian vegetation that gives more detail to evolving habitat and more realistic depth-ET relations for each plant community that cannot be simulated with the standard ET and ETS Packages of MF-2005. While the depth-ET relations are similar between RIP-ET and FMP, the ability to simulate mixed vegetation through multiple polygons is a unique feature for RIP-ET that makes it especially well-suited for simulating complex settings of riparian habitat with mixed vegetation distributions.

\section{New Groundwater Features}

New groundwater features include the inclusion of MODFLOW-NWT solver and related UPW Aquifer Package, the new Seawater Intrusion Package (SWI2) (Bakker and others, 2013), as well as a revised version of the multi-node well Package (MNW2) modified from Konikow and others (2009), and a more complete set of solvers that include the new nonlinear PCG solver (PCGN) (Naff and Banta, 2008), the geometric multigrid solver (GMG) (Wilson and Naff, 2003), as well as the Newton Raphson solvers that were included with the release of MODFLOW-NWT (Niswonger and others, 2011). The PCG and NWT solvers also can now have solver settings for the entire simulation or can vary at the stress-period level. Additional enhancements were made to the Subsidence Package (SUB), the Horizontal Flow-Barrier Package (HFB) and Basic Package, the Multiplier Package (MULT), Zone Package (ZONE), Parameter Package (PVAL), and additional general Utility routines. Finally, the Enhanced Tabfiles structure for specifiying time-series data input was implemented for the SFR, MNW2, and GHB Packages. The original Tabfiles feature is still available in SFR and SWR, and collectively facilitates data structures that are needed to develop self-updating models for operational analysis, linkages to decision-support systems, and climate projections.

\section{New Subsidence Package Features}

New Subsidence Package optional features include the Subsidence Linkage and the Subsidence parameters. The Subsidence (SUB) Package for MODFLOW (Hoffmann and others, 2003) uses Terzaghi's principle of effective stress to solve for changes in thickness of the skeleton of the aquifer and adjacent confining units. Subsidence from groundwater pumping is mostly attributed to non-recoverable (inelastic) vertical compaction of fine-grained interbeds within an aquifer and more extensive fine-grained confining beds that separate aquifers. Such compaction occurs when decreases in pore-pressure from groundwater pumping cause increases in the vertical component of effective stress. Conversely, increases in pore pressure can cause decreases in effective stress and expansion of sediments. In a basin-scale groundwater model, individual fine-grained interbeds cannot be treated individually; however, the total thickness and compaction of all fine-grained interbeds in each model cell are accounted for by the SUB Package. In contrast, extensive fine-grained confining layers may be 
discretized separately into one or more model layers. The smaller elastic compaction of coarse-grained aquifer material can be simulated with the SUB Package, and elastic increases in thickness of coarse- and fine-grained sediments typically are simulated. Rates of release of water resulting from compaction and uptake of water from expansion sediments are accounted for in the equations for groundwater flow solved by MF-OWHM. For each grid cell, the SUB Package computes vertical displacement at the top of the cell as the sum of compaction in that cell and all underlying cells. Compaction is zero in any cells assumed to be rigid or outside of the active model area. Land subsidence for any uppermost active model cell in the model grid is the cumulative displacement of the compaction for cells in all underlying model layers.

Because a commonly asked question is how much of the simulated subsidence is inelastic and nonrecoverable, the ability to split the elastic and inelastic components of subsidence was made available in MF-FMP2 (Schmid and Hanson, 2009). These features have also been included in the SUB Package for separation of initial and simulated elastic and inelastic instantaneous compaction within MF-OWHM. Please refer to appendix B of MF-FMP2 (Schmid and Hanson, 2009) for a description of these additional SUB features and related extensions of HYDMOD in support of these features.

\section{Subsidence Linkage}

The Layer-Property Flow Package (LPF) for MODFLOW is described by Harbaugh (2005) as an "Internal Flow Package," whose purpose is to compute storage terms for each finite-difference cell and hydraulic-conductance values between adjacent cells. The Upstream Weighting Package, (UPW), which is associated with the Newton-Raphson solver of MF-OWHM (Niswonger and others, 2011), is similar to LPF and is also an "Internal Flow Package." Conductance and storage terms are fundamental parts of the system of groundwater-flow equations that MF-OWHM solves to compute aquifer head at each model cell. Conductance terms are functions of hydraulic conductivity, but also are functions of the geometry of the cells and saturated thicknesses of the aquifer in a cell. Aquifer properties are read by LPF or UPW and stored in arrays, and horizontal cell dimensions and top and bottom elevations of each cell are read into MODFLOW in a discretization file and are stored in arrays for use in computing conductance and storage terms. Both the LPF and UPW are linked to the SUB Package displacements through changes in the elevations of cell-by-cell layer boundaries when the SUBlink option is invoked in the SUB Package.

In previous MODFLOW versions, cell thickness was static through time. When linked to the SUB Package, however, incremental displacements in tops and bottoms of cells can change cross-sectional areas between laterally adjacent cells and the computed intra-cell conductance values. Also, when head is above the top elevation of a cell, LPF/UPW applies a storage coefficient that is the product of the thickness of the cell (elevation of top minus elevation of the bottom) and the specific-storage value read for the cell. It is through this calculation that SUB-computed changes in layer elevations can change the computed storage coefficient. In the implementation for MF-OWHM, incremental vertical displacements computed by SUB are used in an explicit, 1-timestep lag coupling to adjust layer top and bottom elevations in calculations of conductance and storage properties carried out by LPF or UPW for the subsequent time step.

Displacements of upper surfaces of cells computed by the SUB Package are used in MF-OWHM to better simulate other processes represented in hydrologic models of areas undergoing land subsidence. Specifically, incremental vertical displacements are used to simulate the effect of vertical displacement of layer tops on the Streamflow Routing Package, SFR2 (Niswonger and Prudic, 2005), the Farm Process, FMP (Schmid and Hanson, 2009), the Layer Property Flow Package, LPF (Harbaugh, 2005), the Upstream Weighting Package, UPW (Niswonger and others,2011), the Surface-Water Routing Process, SWR (Hughes and others,2012), Riparian-ET Package (RIP) (Maddock and others, 2012), and drain packages (DRN/DRNRT) (Harbaugh, 2005). The SUB Package can be used with or without this additional linkage. The new linkage and input requirements are summarized in appendix E.

\section{Subsidence Parameters}

The original SUB Package allowed the user to specify initial preconsolidation stress as a head and stress-independent elastic and inelastic storage coefficients for each model layer that was designated to have subsidence active. This data structure required preprocessing from more fundamental data and did not allow subregional adjustments of subsidence parameters within the MODFLOW parameter framework. The first modifications of the SUB Package resulted in the split of elastic and inelastic initial and simulated layer-specific compaction and total subsidence. Because the SUB Package uses skeletal elastic and inelastic storage coefficients, the addition of parameters allows the user to specify intrinsic properties and construct these storage coefficients from spatial distributions of intrinsic properties such as specific storages and porosities. Furthermore, consolidation tests can be combined with geologic textural or facies data to provide physically based distribution of storage properties. When the SUB Package is used, the skeletal elastic compressibility of the aquifers and the interbedded fine-grained units can be included in the estimates of elastic storage used by the SUB Package. The storage-coefficient fractions from the compressibility of water and specific yield are then retained as specific-storage properties in the definition of specific storage within the aquifer layer Packages (LPF, UPW) (Faunt and others, 2009c; Hanson and others, 2014c).

The parameters are defined by the standard parameter abbreviations that are already provided by PVAL plus the extension for the SUB Package with new parameter variables 
for (RNB), Instantaneous (HC) and Delayed (DHC) Critical Heads, Elastic Storage (Sfe), Inelastic Storage (Sfv), Initial Elastic (ComE) and Inelastic (ComV) Compaction, Starting Displacements (Dstart) and Displacements (DZ). This parameterization allows users to have the option to more easily use facies texture data or geologic framework models directly with zonations and specific-storage values to construct spatially varying subsidence properties, instead of preprocessing the values or having to use external parameterization devices, such as pilot points, for parameter estimation of subsidence properties and performance. With the linkage to the new Expression Parser capabilities of the MULT Package, the user can build critical head and storage properties needed by the SUB process from more fundamental properties with more spatial variation, which can also be treated as parameters to better facilitate estimation of land-subsidence parameters. The input file is modified such that it is backwards compatible with the previous FMP version of SUB. The new subsidence parameters and input requirements are summarized in appendix $\mathrm{B}$ and the the new Multiplier and Parameter Value features are described in the section below "New Parameterization Features."

\section{New Horizontal Flow Barrier Features}

The HFB Package (Hsieh and Freckleton, 1993) was enhanced to facilitate two capabilities that were previously unavailable in HFB. The enhanced package, HFB2, allows the user to redirect flow from one layer to another layer on a cell-by-cell basis across any cell face specified as part of an HFB. This allows users to properly specify flow from one layer to another along either outcrop boundaries or along faults where aquifers are dislocated vertically and the flow is redirected to another aquifer. In addition, HFB parameters can now be specified for each stress period so that they can change through time. This allows the user to simulate changes in flow barriers during one simulation, such as changes in the geohydrologic framework that can result from dislocation of aquifers as a result of seismic or anthropogenic deformations or from the inclusion of man-made features, such as grout curtains or other types of induced flow barriers or discontinuities. This feature allows redirection of flow from a cell in one layer to a cell in another layer on a one-to-one relationship and does not support one-to-many or many-to-one relationships of interlayer flow. The ability to change HFBs with each stress period is available across all the aquifer packages, but the feature to redirect flow between model cells is available only through the use of the NWT and related UPW aquifer package because it can produce a less structured conductance matrix.

Flow is routed between two non-adjacent cells by adjusting the continuity equation. The original formulation assumes that flow occurs across the six faces of a model cell to the adjacent cells that surround it. Flow across one of these faces is described by Darcy's law (fig. 6). To route flow to a different layer, Darcy's law is modified to calculate the conductance across the two non-adjacent cells as if they were adjacent to each other. If the hydraulic characteristic of the barrier is specified as a negative value, the absolute value is used as a scale factor for the harmonic mean of the routed cell conductance. It then uses the head values for each of those cells to calculate the flow (fig. 7).

The new HFB2 is backward compatible with the revised HFB data structures described within MF-2005 (Harbaugh, 2005), so if these features are not used, they do not need to be included in the input data set and older data sets still useable. Please refer to appendix $\mathrm{C}$ for a description of the specific input for the new upgrades for HFB2.

$$
\begin{gathered}
\mathrm{q}_{i, j+1 / 2, k}=\mathrm{CR}_{i, j+1 / 2, k}\left(\mathrm{~h}_{i, j+1, k}-h_{i, j, k}\right) \\
\mathrm{CR}_{i, j+1 / 2, k}=2 \Delta \mathrm{c}_{i} \frac{\mathrm{TR}_{i, j, k} \mathrm{TR}_{i, j+1, k}}{\mathrm{TR}_{i, j, k} \Delta \mathrm{r}_{j+1}+\mathrm{TR}_{i, j+1, k} \Delta \mathrm{r}_{j}}
\end{gathered}
$$

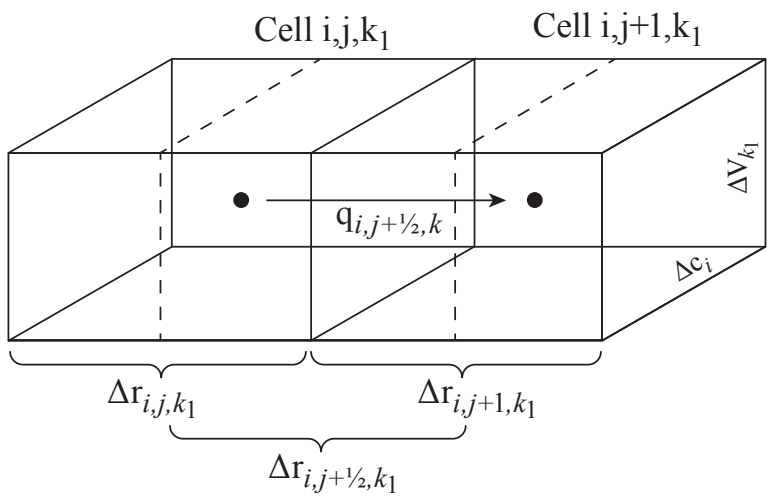

Figure 6. Groundwater-flow equation across an adjacent model cell face by using Darcy's Law (Harbaugh, 2005). 


$$
\begin{gathered}
\mathrm{q}_{i, j+1 / 2, k_{1}: \mathrm{k}_{2}}=\mathrm{CR}_{i, j+1 / 2, k_{1}: \mathrm{k}_{2}}\left(\mathrm{~h}_{i, j+1, k_{2}}-h_{i, j, k_{1}}\right) \\
\mathrm{CR}_{i, j+1 / 2, k_{1}: \mathrm{k}_{2}}=2 \Delta \mathrm{c}_{i} \frac{\mathrm{TR}_{i, j, k_{1}} \mathrm{TR}_{i, j+1, k_{2}}}{\mathrm{TR}_{i, j, k_{1}} \Delta \mathrm{r}_{j+1}+\mathrm{TR}_{i, j+1, k_{2}} \Delta \mathrm{r}_{j}} \\
\mathrm{TR}_{i, j, k_{1}}=\Delta \mathrm{v}_{k_{1}} \mathrm{HK}_{i, j, k_{1}} \text { and } \mathrm{TR}_{i, j+1, k_{2}}=\Delta \mathrm{v}_{k_{2}} \mathrm{HK}_{i, j+1, k_{2}}
\end{gathered}
$$

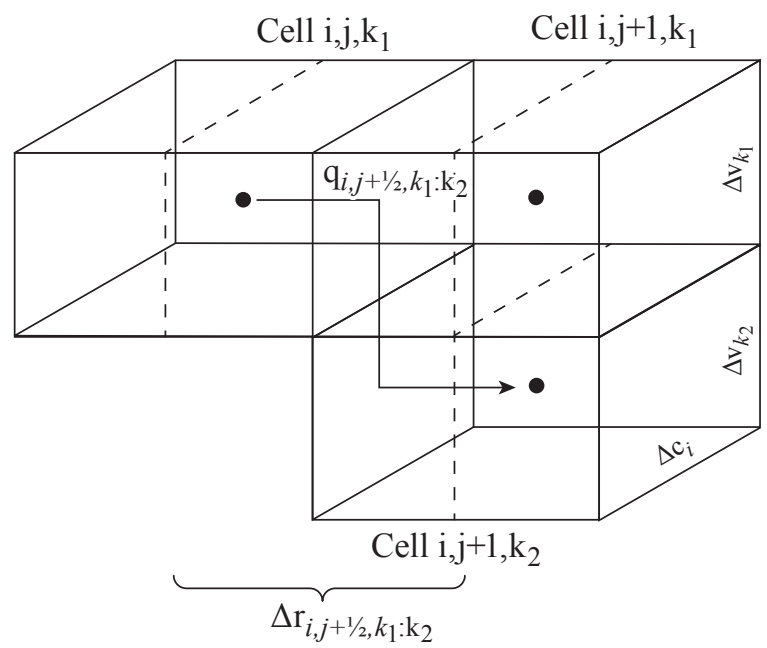

Figure 7. Groundwater flow equation across a non-adjacent model cell face by using Darcy's Law.

\section{New Parameterization Features (MULT, ZONE, PVAL, and SUB)}

Upgrades were made to the Multiplier (MULT), Zone, Parameter-Value (PVAL), and Subsidence (SUB) Packages to facilitate more robust parameterization within MF-OWHM. The upgrades to MULT and Zone Packages were required to facilitate more fundamental model data sets and improved access to model properties required for parameter estimation. The upgrade to the MULT Package represents implementation of complete equations that can more easily be used to construct hydraulic properties using the MULT Package. The MULT Package now includes an expression parser so that entire equations can be entered to construct or adjust hydraulic properties during the initialization of a MF-OWHM simulation. This helps facilitate defining hydraulic properties within MF-OWHM by using fundamental hydraulic parameters combined with lithology/facies texture data. This capability of MF-OWHM has already been used successfully for a variety of recent models of alluvial basins (Faunt and others, 2008b, 2009; Hanson and others, 2014a) and now can be used to provide additional linkage porosity through the definition of storage properties of the aquifers within the groundwaterflow packages and through Darcian flow in MODPATH (Pollock, 1989, 1994) and MODPATH-OBS (Hanson and others, 2013). This allows for more systematic and higherorder observations, as were used for models of the Middle Rio Grande and Cheasapeake Bay (McAda and Barroll, 2002; Sanford and others, 2003, 2004; Sanford, 2011).

The definition of hydraulic properties can now be specified as an input to the model. This facilitates parameterization based on simpler transmission and storage hydraulic properties, such as estimates of geologic properties, combined with lithologic texture data such as percentages of coarse- and fine-grained material for alluvial aquifer systems. For example, Faunt and others (2009c) identify the power mean as a useful approach for estimating hydraulic conductivity values. In addition, their work includes a review of the literature that describes the use of the power mean for calculating hydraulic conductivity. A power mean is a mean (M) of the following form:

$$
M^{p}(x)=\left(\frac{1}{n} \sum_{k=1}^{n} x_{k}^{p}\right)^{1 / p}
$$

where

$$
\begin{array}{cl}
p & \text { is the averaging power-mean exponent, } \\
\mathrm{n} & \text { is the number of elements being averaged, and } \\
x_{k} & \text { is the } k^{\text {th }} \text { element in the list. }
\end{array}
$$

The horizontal hydraulic conductivity $\left(K_{h, i}\right)$ was calculated as the weighted arithmetic mean ( $p=1.0$ in eqn. 1$)$ of the hydraulic conductivities of the coarse-grained $\left(K_{c}\right)$ and fine-grained $\left(K_{f}\right)$ lithologic end members and the sediment texture for each $\left(\mathrm{i}^{\text {th }}\right)$ model cell:

$$
\mathrm{K}_{\mathrm{h}, \mathrm{i}}=\left[K_{c} F_{c, i}+K_{f} F_{f, i}\right]
$$

where

$F_{c, i} \quad$ is the fraction of coarse-grained sediment in a cell, estimated from sediment-texture data as described in the previous section, and

$F_{f, i} \quad$ is the fraction of fine-grained sediment in a cell $\left(1-F_{c, i}\right)$. 
Because $K_{f}$ is much smaller than $K_{c}$, the arithmetic mean heavily weights the coarse-grained end member for horizontal hydraulic conductivity.

$K$ Vertical hydraulic conductivity between model layers $\left(K_{v, k+1 / 2}\right)$ was calculated as the $p^{\text {th }}$ weighted power mean of the hydraulic conductivities of the coarse-and fine-grained lithologic end members (Faunt and others, 2009b):

$$
K_{v, k+1 / 2}=\left[F_{c, k+1 / 2} K_{c}^{p}+F_{f, k+1 / 2} K_{f}^{p}\right]^{1 / p}
$$

where

$$
\begin{array}{cc}
F_{c, k+1 / 2} & \begin{array}{c}
\text { is the fraction of coarse-grained sediment } \\
\text { between layer midpoints, and }
\end{array} \\
F_{f, k+1 / 2} & \begin{array}{c}
\text { is the fraction of fine-grained sediment } \\
\text { between layer midpoints. }
\end{array}
\end{array}
$$

The harmonic mean is a weighted power mean with the exponent $p$ equal to -1.0 in eqn. 3 and results in increased vertical anisotropy. The geometric mean is a weighted power mean with $p$ equal to 0.0 in eqn. 3 and results in decreased vertical anisotropy. Phillips and Belitz (1991) determined that vertical conductivities could be calculated by using either weighted harmonic or weighted geometric means. Belitz and others (1993) represented the vertical conductivities with the weighted harmonic mean. Faunt and others (2008b, 2009c) calculated the vertical conductivities as power means in which $p$ varied between -1.0 (the harmonic mean) and 0.0 (the geometric mean). The relationship between hydraulic conductivity and percentage of coarse-grained deposits based on hydraulic conductivity end members and the exponent of the power mean is nonlinear (fig. 8). The $\mathrm{K}_{\mathrm{h}}$ and $\mathrm{K}_{\mathrm{v}}$ can be sensitive to the values of $K_{f}$, depending on the averaging method used, such as the power mean for $\mathrm{K}_{\mathrm{v}}$, and the contrast in values between $\mathrm{K}_{\mathrm{f}}$ and $\mathrm{K}_{\mathrm{c}}$. Both the harmonic and geometric means weight the fine-grained end member more heavily, and as a result, the calculated vertical hydraulic conductivity is much lower than the horizontal. Dimitrakopoulos and Desbarats (1993) determined that the value of $p$ depended to some extent on the size and thickness of the grid blocks used to discretize the model domain; smaller grid cells resulted in lesser values of $p$. While end-member $\mathrm{K}$ values and $p$ values change during calibration, it is the resulting $\mathrm{K}_{\mathrm{h}} / \mathrm{K}_{\mathrm{v}}$ distribution that is most significant, not the $p$ values or end-member Ks.

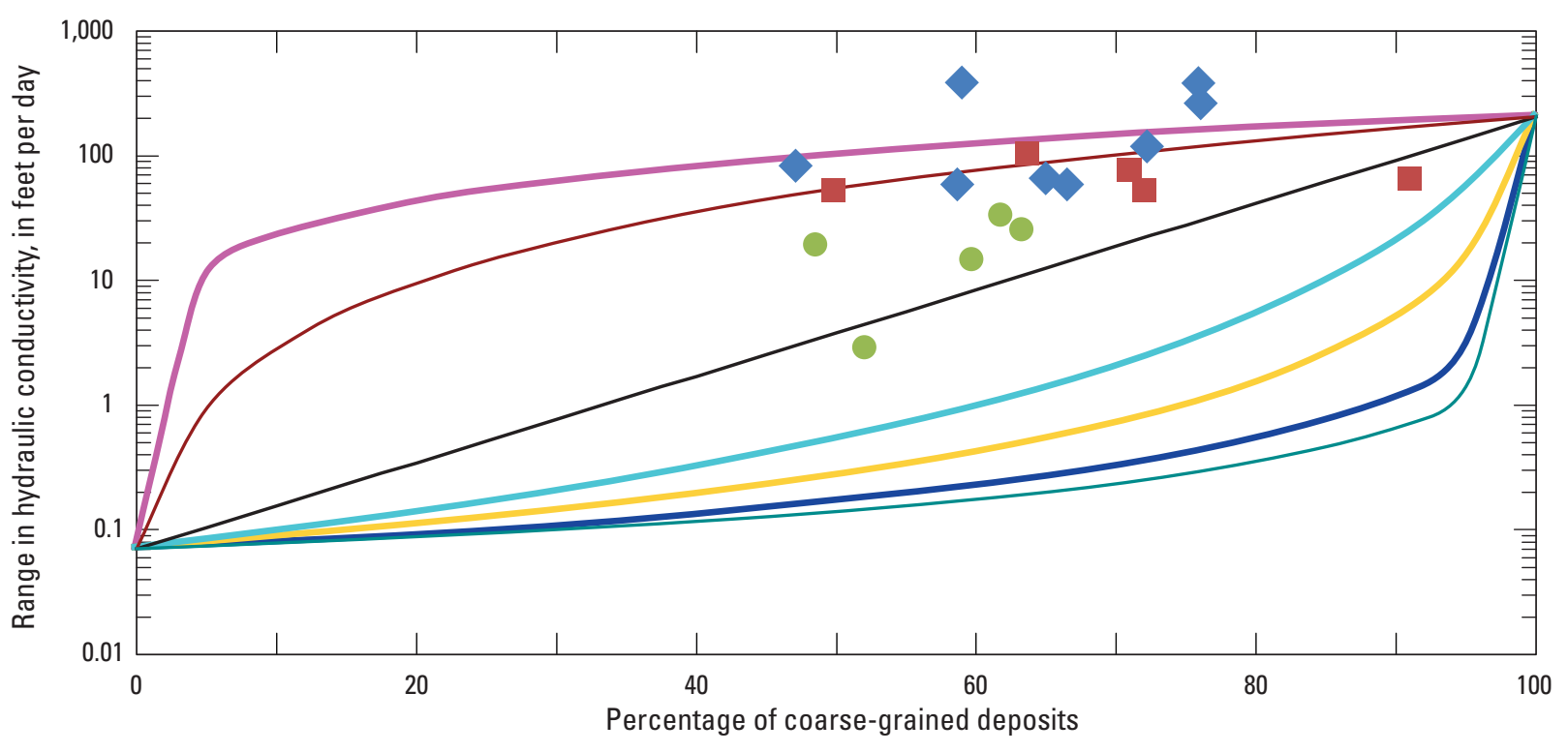

EXPLANATION

Exponent of power mean-

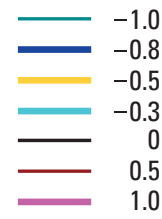

(Harmonic mean)

(Geometric mean)

(Arithmetic mean)
Estimates of lateral hydraulic conductivity from selected water-supply wells-

Upper Aromas

Lower Aromas

- Purisima

Figure 8. Example of relationship between hydraulic conductivity and the percentage of coarse-grained deposits based on hydraulic conductivity end members and the exponent of the power mean, with selected values from aquifer tests or specific capacity tests in Pajaro Valley, California (Hanson and others, 2014a). 
The hydraulic properties used to simulate the changes in storage of water in the aquifer system consist of three components (Hanson, 1988): specific yield, elastic specific storage, and inelastic specific storage. The first two components, specific yield and the elastic specific storage, represent and govern the reversible uptake and release of water to and from storage. Specific yield represents unconfined storage, which is governed by gravity-driven dewatering of the shallow sediments following a decline of the water table. The elastic storage coefficient represents the component of confined storage resulting from the compressibility of water and to the reversible compressibility of the matrix or the skeletal framework of the aquifer system (Jacob, 1940; Hanson, 1988). The inelastic storage coefficient governs the irreversible release of water from the inelastic compaction of fine-grained deposits, or permanent reduction of pore space, which is associated with land subsidence.

Specific storage and specific yield can also be calculated through the use of simple subregional values combined with geologic estimates of aquifer properties such as the textural distributions of coarse- and fine-grained sediments for alluvial aquifers. This can be done using the MULT and ZONE features along with either the aquifer packages such as LPF or UPW or in combination with the SUB Package.

If the LPF or UPW Package is used to define the storage properties in the model without the explicit inclusion of the SUB Package, then the LPF/UPW and multiplier (MULT) Packages can be used to calculate and specify the storage components that included the compressibility of water for all model layers, the specific yield for the unconfined portions of the uppermost active layers, and the specific storage (related to the skeletal elastic compressibility of the coarse and finegrained materials). The resulting equation for the composite storage is represented as follows:

$$
S^{*}=S_{c}+S_{f}+S_{y}
$$

where

$S^{*} \quad$ is the total storage of the aquifer layer,

$S_{c} \quad$ is the storage of the coarse-grained component,

$S_{f} \quad$ is the storage of the fine-grained component, and

$S_{y} \quad$ is the specific yield from the water table drainage for the unconfined portions of an aquifer in a model layer.

Both $S_{c}$ and $S_{f}$ can be further represented by their respective components as follows:

$$
S=b \times S_{s}=\rho g(\alpha+n \beta) \times b
$$

where

$$
\begin{array}{cl}
S_{s} & \text { is the aquifer-system specific storage, } \\
\rho g & \text { is the weight of water, } \\
\alpha & \text { is the compressibility of the coarse- or fine- } \\
& \text { grained matrix material, } \\
n & \text { is the total porosity of the coarse- or fine- } \\
\text { grained material, }
\end{array}
$$

The $S_{s}$ for each model layer can be further subdivided into its components for coarse and fine-grained material on a cell-by-cell basis, resulting in a complete equation of storage based on textural fractions, total porosity, and matrix compressibility as follows:

$$
S_{s}=S_{s F c}+S_{s F f}=\rho g\left[\left(\alpha_{F c}+n_{F c} \beta\right) \times F c_{I, J}+\left(\alpha_{F f}+n_{F f} \beta\right) \times F f_{I, J}\right]
$$

where

$$
\begin{aligned}
& \text { total porosity, } n_{T}=n_{F c}+n_{F f}, \\
& \text { is the sum of the coarse and fine-grained } \\
& \quad \text { fractions of porosity, with } n_{F c}=n_{F c} \times F_{c_{I, J}} \\
& \text { and } n_{F f}=n_{F f} \times F_{f I, J} ;
\end{aligned}
$$

Combined with efficient expression of hydraulic properties in the MULT Package, the user can also extract the modelconstructed versions of hydraulic properties directly from the combination of input and modifications through the MULT and PVAL Packages. This specifically facilitates the ability to make direct parameter comparisons between field-estimated values of hydraulic properties from aquifer tests, wellbore flow logs, other surrogates for wellbore flow such as conductivity or temperature difference profiles, and model estimated properties during parameter estimation. Output of the separate files for the aquifer property values and arrays also can be used by specifying the keyword "PROPPRINT" after NPVAL. Please refer to appendix D for a description of the specific input for the new upgrades including the Expression Parser for MULT and ZONE Packages. These features are also available for the properties of the SUB Package, as described previously in the section on Subsidence Parameters.

\section{New Basic Package and Utility Features}

Changes to the Basic Package include the optional specification and use of a coordinate system, user-specified parameter vector sizes, additional Water Budget (WBGT) output-control option and list-file output suppression, as well as features to monitor and continue simulations. Parameter vector sizes that were previously fixed within MODFLOW can now be specified by the user to increase the capacity of the code to deal with large or highly parameterized problems. The user can now specify in the Basic Package not only MAXPARAM but also MAXPAR, MXCLST, and MXINST. STOPERROR for sustained runs for parameter estimation and PERCENTERROR monitoring have been included. Additional upgrades to the utilites have been implemented to increase model-run speed by optionally reducing I/O to the list file during parameter estimation runs. Please refer to appendix E for specific input instructions for using these new features. 


\section{New LGR Features}

MF-OWHM now incorporates the use of embedded local grid refinement (LGR) (Mehl and Hill, 2005, 2007) to further facilitate conjunctive-use analysis and related parameter estimation that includes the use of multi-grid particle tracking (Dickinson and others, 2012) and multi-grid particle tracking observations (Hanson and others, 2013) as higher order constraints and observations for parameter estimation. The inclusion of LGR allows the user to run a single-grid model without any additional specifications or embedded refined-grid models with the inclusion of the LGR specification file into the MF-OWHM name file. In addition, this version of LGR is now able to communicate other features besides groundwater flow across parent and child models for the Streamflow Routing Package (SFR2) and for (FMP3). Additional details on how the LGR is implemented for LGR-SFR linkage is described by Mehl (2008), for the LGR ghost-node simulation with the Boundary Flow and Head Package (BFH2) (Mehl and Hill, 2013), and implementation for FMP3 is described within appendix A.

\section{Enhanced TABFILE Features}

TABFILEs was first implemented in the revised SFR Package features introduced with MF-NWT (Niswonger and others, 2010) and subsequently added to the SWR Process to allow the user to include time-series input data at any sequence of times for multiple locations, such as stream inflows and diversions. This feature allows for more convenient construction of the model input data set, reduces preprocessing of the information relative to the model temporal dicretization, and eliminates having to remake the entire input data set for the purpose of simply adding temporal information to the input. MF-OWHM provides new enhanced TABFILE's time-series data that is processed based on the quantity of information available within the current time step. The time-series data is either interpolated (no data in a time step), time-weighted (multiple data in a time step), or uses a single value (one data point or point before or after time series). The enhanced TABFILE offers a scale factor to the final result, the ability to link multiple features to the same tabfile with each having a unique scale factor and provides links to additional packages, such as GHB (Bhead), WEL (Q), and MNW2 (Qdes).

The enhanced TABFILE feature allows MF-OWHM to connect to more types of precipitation-runoff models, such as the Basin Characterization Model (BCM, Flint and Flint, 2007a, b, 2008), Variable Infiltration Capacity model (VIC; Lattenmaeir and Gan, 1990; Lattenmaeir and others, 2008), or Precipitation Runoff Modeling system (PRMS, Leavesley and others, 1983, 1992; Hay and others, 2000) models with connections through SFR. This data input structure allows for easier parameter estimation through scale factors of runoff, simpler connections to time varying boundary heads to facilitate the simulation of features such as sea-level rise, and easier model updates or construction of self-updating model connections with data streams from other models and data networks. This feature parallels the SFR and SWR TABFILES feature and can be used in place of this feature or in combination with it. The details of new TABFILES data structures and inputs are summarized in appendix E.

\section{New Surface-Water Features}

New surface-water features include the integration of SFR and SWR as well as the connection of SWR to SFR and UZF. In addition to these fundamental connections between the main surface-water features, the SFR and SWR are optionally connected to subsidence to create additional deformationdependent flows. The drain returnflow Package (DRT) is now optionally connected directly to SWR or indirectly through SWR to SFR, and indirectly to SFR through the semi-routed returnflow connection between FMP and SFR. This connectivity is essential for conjunctive-use simulation and analysis and keeps this water in the model and available for surface flows and reuse.

\section{Surface-Water Routing Linkages}

Connections to canals or other surface-water bodies or structures simulated with SWR as points of diversion for semirouted deliveries or semi-routed returnflows is now indirectly available through the linkage between SFR and SWR that is available in MF-OWHM. The SWR canals can be used to deliver water to SFR diversion segments that can be used to withdraw water for irrigation through semi-routed deliveries to FMP. Returnflows can also be redirected from semi-routed returnflows of FMP back to SFR segments and indirectly to SWR reaches.

\section{Subsidence Linkage}

The subsidence sublink provides a direct feedback to several processes at the land surface that are used to simulate the movement of surface water. These include the simulation of surface-water flow with the Streamflow-Routing Package (SFR; Niswonger and Prudic, 2005) and the Surface-Water Routing Process (SWR; Hughes and others, 2012).

The SFR accounts for the exchange of water in streams and aquifers simulated with MF-OWHM combined with the simple routing of surface water throughout a river system. In SFR, a network of streams or other surface-water features are divided into fundamental lengths called "reaches" and "segments." Reaches are contained within a single model cell and groups of contiguous reaches form segments (fig 1). Segments can join to form larger stream networks. Within each stream reach, SFR accounts for all inflow, including flow from upstream reaches, discharge from the aquifer to the stream, precipitation, overland flow, and outflow, which includes flow to a downstream reach, discharge from the stream to the aquifer, diversions, and evapotranspiration. Surface-water outflow to the downstream stream reach is the residual of all inflow and other outflow terms for the reach. Stream reaches can go dry if outflows exceed inflows. Flow between each stream reach and the aquifer represented in the underlying model cell is a function of the difference in the stream stage and the head in the aquifer computed for the underlying cell. SFR can compute stream stage as a function of streamflow in the center of each reach using one of several available methods. The SFR Package requires non-zero positive slopes between reaches within a stream segment, and as such, may be affected by the linkage to SUB in regions of significant 
land subsidence. In regions where slopes may become zero or negative, the SWR Process can be better suited for simulation of surface-water flows that are traversing regions of land subsidence.

The Surface-Water Routing Process (SWR) is a more detailed approach to simulating surface-water movement in rivers and canals (Hughes and others, 2012). Combined with SFR, SWR provides a means to simulate additional man-made structures as well as assessment of specific features such as dead-pool storage, canal freeboard, flow reversals, and various engineered water-conveyance structures.

When linked to the SUB Package, the incremental displacements are used to update streambed bottom and stream slopes within SFR and canal or drop structure bottom elevations (SWR). Computed stream stage is a function of slope of the streambed and non-uniform vertical deformation of the land surface computed by SUB. Therefore, simulated subsidence can change the slope of the streambed and, hence, the computed stream stage and flow across the reach. Subsidence effects on stream stage, therefore, can affect rates of flow between the aquifer and the stream. In some cases, these effects could cause a stream to go dry in locations different from where the stream would have been dry without subsidence. Furthermore, if a subsidence "bowl" is traversed by a surface-water conveyance, then reduced slopes will result in reduced conveyance or increases in stage and related infiltration. For the simulation of canals with SWR, the additional effects from deformation can be evaluated for the elevation and slope of canals as well as the potential changes in freeboard with changes in land surface.

\section{New Observation Features}

To calibrate integrated hydrologic flow models, additional observations are needed to help constrain the additional parameters that are included through simulation of the landscape, surface-water, and groundwater flow processes within MF-OWHM. These observations need to not only provide feedback for the various processes and linkage between processes, but also need to further constrain the model's conceptual and numerical representation of the state and change (or rate of change) of these processes and feedback on linked processes. The observations of differences and rates of change represent higher-order observations that provide additional constraints and sensitivity during model calibration. While many traditional observations, such as groundwater levels, streamflows, and land subsidence, help to constrain the state of the movement and use of water, additional higher-order observations also can be used to increase parameter and observation sensitivity of the simulated processes. These commonly include observations such as changes in groundwater levels (drawdown), vertical head differences, gains and losses in streams and canals, changes in lake stage, changes in drain or irrigation returnflows, and onset of inelastic compaction. Four types of new observation features are included in MF-OWHM: output of aquifer hydraulic properties, more subsidence observations, additional ET observations, and additional drain return-flow observations.

Complete listing of final values for aquifer hydraulic properties, after all adjustments made by parameter-estimation template files and aquifer packages (LPF, UPW, or HUF) that may have also been modified by the MULT and PVAL Packages, are now available in separate files for processing as observations for use with parameter estimation or for compilation of final properties.

When using MF-OWHM with FMP3, agricultural pumpage, recharge, runoff, and actual ET are now estimates made by the model during simulation that also can be compared directly or indirectly against other estimates. Additional higher-order (rate-based) observations that could be used during model calibration of an IHM can include comparisons with reported pumpage for groups of wells that collectively serve a water-accounting unit, layer distributions of pumpage, supply and demand deliveries, hydraulic properties, drain returnflows, distributions of water sources, and independently derived estimates of actual evapotranspiration.

These observations related to landscape-driven processes are easily derived from existing and new features of MF-OWHM. Observations of pumpage are facilitated through FMP, which hasthe ability to create output of the estimated pumpage as a standard well package (WEL) input file or through the FDS output file of FMP (Schmid and Hanson, 2009). Examples of this type of comparison are demonstrated for the Pajaro Valley, California, where seasonal comparisons to reported pumpage helped to constrain the estimates of simulated pumpage derived from the ET demand from agriculture (Hanson and others, 2014a). The supply-and-demand deliveries, including actual compared to reported diversions of surface water for irrigation and simulated ASR operations, can be compared with reported supplies and deliveries through the output provided by the FDS output of FMP and SFR streamflow observations from HYDMOD (Hanson and Leake, 1998) or GAGE Packages. These types of higher-order observations not only constrain the processes but also the flow-dependent flows that are simulated by the linkages of an IHM. This comparison of streamflow diversions that are affected by stream or canal conveyance are exemplified by the comparisons of diversions for the Central Valley (Faunt and others, 2009a, b, c) and Pajaro Valley, California (Hanson and others, 2010, 2014a), and for the temporal distribution of deliveries for the simulated ASR operation of the coastal distribution system in Pajaro Valley, California (Hanson and others, 2014a). In addition, reported deliveries of recycled water for irrigation were used to help calibrate FMP properties for the Pajaro Valley, California (Hanson and others, 2014a).

Observations for comparison of simulated ET can be derived from independent estimates of actual ET. These observations can include estimates from local station or field-based meteorological estimates of ET and from indirect estimates of actual ET derived from energy-balanced estimates, such as the Surface Energy Balance (SEBAL; Senay and others, 2008; Cassel and others, 2006), Mapping Evapotranspiration at High 
Resolution with Internalized Calibration (METRIC; Allen and others, 2007a, b), or Simplified Surface Energy Balance (SSEB; Gowda and others, 2008) methods. Caution should be used in using the satellite-based estimates because they can vary in accuracy from 67 to 97 percent of field measurements (Gowda and others, 2008; Allen and others, 2005). Output of the simulated actual ET for direct comparisons with other independent estimates of actual ET is now available through FMP3. In addition, these simulated estimates of actual ET also can now be used as potential feedback to regional climate models that could benefit from a more detailed feedback from landscape processes that include ET returning moisture to the atmosphere.

Observations related to the groundwater-flow processes and related linkages are easily derived from existing and new features of MF-OWHM. For example, observations for groundwater flow as the vertical distribution of pumpage derived from the estimated pumpage from FMP farm wells along with output from MNW1 or MNW2 can be used to develop observations to assess the vertical (layer-by-layer) distributions of pumpage. These vertical distributions then can be used as observations and compared against field-based estimates such as wellbore flow profiles (Izbicki and others, 1999).

Additional observations of hydraulic properties can be developed through the output of all hydraulic properties to separate files after manipulation of these properties from anisotropy, multiplier (MULT), and parameter value (PVAL) adjustments. These observations can be used to compare with estimates of hydraulic properties derived from field data, such as hydraulic tests (slug tests, aquifer tests, pumping tests), or comparisons with or with micro-gravity (Pool and Schmidt, 1997; Parker and Pool, 1998) or satellite-based (Scanlon and others, 2012) estimates of change in storage. Observations of hydraulic properties can also be used to supplement regularization targets in the parameter estimation process.

Related to observations of changes in storage for alluvial aquifers, additional subsidence features also are available for the SUB Package (Schmid and Hanson, 2009, appendix B). This includes the ability to separately track the elastic and inelastic components of instantaneous interbed subsidence either as arrays or as time series through HYDMOD. The ability to differentiate elastic from inelastic subsidence greatly enhances the ability to estimate the preconsolidation stress (one of the most sensitive and unknown subsidence parameters) during parameter estimation, and to analyze these components of compaction separately for conjunctive-use and hazards analysis. This can include additional field observations from not only extensometers and benchmark time series, but also continuous GPS and point InSAR time series of surface deformation. The latter is exemplified by the use of observations from Plate Boundary Observation stations and point InSAR time series (Everett and others, 2013) for calibrating land subsidence parameters for the Cuyama Valley, California (Hanson and others, 2014c).
Observations derived from percentages of source water can be obtained through the use of MODPATH (Pollack, 1989, 1994) or MODPATH-LGR (Dickinson and others, 2011) with MODPATH-OBS (Hanson and others, 2013) with geochemical data such as isotopic estimates of mixtures or percentages of recharge, such as those derived for large watersheds such as the Santa Clara Valley (Muir and Coplen, 1981; Newhouse and others, 2004) and the Middle Rio Grande Valley (Sanford and others, 2003, 2004).

Observations of drain returnflows is now facilitated through separate output file of the location and flow rates of drain water. Canal and drain returnflows simulated with SFR, SWR, or DRT can be a critical element of analyzing operating agreements related to conjunctive use, such as that in the Lower Rio Grande region (Hanson and others, 2013b). The structure for drain returnflow observations is summarized in appendix E.

\section{Additional Budgets}

Additional features are now available for the landscape and groundwater budgets. With the additional ability to simulate regional agriculture and detailed local agriculture conditions in embedded child models comes the ability to maintain additional farm budgets. Farm budgets for both parent and child models are now available and include separate FDS and FB_Details budgets for the regional and local landscapes and a combined budget for both. The new groundwater-budget feature, Water Budget (WBGT) output-control option, will write the budget summary information specified by the user to a separate file along with writing it to the list file. Having this summary information isolated in a separate file makes it more convenient to perform conjunctive-use analysis, such as capture analysis, and facilitate post-processing in general.

\section{MF-OWHM Example Problem}

To demonstrate the functionality of MF-OWHM, an example problem is presented that uses the SUB, FMP3, SFR2, UZF1, SWR1, NWT/UPW, and MNW2 Packages to demonstrate the new linkages and flow interdependencies. The problem is also used to compare results with and without the SUBLink functionality active and to demonstrate that the NWT/UPW-MNW2 yields results comparable to those of the PCG/LPF-MNW1 version of the example problem. This example model was originally distributed with MF-FMP2 (Schmid and Hanson, 2009), modified to demonstrate the effects of deformation-dependent flows (Hanson and others, 2014), and here further modified to show the new linkage between FMP3 and NWT, and FMP3 and MNW2. Although not all features of these processes and packages are included in this example, it serves to illustrate many of the fundamental features needed for many regional hydrologic models that are used to simulate and analyze conjunctive use in a 
supply-and-demand framework of water movement and use by irrigated agriculture, natural vegetation and urban areas. A full suite of example problems that can be tested with MF-OWHM are included in the distribution package. This includes the LGR2 example (Mehl and Hill, 2007) with the boundary flow and head package (Mehl and Hill, 2013) and an additional version of this example problem that shows how to implement the FMP-LGR linkages for subgrid models with and without additional SFR (Mehl, 2008) and FMP features. Selected input and output data sets are shown in appendix F, and the complete data sets are included with the distribution package of MF-OWHM.

\section{Model Structure and Input}

The spatial discretization, boundary conditions, and structure of wells, rivers, canals, drains, farms, and other landscape features are summarized in figure 9. General head boundaries (GHB) at the up-gradient and down-gradient edge of the model domain from the example problem from the MF-FMP2 user guide (Schmid and Hanson, 2009) are used in an initial steady-state stress period to develop the predevelopment boundary inflows and outflows that progress to the 10 years of the transient simulation. The example problem spans 10 calendar years with monthly stress periods. The model grid consists of 23 rows and 20 columns with a uniform horizontal spacing of 500 meters $(\mathrm{m})$ and 7 layers with thicknesses ranging from $60 \mathrm{~m}$ to $94 \mathrm{~m}$. The original version of this example problem (Schmid and Hanson, 2009) used the Layer Property Flow Package (LPF) and the Preconditioned Conjugate Gradient Solver Package (PCG) for simulating the aquifers and solving the equations of surface water, landscape, and groundwater flow. For this example, the combination of LPF and PCG was replaced with the Upstream Weighting Package (UPW) that is used in concert with the Newton-Raphson Solver Package (NWT) (Niswonger and others, 2011).

The movement and use of water across the landscape that is simulated by FMP are represented by eight "farms" or water-accounting units, comprising five irrigated agricultural areas, an urban area, a non-irrigated riparian wetland, and a region of native vegetation that represents the largely undeveloped landscape surrounding the other seven accounting units (fig. 9). The landscape is covered by six vegetation types that represent vegetable row crops, orchards, winter grains, urban lawns/gardens, native vegetation, and riparian vegetation. The remaining features used to simulate consumption, recharge, and runoff are summarized by Schmid and Hanson (2009).

The model includes seven hydrostratigraphic layers made up of four aquifers and three intercalated confining-bed layers (fig. 9B) (Hanson and others, 2014). The FMP and SFR are connected with a network of streams (SFR), diversion segments (SFR/SWR), tributary segments used as drains (SFR), and canals (SWR) (fig. 9A). The streambed elevations of diversion segments follow the slope of a variable ground surface at defined depths (Schmid and others, 2006; Schmid and
Hanson, 2009, p. 93), which allows locally changing smaller and steeper streambed slopes and changes in slope from land subsidence. Using the default interpolation of SFR between streambed elevations at up- and down-stream end of diversion segments would create streambed elevations either cutting through variable morphological relief or high above the land surface. In addition, linear interpolation between different elevations would create relatively steep slopes that do not allow detection code limitations that arise for minimal slopes when using Manning's equation (slope in denominator leads to overestimation of stream stages). FMP is also linked to MNW2 with multi-node wells screened across several layers that supply water to Farm 5 (UZF Farm) and Farm 6 (Urban area) (fig. 9A). The MNW1 wells that were in the original version of this example (Schmid and Hanson, 2009) were simply replaced with MNW2 wells. FMP is also linked with UZF to simulate unsaturated-zone processes below Farm 5 and Farm 8 to include the effects of rejected infiltration and groundwater discharge to the surface in Farm 8 (Riparian area) (fig. 9A). The canal that loops through the urban area is simulated with SWR. It receives all of the flow from the SFR diversion on the main stem of the river below the simulated agricultural returnflows and returns flows back to the SFR river segment just before the river exits the model. SWR discharge to SFR is controlled by a fixed crest weir with a $5.5 \mathrm{~m}$ flow width and an invert elevation of $276.989 \mathrm{~m}$; a weir discharge coefficient and submergence exponent of 0.61 and 0.5 were specified, respectively. The canal is a trapezoidal channel with a 2:1 slope for the sides, an initial water depth of one meter, an initial slope of $4.35 \mathrm{e} \times 10^{-4} \mathrm{~m} / \mathrm{m}$, and a Manning coefficient of 0.4 .

The example model includes eight model farm IDs (fig. 9A), six model crop-type IDs (fig. 10A), and three model soil-type IDs (fig. 10B). Even though all model cells in FMP do not necessarily need to be assigned to "model farm IDs," in this particular example, all model cells of the model domain were assigned to eight "virtual farms" that represents wateraccounting regions. Six of these "virtual farms" are associated with farm wells for the potential delivery of groundwater, if needed. (fig. 9A). There are two additional non-irrigated, "rain-fed" water-accounting regions that represent a riparian wetland on the eastern boundary surrounding the river outflow (virtual farm 8) and natural vegetation throughout the remainder of the model (virtual farm 7).

The example model includes six virtual crop types that represent groups of crops aggregated by similar crop coefficients and growth-stage lengths (fig. 11). Although FMP provides the option to change the spatial distribution of crop types from stress period to stress period (often called "crop rotation"), in the present example the distribution of crop types does not change over time. Crop type 1 represents vegetable row crops consisting of 20 percent cabbage, 50 percent lettuce, and 30 percent green beans. Crop type 2 represents apple, cherry, and walnut-tree orchards. Crop type 3 represents winter grains, such as barley, wheat, and oats. The landscaping of the urban area, crop type 4, represents lawns and gardens, which are simulated with crop coefficients of turf. Crop type 5 


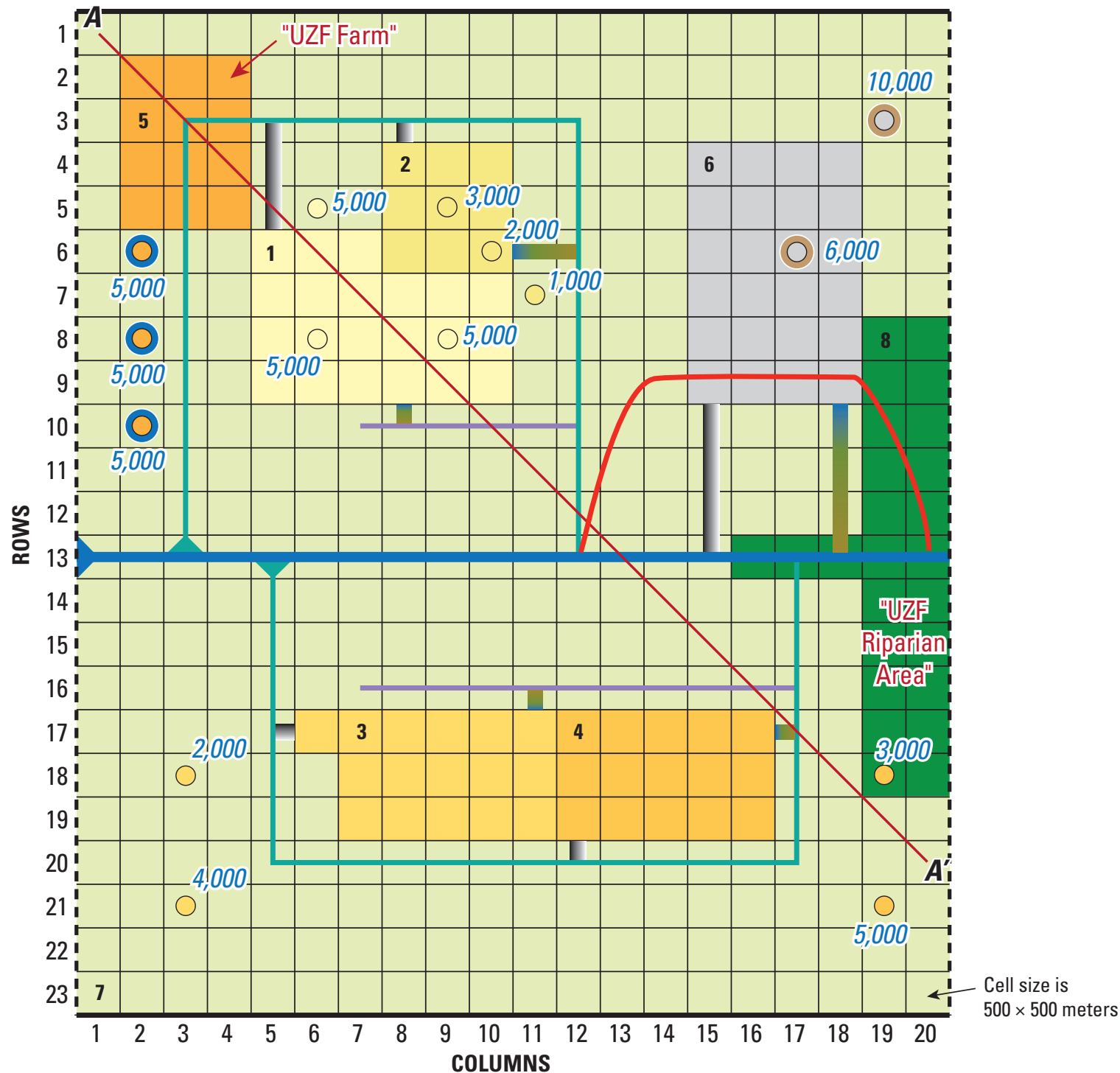

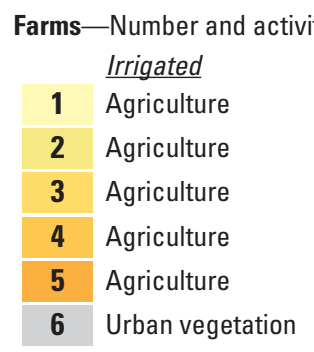

Streamflow routing network (SFR)

Inflow into stream,

Odd years: 100,000 cubic meters per day

Even years: 50,000 cubic meters per day

Diversion into canals,

10,000 cubic meters per day

(reduced to 8,000 cubic meters per day)

\section{EXPLANATION}

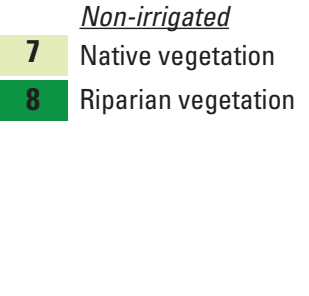

Semi-routed deliveries

Semi-routed remote return-flow locations

No-flow boundary

- - - General-head boundary

Stream (6-meter width) $\mathrm{K}_{\mathrm{v}}=0.2$ meter per day

Canal (3-meter width), $\mathrm{K}_{\mathrm{v}}=0.01$ meter per day

Drain (3-meter width), $\mathrm{K}_{\mathrm{v}}=1$ meter per day

$\mathrm{K}_{\mathrm{v}}$ is vertical hydraulic conductivity
Wells-Supply to

Farm 1

$\bigcirc$ Farm 2

Farm 3

Farm 4

Farm 5

Farm 6

\section{5,000}

Multi-node farm well screened in layers $1-4$

Multi-node farm well screened in layers 2 - 4

Maximum pumping capacity, in meters cubed per day

Surface-water routing network (SWR) Urban canal (12 reaches)

Water depth $=1$ meter Length $=500$ and 603 meters Width $=6$ meters

Manning coefficient $=0.04$

A-A' Section shown on figure 12

Figure 9. Example model structure and features with $A$, plan view of model domain, grid resolution, boundary conditions, distribution of farms and farm wells, and streamflow routing network with points of diversion to farms and points of returnflow from farms and surfacewater canal traversing an urban area, $B$, block view of model layering, and $C$, simulated land subsidence (Schmid and others, 2014). (Abbreviations: $\mathrm{m} / \mathrm{d}$, meter per day; UZF, Unsaturated Zone Flow Package) 
B

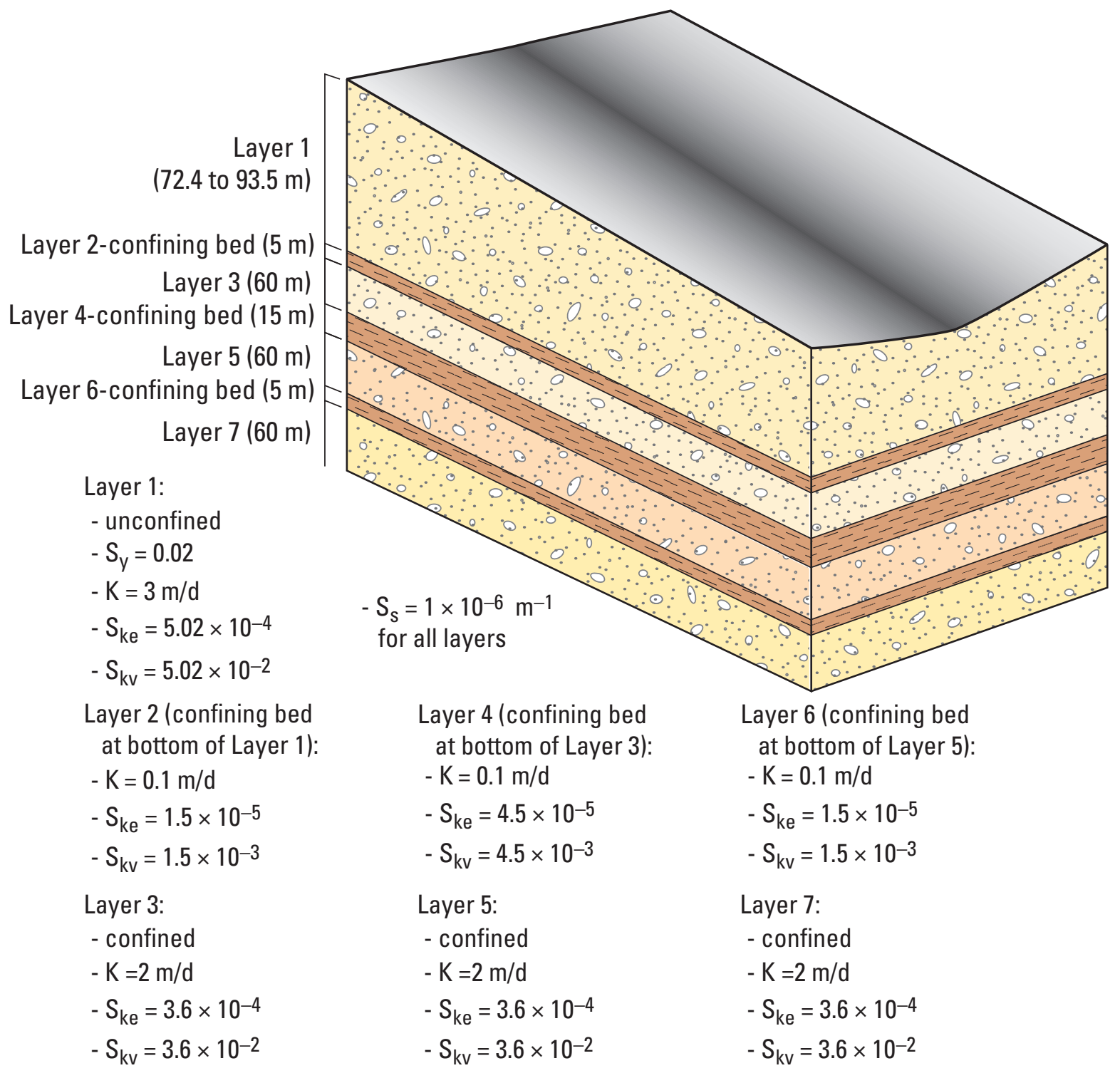

C

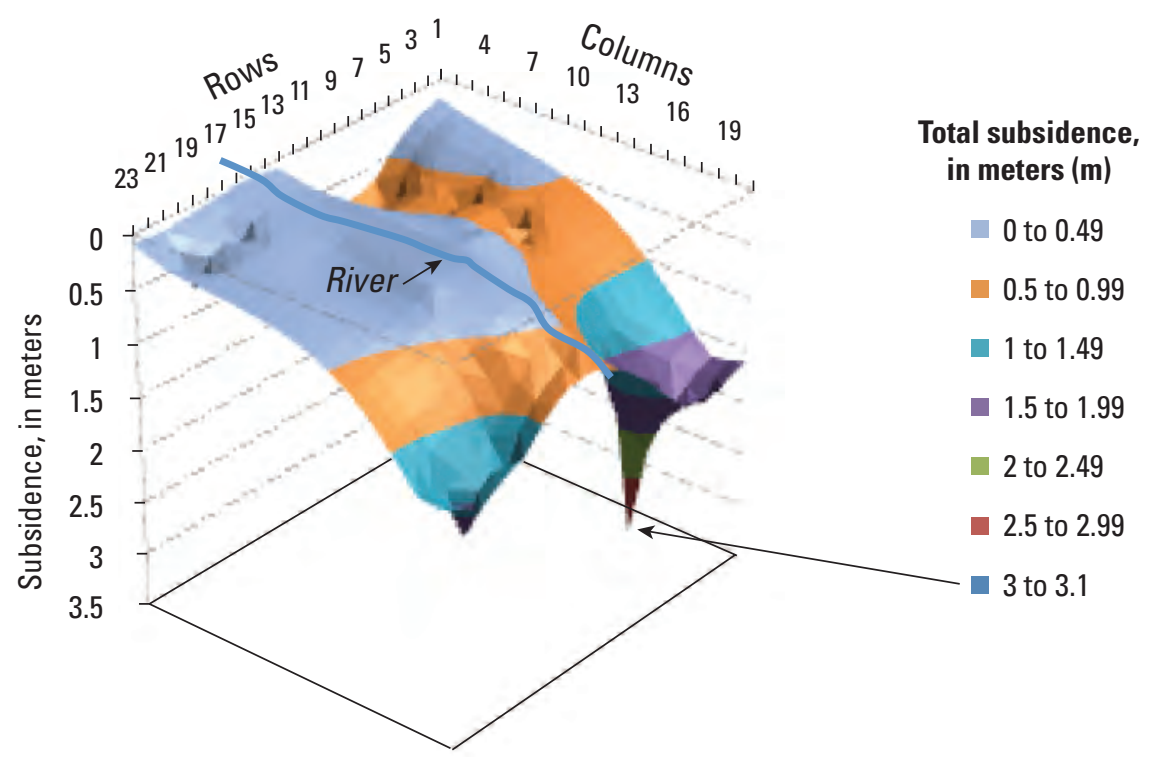

Figure 9. - Continued 
represents native vegetation comprising equal areas of pasturegrazed, grass-clover, wildlife area, and non-bearing trees and vines. Crop type 6 represents a riparian area with willows that are capable of taking up water under variable saturated conditions.

For each crop group, weighted averages of individual crop coefficients and growth-stage lengths were computed on the basis of the percentage contributed by each individual crop. The individual values for initial-, mid-, and end-season crop coefficients, as well as the durations for initial, development, mid, and late growth stages, were compiled from databases in various sources of literature (for example, Food and Agriculture Organization Irrigation and Drainage Paper 56, in Allen and others, 1998). For each crop group that represents average growth and harvest attributes, a daily time series (365 days) of crop coefficients was calculated using the "composite" crop coefficients and "composite" growth-stage lengths. Finally, 12 monthly averages of crop coefficients were calculated on the basis of the daily time series and applied over the 10-year simulation period to stress periods 1 through 12 and 13 through 24 of the example model. The monthly crop coefficients allow the different types of vegetation to be active at different times of the year as they each cycle through their seasonal growth stages (fig. 11A). Virtual crop coefficients for virtual crop types (crop groups), as described above, were preprocessed for the example model prior to assembling the FMP data input. The technique and algorithms applied are formulated in EXCEL spreadsheets that also contain a compilation of crop coefficients and growth-stage lengths obtained from the literature. These EXCEL spreadsheets are provided with the release package of MF-OWHM. Other approaches on how to preprocess crop coefficients for each model stress period could be possible.

Crop-specific parameters required by the FMP include fractions of transpiration and fractions of evaporation related to precipitation or to irrigation for the six crop groups. The separate simulation of transpiration and evaporation is an essential difference of FMP from many other hydrologic models, which assume a common extinction depth for a composite evapotranspiration term. In FMP3, though the evaporation from groundwater is extinct at a depth to water equal to a specified capillary fringe, the transpiration from groundwater is extinct at a depth to water equal to the root zone plus the capillary fringe. The example problem simulates crop transpiration both under unsaturated conditions (crop types 1 through 5) and saturated conditions (for example, crop type 6 simulated as riparian willows) by analytical solutions. Fractions of transpiration and evaporation are varied on a monthly basis (figs. 11B-D).

The fraction of transpiration, FTR, can be derived as $\mathrm{FTR}=\mathrm{K}_{\mathrm{cb}} / \mathrm{K}_{\mathrm{c}}$ (from the literature) if, in addition to the total crop coefficient, $\mathrm{K}_{\mathrm{c}}$, a "basal" transpiratory crop coefficient, $\mathrm{K}_{\mathrm{cb}}$, is available (Allen and others, 1998; Allen and others 2005; Food and Agriculture Organization, 2007). The fraction of evaporation that is related to exposed areas wetted by precipitation, FEP, depends on the exposed nonvegetative bare soil surface wetted by precipitation. Even though, in reality, transpiration and evaporation can be related nonlinearly, for the virtual crop types 1 through 3 and 5 in this example model, we simplify the fraction of evaporation to equal to the complement of the fraction of transpiration, that is, FEP $=1-$ FTR. The fraction of evaporation related to irrigation (FEI) depends on the fraction of the exposed soil surface that is wetted by irrigation. Unlike the soil surface wetted by precipitation, the exposed areas wetted by irrigation may not be entirely wetted. The extent to which the exposed area is wetted depends on the irrigation method used, which, in reality, commonly follows a particular crop type. For the virtual crop types 1 through 3 in the example model, the fraction of transpiration related to irrigation is assumed to be constrained by the lesser of the complement of the fraction of transpiration or by the wetted fraction, $\mathrm{f}_{\mathrm{w}}$ (available from the literature), for certain irrigation methods (Allen and others, 1998; Allen and others 2005; Food and Agriculture Organization, 2007), that is, FEI $=\min \left(1-F T R, f_{w}\right)$. Fractions of transpiration and evaporation are FMP parameters that bear a high uncertainty, and MF-OWHM models are quite sensitive to these parameters (Schmid and others, 2008). The demonstrated approach is one of many ways that the fraction of transpiration and evaporation can be either physically based or based on published data. Rough initial estimates of these fractions may be specified, but one is advised to improve these parameters with estimates derived during the model calibration process.

For the urban area (crop type 4), the fraction of transpiration is assumed to be equal to the fraction of the entire area from which transpiration takes place (for example, lawns and gardens). In many cases, land-use surveys specify the percentage of irrigated land in urban areas. In the example model, an average value of such a percentage range (for example, 12.5 percent as the average of 0 to 25 percent) is used to represent the fraction of the area (that is, 0.125 ) where transpiration occurs. The fraction of evaporation then is assumed to be equal to the fraction of the entire urban area that is open and exposed (such as housing and other buildings, parking lots, industry, airports). For the Native Vegetation (crop type 5), the fraction of evaporation related to irrigation is specified using placeholder zero values because no irrigation is applied. For Riparian Vegetation (crop type 6), the fractions of transpiration and of evaporation related to precipitation are pure assumptions. No basal crop coefficients, $\mathrm{K}_{\mathrm{cb}}$, were found in the literature that could be applied. The fractions of evaporation related to irrigation again are placeholder zero values because no irrigation is applied.

The model represents the three soil types that are internally defined by FMP as silt, sandy loam, and silty clay (fig. 10B). Root depths are specified for all crop types for every stress period $(I R T F L=2)$ and vary for some of the crop types, such as vegetable row crops and winter grains, while they are held constant for the others. For the example model, the maximum rooting depth is taken to be the average between values available through Allen and others (1998, table 22) and Brush and others (2006). For perennial crops, such as orchards and turf, or for native and riparian vegetation, the rooting depth is assumed to be constant over time. For annuals like 
$\boldsymbol{A}$

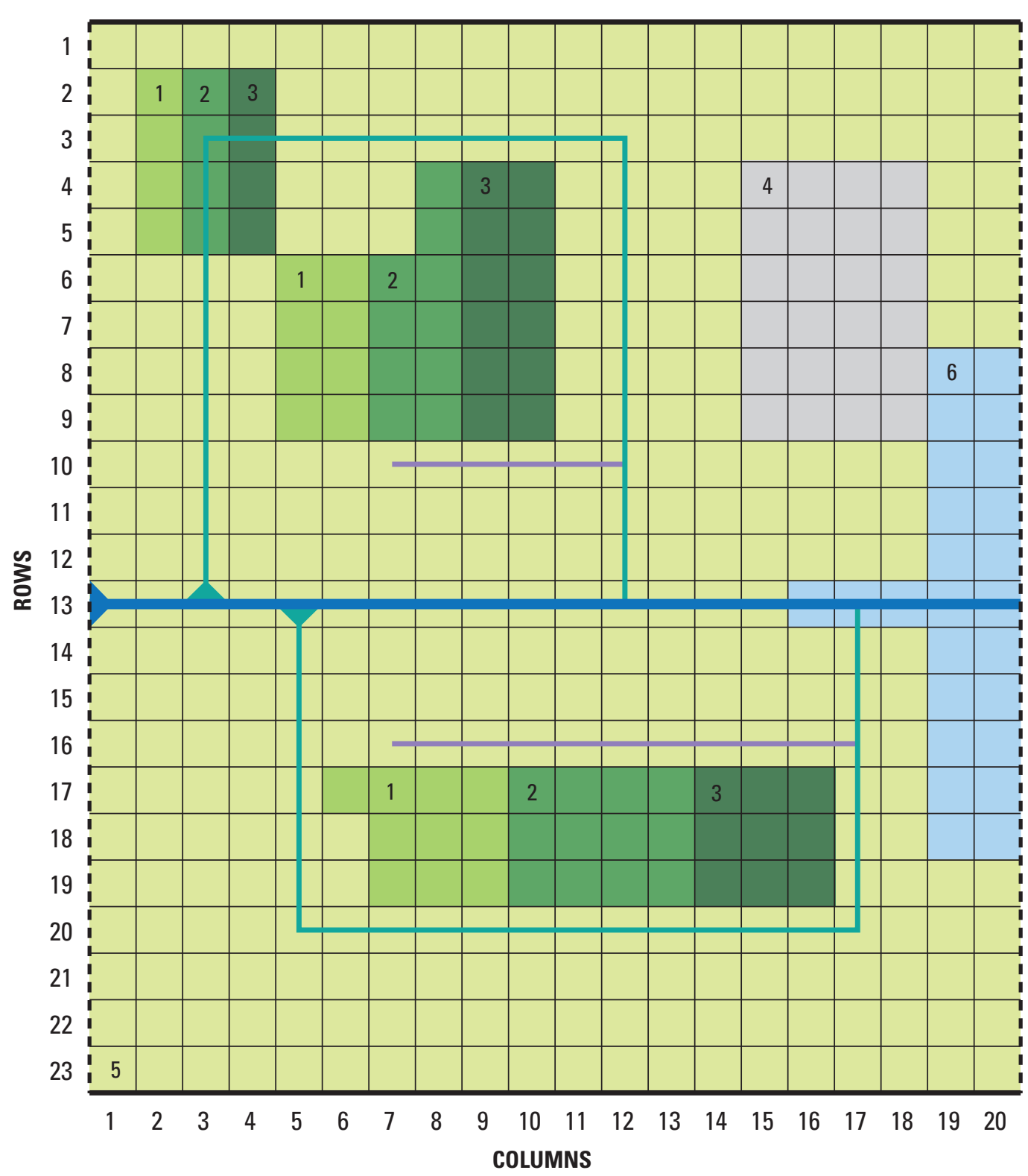

Crop or vegetation type-

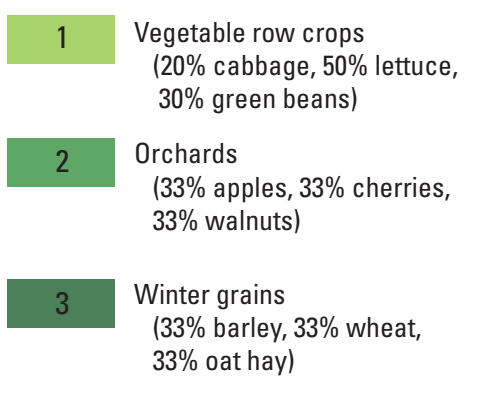

\section{EXPLANATION}

$4 \quad$ Irriagted urban

(Lawns and gardens

simulated as turf)

5

Native

(25\% pasture-grazed, $25 \%$ grass-clover, $25 \%$ wildlife area, $25 \%$ nonbearing trees and vines)

6
Riparian

(Willows)

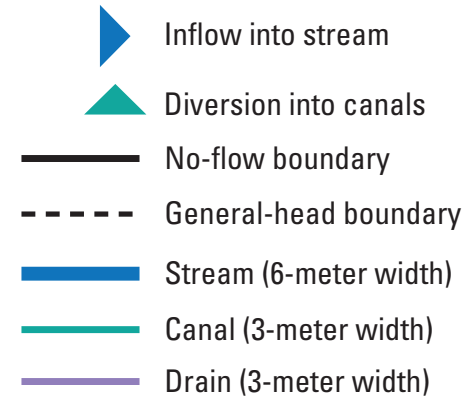

Figure 10. Grid showing $A$, crop and other vegetation distribution, and $B$, distribution of soils for MF-OWHM example model (Schmid and Hanson, 2009). 
B

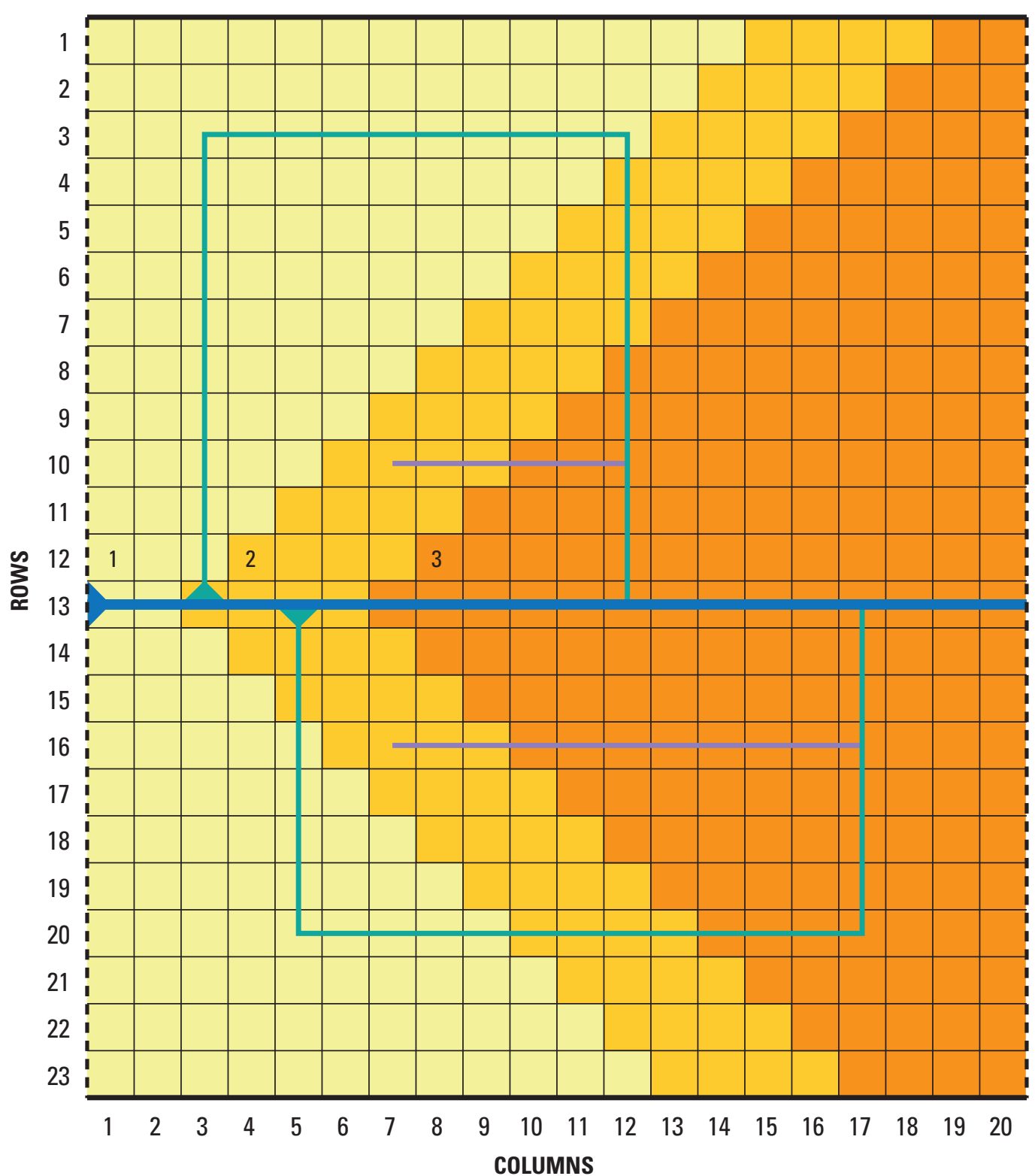

\begin{tabular}{|c|c|}
\hline Soil type- & \\
\hline 1 & Silt \\
\hline 2 & Sandy loam \\
\hline 3 & Silty clay \\
\hline
\end{tabular}

EXPLANATION

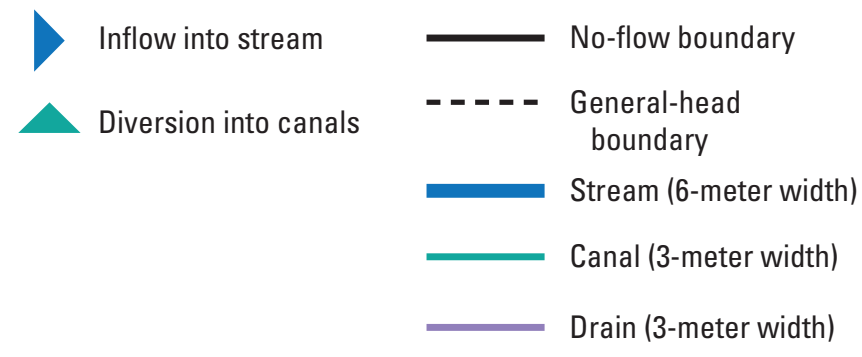

Figure 10. - Continued 


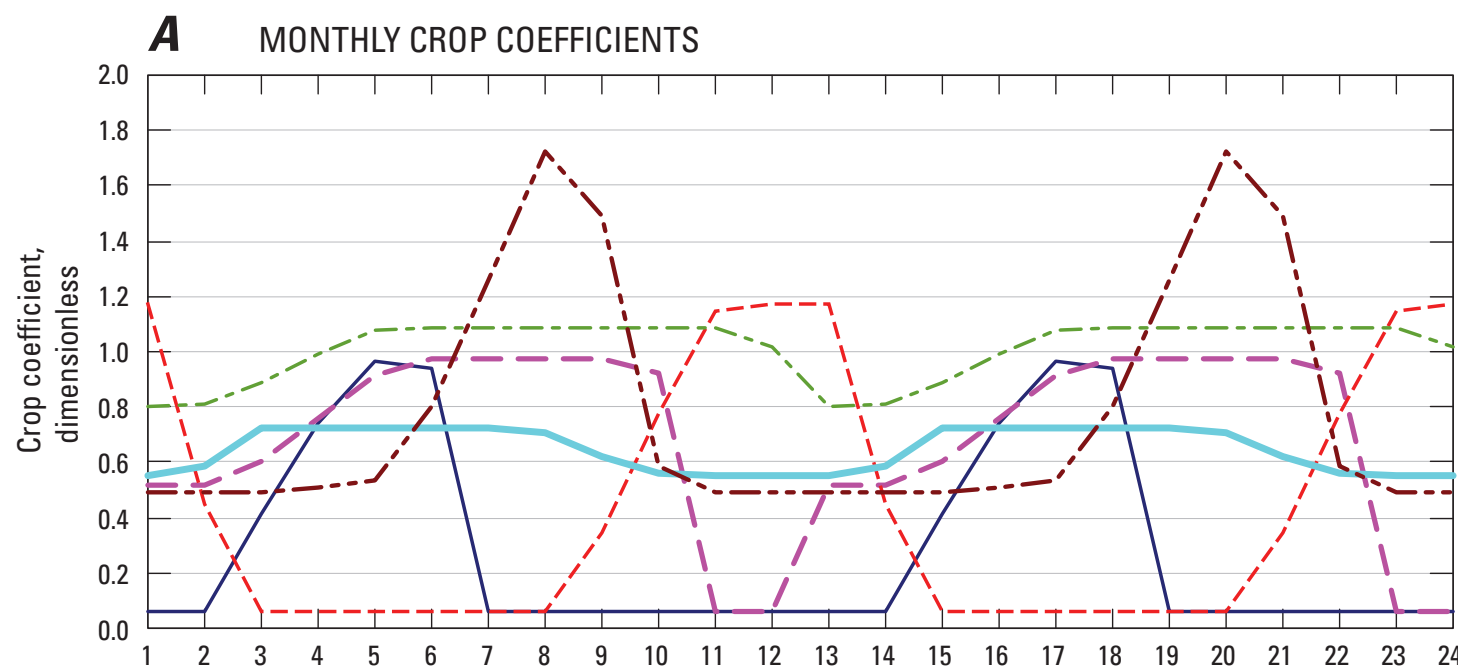

\section{EXPLANATION}

Crop or vegetation type-

- Vegetable row crops (20\% cabbage,

$50 \%$ lettuce, $30 \%$ green beans)

- Orchards

(33\% apples,

$33 \%$ cherries $33 \%$ walnuts

- - - - Winter grains (33\% barley, $33 \%$ wheat, $33 \%$ oat hay)

B MONTHLY FRACTIONS OF TRANSPIRATION

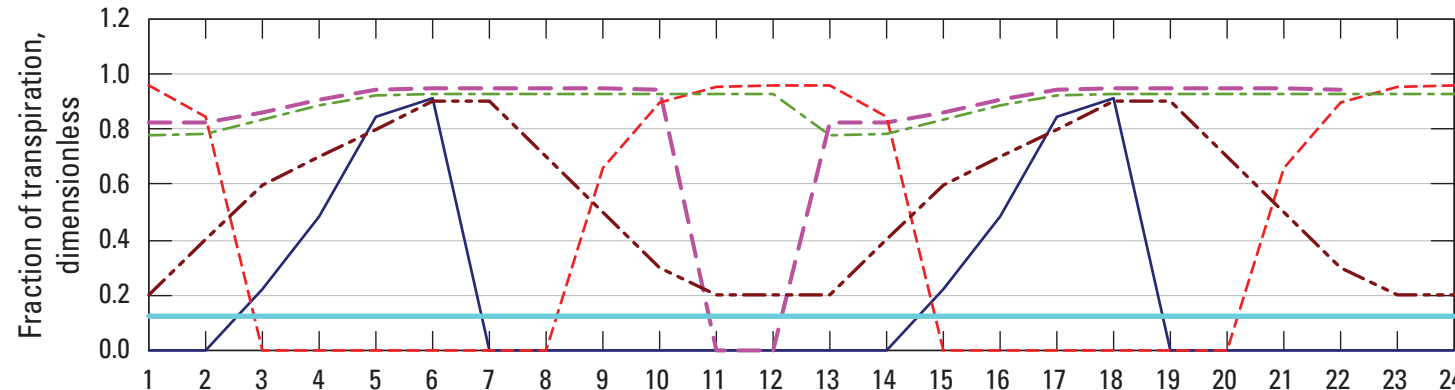

rrigated urban

(Lawns and

gardens

simulated as turf

- - Native

(25\% pasture-

grazed,

$25 \%$ grass-clover,

$25 \%$ wildlife area

$25 \%$ nonbearing

trees and vines)

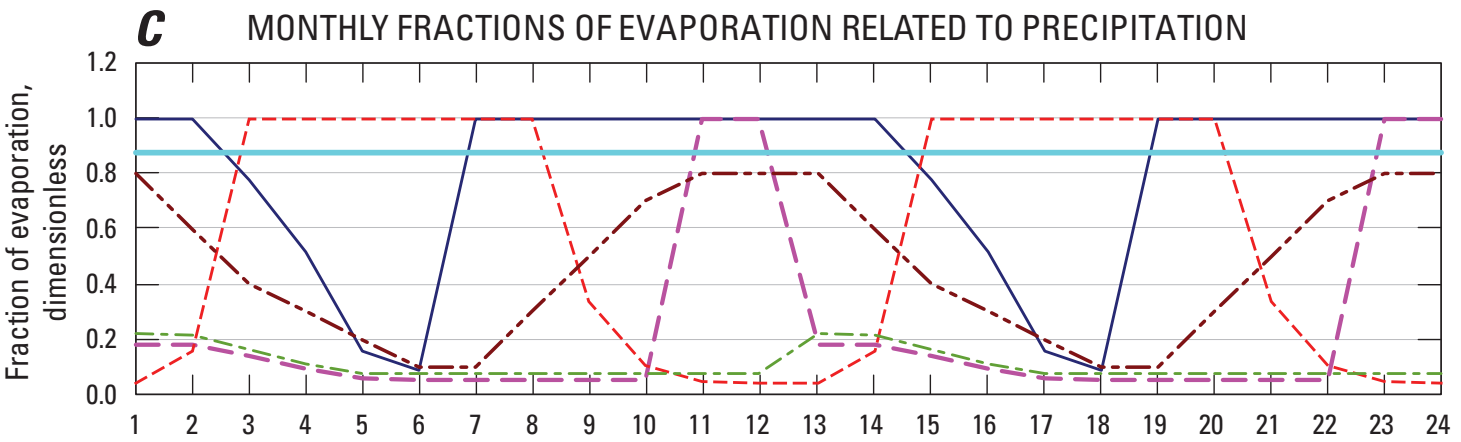

Riparian

(Willows)

\section{MONTHLY FRACTIONS OF EVAPORATION RELATED TO IRRIGATION}

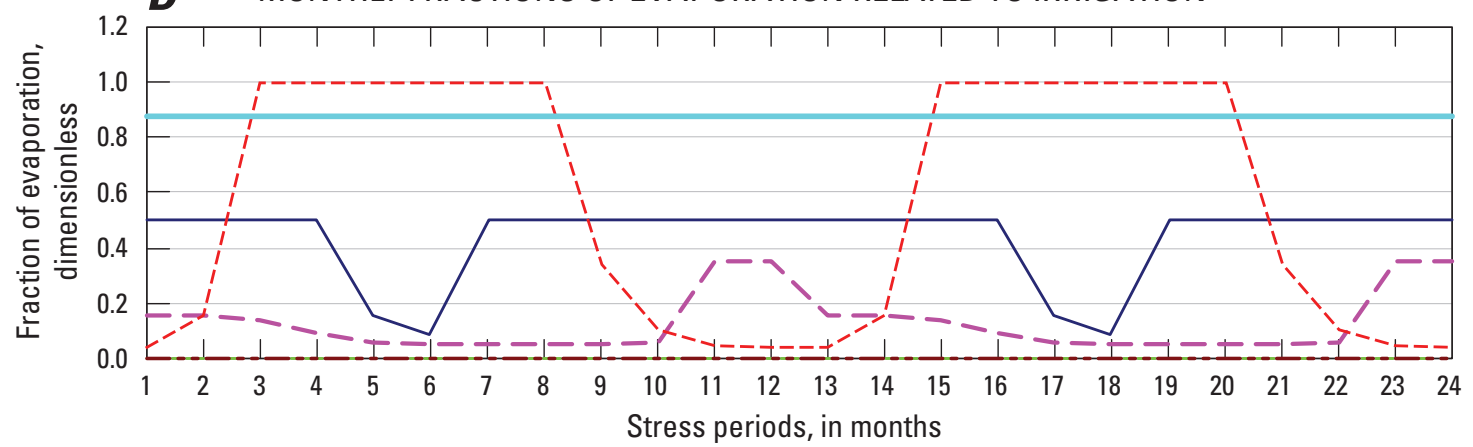

Figure 11. Graphs showing $A$, crop coefficients, $B$, fractions of transpiration, $C$, fractions of evaporation related to precipitation, and $D$, fractions of evaporation related to irrigation through time for the 6 virtual crop types in the MF-OWHM example problem (Schmid and Hanson, 2009). 
vegetable row crops and winter grains, the root zone depth is assumed to vary proportionally to the crop coefficient of each stress period, with a proportionality factor equal to the ratio of maximum rooting depth to maximum crop coefficient. This algorithm is used as long as the crop coefficient increases or remains constant at its maximum or minimum.

$$
\begin{array}{rllll}
R Z^{\mathrm{t}}=\left(\mathrm{RZ}_{\max } / \mathrm{K}_{\mathrm{c}-\max }\right) \times \mathrm{K} c^{\mathrm{t}}, & \text { if } & \mathrm{K} c^{\mathrm{t}} \geq \mathrm{K} c^{\mathrm{t}-1} & \text { or } & \mathrm{K} c^{\mathrm{t}}=\mathrm{K}_{\mathrm{c}-\min } \\
\mathrm{RZ} Z^{\mathrm{t}}=\mathrm{RZ} Z^{\mathrm{t}-1}, & \text { if } & \mathrm{K} c^{\mathrm{t}}<\mathrm{K} c^{\mathrm{t}-1} & \text { and } & \mathrm{K} c^{\mathrm{t}} \neq \mathrm{K}_{\mathrm{c}-\text { min }}
\end{array}
$$

During the end period, the crop coefficient decreases until harvest takes place. Yet, the root zone that reached a maximum during the mid-period is assumed to remain at the maximum until the crop coefficient drops to the off-season minimum value corresponding to harvest or senescence.

Fractions of inefficient losses to surface-water runoff are specified for each virtual crop type for the each stress period. In FMP, surface-water runoff is assumed to depend on irrigation methods, which in turn may depend in part on the crop type. Because rainfall intensity and irrigation application methods further influence runoff, FMP requires input of two separate fractions of inefficient losses to surface-water runoff: one related to precipitation (FIESWP) and another related to irrigation (FIESWI), which may be omitted or set to placeholder zero values for non-irrigated crop types, such as native vegetation (crop type 5) and riparian (crop type 6). In the example model, FIESWP and FIESWI are held constant over time for crop types 1 through 4. However, FIESWP increases for native vegetation (crop type 5) and riparian (crop type 6) during the winter-spring months, indicating an increased fraction of inefficient losses to runoff during the heavy winterspring precipitation typical of the climate in Davis, California. Additional runoff components are calculated by the UZF-FMP link for farm 5 and the riparian area (farm 8) stemming from infiltration in excess of the saturated hydraulic conductivity, the groundwater discharge to land surface, and rejected infiltration for high groundwater levels. In FMP, two flags indicate the design of the runoff return-flow routing system (see later). In UZF1, a two-dimensional integer array, IRUNBD, specifies the SFR streamflow segment for each UZF-active cell in which the potential runoff is returned to the river (Schmid and Hanson, 2009; appendix A).

Crop-specific parameters, such as crop coefficients, root zone depths, fractions of transpiration and evaporation, and fractions of inefficient losses to surface-water runoff, can vary from stress period to stress period. Contrary to that, pressure heads that define stress-response function coefficients are the only crop-related set of parameters that are specified for the entire simulation. Noticeably, in FMP a stress-response function can be defined under both unsaturated and saturated conditions for either negative or positive pressure heads at which uptake is either zero or at maximum. In the example model simulation, the stress response of riparian willow trees (crop type 6) to water uptake is described by a stress-response function, where the optimal uptake occurs under unsaturated conditions, but a reduced uptake is still possible in saturated conditions until the pressure head reaches 20 centimeters (cm) and uptakes becomes zero (Schmid and Hanson, 2009; appendix A, file PSI.IN).

Reference evapotranspiration and precipitation are set as constant within each monthly stress period, but vary from stress period to stress period. The data are derived from CIMIS data for the weather station at the University of California, Davis (http://wwwcimis.water.ca.gov/, accessed April 20, 2009). For each month of the year, a median was determined from the monthly values during the period from 1982 to 2008 .

Surface-water deliveries to irrigated farms include nonrouted water transfers from outside the model domain and equally appropriated semi-routed deliveries along a streamflow routing network simulated with the SFR2 Package. Nonrouted deliveries (NRDs) are assumed to be known volumes of deliverable water for each stress period (Schmid and Hanson, 2009; appendix A, file NRDV.IN). NRDs are supplied to all but the natural vegetation and riparian areas with a variable monthly scale factor that changes the volume of the NRDs over the course of each model year (Schmid and Hanson, 2009; appendix A, file NRDFAC.IN). Semi-routed surfacewater deliveries to irrigated farms are diverted from specified stream reaches (Schmid and Hanson, 2009; appendix A, file SRD.IN) located outside the farm domain. The term "semi" is used in the following sense:

a) Deliveries routed along the stream network to a userspecified point of diversion.

b) Non-routed delivery (for example, pipe flow) from the user-specified point of diversion (perceived as 'remote head-gate') to the farm.

Semi-routed runoff is returned to the stream network (simulated by SFR2) at a specified location only for farm 1 (Schmid and Hanson, 2009; appendix A, file SRR.IN). In FMP3, ISRRFL was set to 1, indicating that these locations are specified only once for the entire simulation. For all farms other than farm 1, zeros are specified, indicating that no returnflow location is specified, and if, alternatively, no stream segment is within the farm's domain, it automatically searches for a stream reach nearest to the lowest elevation of the farm to which runoff returnflow will be discharged. The new flag in FMP2, IRRFL, was set to -1 , so that the farm's runoff would be prorated as fully routed return-flow over the reaches of "any type of stream segment," found within the farm (as opposed to "non-diversion segments" if IRRFL =1). For three farms [farm 5, the native vegetation (farm 7), and the riparian area (farm 8)], stream segments were found within the domain of each farm, and each farm's returnflow was prorated accordingly over those reaches. An output file ROUT.OUT was written that informs the system of routing deliveries to, and runoff away from, each farm (Schmid and Hanson, 2009; appendix A contains the portion of the file that pertains to stress period 1 , time step 1). 
The data input for linked packages can be found in appendix F. The reader is referred to the NWT, SFR2, UZF1, SWR1, and MNW2 input instructions for the explanations of the NWT, SFR2, UZF1, SWR1, and MNW2 data input used in the example model (Niswonger and Prudic, 2005; Niswonger and others, 2006, 2011; Hughes and others, 2012; Konikow and others, 2009). The streamflow network and its hydraulic properties are summarized in figure 9 along with the location and screening of multi-node wells (fig. 10).

The linkage to the UZF1 Package facilitates delayed recharge through the unsaturated zone in the upgradient areas (western part of the model domain), such as at farm 5 (fig. 9). This linkage also allows simulation of rejected infiltration in the riparian areas in the discharge region along the river outflow at the eastern part of the model domain (farm 8) (fig. 9). The areas where this linkage is active, specified through the UZF Package input in the IUZFBND array, are only coincident with farm 5 and the riparian area (farm 8). The additional unsaturated-zone properties that are specified include a Brooks-Corey epsilon of 0.35 , a saturated water content of 0.2 , an initial water content of 0.16 , and a saturated vertical hydraulic conductivity for the unsaturated zone of 0.001 meters per day. The relations among the land surface, the initial water table, and the peak-season water table for model layer 1 are shown for the unsaturated zone beneath farm 5 (fig. 12).

FMP features include temporally distributed precipitation as a specified-flux boundary condition that is typical of the rainfall for Davis, California, in the Central Valley. This helps to facilitate delayed recharge following more time-varying supplies from precipitation and irrigation to crops, urban areas, and native vegetation. The FMP is also using semi-routed deliveries and returnflows to connect agriculture with surface water derived from the river (fig. 9). The distribution of crops demonstrates the combined use of precipitation and irrigation for winter wheat compared to surface and groundwater supplies for irrigation of orchard and vegetable crops grown during the spring and summer.

The SUB Package used steady-state heads as critical heads to facilitate land subsidence with the onset of pumpage. To ensure that the pumpage provide significant drawdowns to drive subsidence, the transient model was extended to a 10 -year model by repeating the 2 years of monthly stress periods of the FMP model five times. The subsidence-package data-input set contains elastic and inelastic specific-storage coefficients $\left(\mathrm{S}_{\text {ske }}\right.$ and $\left.\mathrm{S}_{\text {skv }}\right)$ of $6 \times 10^{-6} \mathrm{~m}^{-1}$, respectively, and $6 \times 10^{-4} \mathrm{~m}^{-1}$ for fine-grained interbeds of all aquifer layers and $3 \times 10^{-6} \mathrm{~m}^{-1}$ and $3 \times 10^{-4} \mathrm{~m}^{-1}$, respectively, for all confining bed layers (fig. 9B). All subsidence is assumed to be instantaneous with no-delay interbeds or confining beds and is active in all cells of all model layers. Land subsidence ranged from 0 to $3.1 \mathrm{~m}$, and was greatest beneath the city near the urban supply wells after the 10 years (fig. 9C). This is also the region where a canal is routing flow with SWR to demonstrate the effects on conveyance and stage from the subsidence linkage.

All of the previous features and behavior of the example model described for MF-FMP2 (Schmid and Hanson, 2009) remain similar, with the exception of the addition of subsidence as a source of water and the effects of the linkage with land subsidence on landscape, surface-water, and groundwater flows.

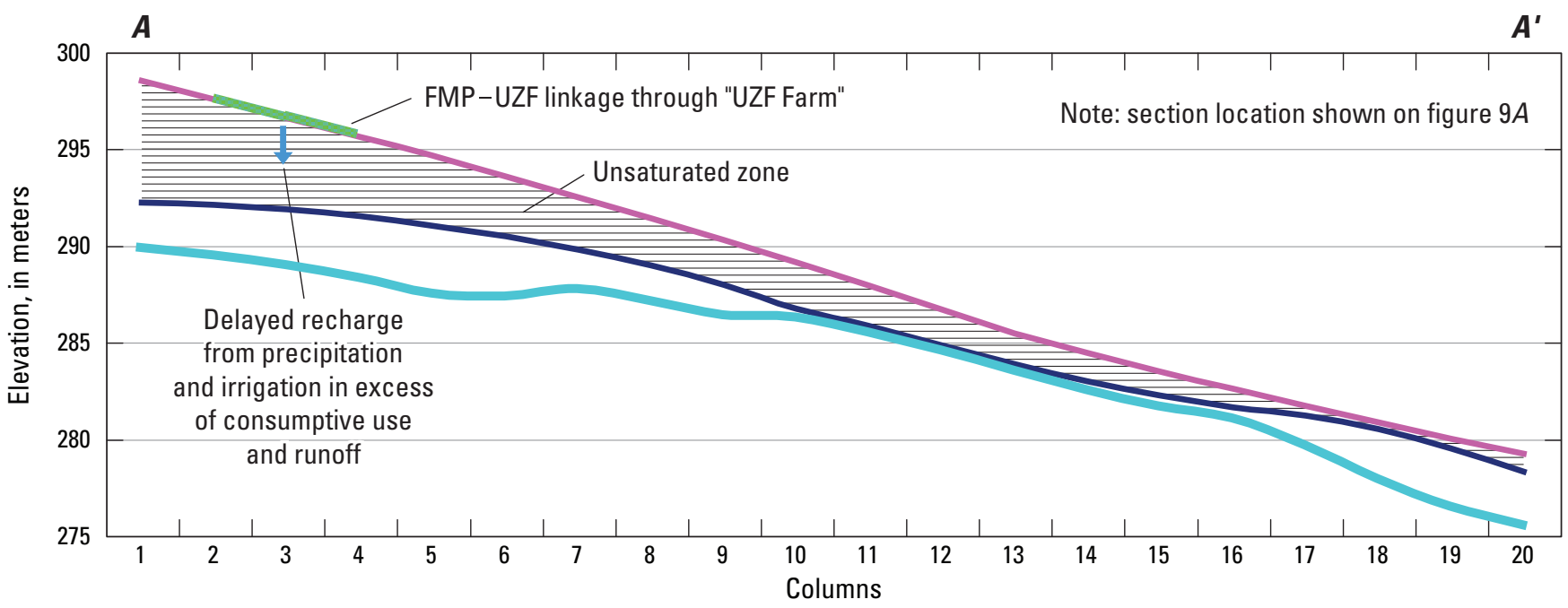

EXPLANATION

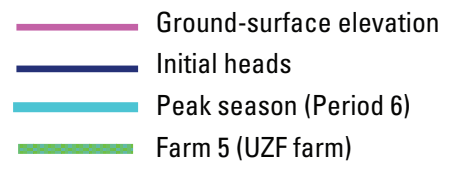

Figure 12. Relation between the land surface and the water table with an unsaturated zone for the MF-OWHM example (Schmid and Hanson, 2009). (Abbreviations: FMP, Farm Process; UZF, Unsaturated Zone Flow Package). 


\section{Comparison of Results With and Without Subsidence Linkage}

The connection between land subsidence and other processes in MODFLOW has a significant effect on surface and subsurface processes that can affect conjunctive water use. Secondary effects, such as land subsidence, can limit development and dictate the management of conjunctive water use through deformation-dependent flows. The relative differences in simulation results with and without the subsidence linkage (SUBLink) in the example model indicate that there are potentially important differences in groundwater, landscape, and surface-water flows (Schmid and others, 2014). Using SUBLink compared to using SUB without any links (NoLinks) produces 11 percent more net stream seepage and 36 percent less net farm net-recharge, but 4 percent more net release from aquifer and interbed storages. The overall groundwater budget also is increased by 2.2 percent over the 10 -year period simulated with the linkage.

Groundwater levels, critical heads, elastic and inelastic compaction, and farm irrigation-well pumpage also show large relative differences during periods of land subsidence for the overall simulation and larger differences locally and temporally. These effects are largest near the urban center, where withdrawals from the urban wells drive the largest amounts of land subsidence (fig. 9C). This feedback of land subsidence through SUBLink changes to the land surface alone results in a reduction of net stream seepage and net farm net-recharge.
Even though hydraulic diffusivity remains the same with reduced aquifer thickness, the capacity to transmit and store the same inflows and outflows is reduced. Thus, seepage from the river increases to compensate for less water available from the subsurface. Net aquifer and interbed storage increases when SUBLink-dominated surface sources are decreased. Differences in supply-and-demand components related to irrigation also occur with the addition of linkage to land subsidence. The fact that net farm net-recharge is lessened across all three comparisons is the result of about a 1 percent increase in deep percolation and about 48 percent increase in direct uptake as ET from groundwater because the root zone is now closer to the water table and the related capillary fringe.

While the difference in cumulative groundwater shows a small increase, the farm budget components are generally less than about 48 percent, with the net stream seepage increased by 11 percent with loss of storage, and net farm net-recharge decreased by 36 percent. This demonstrates the importance of including land subsidence in the simulation of alluvial aquifer systems that are subject to deformation. The groundwater inflow and outflow components that have the largest relative differences are stream leakage, recharge, and evapotranspiration from groundwater; however, larger relative differences in aquifer and interbed storage occur temporally during critical periods of pumpage and irrigation when conjunctive water use is most important (fig. 13).

The coupling not only affects water use but also the movement of water across the landscape related to irrigation

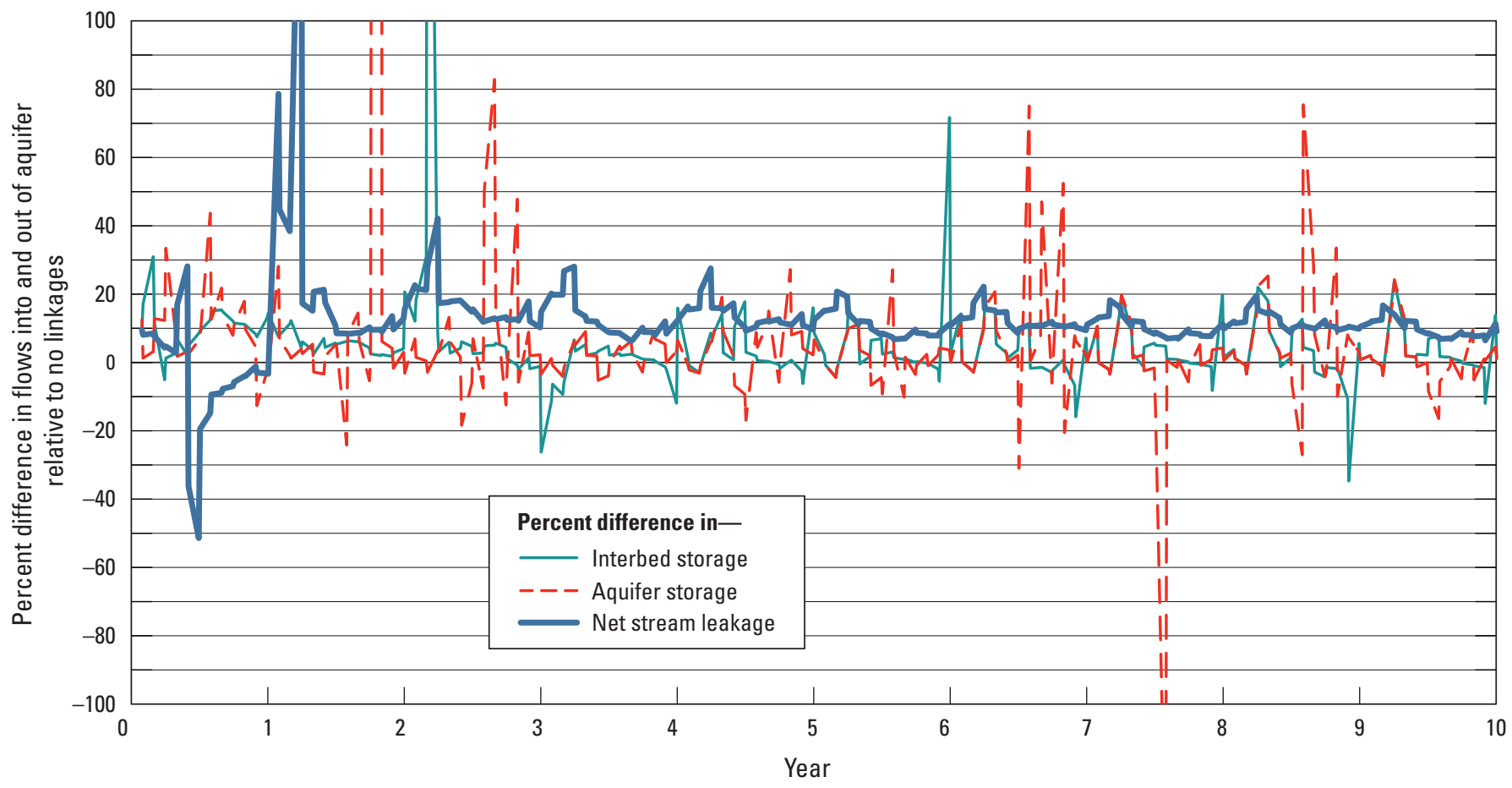

Figure 13. Differences in groundwater storage, interbed (instantaneous) storage, and net flow into the model domain between using SUBLink and using SUB with no linkage (SUB-NoLink) (Schmid and others, 2014). 
and urban deliveries (Schmid and others, 2014). Substantial relative temporal and overall differences in streamflow occur at diversions to (fig. 14A) and returnflows (fig. 14B) from farms that affect the amounts of surface water that is available to farms for irrigation. There are increased deliveries and reduced returnflows during periods of subsidence (figs. 14A, B). Thus, the amounts and sources of irrigation water are altered, and the amount of water that is potentially divertable again for downstream farms is affected. The supply-and-demand timing and amount of water available for conjunctive use of surface water is affected within the valley, along the urban canal, and as an inflow to the downstream valley (fig. 15). Finally, the stage (and related freeboard) and flows in the urban canal are also adversely affected by land subsidence and differential land subsidence (fig. 16). There are reductions in outflow of as much as 8 percent during the summer months and reduction in stage elevation in the urban canal as much as 0.62 meters, which is potentially a reduction in freeboard simulated with SWR. The reductions in flows and stage affect the ability to deliver water through the urban canal and ultimately could also affect inter-basin transfers and the integrity of the surface-water control structures. A more expanded use of SWR or the LAK Package could have been used to explore the risk of reduced drainage or additional flooding as well as canal overbank spillage in subsidence regions.

Reduced deliveries of surface water for irrigation could require more demand on groundwater pumping, but the groundwater deliveries were also found to be decreased as a result of less demand in general. This is a result of regionally increased ET directly from groundwater for SUB/LPFLinks, which reduces the irrigation demand by allowing more direct uptake of groundwater to satisfy ET. If the depth to groundwater was greater this offset would be less, and the effects of the deformation could be relatively greater. In addition, groundwater pumping is constrained because of compressed aquifer thickness. Thus, external deliveries also are affected. This exemplifies the indirect feedback of subsidence on the interplay between different conjunctive-use components in addition to its influence on each component individually.

\section{Limitations and Future Enhancements}

While model development continues, each new version has new features, the potential for future enhancements, and some limitations. For MF-OWHM, possible additional capabilities could include analyses or simulations of the following:

1. Soil moisture capacity, snowmelt runoff, and additional water reuse linkages.

2. Additional linkages to grid-based landscape properties that facilitate the use of data streams from land-based SCADA (supervisory control and data acquisition) and remotely-sensed networks needed for self-updating models.
3. A hierarchy of water-supply prioirites that are specific to each water-accounting unit and additional levels of water-accounting units needed for simulation of project operations.

4. Water-quality based components of conjunctive use that affect ET and deliveries.

5. Additional features, such as SWR, that can operate between parent and embedded LGR child models.

6. Inclusion of the conduit-flow process (Shoemaker and others, 2008).

Current limitations include the compatibility of the HFB2 flow structures with other post-processing programs, such as MODPATH and ZoneBudget, and the ability to use all of the solvers with embedded models if HFB2 layer flow routing is used. Also, certain program structures and programming features and protocols need to be followed if developers want to add other features to MF-OWHM. For example, if a developer wants to add a landscape-based feature to MF-OWHM, the addition of an $\mathrm{AD}$ routine will be required if this new feature is going to be connected to the subsidence-linkage option.

Some of the limitations and abilities are also summarized in several model comparisons that occurred between selected IHM codes, such as MF-FMP with the Integrated Water Flow Model (IWFM) (Dogural and others, 2001; Schmid and others, 2011; Dogural, 2009a,b), and among MF-FMP, IWFM, and Hydrogeosphere (Therrien, 2007; Harter and Morel-Seytoux, 2013). Other fine-scaled comparisons of MF-FMP simulated groundwater uptake as ET compared to empirical methods have also been completed (Liu and Luo, 2012) that continue to provide insight about how these processes are represented.

\section{Summary and Conclusions}

The One-Water Hydrologic Flow Model (MF-OWHM) is an integrated hydrologic model (IHM) that is the most complete version of the MODFLOW family of hydrologic simulators that includes the comprehensive functionality needed by water managers for the analysis of a broad range of conjunctive water-use issues. MF-OWHM allows the simulation, analysis, and management of nearly all components of human and natural water movement and use in a physically based supply-and-demand framework. MF-OWHM is based on the Farm Process for MODFLOW-2005 (MF-FMP2) combined with Local Grid Refinement for embedded models to allow use of the Farm Process (FMP) and Streamflow Routing (SFR) within embedded grids. The ability to still allow embedded models facilitates the use and linkage of models developed by local water agencies within the framework of regional models that simulate the entire watershed.

MF-OWHM combines several existing capabilities, such as the Surface-Water Routing Process (SWR) and Riparian Evapotranspiration (RIP-ET), and new solvers, such as 

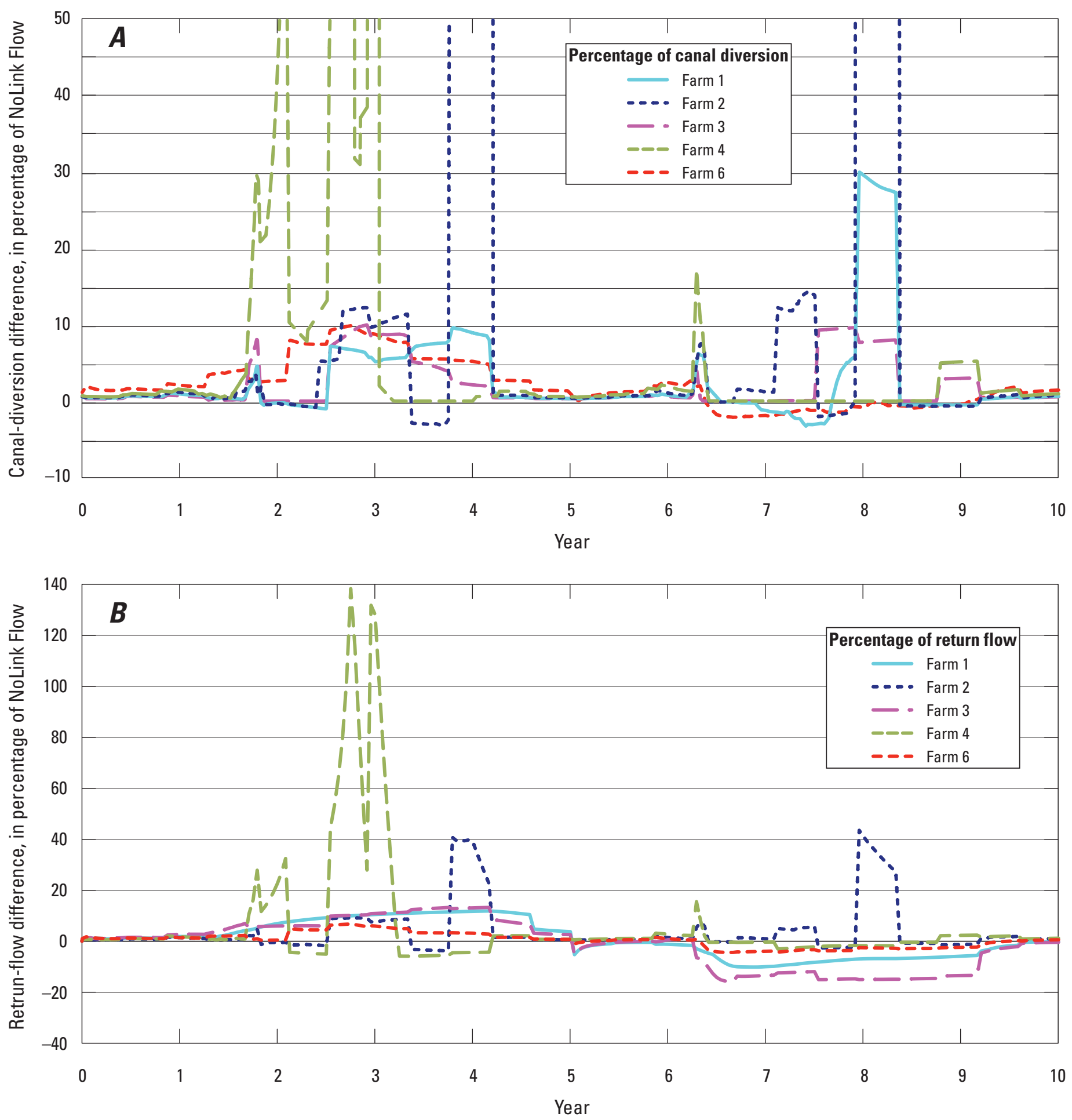

Figure 14. Differences in streamflow $A$, diversions and $B$, returnflows between using SUBLink and using SUB with no linkage (SUB-NoLink) (Schmid and others, 2014). 


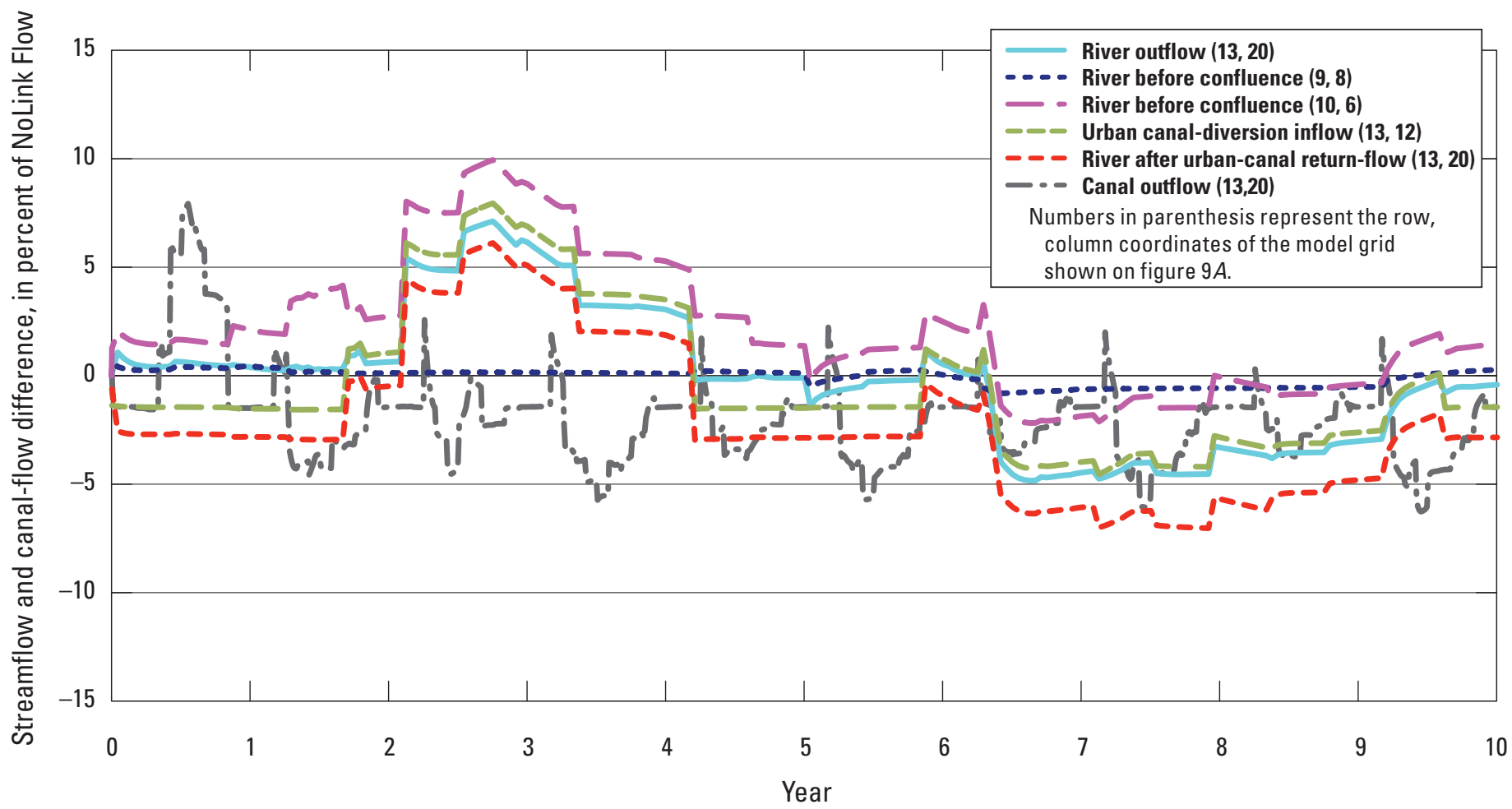

Figure 15. Differences in streamflow between using SUBLink and using SUB with no linkage (Schmid and others, 2014).

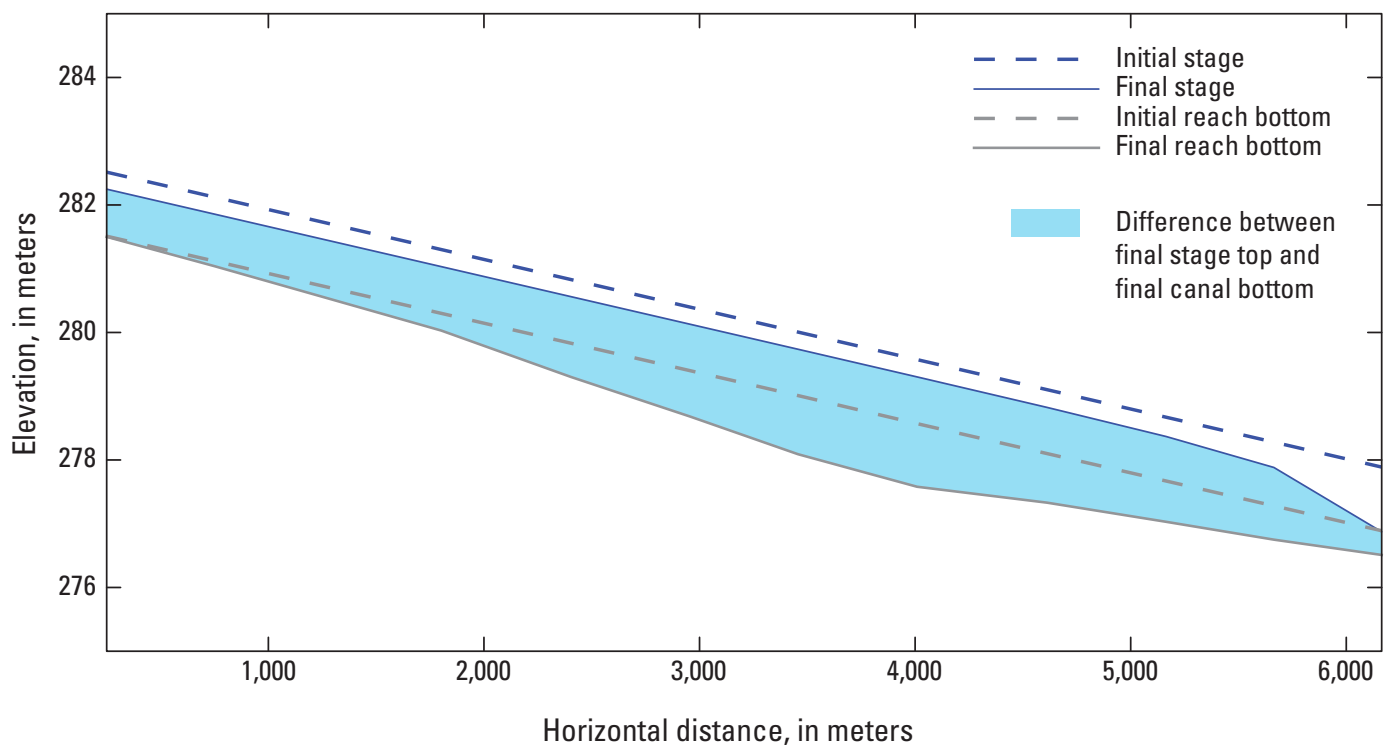

Figure 16. Differences in stage, top, and bottom of canal using SUBLink and using SUB with no linkage (Schmid and others, 2014). 
Newton-Raphson (NWT) and nonlinear preconditioned conjugate gradient (PCGN). MF-OWHM also includes new connectivities to expand the linkages for deformation-, flow-, and head-dependent flows. Deformation-dependent flows are simulated through the optional linkage to simulated land subsidence with a vertically deforming mesh. Flow-dependent flows include linkages between the new SWR with SFR and FMP, as well as connectivity with embedded models for SFR and FMP through LGR and Drain returnflows (DRT). Headdependent flow processes include a modified Hydrologic Flow Barrier Package that allows optional transient HFB capabilities, and the flow between any two layers that are adjacent along a depositional or erosional boundary or displaced along a fault. The expansion of the Subsidence Package allows easier parameterization and the separation of the elastic and inelastic deformation within the Subsidence Package for better understanding and estimation of land subsidence. Additional features include an expression parser in the Multiplier Package as well as more systematic time-series input for SFR, GHB, SWR, WEL, and MNW Packages. These new features facilitate more physically based parameterization and fundamental input structures needed to build self-updating models for operational and forecasting analysis.

MF-OWHM represents a complete hydrologic model that fully links the movement and use of groundwater, surface water, and imported water for consumption not only by irrigated agriculture, but also water used in urban areas and by natural vegetation. Supply and demand components of water use are analyzed under demand-driven and supply-constrained conditions. From large- to small-scale settings, MF-OWHM has capabilities to simulate and analyze historical, present, and future conjunctive-use conditions and the secondary effects on flow-rate or water-availability (state of hydrologic system) that can limit resource development for sustainability or the drivers of adaptation. MF-OWHM is especially useful for the analysis of agricultural water use where little data are available on pumpage, land use, or agricultural practices. The features presented in this new IHM include additional linkages with SFR, SWR, Drain-Return (DRT), Multi-Node Wells (MNW1 and MNW2), and Unsaturated Zone Flow (UZF). Thus, MF-OWHM helps to retain water within the simulation and reduce the amount of water not accounted for in the simulation. Accounting for "all of the water everywhere and all of the time," in turn, facilitates a more holistic simulation and analysis of the conjunctive use and movement of precipitation, surface water, and groundwater. This provides a more complete representation of the hydrosphere and its potential connection to humans, habitat, climate, agriculture, land use, and other related socioeconomic or physical elements that are affected by the distribution of water.
In addition to groundwater, surface-water, and landscape budgets, MF-OWHM provides more options for observations of land subsidence, hydraulic properties, and evapotranspiration (ET). Detailed landscape water budgets combined with output of estimates of actual evapotranspiration facilitates linkage to remotely sensed observations as input or as additional observations for parameter estimation or water-use analysis. The features of FMP have been extended to allow for temporally variable water-accounting units that can be linked to land-use models and the specification both of surfacewater and groundwater allotments to facilitate sustainability analysis and connectivity to the Groundwater Management Process (GWM) as well as using with FMP prior appropriation schemes for surface-water allotments.

The example model demonstrates the application of MF-OWHM with land subsidence and a vertically deforming mesh. This feature is combined with delayed recharge through an unsaturated zone, rejected infiltration in a riparian area, changes in demand caused by deficiency in supply, and changes in multi-aquifer pu mpage resulting from constraints imposed through the Farm Process and the MNW2 Package. In addition, the simulation and linkages exemplify the use of unsaturated conditions with a combination of the NWT and UZF Packages, and changes in surface water such as runoff, streamflow, and canal flows through linkages and flows using SFR and SWR.

The effects of feedback on the land surface and aquifer processes and properties from mesh deformation through MF-OWHM flow terms were found to be relatively pronounced with respect to simulations without the subsidence linkage (Schmid and others, 2014). While the inclusion of land subsidence in the simulation resulted in an even larger difference compared to simulations that did not consider land subsidence, the effects of the linkages demonstrated by the example model were fairly substantial as well as locally and temporally important. Thus, these linkages can be critical to a complete analysis for selected supply-and-demand components of conjunctive water use compared to simulations that did not consider land-subsidence feedback, such as the sustained agricultural and urban demand that drive related secondary effects, such as land subsidence, that become the limiting factors for sustainability, adaptation, or further resource development. Therefore, these linkages are best suited for evaluating conjunctive water use where the vertical displacements or differential displacements can affect the sources of water, the proportions of multiple sources of water, as well as their use and movement across the landscape, the performance of conveyance through canals and rivers across the landscape, and the flow to and from the aquifers. 


\section{References Cited}

Ahlfeld, D.P., and Barlow, P.M., 2013, Use of multi-node wells in the groundwater-management process of MODFLOW-2005 (GWM-2005): U.S. Geological Survey Techniques and Methods, book 6, chap. A47, 26 p., http://pubs. usgs.gov/tm/06/a47/.

Ahlfeld, D.P., Barlow, P.M., and Baker, K.M., 2011, Documentation for the state variables package for the groundwater-management process of MODFLOW-2005 (GWM2005): U.S. Geological Survey Techniques and Methods 6-A36, $45 \mathrm{p}$.

Ahlfeld, D.P., Baker, K.M., and Barlow, P.M., 2009, GWM2005-A groundwater-management process for MODFLOW-2005 with local grid refinement (LGR) capability: U.S. Geological Survey Techniques and Methods 6-A33, $65 \mathrm{p}$.

Ahlfeld, D.P., Barlow, P.M., and Mulligan, A.E., 2005, GWM-A ground-water management process for the U.S. Geological Survey modular ground-water model (MODFLOW-2000): U.S. Geological Survey Open-File Report 2005-1072, $124 \mathrm{p}$.

Allen, R.G., Pereira, L.S., Raes, D., and Smith, M., 1998, Crop evapotranspiration - guidelines for computing crop water requirements: Food and Agriculture Organization of the United Nations, Irrigation and Drainage Paper 56, $300 \mathrm{p}$.

Allen, R.G., Clemmens, A.J., Burt, C.M., Solomon, K., and O'Halloran, T., 2005, Prediction accurary for project-wide evapotranspiration using crop coefficients and reference evapotranspiration: Journal of Irrigation and Drainage Engineering, ASCE, v. 131, no. 1, p. 24-36.

Allen, R. G., Tasumi, M., and Trezza, R., 2007a, Satellitebased energy balance for mapping evapotranspiration with internalized calibration (METRIC) Model: Journal of Irrigation Drainage Engineering, v. 133, no. 4, p. 380-394.

Allen, R.G., Tasumi, M., Morse, A., Trezza, R., Wright, J.L., Bastiaanssen, W., Kramber, W., Lorite, Torres, I., and Robison, C.W., 2007b, Satellite-based energy balance for mapping evapotranspiration with internalized calibration (METRIC) Applications: Journal of Irrigation Drainage Engineering, v. 133, no. 4, p. 395-406.

Bakker, M., Schaars, F., Hughes, J.D., Langevin, C.D., and Dausman, A.M., 2013, The seawater intrusion (SWI2) package for modeling vertically-integrated variable-density groundwater flow in regional aquifers using the U.S. Geological Survey Modular Groundwater Flow Model (MODFLOW-2005): U.S. Geological Survey Techniques in Water Resources Investigations, Book 6, Chapter A46, 47 p.
Banta, E.R., and Ahlfeld, D.P., 2013, GWM-VI-Groundwater management with parallel processing for multiple MODFLOW versions: U.S. Geological Survey Techniques and Methods, book 6, chap. A48, 33 p., http://dx.doi. org/10.3133/tm6a48.

Belitz, Kenneth, Phillips, S.P., and Gronberg, J.M., 1993, Numerical simulation of ground-water flow in the central part of the Western San Joaquin Valley, California: U.S. Geological Survey Water-Supply Paper 2396, 69 p.

Brush, C.F., Belitz, Kenneth, Phillips, S.P., Burow, K.R., and Knifong, D.L., 2006, MODGRASS: Update of a groundwater flow model for the central part of the western San Joaquin Valley, California: U.S. Geological Survey Scientific Investigations Report 2005-5290, 81 p.

Cassel F.S., 2006, Remote sensing of evapotranspiration for verification of regulated deficit irrigation: U.S. Bureau of Reclamation Report USBR \#04FG203069 submitted from the Center for Irrigation Technology California State University, Fresno, 70 p.

Clarke, K.M., 1986, The top-down parsing of expressions: Tech. Report 383, Department of Computer Science, Queen Mary College, University of London, England, v.p.

Dickinson, J.E., Hanson, R.T., Mehl, S.W., Hill, M.C., 2011, MODPATH-LGR - Documentation of a computer program for particle tracking in shared-node locally refined grids using MODFLOW-LGR: U.S. Geological Survey Techniques and Methods 6-A38, $41 \mathrm{p}$.

Dimitrakopoulos, Roussos, and Desbarats, A.J., 1993, Geostatistical modeling of grid block permeabilities for 3D reservoir simulators: Reservoir Engineering, v. 8, p. 13-18.

Dogrul, E.C., 2009a, Integrated Water Flow Model (IWFM v3.1): Theoretical documentation, Sacramento (CA): Integrated Hydrological Models Development Unit, Modeling Support Branch, Bay-Delta Office, California Department of Water Resources, variously paged.

Dogrul, E.C., 2009b, Integrated Water Flow Model (IWFM v3.1): User's manual, Sacramento (CA): Integrated Hydrological Models Development Unit, Modeling Support Branch, Bay-Delta Office, California Department of Water Resources, variously paged.

Dogrul , E.C., Schmid, Wolfgang, Hanson, R.T., Kadir, T.N., and Chung, F.I., 2011, Integrated Water Flow Model and Modflow-Farm Process: A Comparison of Theory, Approaches, and Features of two Integrated Hydrologic Models: California Department of Water Resources Technical Information Record, TIR-1, 80p. 
Everett, R.R., Gibbs, D.R., Hanson, R.T., Sweetkind, D.S., Brandt, J.T., Falk, S.E., and Harich, C.R., 2013, Geology, water-quality, hydrology, and geomechanics of the Cuyama Valley groundwater basin, California, 2008-12: U.S. Geological Survey Scientific Investigations Report 2013-5108, $62 \mathrm{p}$.

Food and Agriculture Organization, 2007, Chapter 8-ET under soil water stress conditions: accessed September 9 , 2008, at http://www.fao.org/docrep/x0490e/x0490e0e.htm.

Faunt, C.C., Hanson, R.T., and Belitz, Kenneth, 2008a, Development of a model to assess ground-water availability in California's Central Valley: Water Resources IMPACT, American Water Resources Association, v. 10, no. 1, p. 27-30.

Faunt, C.C., Hanson, R.T., Schmid, Wolfgang, Belitz, Kenneth, 2008c, Application of MODFLOW's farm process to California's Central Valley: Modflow and more-ground water and public policy, Golden, Colorado, May 18-21, 2008, p. 496-500.

Faunt, C.C., Hanson, R.T., and Belitz, Kenneth, 2009a, Introduction and conceptual model of the Central Valley, California, Chapter A of Faunt, C.C., ed.,Ground-Water Availability of California's Central Valley: U.S. Geological Survey Professional Paper 1766, p. 1-56.

Faunt, C.C., Hanson R.T., and Belitz, Kenneth, 2009b, Ground-water availability in California's Central Valley, Chapter B of Faunt, C.C., ed., Ground-Water Availability of California's Central Valley: U.S. Geological Survey Professional Paper 1766, p. 58-120.

Faunt, C.C., Hanson R.T., Schmid, Wolfgang, Belitz, Kenneth, and Predmore, S.K., 2009c, Documentation of the Groundwater Flow Model, Chapter C of Faunt, C.C., ed., GroundWater Availability of California's Central Valley: U.S. Geological Survey Professional Paper 1766, p. 121-212.

Flint, A.L., and Flint, L.E., 2007a, Application of the basin characterization model to estimate in-place recharge and runoff potential in the Basin and Range carbonate-rock aquifer system, White Pine County, Nevada, and adjacent areas in Nevada and Utah: U.S. Geological Survey Scientific Investigations Report 2007-5099, 20 p.

Flint, L.E. and Flint, Alan L., 2007b, Regional analysis of ground-water recharge: U.S. Geological Survey Professional Paper 1703-B, p. 29-60.

Flint, L.E., and Flint, A.L., 2008, Regional analysis of groundwater recharge, in Stonestrom, D.A., Constantz, J., Ferré, T.P.A., and Leake, S.A., eds., Ground-water recharge in the arid and semiarid southwestern United States: U.S. Geological Survey Professional Paper 1703, p. 29-59.
Gowda, P.H., Chavez, J.L., Colaizzi, P.D., Evett, S.R., Howell, T.A., and Tolk, J.A., 2008, ET mapping for agricultural water management: present status and challenges: Irrigation Science, v. 26, p. 223-237

Gowda, P.H., Senay, G.B., Howell, T.A., and Marek, T.H., 2008, Lysimetric evaluation of simplified surface energy balance approach in the Texas high plains (SSEB): Journal of Applied Engineering in Agriculture, v. 25, no. 5, p. 665-669

Halford, K.J. and Hanson, R.T., 2002, User guide for the drawdown- limited, multi-node well (MNW) package for the U.S. Geological Survey's modular three-dimensional finite-difference ground-water flow model, versions MODFLOW-96 and MODFLOW-2000: U.S. Geological Survey Open-File Report 02-293, 33 p.

Hanson, R.T., 1988, Aquifer-system compaction, Tucson basin and Avra Valley, Arizona: U.S. Geological Survey WaterResources Investigation Report 88-4172, 69 p.

Hanson, R.T., and Leake, S.A., 1998, Documentation for HYDMOD, A program for time-series data from the U.S. Geological Survey's modular three-dimensional finite-difference ground-water flow model: U.S. Geological Survey Open-File Report 98-564, 57 p.

Hanson, R.T., Schmid, Wolfgang and Leake, S.A., 2008a, Assessment of conjunctive use water-supply components using linked packages and processes in MODFLOW: Modflow and More-Ground Water and Public Policy, Golden, Colo., May 18-21, 2008, p. 5.

Hanson, R.T., Schmid, Wolfgang, Lear, J., and Faunt, C.C., 2008b, Simulation of an aquifer-storage-and-recovery (ASR) system using the Farm Process in MODFLOW for the Pajaro Valley, Monterey Bay, California: Modflow and More-Ground Water and Public Policy, Golden, Colorado, May 18-21, 2008, p. 501-505.

Hanson R.T., Leake, S.A., and Schmid, Wolfgang, 2009, Appendix B: Summary of other enhancements to MODFLOW-2005, in The Farm Process Version 2 (FMP2) for MODFLOW-2005-Modifications and Upgrades to FMP1: U.S. Geological Survey Techniques in Water Resources Investigations, Book 6, chap. A32, p. 93-101

Hanson, R.T., Flint, A.L., Flint, L.E., Faunt, C.C., Schmid, Wolfgang, Dettinger, M.D., Leake, S.A., and Cayan, D.R., 2010a, Integrated simulation of consumptive use and land subsidence in the Central Valley, California, for the past and for a future subject to urbanization and climate change: Proceedings of the Eighth International Symposium on Land Subsidence (EISOLS), Queretaro, Mexico, October, 2010, p. 467-471 
Hanson, R.T., Schmid, Wolfgang, Faunt, C.C., and Lockwood, B., 2010, Simulation and analysis of conjunctive use with MODFLOW's Farm Process: Ground Water v. 48, no. 5, p. 674-689. (DOI: 10.1111/j.1745-6584.2010.00730.x)

Hanson, R.T., Flint, L.E., Flint, A.L., Dettinger, M.D., Faunt, C.C., Cayan, D., and Schmid, Wolfgang, 2012, A method for physically based model analysis of conjunctive use in response to potential climate changes: Water Resources Research, v. 48, 23 p., doi:10.1029/2011WR010774

Hanson, R.T., Kauffman, L.K., Hill, M.C., Dickinson, J.E., and Mehl, S.W., 2013a, Advective transport observations with MODPATH-OBS - Documentation of the MODPATH observation process, using four types of observations and Predictions: U.S. Geological Survey Techniques and Methods book 6-chap. A42, 94 p.

Hanson, R.T., Schmid, Wolfgang, Knight, Jake, and Maddock III, T., 2013b, Integrated hydrologic modeling of a transboundary aquifer system - Lower Rio Grande: MODFLOW and More 2013: Translating Science into Practice, Golden, Colo., June 2-6, 2013

Hanson, R.T., and Schmid, Wolfgang, 2013, Economic resilience through "One-Water" Management: U.S. Geological Survey Open-File Report 2013-1175, 2 p.

Hanson, R.T., Schmid, Wolfgang, Faunt, C.C., Lear, Jonathan, Lockwood, B., and Harich, C., 2014a, Integrated hydrologic model of Pajaro Valley, Santa Cruz and Monterey Counties, California: U.S. Geological Survey Scientific Investigations Report 2014-5111, 166 p.

Hanson, R.T., Lockwood, B., and Schmid, Wolfgang, 2014b, Analysis of projected water availability with current basin management plan, Pajaro Valley, California: Journal of Hydrology, v. 519, p. 131-147.

Hanson, R.T., Flint, L.E., Faunt, C.C., Gibbs, D.R., and Schmid, W., 2014c, Integrated hydrologic models of Cuyama Valley, Santa Barbara County, California: U.S. Geological Survey Scientific Investigations Report 2014$5150,151 \mathrm{p}$.

Harbaugh, A.W., 1990, A computer program for calculating subregional water budgets using results from the U.S. Geological Survey modular three-dimensional finite-difference ground-water flow model: U.S. Geological Survey OpenFile Report 90-392, 24 p.

Harbaugh, A.W., 2005, MODFLOW-2005, the U.S. Geological Survey modular ground-water model-the GroundWater Flow Process: U.S. Geological Survey Techniques and Methods 6-A16, variously paged.
Harter, T., and Morel-Seytoux, H., 2013, Peer review of the IWFM, MODFLOW and HGS Model Codes: Potential for water management applications in California's Central Valley and other irrigated groundwater basins: Final Report, California Water and Environmental Modeling Forum, 112 p., Sacramento, California (http://www.cwemf.org/Pubs/ index.htm)

Hay, L.E., Wilby, R.L., and Leavesley, G.H., 2000, A comparison of Delta change and downscaled GCM scenarios for three mountainous basins in the United States: Journal of the American Water Resources Association, v. 36, no. 2, p. 387-397.

Hsieh, P.A., and Freckleton, J.R., 1993, Documentation of a computer program to simulate horizontal-flow barriers using the U.S. Geological Survey modular three-dimensional finite-difference ground-water flow model: U.S. Geological Survey Open-File Report 92-477, 32 p.

Hoffmann, J., Leake, S.A., Galloway, D.L., and Wilson, A.M., 2003, MODFLOW-2000 ground-water model-user guide to the subsidence and aquifer-system compaction (SUB) package: U.S. Geological Survey Open-File Report 03-233, $46 \mathrm{p}$.

Hughes, J.D., Langevin, C.D., Chartier, K.L., and White, J.T., 2012, Documentation of the Surface-Water Routing (SWR1) process for modeling surface-water flow with the U.S. Geological Survey Modular Ground-Water Model (MODFLOW-2005): U.S. Geological Survey Techniques and Methods, book 6, chap. A40, 113 p.

Izbicki, J.A., Christensen, A.H., and Hanson, R.T., 1999, U.S. Geological Survey combined well-bore flow and depthdependent water sampler: U.S. Geological Survey Fact Sheet 196-99, 2 p.

Jacob, C.E., 1940, On the flow of water in an elastic artesian aquifer: Transactions American Geophysical Union, pt. 2, p. 574-586.

Konikow, L.F., Hornberger, G.Z., Halford, K.J., and Hanson, R.T., 2009, Revised Multi-Node Well (MNW2) package for MODFLOW Groundwater Flow Model: U.S. Geological Survey Techniques in Water Resources Investigations, book 6, chap. A30, 67 p.

Leavesley, G.H., Lichty, R.W., Troutman, B.M., Saindon, L.G., 1983, Precipitation-Rrunoff Modeling System-User's Manual: U.S. Geological Survey Water Resources Investigations Report 83-4238.

Leavesley, G.H., Branson, M.D., and Hay, L.E., 1992, Using coupled atmospheric and hydrologic models to investigate the effects of climate change in mountainous regions, in Herrmann, Raymond, ed., managing water resources during global change: American Water Resources Association Annual Conference and Symposium, p. 691-700. 
Lettenmaier, D.P. and Gan, T.Y., 1990, Hydrologic sensitivities of the Sacramento-San Joaquin River basin, California, to global warming: Water Resources Research, v. 26, p.69-86.

Lettenmaier, D.P., Major, D., Poff, L., and Running, S., 2008, Water Resources, in The effects of climate change on agriculture, land resources, water resources, and biodiversity in the United States: A report by the U.S. Climate Change Science program and the subcommittee on Global Change Research, Washington, D.C., p. 121-150.

Liu, T. and Luo, Y., 2012, An empirical approach simulating evapotranspiration from groundwater under different soil water conditions: Journal of Environmental Earth Sciences, 11 p. (DOI 10.1007/s12665-012-1577-3)

Markstrom, S.L., Niswonger, R.G., Regan, R.S., Prudic, D.E., and Barlow, P.M., 2008, GSFLOW-coupled ground-water and surface-water FLOW model based on the integration of the Precipitation-Runoff Modeling System (PRMS) and the Modular Ground-Water Flow Model (MODFLOW-2005): U.S. Geological Survey Techniques and Methods book 6, chap. D1, 240 p.

Maddock III, T., Baird, K.J., Hanson, R.T., Schmid, Wolfgang, and Ajami, H., 2012, RIP-ET: A riparian evapotranspiration package for MODFLOW-2005, U.S. Geological Survey Techniques and Methods 6-A39 p. 39

Maxwell, R.M. and Miller, N.L., 2005, Development of a coupled land surface and groundwater model: Journal of Hydrometeorology, v. 6, no. 3, p. 233-247.

McAda, D.P. and Barroll, P., 2002, Simulation of groundwater flow in the middle Rio Grande Basin between Cochiti and San Acacia, New Mexico: U.S. Geological Survey Water-Resources Investigations Report 02-4200, 88 p.

Mehl, Steffen, and Hill, M.C., 2005, MODFLOW-2005, The U.S. Geological Survey Modular Groundwater ModelDocumentation of shared node local grid refinement (LGR) and the boundary flow and head (BFH) package: U.S. Geological Survey Techniques and Methods book 6, chap. A12, 68 p.

Mehl, Steffen, and Hill, M.C., 2007, MODFLOW-2005, The U.S. Geological Survey modular groundwater model-Documentation of the multiple-refined-areas capability of local grid refinement (LGR) and the boundary flow and head (BFH) package: U.S. Geological Survey Techniques and Methods book 6, chap. A21, 13 p., http://water.usgs.gov/ nrp/gwsoftware/modflow2005_lgr/mflgr.html.

Mehl, Steffen, 2008, Coupling MODFLOW-LGR with SFR to represent stream-aquifer interactions, in Poeter, E.P., Zheng, Chunmio, and Hill M.C., eds., Proceedings of MODFLOW and More 2008 Conference: Ground Water and Public Policy Conference, Golden, Colo., May 19-21, 2008, p. 506-509.
Mehl, S.W., and Hill, M.C., 2013, MODFLOW-LGR-Documentation of ghost node local grid refinement (LGR2) for multiple areas and the boundary flow and head (BFH2) package: U.S. Geological Survey Techniques and Methods book 6, chap. A44, 43 p., http://pubs.usgs.gov/tm/6A44/.

Muir, K.S. and Coplen, T.B., 1981, Tracing groundwater movement by using the stable isotopes of oxygen and hydrogen, upper Penitencia Creek alluvial fan, Santa Clara Valley, California: U.S. Geological Survey Water-Supply Paper 2075, 18 p.

Naff, R.L. and Banta, E.R., 2008, The U.S. Geological Survey modular ground-water model-PCGN: A preconditioned conjugate gradient solver with improved nonlinear control: U.S. Geological Survey Open-File Report 2008-1331, 35 p.

Newhouse, M.W., Hanson, R.T., Wentworth, C.M., Everett, R., Williams, C.F., Tinsley J., Noce, T.E., and Carkin, B.A., 2004, Geologic, water-chemistry, and hydrologic data from multiple-well monitoring sites and selected water-supply wells in the Santa Clara Valley, California, 1999-2003: U.S. Geological Survey Scientific Investigations Report 2004-5250, 134 p.

Niswonger, R.G., and Prudic, D.E., 2005, Documentation of the streamflow-routing (SFR2) package to include unsaturated flow beneath streams - A modification to SFR1: U.S. Geological Survey Techniques and Methods 6-A13, 48 p.

Niswonger, R.G., Prudic, D.E., and Regan, R.S., 2006, Documentation of the unsaturated-zone flow (UZF1) package for modeling unsaturated flow between the land surface and the water table with MODFLOW-2005: U.S. Geological Survey Techniques and Methods 6-A19, $62 \mathrm{p}$.

Niswonger, R.G., Panday, Sorab, and Ibaraki, Motomu, 2011, MODFLOW-NWT, A Newton formulation for MODFLOW-2005: U.S. Geological Survey Techniques and Methods 6-A37, 44 p.

Panday, S, Langevin C.D., Niswonger, R.G., Ibaraki, M, and Hughes, J.D., 2013, MODFLOW-USG version 1: An unstructured grid version of MODFLOW for simulating groundwater flow and tightly coupled processes using a control volume finite-difference formulation: U.S. Geological Survey Techniques and Methods, 6-A45, 66 p.

Parker, J.T.C., and Pool, D.R., 1998, Use of microgravity to assess the effects of El Niño on ground-water storage in Southern Arizona: U.S. Geological Survey Fact Sheet 06098, 2 p.

Phillips, S.P., and Belitz, Kenneth, 1991, Calibration of a textured-based model of a ground-water flow system, western San Joaquin Valley, California: Groundwater, v. 29, no. 5, p. 702-715. 
Pollock, D.W., 1989, Documentation of computer programs to compute and display pathlines using results from the U.S. Geological Survey modular three-dimensional finitedifference groundwater flow model: U.S. Geological Survey Open-File Report 89-381, 188 p.

Pollock, D.W., 1994, User's guide for MODPATH/MODPATH-PLOT, version 3: A particle tracking post-processing package for MODFLOW, the U.S. Geological Survey finitedifference groundwater flow model: U.S. Geological Survey Open-File Report 94-464, 249 p.

Pool, D.R. and Schmidt, Werner, 1997, Measurement of ground-water storage change and specific yield using the temporal-gravity method near Rillito Creek, Tucson, Arizona: U.S. Geological Survey Water-Resources Investigations Report 97-4125, 30 p.

Sanford, W.E., Plummer, L.N., McAda, D.P., Bexfield, L.M., and Anderholm, S.K., 2003, Use of environmental tracers to estimate parameters for a predevelopment groundwater flow model of the Middle Rio Grande basin, New Mexico: U.S. Geological Survey Water Resources Investigations Report 03-4286, 102 p.

Sanford, W.E., McAda, D.P., and Anderholm, S.K., 2004, Hydrochemical tracers in the middle Rio Grande Basin, USA: 2. Calibration of a groundwater-flow model: Hydrogeology Journal, v. 12, no. 4, p. 389-407.

Sanford, W.E., 2011, Calibration of models using groundwater age: Hydrogeology Journal, v. 19, no. 1, p. 13-16.

Scanlon, B.R., Longuevergne, L., and Long, D., 2012, Ground referencing GRACE satellite estimates of groundwater storage changes in the California Central Valley, USA: Water Resources Research, v. 48, W04520, doi:10.1029/2011WR011312, 9 p.

Schmid, W., 2004, A farm package for MODFLOW-2000: Simulation of irrigation demand and conjunctively managed surface-water and ground-water supply; Ph. D Dissertation: Department of Hydrology and Water Resources, The University of Arizona, $278 \mathrm{p}$.

Schmid, W., Hanson, R.T., Maddock III, T.M., and Leake, S.A., 2006, User's guide for the farm process (FMP) for the U.S. Geological Survey's modular three-dimensional finitedifference ground-water flow model, MODFLOW-2000: U.S. Geological Survey Techniques and Methods 6-A17, $127 \mathrm{p}$.

Schmid, Wolfgang, and Hanson, R.T., 2007, Simulation of intra- or trans-boundary water-rights hierarchies using the farm process for MODFLOW-2000, American Society of Civil Engineers Journal of Water Resources Planning and Management, v. 133, no. 2, p. 166-178 (DOI: 10.1061/ (ASCE)0733-9496(2007)133:2(166))
Schmid, Wolfgang, Hanson, R.T., Faunt, C.C., and Phillips, S.P., 2008, Hindcast of water availability in regional aquifer systems using MODFLOW's Farm Process: Proceedings of Hydropredict 2008, Prague, Czech Republic, September 15-19, 2008, p. 311-314.

Schmid, Wolfgang, and Hanson R.T., 2009, The farm process version 2 (FMP2) for MODFLOW-2005-Modifications and upgrades to FMP1: U.S. Geological Survey Techniques in Water Resources Investigations, book 6, chap. A32, 102 p.

Schmid, Wolfgang, Dogrul , E.C., Hanson, R.T., Kadir, T.N., and Chung, F.I., 2011, Comparison of simulations of landuse specific water demand and irrigation water supply by MF-FMP and IWFM: California Department of Water Resources Technical Information Record TIR-2, 80 p.

Schmid, Wolfgang, Hanson, R.T., Hughes, J., Leake, S.A., and Niswonger, R., 2014 (in press), Feedback of land subsidence on the movement and conjunctive use of water resources: Environmental Modelling and Software, http:// www.journals.elsevier.com/environmental-modelling-andsoftwarel.

Senay, G.B., Verdin, J.P., Lietzow, R., and Melesse, A.M., 2008, Global daily reference evapotranspiration modeling and evaluation: Journal of the American Water Resources Association (JAWRA), v. 44, no. 4, p.969-979. DOI:10.1111 /j.1752-1688.2008.00195.x

Shoemaker, W.B., Kuniansky, E.L., Birk, S., Bauer, S., and Swain, E.D., 2008, Documentation of a conduit flow process (CFP) for MODFLOW-2005: U.S. Geological Survey Techniques and Methods, book 6, chap. A24, 50 p.

Therrien, R., McLaren, R.G., and Sudicky, E.A. 2007, HydroGeoSphere-A three-dimensional numerical model describing fully-integrated subsurface and surface flow and solute transport, Groundwater Simulations Group, University of Waterloo, variously paged.

United Nations Organization for Education, Science and Culture, 2010, UNESCO Glossary: accessed August 1, 2014, http://webworld.unesco.org/water/ihp/db/glossary/ glu/EN/GF0237EN.HTM.

Wilson, J.D. and Naff, R.L., 2004, The U.S. Geological Survey modular ground-water model-GMG linear equation solver package documentation: U.S. Geological Survey Open-File Report 2004-1261, 47 p. 
Appendix 


\section{Appendix A. Data Input Instructions for FMP1/2 and New FMP3 Features}

The summary of data input parameters (tables 1 and 2) includes the previous unchanged FMP $1 / 2$ and changed or new FMP3 input items. The position of changed or new itemsin the previous FMP1/2-numbering scheme of data input items is highlighted in yellow. Flags or parameters printed in red text represent features modified from FMP1, and flags or parameters printed in dark blue text represent new or changed features in FMP2 or features added between FMP2 to FMP3, and light blue text represents new features in FMP3 not previously available in FMP1 or FMP2. We have included a description and list of all of the input needed for FMP that helps facilitate upgrading previous FMP1 or FMP2 applications to FMP3 (table A1). For a complete on-line description of FMP input data requirements the user can also refer to http://water.usgs.gov/ogw/modflow-owhm/Guide/ index.html.

Data input for FMP3 is read from the file designated as type "FMP" in the name file. This chapter contains three sections. The first section describes the data input requirements for each input item. An input item can consist of a comment, of flags, or of scalar-, list-, or array-variables. Optional variables and optional flags are shown in brackets, [ ], and curly braces, \{\} , respectively. Two-dimensional arrays are listed together with their array dimensions (NCOL, NROW). Data lists or arrays, which are read by MF-OWHM or FMP3 utility modules, are indicated by "read*" and by a footnote that explains which utility array readers are used. The second section explains the input structure of the array, lists reading utility modules, and instructs how to apply scale factor multipliers to the variables. The third section provides an explanation of the fields itemized in the input instructions in the first section.

\section{Input Data for FMP3}

\section{Data for Each Simulation}

Table A1 summarizes the data input for parameters the user may need to specify for the entire period of the simulation.

Table A1. Summary of FMP3 input for data required for the entire period of simulation.

[Number in brackets [], represents the control record options described in the section below "Control Record Item a, b, c, or d" that are available for each item that may be used and read as FMP input such as file structure, type, manner of and source of reading (OPEN/CLOSE, INTERNAL, EXTERNAL) and additional feature such as scale factors (SFAC). Yellow: Position of changed or new items within FMP1-numbering scheme. Blue text: Flags or parameters representing modified features from FMP1. Red text: Flags or parameters representing new features of FMP2. Light blue text flags or parameters representing new features of FMP3. Abbreviations: no., number; >, greater than; =, equal]

\begin{tabular}{|c|c|c|}
\hline Item no. & \multicolumn{2}{|l|}{ Input instruction for each item } \\
\hline 0 & \multicolumn{2}{|l|}{ [\#Text] read if '\#' is specified (can be repeated multiple times) } \\
\hline 1 & \multicolumn{2}{|c|}{ [PARAMETER NPFWL MXL $\{\mathrm{MXLP}\}]$ read with READOP [9] if word 'PARAMETER' is specified } \\
\hline $2 \mathrm{a}$ & \multicolumn{2}{|c|}{ [FLAG_BLOCKS] specify word 'FLAG_BLOCKS' only if flags are to be specified by blocks } \\
\hline $2 \mathrm{~b}$ & \multicolumn{2}{|c|}{$\begin{array}{l}\text { read flags from a single line if word 'FLAG_BLOCKS' is not specified in Item 2a: } \\
\text { MXACTW }\{\text { MXACTFWP }\} \text { NFARMS NCROPS NSOILS IFRMFL IRTFL ICUFL IPFL IFTEFL IIESWFL IEFFL IEBFL } \\
\text { IROTFL IDEFFL }\{\text { IBEN }\} \text { ICOST }\} \text { IALLOTGW ICCFL INRDFL }\{\text { MXNRDT }\} \text { ISRDFL IRDFL ISRRFL IRRFL IALLOTSW } \\
\text { \{PCLOSE }\} \text { IFWLCB IFNRCB ISDPFL IFBPFL IETPFL \{IRTPFL }\{\text { IOPFL }\}\{\text { IPAPFL }\} \text { Flags for Auxiliary Variables }\}\{\text { Flags } \\
\text { for Options }\} \text { QQCLOSE HPCT RPCT }\}\end{array}$} \\
\hline $2 \mathrm{c}$ & $\begin{array}{l}\text { read flags by blocks if word 'FLAG_BLOCKS' is specified in Item 2a: } \\
\text { MXACTW \{MXACTFWP }\} \text { NFARMS NCROPS NSOILS } \\
\text { IFRMFL IRTFL ICUFL IPFL IFTEFL IIESWFL IEFFL } \\
\text { IEBFL IROTFL IDEFFL \{IBEN\}\{ICOST\} IALLOTGW } \\
\text { ICCFL } \\
\text { INRDFL \{MXNRDT }\} \text { ISRDFL IRDFL ISRRFL IRRFL IALLOTSW \{PCLOSE\} } \\
\text { IFWLCB IFNRCB ISDPFL IFBPFL IETPFL \{IRTPFL\} \{IOPFL\} \{IPAPFL\} } \\
\text { Flags for Auxiliary Variables } \\
\text { Flags for Options } \\
\text { \{QCLOSE HPCT RPCT }\}\end{array}$ & $\begin{array}{l}\text { Dimensions } \\
\text { When-to-read Flags } \\
\text { Water Policy Flags } \\
\text { Consumptive Use Concept Flag } \\
\text { Surface-Water Flags } \\
\text { Print Flags or Print Units }\end{array}$ \\
\hline
\end{tabular}


Table A1. Summary of FMP3 input for data required for the entire period of simulation.-Continued

[Number in brackets [], represents the control record options described in the section below "Control Record Item a, b, c, or d" that are available for each item that may be used and read as FMP input such as file structure, type, manner of and source of reading (OPEN/CLOSE, INTERNAL, EXTERNAL) and additional feature such as scale factors (SFAC). Yellow: Position of changed or new items within FMP1-numbering scheme. Blue text: Flags or parameters representing modified features from FMP1. Red text: Flags or parameters representing new features of FMP2. Light blue text flags or parameters representing new features of FMP3. Abbreviations: no., number; >, greater than; =, equal]

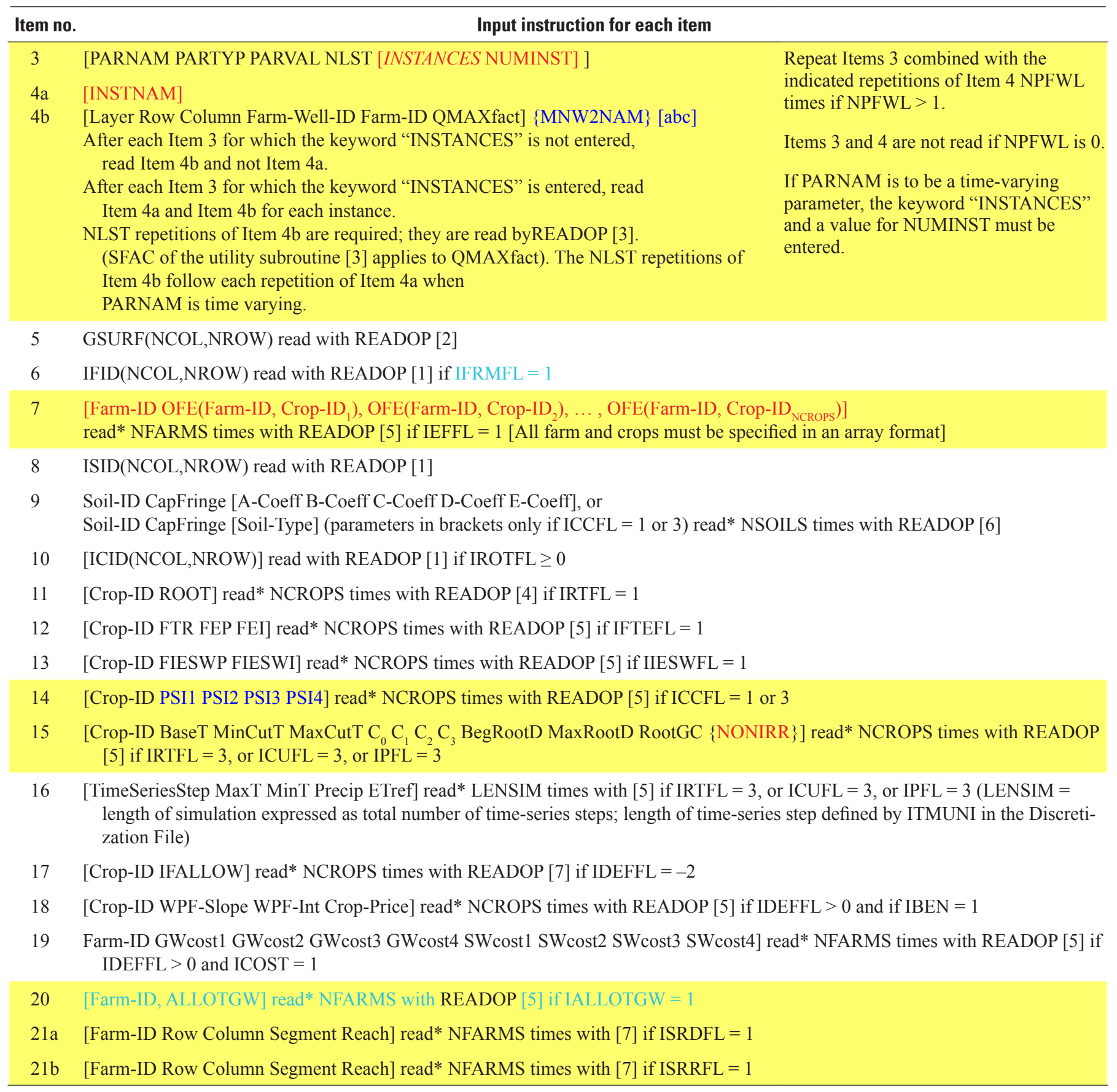




\section{Data for Each Stress Period}

Table A2 summarizes the data input for parameters the user may need to specify for each stress period over the entire period of the simulation.

Table A2. Summary of FMP3 input for data required for each stress period during the entire period of simulation.

[Number in brackets [], represents the control record options described in the section below "Control Record Item a, b, c, or d" that are available for each item that may be used and read as FMP input such as file structure, type, manner of and source of reading (OPEN/CLOSE, INTERNAL, EXTERNAL) and additional feature such as scale factors (SFAC). Yellow: Position of changed or new items within FMP1-numbering scheme. Blue text: Flags or parameters representing modified features from FMP1. Red text: Flags or parameters representing new features of FMP2. Light blue text flags or parameters representing new features of FMP3. Abbreviations: no., number; >, greater than; =, equal]

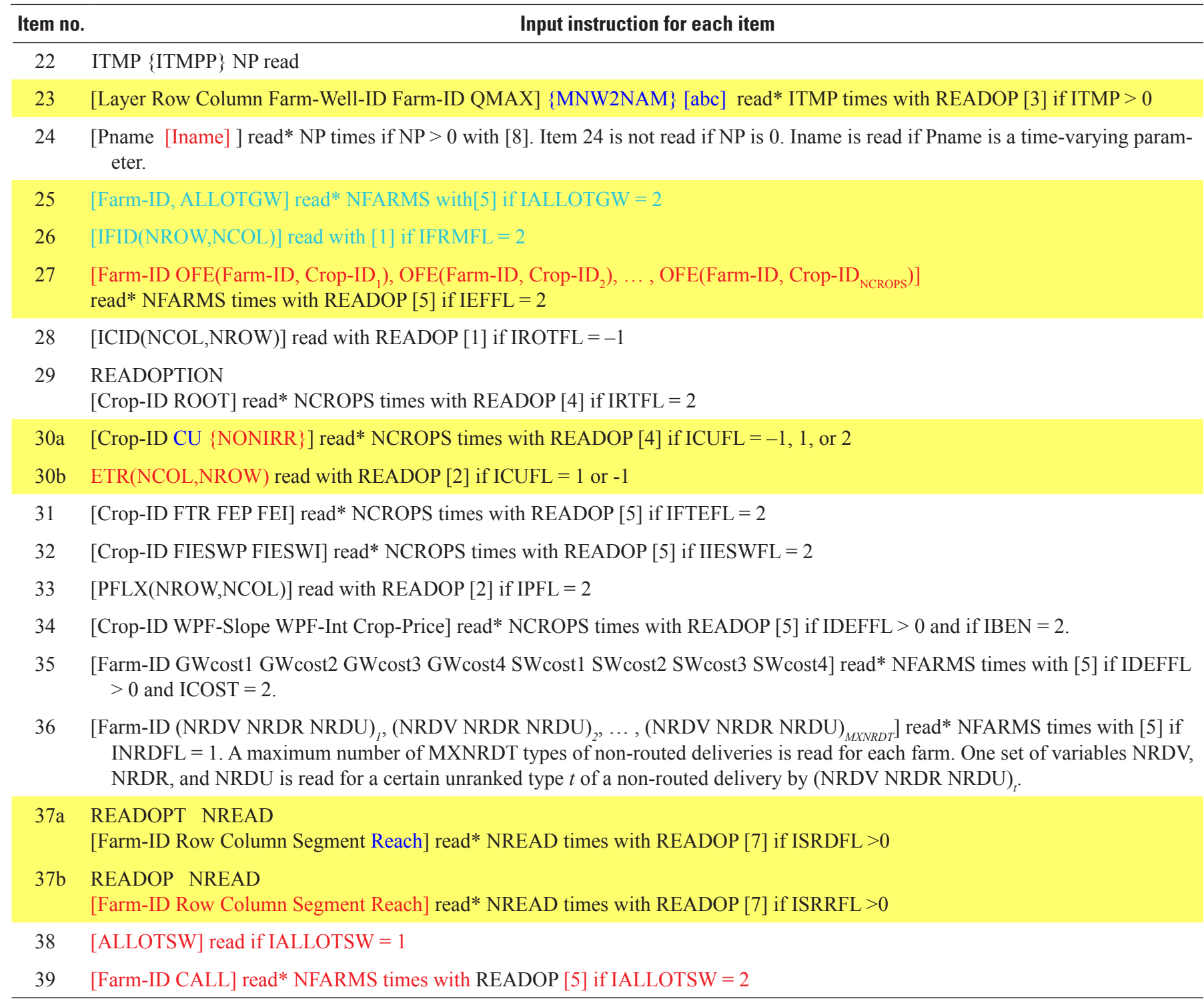

\section{Explanation of the use of Array-Reading Utility Modules [READOPTION]}

In order to keep the structure of the FMP-data-input-file simple, it is recommended to specify for each respective line of the FMP-input-file, from which a utility module reads, one of the following:

$>$ Name of a file or cross-reference to a file, from which the utility module will read the data array or list records (see use of the keywords "OPEN/ CLOSE" and "EXTERNAL" below),

$>$ Constant(s), in case 2D-arrays or lists may be lumped together. 


\begin{tabular}{lllccc}
\hline & & \multicolumn{3}{c}{ Free-format control record options } \\
\cline { 3 - 6 } READOP & Utility - module & Constant & Internal & External & $\begin{array}{c}\text { Open/ } \\
\text { close }\end{array}$ \\
\cline { 3 - 6 } & & 1 & $\mathrm{x}$ & $\mathrm{x}$ & 1 \\
\hline$[1]$ & U2DINT & 1 & $\mathrm{x}$ & $\mathrm{x}$ & 1 \\
{$[2]$} & U2DDP & & $\mathrm{x}$ & $\mathrm{x}$ & 1 \\
{$[3]$} & FMP2WELRD & 1 & $\mathrm{x}$ & $\mathrm{x}$ & 1 \\
{$[4]$} & FMP2LSTRD & 1 & $\mathrm{x}$ & $\mathrm{x}$ & 1 \\
{$[5]$} & FMP2DPLSTRD & 1 & $\mathrm{x}$ & $\mathrm{x}$ & 1 \\
{$[6]$} & FMP2DPWDLSTRD & 1 & $\mathrm{x}$ & $\mathrm{x}$ & 1 \\
{$[7]$} & FMP2INTLSTRD & & & & \\
{$[8]$} & FMP2WELPARRD & & & & \\
{$[9]$} & UPARLSTALPRTOCH & & & & \\
\hline
\end{tabular}

${ }^{1}$ Constants or file-names are recommended in order to maintain a line-by-line FMP1 input file structure for each input item.

${ }^{x}$ Internal arrays or unit numbers for external files are technically possible, but the user has to define such unit numbers in the Name File. However, if data are desired to be read from the same file for multiple stress periods, then cross-referenced "external" files are of advantage, since they remain open.

\section{Input Structure of Array and List Reading Utility Modules}

A control record item "a" is read from the Farm Process input file by all utility modules. A keyword signals whether to use a constant value for two-dimensional- (2D-) arrays or data lists, or whether to read 2D-data arrays and data lists internally from the Farm Process input file or externally from a data file. For 2D-data arrays read by standard MODFLOW utility modules, a "Multiplier Constant" can be applied to scale any input-data array.

For data lists read by FMP-embedded list reading utility modules, a second control record item "b" is optionally read if the use of scale factor multipliers is desired. If item $b$ is included, the respective line must begin with "SFAC." For internal data lists, this control record item $b$ is read from the next line of the Farm Process input file. For external lists, item $b$ is read from the first line of the external data file.

Control-Record Item a

\begin{tabular}{|c|c|c|c|c|c|}
\hline READOP & Keyword & $\begin{array}{l}\text { Constant(s) or } \\
\text { cross-reference }\end{array}$ & $\begin{array}{l}\text { Multiplier } \\
\text { constant }\end{array}$ & $\begin{array}{l}\text { Read } \\
\text { format }\end{array}$ & $\begin{array}{l}\text { Print } \\
\text { flag }\end{array}$ \\
\hline \multicolumn{6}{|c|}{ For the use of Standard MODFLOW 2D-array reading Utility Modules: } \\
\hline \multirow{2}{*}{ [1] } & INTERNAL & & ${ }^{1} 1$ & $(\mathrm{FREE})^{2}$ & $3-1$ \\
\hline & OPEN/CLOSE & FILENAME & ${ }^{1} 1$ & $(\mathrm{FREE})^{2}$ & ${ }^{3}-1$ \\
\hline \multicolumn{6}{|c|}{ For the use of list reading Utility Modules embedded in the FMP1: } \\
\hline \multirow[t]{2}{*}[2]{} & CONSTANT & Double precision scalar & & & \\
\hline & INTERNAL & & Real scalar & $(\mathrm{FREE})^{2}$ & $3^{3}-1$ \\
\hline \multirow[t]{4}{*}[3]{$,[4],[5],[6],[7]$} & CONSTANT & $\begin{array}{l}\text { Real [3],[4] or double precision } \\
\quad[5],[6], \text { or integer [7] scalar(s) }\end{array}$ & & & \\
\hline & INTERNAL & & & & \\
\hline & OPEN/CLOSE & FILENAME & & & \\
\hline & EXTERNAL & Nunit & & & \\
\hline
\end{tabular}

${ }^{1}$ It is not recommended to "scale" $2 \mathrm{D}$ integer arrays of identifiers (such as IFID, ICID, or ISID).

${ }^{2}$ Since the FMP1 allows the use of free format, the user is advised to read 2D-data arrays by the standard MODFLOW utility modules as well in free format.

${ }^{3}$ Known input data should not be 're-printed' in order to avoid a very large list file, where results are to be printed. 


\section{Keywords}

The keyword "CONSTANT" indicates that the scalar, which follows the keyword, represents a single value for 2D-arrays or for data lists with only one attribute. For data lists with multiple attributes, as many constants must be entered after the keyword "CONSTANT" as there are fields attributed to the multi-dimensional variable, but omit the keyword attribute in the first field. Distributed data may be read as 2D arrays or as data lists either internally in the FMP1 input file, as indicated by the keyword "INTERNAL," or externally from a file.

External data can be read by using a keyword of "OPEN/CLOSE" and then specifying a filename directly in the FMP1 input file. The obvious advantage of using "OPEN/CLOSE" is that no further referencing of the file name in the Name File is necessary. However, each file will be closed after reading and can be reopened and reused for future stress periods.

Alternatively, data can be read by using a keyword of "EXTERNAL" and specifying a file unit number, Nunit, in the FMP1 input file that cross-references a file name contained in the name file and the key term "DATA." The advantage of using "EXTERNAL" is that the file, from which a respective module reads, will not be closed, and data for future stress periods can continuously be read from the same file.

\section{Read Format}

The read format for the Standard MODFLOW 2D-array reading utility modules, [1] and [2], must either be a standard Fortran format that is enclosed in parentheses, "(FREE)," which indicates free format, or "(BINARY)" which indicates binary (unformatted) data. A suggested print flag of -1 indicates that an array should not be printed to the list file after it has been read. For further instructions on use of array readers, print flags, and associated codes, refer to Harbaugh and others (2000, p. 86) and Schmid (2004, p. 159).

The read format for the list reading utility modules embedded in the FMP1, [3],[4],[5], [6], and [7] is, by standard, in free format and, therefore, not required to be specified. The farm-wells list-reading utility module [3] prints the read variables, including auxiliary variables, to the list file in integer and scientific notation unless "NOPRINT" is not specified for \{option in item 2. The other, less complex, list-reading modules, [4], [5], [6], and [7], do not re-print the read input data to the list file.

\section{Control-Record Item b}

If item "b" is included, it must begin with the keyword "SFAC." The keyword "SFAC" indicates whether a scale factor is to be multiplied with parameter values of a designated attribute or a range of attributes. Alternatively, a list of scale factors can be read from yet another external data file. If the control-record item "b" is not included, the Scale is 1.0.

\begin{tabular}{llll}
\hline READOP & Keyword 1 & \multicolumn{1}{c}{ Constant or keyword 2 } & Cross-reference \\
\hline & For the use of list reading Utility Modules embedded in the FMP1: & \\
\hline$[3],[4],[5],[6]$ & SFAC & Real ([3],[4]) or Double Precision ([5],[6]) Scalar(s) & \\
{$[5]$} & SFAC & OPEN/CLOSE & FILENAME \\
& SFAC & EXTERNAL & Nunit \\
\hline
\end{tabular}

\section{Constant Scale Factor}

A scale factor can be applied to all lists read by the utility modules embedded in the FMP1, [3], [4], [5], and [6]. For each item, a constant real or double precision scalar may be multiplied by the parameter value(s) associated with the following respective attribute or range of attributes:

\begin{tabular}{cllr}
\hline Item & \multicolumn{1}{c}{ SFAC applies to parameter(s) } & READOP \\
\hline 4. & QMAXfact & {$[3]$} \\
7. & OFE & {$[5]$} \\
9. & CapFringe & {$[6]$} \\
11. & ROOT & {$[4]$} \\
12. & FTR,FEP,FEI & {$[5]$} \\
13. & FIESWP, FIESWI & {$[5]$} \\
14. & PSI1, PSI2, PSI3, PSI4 & {$[5]$} \\
19. & GWcost1, GWcost2, GWcost3, GWcost4, & {$[5]$}
\end{tabular}




\begin{tabular}{clc}
\hline Item & \multicolumn{1}{c}{ SFAC applies to parameter(s) } & READOP \\
\hline 23. & QMAX & {$[3]$} \\
27. & OFE & {$[5]$} \\
29. & ROOT & {$[4]$} \\
$30 \mathrm{a}$. & CU & {$[4]$} \\
31. & FTR, FEP, FEI & {$[5]$} \\
32. & FIESWP, FIESWI & {$[5]$} \\
35. & GWcost1, GWcost2, GWcost3, GWcost4, SWcost1, & {$[5]$} \\
39. & SWcost2, SWcost3, SWcost4 & {$[5]$} \\
\hline
\end{tabular}

For items 4 and 22, the values of the list variables that are automatically printed to the list file include the effect of the Scale.

\section{List of Scale Factors}

A list of scale factors can be applied to parameters of a data list that require different multipliers for each parameter. This option is available only for lists read by utility module [5]. As before, item b must begin with the first keyword "SFAC." A second control record keyword indicates whether the file containing the list of scale factors is specified directly by its file name or by a file unit number that cross-references to a file name contained in the Name File.

The first column in a list of scale factors contains the attribute or field number of a data list. The second column contains the individual scale factor for each respective attribute. For example, multiple scale factors for the three different attributes (1: WPF-Slope, 2: WPF-Int, 3: Crop-Price) in item 18 could be defined as follows:

\begin{tabular}{cc}
\hline Attribute & Scale factor \\
\hline 1 & 1.0 \\
2 & 2.0 \\
3 & 1.0 \\
4 & 10.0 \\
\hline
\end{tabular}

The first attribute always defines an ID, which is why the scale factor always must be 1.0, as shown in the previous table above. Parameters related to any other attribute that is not to be scaled must also be equipped with a scale factor of 1.0. In the example, the slope of the water-production function was multiplied by 2.0 , and the crop market price per unit weight was multiplied by 10 .

\section{Explanation of Fields Used in the Input Instructions}

\section{Dimensions and Flags (Item 2)}

\section{Parameter Dimensions (Item 2)}

NPFWL

MXL

MXLP
Number of farm well parameters (changeable parameter is a multiplier of the maximum capacity).

Maximum number of parameter farm wells.

Flag indicating the automatic use of parent parameter farm-well list entries for the child model (if ILGR $>0$ and for child model grids where IGRID>1) (only character "P" or blank possible).

If MXLP is set to P after MXL, then the maximum number of parent model parameter farm-well list entries may be used as child model parameter farm wells in well locations, where the child model farm ID coincides with the parent model farm ID. IF MXLP=P, then the maximum number of parent model parameter farm-well list entries as specified for the parent model (MXL of parent model) is added to the maximum number of parameter wells list entries specified in the child model, MXL, to allocate space for parameter farm-wells list entries specified in the child model AND pulled from the parent model. If only the use of parent model parameter wells for a child model is desired, and no child model specific parameter farm wells exist, MXL still needs to be specified as zero. If only the use of child model parameter wells is desired, and no parent model parameter farm wells are to be pulled from the parent mode, then MXLP is omitted. 
MXACTFW

MXACTFWP

NFARMS

NCROPS

NSOILS

For child model

NFARMS, NCROPS,

NSOILS:
Maximum number of active farm wells, including parameter and nonparameter farm wells. Nonparameter farm wells are wells whose maximum capacity is different for each stress period. In this case, each well-list (layer, location, farm-well farm ID, and maximum capacity) would have to be read for each stress period. However, since the maximum capacity in most cases is thought to be constant for the entire simulation, usually the maximum number of nonparameter farm wells will be zero, that is, MXL $=$ MXACTFW.

Flag indicating the automatic use of parent nonparameter farm-well list entries for the child model (if ILGR $>0$ and for child model grids where IGRID>1) (only character "P" or blank possible).

If MXACTFWP is set to P after MXACTFW, then the maximum number of parent model nonparameter farm-well list entries may be used as child model nonparameter farm wells in well locations where the child model farm ID coincides with the parent model farm ID. If MXACTFWP $=\mathrm{P}$, then the maximum number of parent model nonparameter farm-well list entries specified for the parent model (MXACTFW of parent model) is added to the maximum of nonparameter wells list entries specified in the child model, MXACTFW, to allocate space for nonparameter farm-wells list entries specified in the child model AND pulled from the parent model. If only the use of parent model nonparameter wells for a child model is desired, and no child model specific nonparameter farm wells exist, MXACTFW still needs to be specified as zero. If only the use of child model nonparameter wells is desired, and no parent model nonparameter farm wells are to be pulled from the parent model, then MXACTFWP is omitted.

Maximum number of water-balance subregions (farms) specified during the entire simulation.

Number of crop types.

Number of soil types.

Attributing parent-model list entries to farm IDs, crop IDs, or soil IDs present in the child model domain can be enabled by setting IFID, ICID, and ISID in items 5, 7, 8, and 28 to "P." If such a derivation of farm, crop-type, or soil-type specific attributes from the parent model is desired, then maximum number of farms, crop types, and soil types in the child model must be equal to the dimension specified in the parent model.

\section{'When-to-Read-Flags' (Item 2):}

When-to-Read-Flags indicate when to read or calculate a variable:

IFRMFL

IRTFL

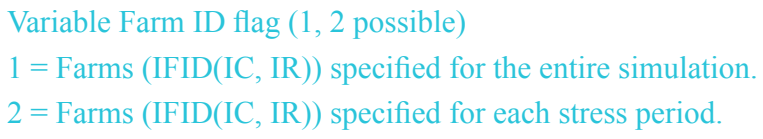

Root-depth flag (1, 2, 3, "P” possible)

$1=$ Root depth specified for the entire simulation.

$2=$ Root depth specified for each stress period.

$3=$ Root depth calculated as the average for each time step from the daily time series of root depth calculated from climate-data $\left(\mathrm{T}_{\min }, \mathrm{T}_{\max }\right)$, read as time series for the entire simulation in Item 16 and a list of crop-specific coefficients (coefficients for growing degree day calculation, polynomial coefficients, coefficients for root depth calculation) (Schmid and others, p. 47f), read for the entire simulation in Item 15.

$\mathrm{P}=$ Root depths specified or calculated for the parent model (as defined by the parent model's IRTFL entry) are automatically used for crop IDs present in the child model. No additional crop-specific root depth list entries (for parent IRTFL=1, 2, 3) or climate data time series (for parent IRTFL=3) are necessary. 
3 = FMP3 calculates a daily potential crop-evapotranspiration flux $\left(\mathrm{ET}_{\mathrm{c}-\mathrm{pot}}\right)$ by multiplying a daily reference evapotranspiration flux $\left(\mathrm{ET}_{\mathrm{ref}}\right)$, read as time series for the entire simulation in Item 16, with a daily crop coefficient $\mathrm{K}_{\mathrm{c}}$ derived from parameters read for the entire simulation as Item $15\left(\mathrm{ET}_{\text {c-pot }}=\mathrm{K}_{\mathrm{c}}{ }_{\mathrm{e}} \mathrm{ET}_{\mathrm{ref}}\right)$. FMP3 multiplies a daily $\mathrm{ET}_{\text {c-pot }}$ averaged over each time step by the area of each cropped cell (ICID(IC,IR) $\left.>0\right)$ to yield a cell-by-cell ET $\mathrm{ET}_{\text {c-pot }}$ flow rate for each time step. FMP3 multiplies the daily $\mathrm{ET}_{\text {ref }}$ flux averaged over each time step by the area of each fallow cell $(\operatorname{ICID}(\mathrm{IC}, \mathrm{IR})=-1)$ to yield a cell-by-cell $\mathrm{ET}_{\text {ref }}$ flow rate for each time step. The $\mathrm{ET}_{\text {ref }}$ is assumed to be 100 percent evaporation for fallow cells, where no transpiration exists.

$2=$ A list of crop-specific fluxes of potential crop evapotranspiration $\left(\mathrm{ET}_{\text {c-pot }}\right)$ is read as Item 30a (Crop-ID, $\mathrm{ET}_{\text {c-pot }}$ flux) for every stress period. FMP3 multiplies this $\mathrm{ET}_{\text {c-pot }}$ flux by the area of the each cropped cell (ICID(IC,IR)

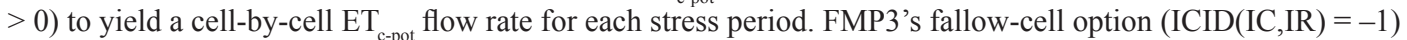
cannot be used because no $\mathrm{ET}_{\text {ref }}^{\text {rept }}$ flux is read if ICUFL $=2$.

$1=$ A list of crop-specific fluxes of potential crop evapotranspiration $\left(\mathrm{ET}_{\mathrm{c}-\mathrm{pot}}\right)$ is read as Item 30a $\left(\mathrm{Crop}-\mathrm{ID}, \mathrm{ET}_{\text {c-pot }}\right.$ flux) for every stress period, and a constant or 2D real array reference evapotranspiration $\mathrm{ET}_{\text {ref }}(\mathrm{NCOL}, \mathrm{NROW})$ is read as Item $30 \mathrm{~b}$ for every stress period. FMP3 multiplies the $\mathrm{ET}_{\text {c-pot }}$ flux by the area of the cropped cell $\left(\mathrm{ICID}(\mathrm{IC}, \mathrm{IR})>0\right.$ ) to yield a cell-by-cell $\mathrm{ET}_{\text {c-pot }}$ flow rate for each stress period. FMP3 multiplies the $\mathrm{ET}_{\text {ref }}$ flux by the area of each fallow cell $(\operatorname{ICID}(\mathrm{IC}, \mathrm{IR}) \stackrel{\mathrm{c} \text {-pot }}{=}-1)$ to yield a cell-by-cell $\mathrm{ET}_{\text {ref }}$ flow rate for each stress period. $\mathrm{The}_{\mathrm{Erf}}$ is assumed to be 100 percent evaporation for fallow cells, where no transpiration exists.

$-1=$ A list of crop-specific crop coefficients $\left(\mathrm{K}_{\mathrm{c}}\right)$ is read as Item 30a (Crop-ID, $\mathrm{K}_{\mathrm{c}}$ ) for every stress period, and a constant or $2 \mathrm{D}$ real array of reference evapotranspiration $\mathrm{ET}_{\text {ref }}(\mathrm{NCOL}, \mathrm{NROW}$ ) is read as Item $27 \mathrm{~b}$ for every stress period. FMP3 multiplies the $\mathrm{K}_{\mathrm{c}}$ by the $\mathrm{ET}_{\mathrm{ref}}$ flux and by the area of each cropped cell (ICID(IC,IR) $>0$ ) to yield a cell-by-cell ET $\mathrm{T}_{\text {c-pot }}$ flow rate for each stress period. FMP3 multiplies the $\mathrm{ET}_{\text {ref }}$ flux by the area of each fallow cell $(\operatorname{ICID}(\mathrm{IC}, \mathrm{IR})=-1)$ to yield a cell-by-cell $\mathrm{ET}_{\text {ref }}$ flow rate for each stress period. The $\mathrm{ET}_{\text {ref }}$ is assumed to be 100 percent evaporation for fallow cells, where no transpiration exists.

$\mathrm{P}=$ Potential crop-evapotranspiration flux $\left(\mathrm{ET}_{\mathrm{c}-\mathrm{pot}}\right)$ or crop coefficients $\left(\mathrm{K}_{\mathrm{c}}\right)$ specified or calculated for parent model (as defined by the parent model's ICUFL entry) are automatically used for crop IDs present in child model. No additional crop-specific ET $\mathrm{c}_{\mathrm{c} \text {-pot }}$ list entries (for parent ICUFL=1,2), $\mathrm{K}_{\mathrm{c}}$, list entries (for parent $\mathrm{ICUFL}=-1$ ), reference ET arrays (for parent ICUFL $=-1,1$ ), or crop-specific growing degree coefficients and climate data time series (for parent ICUFL $=3$ ) are necessary. For parent ICUFL $=1,1$, the child-model reference evapotranspiration at the child-model grid resolution is automatically derived from the parent-model reference evapotranspiration by bilinear interpolation.

IPFL

Precipitation flag (2, 3, "P" possible)

$2=$ Precipitation flux specified for the each stress period

3 = Precipitation flux calculated as the average for each time step from the daily time series of precipitation flux specified in climate-data time series read in Item 16 for the entire simulation.

$\mathrm{P}=$ Precipitation flux specified or calculated for the parent model (as defined by the parent model's IPFL entry) is automatically used for the child model. No additional precipitation-flux array (for parent IPFL=2) or time-series (for parent IPFL=3) data sets are necessary. For parent IPFL=2, the child-model precipitation-flux array at the child-model grid resolution is automatically derived from the parent-model array by bilinear interpolation. 
IFTEFL

IIESWFL

IEFFL
Fraction-of-transpiration-and-evaporation-of-crop-consumptive-use flag (1, 2, "P" possible)

$1=$ Transpiratory and evaporative fractions of consumptive use specified for the entire simulation.

$2=$ Transpiratory and evaporative fractions of consumptive use specified for each stress period.

$\mathrm{P}=$ Transpiratory and evaporative fractions of consumptive use specified for the parent model (as defined by the parent model's IFTEFL entry) are automatically used for the child model. No additional crop-specific FTR, FEP, or FEI list entries are necessary.

Fraction-of-inefficiency-losses-to-SW-runoff flag $(0,1,2$, "P" possible)

$0=$ The fraction of inefficiency losses to surface-water runoff is proportional to the slope of ground surface. The slope is estimated by FMP by a third order finite-difference method using all eight outer points of the 3 by 3 kernel surrounding the cell. At cells directly adjacent to the boundary or the corners of the grid domain, the slope is calculated by using a 2 by 3 or 2 by 2 kernel, respectively. There is no data input required for FIESWP and FIESWI if IIESWFL is zero.

$1=$ Fractions of inefficiency losses to surface-water runoff related to precipitation and irrigation specified for the entire simulation.

$2=$ Fractions of inefficiency losses to surface-water runoff related to precipitation and irrigation specified for each stress period.

$\mathrm{P}=$ Fraction of inefficiency losses to surface-water runoff specified for the parent model (as defined by the parent model's IIESWFL entry) are automatically used for the child model. No additional crop-specific FIESWP or FIESWI list entries are necessary. For parent IESWFL=0, the slope of child-model cells is calculated as described above on the basis of a ground surface-elevation array either derived automatically the parent elevation by bilinear interpolation (GSURF=P) or on a child-model specific elevation array.

Efficiency Flag (1, 2, "P" possible)

$1=$ On-farm efficiency either as OFE (Farm-ID) per farm or as OFE (Farm-ID, Crop-ID ${ }_{\text {NCROPS }}$ ) per farm and per crop specified for the entire simulation.

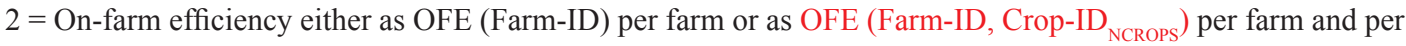
crop specified for each stress period.

$\mathrm{P}=$ Efficiency list entries or arrays specified for the parent model (as defined by the parent model's IEFFL entry) are automatically used for the child model. No additional crop-specific OFE list entries are necessary. 
Water-Policy Flags (Item 2)

IEBFL

Efficiency-Behavior Flag:

For IEBFL = 0, 1: Cell-by-cell efficiency does not vary with changing groundwater level, but cell-by-cell delivery may vary with changing groundwater level. However, farm efficiency may vary in response to reduced delivery during deficit irrigation (if IDEFFL $=-1$ ).

$0=$ Conservative Behavior - Cell-by-cell efficiency is held constant over time step with respect to changing groundwater level. Farm efficiency resets to specified efficiency at each stress period.

1 = Conservative Behavior-Cell-by-cell efficiency is held constant over time step with respect to changing groundwater level. Farm efficiency resets to specified efficiency at each time step.

For IEBFL $=2,3$ : Cell-by-cell efficiency varies with changing groundwater level, but cell-by-cell delivery does not vary with changing groundwater level. However, farm delivery may vary in response to deficit irrigation (if IDEFFL $=-1$ ).

2 = Conservative Behavior - Cell-by-cell delivery is held constant over time step with respect to changing groundwater level (evaluation of initial total delivery requirement (TDR) per cell at first iteration of first time step of each stress period). Farm efficiency resets to specified efficiency at each stress period.

3 = Conservative Behavior - Cell-by-cell delivery is held constant over time step with respect to changing groundwater level (evaluation of initial total delivery requirement (TDR) per cell at first iteration of each time step). Farm efficiency resets to specified efficiency at each time step.

IROTFL Crop-rotation flag:

$<0$ Crop Type changes temporally and spatially at every stress period (ICID 2D array is read for each stress period)

$=0$ No crop rotation (ICID 2D array is read for the entire simulation).

$>0$ No crop rotation (ICID 2D array is read for the entire simulation), and IROTFL $=$ Stress period that is equal to Non-Irrigation Season.

IDEFFL

Deficiency Scenario flag:

$-2=$ Water Stacking.

$-1=$ Deficit Irrigation.

$0=$ "Zero Scenario" where no policy is applied, and if demand exceeds supply, it is assumed to be supplied by other imported sources.

$1=$ Acreage Optimization

2 = Acreage Optimization with Water Conservation Pool.

(Only if SFR is specified in Name File, if a diversion from a river segment into a diversion-segment is specified in the SFR input file, and if routed or semi-routed deliveries from such a diversion segment into farms can occur $(\operatorname{IRDFL}=1,-1$, or ISRDFL $=1,2)$.

IBEN

ICOST

Crop-Benefits Flag (only to specify if IDEFFL $>0$ ):

$1=$ crop benefits list read for the entire simulation.

$2=$ crop benefits list read for each stress period.

Water-Cost Coefficients Flag (only to specify if IDEFFL $>0$ ):

$0=$ lumped water-cost coefficients for the entire simulation.

$1=$ water-cost coefficients for each farm for the entire simulation.

$2=$ water-cost coefficients for each farm for each stress period .

Variable Groundwater Allotment flag (0, 1, 2, "P" possible).

$0=$ Groundwater Allotments (ALLOTGW(NF)) are not specified, and the maximum capacity of each farm to deliver potential groundwater supply is limited by the total pumping capacity of all farm wells that are related to each water-balance subregion (farm).

$1=$ Groundwater Allotments (ALLOTGW(NF)) specified for the entire simulation.

$2=$ Groundwater Allotments (ALLOTGW(NF)) specified for each stress period.

$\mathrm{P}=$ use parent-model groundwater allotments and bypass reading ALLOTGW per simulation or stress period. For child IALLOTGW=P and parent IALLOTGW=1, no additional data are required for the child model. 


\section{Crop Consumptive-Use Flag (Item 2):}

ICCFL Concept used for the approximation of ET-fluxes with changing head:

1 - for consumptive use Concept 1 = plant-and soil-specific pseudo steady-state transpiration approximated by analytical solution: A restriction of active root zone corresponding to anoxia- or wilting-related pressure heads is determined by FMP by using analytical solutions of a vertical pseudo steady-state pressure head distribution over the depth of the total root zone. (FMP3 not linked to UZF1).

2 -for consumptive use Concept 2 = nonplant- and nonsoil-specific simplification of Concept 1. (FMP3 not linked to UZF1).

3-for consumptive use Concept 1 = plant-and soil-specific pseudo steady-state transpiration approximated by analytical solution: A restriction of active root zone corresponding to anoxia- or wilting-related pressure heads is determined by FMP by using analytical solutions of a vertical pseudo steady-state pressure head distribution over the depth of the total root zone. (FMP3 linked to UZF1: FMP3 farm identification arrays linked to coinciding UZF1 infiltration arrays).

4-for consumptive use Concept 2 = nonplant- and nonsoil-specific simplification of Concept 1. (FMP3 linked to UZF1: FMP3 farm identification arrays linked to coinciding UZF1 infiltration arrays).

$\mathrm{P}=$ Consumptive use Concept specified in parent model is used for child model. For child ICCFL $=\mathrm{P}$ and parent $\mathrm{ICCFL}=1$, no additional data are required for crop-specific PSI list entries for the child model.

\section{Surface-Water Flags (Item 2):}

INRDFL

Non-Routed Surface-Water Delivery Flag (0, 1, "P" possible) :

$0=$ no Non-Routed Surface-Water Delivery (NRD) exists.

$1=$ NRDs exist. A farm related list of Volumes, Ranks, and Use-Flags of NRD will be read.

$\mathrm{P}=\mathrm{A}$ farm related list of Volumes, Ranks, and Use-Flags of NRDs for the parent model (as specified by the initial parent model's INRDFL entry) is automatically used for the child model. No additional list entries for the child model are necessary. INRDFL $=\mathrm{P}$ allows the scaling of ranked NRDs to parent or child model farm by the ratio between the residual parent or child farm demand and the joint residual parent plus child demand. For IGRID=1, the ranked NRDs to the residual parent model farm are scaled by the ratio (residual parent farm demand/joint residual parent+child farm demand). For IGRID $>1$, the ranked NRDs to the child model farm are scaled by the ratio (child farm demand/joint residual parent+child farm demand) and adopt NRD-Ranks and NRD-Use flag setting from the parent model NRD data input.

MXNRDT (Limitation: not allowed for WELLFIELD option).

Maximum number of non-routed delivery types (read if INRDFL $=1$, if ILRG $=0$, or if ILGR $>0$, and for parent model grids where IGRID $=1$, or if ILGR $>0$, and for child model grids where IGRID $>1$ and INRDFL=1). MXNRDT is omitted if ILGR $>0$ and for child model grids where IGRID $>1$ and INRDFL $=P$. In this case, memory for NRD related attributes is allocated by twice the number of parent-MXNRDT to save old RNDRs for each type before scaling it down as a result of prorating for parent and child farm NRDs. 
Semi-Routed Surface-Water Delivery Flag (0, 1, 2, "P" possible):

$0=$ no Semi-Routed Surface-Water Delivery (SRD) exists.

1 or 2 = Semi-Routed Surface-Water Deliveries exist. (Routing surface-water along a river or major canal, and allocating non-routed deliveries from a point of diversion). A farm related list of Row- and Column-coordinates or segment and reach numbers for a point of diversion will be read (only if SFR or SWR1 is specified in Name File). An additional flag for each.

$1=$ List of Row- and Column-coordinates or segment and reach numbers for SFR is read for the entire simulation. $2=$ List of Row- and Column-coordinates or segment and reach numbers for SFR is read for each stress period.

For a parent model farm (IGRID=1) with a head-gate (SFR in Name File), for a child model farm without any stream network (IGRID $>1$; SFR not in Name File), and where a residual parent farm and child farm have equal farm ID:

$\mathrm{P}=\mathrm{A}$ point of diversion along the stream network defined for the parent model by row and column coordinates or segment and reach number (as defined by the parent model's ISRDFL settting) is also used to receive the residual demand of child model farm in addition to the residual demand of parent model farm. No additional farm-specific SRD list entries are required for the child model.

The child model farm without a head-gate reach does not have any actual farm delivery from surface water from an own source, but may receive deliveries from the parent farm head gate subject to availability. Parent and child farms may either receive actual surface-water deliveries in full or at a reduced rate depending on whether their cumulative demand is less or more than the available supply:

- If the sum of residual demands of parent and child model farms exceeds any supply constraints, such as the available streamflow or surface-water allotment in the parent model head-gate reach, then

the entire constraint will be diverted from the streamflow available at the parent farm's head-gate reach, and

the residual delivery requirement of both farms will be reduced to the respective constraint. This is accomplished by scaling the delivery requirement of the residual parent or child farm farm by the ratio $\left[\frac{\text { constraint }}{\text { (parent farm demand }+ \text { sum of demands of all child model farms) }}\right]$. The reduced demand will be passed on to the farm budget.

- If the sum of residual demands of parent and child model farms does not exceed any supply constraints, then - the child farm demand, in addition to parent farm demand, is diverted from the streamflow available at the parent farm's head-gate reach, and the residual delivery requirement of both farms will by supplied in full and passed on to the farm budget.

Routed Surface-Water Delivery Flag (0, 1, -1, "P" possible):

$0=$ no fully routed surface-water delivery exists.

1 = fully routed surface-water delivery may occur from the uppermost reach of a series of diversion-segment reaches located within a farm. Caution: Streamflow fully routed through a conveyance network directly to a farm can only occur (1) if SFR is specified in Name File, (2) if at least one reach of a diversion segment is located within the farms, and (3) if streamflow is available.

$-1=$ fully routed surface-water delivery may occur from the uppermost reach of a series of reaches of any type of stream segment located within a farm. Caution: Streamflow fully routed through a conveyance network directly to a farm can only occur (1) if SFR is specified in Name File, (2) if at least one reach of any type of segment is located within the farms, and (3) if streamflow is available.

$\mathrm{P}=$ The IRDFL flag setting defined for the parent model will be applied. Fully routed surface-water delivieries within a child model are subject to SFR being specified in the child model Name File and the existence of a respective segment (diversion segment for $I R D F L=1$; any type of segment for $I R D F L=-1$ ). 
$0=$ No locations along the stream network are specified for any farm where semi-routed runoff return flow is recharged into the stream network. Runoff is either automatically prorated over non-diversion-segment reaches located within a farm or automatically recharged into one non-diversion-segment reach nearest to the lowest elevation of the farm.

1 or 2 = For each farm, a location is specified anywhere along the stream network where semi-routed runoff return flow is recharged anywhere in the active model domain. A farm-related list of row and column coordinates or segment and reach numbers for a point of runoff return flow recharge will be read (only if SFR is specified in Name File).

$1=$ List of row and column coordinates or segment and reach numbers and target of Semi-routed Delivery to SFR or indirectly to SWR through an SFR segment is read for the entire simulation.

$2=$ List of row and column coordinates or segment and reach numbers and target of Semi-routed Delivery to SFR or indirectly to SWR through an SFR segment is read for each stress period.

For a parent model farm (IGRID=1) with a head-gate (SFR in Name File), for a child model farm without any stream network (IGRID>1; SFR not in Name File), and where a residual parent farm and child farm have equal farm ID:

$\mathrm{P}=\mathrm{A}$ point of return flow recharge along the stream network for the parent model by row and column coordinates or segment and reach number (as defined by the parent model's ISRRFL setting) is also used to receive the cumulative runoff return flow of the child model farm in addition the return flow of the parent-model farm. If the parent ISRRFL $\geq 1$ and zero coordinates are specified for the return flow location of a parent farm, then the return flow from the child model is added to "automatic fully routed runoff return flow" prorated over drain segments found within the parent model farm or to "automatic semi-routed runoff return flow" discharged into a reach remote from the parent farm, but nearest to the lowest elevation of the parent farm. No additional farmspecific SRR list entries are required for the child model.

The absence of a SFR network within the child model domain does not allow the child farm to return runoff to any specified our automatically detected reaches. However, the child farm may return runoff to the parent farm's return flow reaches, which may be specified or automatically detected as reaches within the farm domain or as a remote reach nearest to the lowest elevation of the parent farm.

Routed Surface-Water Runoff Return Flow Flag (0, 1, -1, "P" possible):

$0=$ no fully routed surface-water runoff return flow possible (no SFR specified in Name File).

1 = surface-water runoff may be returned as fully routed return flow to a series of non-diversion-segment reaches located within a farm (prorated over each reach weighted by the reach length). Caution: Fully routed return flow directly from a farm to a series of non-diversion-segment reaches can only occur (1) if SFR is specified in Name File and (2) if at least one reach of a non-diversion segment is located within the farm. Also, it occurs if segment and reach of farm in the SRD input file are set to 0 .

$-1=$ fully routed surface-water runoff may be returned as fully routed return flow to a series of reaches of any segment of stream type located within a farm (prorated over each reach weighted by the reach length). Caution: Fully routed return flow directly from a farm to a series of reaches of any type of stream segment can only occur (1) if SFR is specified in Name File and (2) if at least one reach of a non-diversion segment is located within the farm. Also, it occurs if the segment and reach of farm in the SRD input file are set to 0 .

$\mathrm{P}=$ The IRRFL flag setting defined for the parent model will be applied. Fully routed surface-water runoff return flow within a child model are subject to SFR being specified in the child model Name File and the existence of a respective segment (return flow to non-diversion segment for IRRFL=1; return flow to any type of segment for $\mathrm{IRDFL}=-1$ ). 
Surface-water allotment flag (IALLOTSW > 1 not yet tested for parent model farm (IGRID=1) and child model farm (IGRID $>1$ ) straddling the parent/child model boundary and with equal farm ID):

0 -No surface-water allotment specified,

1-Equally appropriated surface-water allotment height [L] specified per stress period (specification of diversions from a river into diversion segments in SFR input file required if ISRDFL $=1$ or 2 , or IRDFL $=1$ ).

2-Prior appropriation system with Water Rights Calls $\left[\mathrm{L}^{3} / \mathrm{T}\right]$ (diversion rates from a river into diversion segments are simulated if ISRDFL $=1$ or 2 , or IRDFL $=1$; specification of a farm-specific water rights calls list required for each stress period).

3-Prior appropriation system without Water Rights Calls $\left[\mathrm{L}^{3} / \mathrm{T}\right]$ (diversion rates from a river into diversion segments are simulated based on estimate of TFDR if ISRDFL $=1$ or 2 , or IRDFL $=1$ ).

For a parent model farm (IGRID=1) and child model farm(s) (IGRID>1) and where a residual parent farm and child farm have equal farm ID:

$\mathrm{P}=$ use parent model equal appropriation allotment heights and bypass reading ALLOTSW per stress period. For child IALLOTSW=P and parent IALLOTSW=1, no additional data are required for the child model.

Allotment rates for the residual parent farm and the child farms are calculated on the basis of each area. Each child farm allotment rate is then added to the residual parent farm allotment rate. This joint allotment rate is then used to constrain the available streamflow in head-gate, from which water is diverted that accounts for the residual demands of the parent and child farms.

PCLOSE

User-specified closure criterion for simulated diversions into diversion segments if prior appropriation is chosen $\left[\mathrm{L}^{3} / \mathrm{T}\right]$ (only to specify if IALLOT $>1$ )

\section{Mandatory Print Flags (Item 2):}

For ILGR $>0$ and IGRID $>1$, that is, for more than one model grid, several farm-ID related budget lists required the addition of a "GRID" number after the "TIME[UNIT]" column. As a new standard, the introduction of this column is not backwards compatible to FMP3, so if LGR is not active and there is only one parent grid, the GRID column will simple show "1."

So far, this was implemented for IFWLCB=1, IFWLCB $>1$ (if "Compact Budget" is specified in Output Control), ISDPFL $\geq 1$, and IFBPFL $\geq 1$. That is, for any time step, budgets for each model are listed in sequence of the GRID number.

IFWLCB

Farm well budget print flags

$<0 \quad$ A list (farm-well ID, farm ID, layer, row, column, farm-well flow rate) is printed to list file for time steps, for which in Output Control "Save Budget" is specified (using words) or ICBCFL is not zero (using numeric codes).

$=0 \quad$ farm-well flow rates not written.

$=1$ A list (farm-well ID, farm ID, layer, row, column, farm-well flow rate) is saved on ASCII file "FWELLS.OUT" for all time steps.

$>1$ if "Compact Budget" is not specified in Output Control:

A cell-by-cell 2D-array of farm-well flow rates will be saved as binary file on a unit number specified in the Name File for time steps for which in Output Control "Save Budget" is specified (using words) or ICBCFL is not zero (using numeric codes).

if "Compact Budget" is specified in Output Control:

A list (node, farm-well flow rate) will be saved as binary file on a unit number specified in the Name File for time steps for which in Output Control "Save Budget" is specified (using words) or ICBCFL is not zero (using numeric codes). 
IFNRCB

ISDPFL
Farm net recharge budget print flags

$<0 \quad$ A cell-by-cell 2D-array of farm net recharge flow rates is printed to list file for time steps, for which in Output Control "Save Budget" is specified (using words) or ICBCFL is not zero (using numeric codes).

$=0 \quad$ farm net recharge flow rates not written.

$=1$ A cell-by-cell 2D-array of farm net recharge flow rates is saved on ASCII file FNRCH_ARRAY.OUT" for all time steps.

$=2 \quad$ A list (stress period, time step, total time, farm ID, cumulative farm net recharge flow rates) will be saved as ASCII file "FNRCH_LIST.OUT."

$=3$ A list (stress period, time step, total time, farm ID, cumulative farm net recharge flow rates) will be saved as binary file "FNRCH_LIST_BIN.OUT" for all time steps.

$>3$ if "Compact Budget" is not specified in Output Control:

A list (farm ID, cumulative farm net recharge flow rates) will be saved as binary file on a unit number specified in the Name File for time steps for which in Output Control "Save Budget" is specified (using words) or ICBCFL is not zero (using numeric codes).

if "Compact Budget" is specified in Output Control:

if number of model layers $=1$ :

A cell-by-cell 2D-array of farm net recharge flow rates will be saved as binary file on a unit number specified in the Name File for time steps for which in Output Control "Save Budget" is specified (using words) or ICBCFL is not zero (using numeric codes).

if number of model layers $>1$ :

A 2D integer-array of each cell's uppermost active layer and a 2D real-array of each cell's farm net recharge flow rate will be saved as binary file on a unit number specified in the Name File for time steps for which in Output Control "Save Budget" is specified (using words) or ICBCFL is not zero (using numeric codes).

Farm supply and demand print flags

$=-3$ A list (A) of current demand and supply flow rates will be printed to the list file at each iteration, and a list (B) of final demand and supply flow rates will be printed to the list file for each time step:

List (A): (Farm-ID, OFE, TFDR, NR-SWD, R-SWD, QREQ);

List (B): (Farm-ID, OFE, TFDR, NR-SWD, R-SWD, QREQ, Q,[COMMENTS]).

$=-2 \quad$ A list of final demand and supply flow rates will be printed to the list file for each time step:

List: (Farm-ID, OFE, TFDR, NR-SWD, R-SWD, QREQ, Q, [COMMENTS]).

$=-1 \quad$ A list of final demand and supply flow rates will be printed to the list file for time steps for which in Output Control "Save Budget" is specified (using words) or ICBCFL is not zero (using numeric codes):

List: (Farm-ID, OFE, TFDR, NR-SWD, R-SWD, QREQ, Q, [COMMENTS]).

$=0 \quad$ farm demand and supply flow rates not written.

$=1 \quad$ A list of initial demand and supply flow rates and of final demand \& supply flow rates after the application of a deficiency scenario will be saved on ASCII file "FDS.OUT" for all time steps:

List: (PER, TSTP, TIME, Farm-ID, OFE, TFDR-INI, NR-SWD-INI, R-SWD-INI, QREQ, TFDR-FIN, NR-SWD-FIN, R-SWD-FIN, QREQ, Q, DEF-FLAG).

$>1$ if "Compact Budget" is not specified in Output Control:

A list of initial demand and supply flow rates and of final demand and supply flow rates after the application of a deficiency scenario will be saved as binary file on a unit number specified in the Name File for all time steps.

List: list attributes are equal to ISDPFL $=1$.

if "Compact Budget" is specified in Output Control:

A list of initial demand and supply flow rates and of final demand and supply flow rates after the application of a deficiency scenario will be saved as binary file on a unit number specified in the Name File for time steps for which in Output Control "Save Budget" is specified (using words) or ICBCFL is not zero (using numeric codes).

List: list attributes are equal to ISDPFL $=1$. 
Farm budget print flags

$=0 \quad$ Farm budget flow rates not written.

$=1 \quad$ A compact list of Farm Budget components (flow rates $\left[\mathrm{L}^{3} / \mathrm{T}\right]$ and cumulative volumes $\left[\mathrm{L}^{3}\right]$ into and out of a farm) is saved on ASCII file "FB_COMPACT.OUT" for all time steps:

List: (PER, TSTP, TIME, Farm-ID,

Q-p-in, Q-sw-in, Q-gw-in, Q-ext-in, Q-tot-in,

Q-et-out, Q-ineff-out, Q-sw-out, Q-gw-out, Q-tot-out, Q-in-out, Q-discrepancy[\%],

V-p-in, V-sw-in, V-gw-in, V-ext-in, V-tot-in,

V-et-out, V-ineff-out, V-sw-out, V-gw-out, V-tot-out, V-in-out, V-discrepancy[\%]).

$=2$ A compact list of Farm Budget components (flow rates $\left[\mathrm{L}^{3} / \mathrm{T}\right]$ and cumulative volumes $\left[\mathrm{L}^{3}\right]$ into and out of a farm) is saved on ASCII file "FB_COMPACT.OUT" for all time steps:

List: (PER, TSTP, TIME, Farm-ID,

Q-p-in, Q-nrd-in, Q-srd-in, Q-rd-in, Q-wells-in, Q-egw-in, Q-tgw-in, Q-ext-in, Q-tot-in,

Q-ep-out, Q-ei-out, Q-egw-out, Q-tp-out, Q-ti-out, Q-tgw-out, Q-run-out, Q-dp-out, Q-nrd-out, Q-srd-out, Q-rd-out, Q-wells-out, Q-tot-out, Q-in-out, Q-discrepancy[\%],

V-p-in, V-nrd-in, V-srd-in, V-rd-in, V-wells-in, V-egw-in, V-tgw-in, V-ext-in, V-tot-in,

V-ep-out, V-ei-out, V-egw-out, V-tp-out, V-ti-out, V-tgw-out, V-run-out, V-dp-out, V-nrd-out, V-srd-out, V-rd-out, V-wells-out, V-tot-out, V-in-out, V-discrepancy[\%]).

$>2$ if "Compact Budget" is not specified in Output Control:

A list of farm budget flow rates will be saved as binary file on a unit number specified in the Name File for all time steps:

List: list attributes are equal to IFBPFL $=1$, if unit number $>2$ is odd, or equal to IFBPFL $=2$, if unit number $>2$ is even.

if "Compact Budget" is specified in Output Control:

A list of farm budget flow rates will be saved as binary file on a unit number specified in the Name File for time steps for which in Output Control "Save Budget" is specified (using words) or ICBCFL is not zero (using numeric codes):

List: list attributes are equal to IFBPFL $=1$, if unit number $>2$ is odd, or equal to IFBPFL $=2$, if unit number $>2$ is even.

$0=$ No ET is written out to list or external files.

$1=$ A cell-by-cell 2D-array of Evaporation and Transpiration as one SUMMED array is saved on ASCII file "ET ARRAY.OUT" for all time steps.

$2=$ A cell-by-cell 2D-array of Evaporation and Transpiration as SEPARATE arrays are saved on ASCII file "ET_ARRAY.OUT" for all time steps.

$3=\mathrm{A}$ list (stress period, time step, total time, farm ID, EVAP, TRAN, and EVAP+TRAN will be saved as ASCII file 'ET LIST.OUT.'

$4=$ Does both IETPFL $=2$ and 3 and writes to ET_ARRAY.OUT and ET_LIST.OUT, respectively.

$-1=$ Same as 1 , but prints to LST file on the basis of Output Control.

$-2=$ Same as 2, but prints to LST file on the basis of Output Control.

$-3=$ Same as 3, but prints to LST file on the basis of Output Control. 


\section{Optional Print Flags (Item 2):}

IRTPFL

Optional routing information print flag if the SFR Package is specified in Name file.

Information regarding the routing of farm deliveries and farm runoff return flows will be written either to the list file or to a separate ASCII file, called ROUT.OUT.

The information regarding deliveries tells whether the farm can potentially receive either:

(a) fully-routed deliveries from the first, most upstream reach of a sequence of automatically detected deliverysegment reaches within a farm, or whether

(b) the farm can potentially receive semi-routed deliveries from specified stream reaches.

The information regarding return flows tells whether potential runoff from the farm is returned either

(a) full-routed to automatically detected return flow-segment reaches within a farm, over which the runoff-return flow is prorated, weighted by the length of each reach, or

(b) semi-routed to specified stream reaches, or, in lack of this first two options,

(c) semi-routed to automatically detected return flow-segment reach nearest to the lowest elevation of a farm.

$=-2$ Routing information written to the list file for the first stress period only.

$=-1 \quad$ Routing information written to the list file for every stress period.

$=0$ Routing information not written.

$=1$ Routing information written to ASCII file "ROUT.OUT" for every stress period.

$=2$ Routing information written to ASCII file "ROUT.OUT" for the first stress period only.

Options IRTPFL $=-2$ or 2 may be chosen if the geometry and the diversion rules specified in the SFR Package do not change from stress period to stress period.

For ILGR $>0$ and IGRID $>1$, that is, for more than one model grid, the routing information is written in sequence of the GRID number to the same ASCII file "ROUT.OUT" for IRTPFL $>0$.

IOPFL

Optional print settings if Acreage-Optimization is chosen (if IDEFFL $>0$ ).

$=-4 \quad$ A tableaux matrix will be printed to the list file for iterations, during which optimization occurs.

$=-3 \quad$ Original and optimized flow rates of resource constraints and a list of fractions of optimized cell areas will be printed to the list file for any farm and iteration that are subject to optimization:

\begin{tabular}{|l|l|l|l|l|l|l|l|}
\hline List: & Row, & Column, & Crop ID, & $\begin{array}{l}\text { A-tot-opt/ } \\
\text { A-tot-max, }\end{array}$ & $\begin{array}{l}\text { A-gw-opt/ } \\
\text { A-tot-opt, }\end{array}$ & $\begin{array}{l}\text { A-sw-opt/ } \\
\text { A-tot-opt, }\end{array}$ & $\begin{array}{l}\text { A-nr-opt/ } \\
\text { A-tot-opt })\end{array}$ \\
\hline
\end{tabular}

$=-2$ Original and optimized flow rates of resource constraints will be printed to the list file for any farm and iteration that are subject to optimization

$=-1$ A cell-by-cell 2D-array of fractions of active cell acreage will be printed to the list file for all time steps.

$=0 \quad$ No original and optimized flow rates, and no optimized cell areas are written.

$=1$ A cell-by-cell 2D-array of fractions of active cell acreage is saved on ASCII file "ACR_OPT.OUT" for all time steps.

$=2$ Original and optimized flow rates of resource constraints are saved on ASCII file "ACR_OPT.OUT" for any farm and iteration that are subject to optimization.

$=3$ Original and optimized flow rates of resource constraints and a list of fractions of optimized cell areas is saved on ASCII file "ACR_OPT.OUT" for any farm and iteration that are subject to optimization:

\begin{tabular}{|l|l|l|l|l|l|l|l|}
\hline List: & (Row, & Column, & Crop ID, & $\begin{array}{l}\text { A-tot-opt/ } \\
\text { A-tot-max, }\end{array}$ & $\begin{array}{l}\text { A-gw-opt/ } \\
\text { A-tot-opt, }\end{array}$ & $\begin{array}{l}\text { A-sw-opt/ } \\
\text { A-tot-opt, }\end{array}$ & $\begin{array}{l}\text { A-nr-opt/ } \\
\text { A-tot-opt }\end{array}$ \\
\hline
\end{tabular}

$=4$ A tableaux matrix is saved on ASCII file "ACR_OPT.OUT" for iterations, during which optimization occurs.

IPAPFL

Optional print settings if Prior Appropriation is chosen (if IALLOTSW >1)

$=-1 \quad$ A budget at the point of diversions from the river into diversion segments and a budget at the point of a farm-diversion from the diversion segment will be printed to the list file for all iterations.

$=1 \quad$ A budget at the point of diversions from the river into diversion segments and a budget at the point of a farm-diversion from the diversion segment will be saved on ASCII file "PRIOR.OUT" for all iterations. 


\section{Flags for Auxiliary Variables (Item 2):}

NOAUX

AUX “abc"

AUX QMAXRESET

AUX NOCIRNOQ

AUX LGRGRID
Indicates that no optional flags for auxiliary variables are specified. NOAUX is only required if Flag Blocks are used. If flags are read in Item $2 b$ from a single line (as before in FMP1), then no entry is required if no optional flags for auxiliary variables are specified.

Defines an auxiliary variable, "abc," which will be read for each farm-well as part of Items 4 and 23. Up to five auxiliary attributes "abc" can optionally be specified, each of which must be preceded by "AUX." These values will be read after the QMAXfact or QMAX variable of Item 4 or Item 23, respectively.

The specification of the optional flag "AUX QMAXRESET" for \{option\} in Item 2 will prompt FMP to reset QMAX, as simulated by the MNW Package to the default QMAX as defined by FMP at the beginning of each time step. The optional flag "AUX QMAXRESET requires FMP to read an auxiliary variable after the QMAXfact or QMAX variable of the farm wells list in Items 4 or 23, or after any other preceding auxiliary variable (for example, AUX NOCIRNOQ). If a " 1 " is read, then the MNW-simulated QMAX is reset to the default QMAX in the first iteration of each time step.

The specification of the optional flag "AUX NOCIRNOQ" for \{option\} in Item 2 will prompt FMP to limit the distribution of farm pumpage to farm wells whose row and column coincides with a top layer cell with a current irrigation requirement from active crops. "NOCIRNOQ" stands for "no crop irrigation requirement (CIR), no pumping (Q)." The optional flag “AUX NOCIRNOQ" requires FMP to read an auxiliary variable after the QMAXfact or QMAX variable of the farm wells list in Item 4 or 23, or after any other preceding auxiliary variable (for example, AUX QMAXRESET). The auxiliary variable for "AUX NOCIRNOQ" is defined to be a binary parameter that tells which wells are selected for the NOCIRNOQ option. If a "1" is read, then the respective well is selected for setting its maximum capacity to zero if, during a particular time step, no crop irrigation requirement of the top layer cell exists. At each new time step the maximum capacity of such a select well will be reset to the default value.

Identifies a child model grid with respect to a parent model for FMP transfer of properties.

Flags for Options (Item 2):

NOOPT

$\mathrm{CBC}$

NOPRINT

WELLFIELD
Indicates that no Options are specified. NOOPT is only required if Flag Blocks are used. If flags are read in Item $2 \mathrm{~b}$ from a single line (as before in FMP1/2), then no entry is required if no Options are specified.

Indicates that memory should be allocated to store cell-by-cell flow for each well to make these flows available for use in other process.

Indicates that a list of specified farm well attributes will not be printed to the list file.

Allows a series of irrigated farms to receive their cumulative irrigation demand as simulated non-routed deliveries from well fields simulated as virtual farms. A virtual well-field farm with one or several wells (well fields) receives a cumulative pumping requirement equal to the cumulative irrigation delivery requirement of irrigated farms that are supplied by the well field. If the cumulative demand exceeds the cumulative maximum pumping capacity of the well field, then other well field can supply the residual demand. The cumulative pumpage of the well field that is equal or less than the desired demand will then be re-distributed to the farms supplied by the well field weighted by the total delivery requirement (or residual delivery requirement for lower priority well fields) of the receiving farms. FMP3 then applies this re-distributed rate as non-routed deliveries to the respective farms.

For farms that receive water from a particular well field, in Item 36, the non-routed delivery volume may be set to a dummy zero, because the non-routed delivery is simulated by the well-field option. The rank of the non-routed delivery, NRDR, must consistently be equal to the priority of the well-field. The NRDU flag has to be set to "minus the Farm ID of the virtual farm that contains the well field" for the farms receiving water from the respective well field. For the virtual well-field farm itself, the NRDU flag has to be set to one.

For first priority well field and farms receiving water from that well field:

$\begin{array}{ll}\text { NRDV } t_{l}(\mathrm{NFARMS}) & =0 \text { (dummy zero: simulated when option WELLFIELD is set). } \\ \operatorname{NRDR} t_{l}(\mathrm{NFARMS}) & =1 \text { (Type } 1 \text { must be of rank } 1 \text { for well-field farm and for receiving farms). } \\ \text { NRDU } t_{l}\left(\mathrm{FID}_{\text {rec-wf-l }}\right) & =\text { negative value of Farm-ID of virtual well-field farm. } \\ \mathrm{NRDU} t_{l}\left(\mathrm{FID}_{w f-1}\right) & =1 . \\ \mathrm{NRDU} t_{l}\left(\mathrm{FID}_{\text {other }}\right) & =0 .\end{array}$

For second priority well field and farms receiving water from that well field:

NRDV $t_{2}$ (NFARMS) $\quad=0$ (dummy zero: simulated when option WELLFIELD is set). 


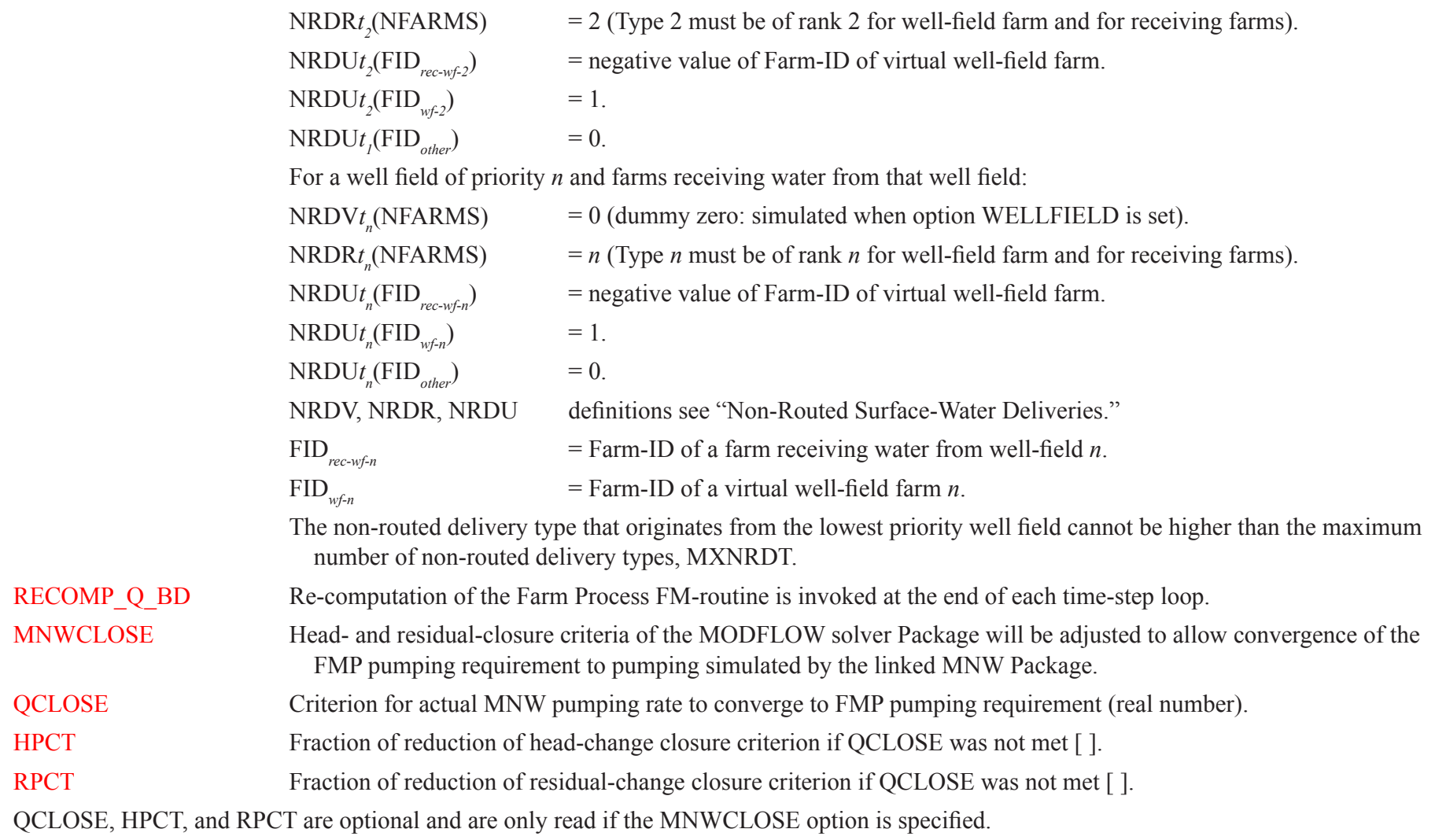

Farm-Well Related Variables (Items 3, 4, 22, 23, 24)

Farm Well Parameter Definition (Item 3):

PARNAM

PARTYP

PARVAL

NLST

INSTANCES

NUMINST

INSTNAM
Parameter name for list of parameter farm-wells (called for each stress period to activate a list of parameter wells). This name can consist of 1 to 10 characters and is not case sensitive.

Parameter type (the only allowed parameter type is QMAX, which defines values of the volumetric maximum well capacity).

Parameter value (multiplier applied to parameter-wells).

Number of parameter farm-wells included in the parameter-well-list related to one parameter.

When NLST is set to "P," up to the maximum number of parent model parameter farm-well list entries may be used as child model parameter farm wells in well locations where the child model farm ID coincides with the parent model farm ID. For child model parameter farm wells pulled from parent model parameter farm wells, the list entries printed to the list file are appended to the list entries of parameter farm wells specified for the child model under a separate parameter name.

Parent parameter farm wells are excluded from being used for a child model farm if the same child model parameter wells are specified for that child model farm.

Optional keyword that designates a parameter as time varying. The keyword is not case sensitive; that is, any combination of the same characters with different cases can be used. If INSTANCES is present, it must be followed by a value for NUMINST. If INSTANCES is absent, PARNAM is non-time-varying, and NUMINST should not be present.

Number of instances for a time-varying parameter, where each instance is a list of river reachesand associated properties. If the keyword INSTANCES is present, it must be followed by a value for NUMINST. If INSTANCES is absent, NUMINST should not be present.

Name of an instance associated with the parameter named in the corresponding Item 3 . The instance name can be 1 to 10 characters and is not case sensitive. That is, any combination of the same characters with different cases will be equivalent. Instance names must be unique for a parameter, but instance names may be reused for different parameters. 


\section{Farm-Wells List (Items 4, 23):}

If, for ILGR >0 and IGRID>1, NLST (item 3) or ITMPP (item 22) are equal to "P," then no parameter or nonparameter farm-well list entries, respectively, as defined below need to be specified.
Layer
Layer number of cell containing the farm-well (for farm-wells linked to multi-layer wells defined in the
Row Multi-Node Well Package: Layer No. $=0$ ).
Column
Row number of cell containing the farm well.
Farm-Well-ID
Column number of cell containing the farm well.
Farm-ID
Farm-well identity associated with the farm well (to establish a link of a farm-well to a well defined in the Multi-Node Well Package Version 1 and 2: use "negative" Farm-Well-ID, for example, -10).
QMAXfact
QMAX
Farm identity to which the farm-well is attributed.
Maximum Well Capacity factor (QMAXfact $\times$ PARVAL $=$ QMAX) $\left[\mathrm{L}^{3} / \mathrm{T}\right]$.
MNW2NAM
Maximum Well Capacity $\left[\mathrm{L}^{3 / \mathrm{T}}\right]$ (positive value = maximum possible discharge rate).
Multi-Node Well Package Version 2 Well Name that will be linked to the farm process. MNW2NAM is a character variable of maximum length 20 that is read only when MNW2 package is active and Farm-Well-ID $<0$. When linked to MNW2 the the layer, row and column specified by well MNW2NAM in MNW2 will overwrite the previously defined values.
$[\mathrm{abc}]$
Represents a one-to-one agreement with the order of declared auxiliary variables for a farm-well that have been defined in Item 2. One to one agreement with declared AUX "abc" variables.
The auxiliary variables must be present in each repetition of Items 4 and 23. If the optional flag for \{Option $\}$ in Item 2 is set to "AUX QMAXRESET," then the auxiliary variable for [xyz] in column 7 of the farm wells list is defined to be a binary parameter that tells when to reset the MNW-simulated QMAX rate to the FMP-defined default QMAX rate. The parameter in column 7 of the well list is ignored if the option flag "AUX QMAXRE- SET" is not specified.
$0=$ The MNW-simulated QMAX is reset at the beginning of each stress period.
$1=$ The MNW-simulated QMAX is reset at the beginning of each time step.

\section{Farm Process Farm Wells with the NWT Solver (FMP)}

If the user specifies the NWT solver option, the additional option for smooth reduction of farm well pumpage is available. This smoothing is identical to what NWT does to the WEL Package (Niswonger and others, 2011) and is initiated by including at the start of each Farm well input data set (Item 4 and 23) with the key word "SPECIFY" as follows:

\begin{tabular}{ccc} 
Keyword & PSIRAMPF & SATTHK \\
\hline SPECIFY & 0.05 & 0.1
\end{tabular}
PSIRAMPF Minimum fraction of model cell thickness before pumping reduction is initiated, same as PHIRAMP (Niswonger and others, 2011)
SATTHK Minimum saturated thickness of model cell before pumping reduction is initiated.

Pumping reduction is initiated depending on whichever of these two variables is a smaller fraction of model cell thickness for each model cell containing a farm well.

\section{Farm-Well Flags and Dimensions for Each Stress Period (Items 22, 24):}

\begin{tabular}{|c|c|c|}
\hline \multirow[t]{3}{*}{ ITMP } & \multicolumn{2}{|c|}{ Flag and counter } \\
\hline & $>0$ & ITMP = number of nonparameter farm-wells read for the current stress period. \\
\hline & $=0$ & no nonparameter farm-wells are read for the current stress period. \\
\hline & $<0$ & nonparameter farm-well data from the last stress period will be reused. \\
\hline \multirow[t]{3}{*}{ ITMPP } & $=\mathrm{P}$ & $\begin{array}{l}\text { for ILGR }>0 \text { and IGRID }>1 \text {, up to the maximum number of parent model nonparameter farm-well } \\
\text { list entries may be used as child model nonparameter farm wells in well locations, where the child } \\
\text { model farm ID coincides with the parent model farm ID. For child model nonparameter farm } \\
\text { wells pulled from parent model nonparameter farm wells, the list entries printed to the list file are } \\
\text { appended to the list entries of nonparameter farm wells specified for the child model. }\end{array}$ \\
\hline & & $\begin{array}{l}\text { Nonparent parameter farm wells are excluded from being used for a child model farm if the same } \\
\text { nonparameter wells are already specified for that child model farm. }\end{array}$ \\
\hline & & (ITMPP is optional only for for ILGR > 0 and IGRID $>1$ ). \\
\hline NP & Nun & nultiplier parameters in use in the current stress period. \\
\hline Pname & Nan & ltiplier parameter being used in the current stress period. NP parameter names will be read. \\
\hline Iname & $\begin{array}{r}\text { Inst: } \\
\text { al }\end{array}$ & $\begin{array}{l}\text { ne read only if Pname is a time-varying parameter. Multiple instances of the same parameter are not } \\
\text { a stress period. }\end{array}$ \\
\hline
\end{tabular}




\title{
Two-Dimensional Arrays (Items 5, 6, 8, 10 or 26, 28, 30b, 33)
}

\author{
GSURF (NCOL, NROW) Ground-surface elevation (Item 5) \\ If, for ILGR $>0$ and IGRID $>1$, GSURF $=$ P, then the child model's ground surface-elevation array is derived \\ automatically from the parent elevation by bilinear interpolation. \\ IFID (NCOL, NROW) \\ Farm identity (Item 6 or Item 26) \\ If, for ILGR $>0$ and IGRID $>1$, IFID $=$ P, then the child model's farm identity array is derived automatically \\ from the parent farm identity. In this case, farm related data lists (see below) are skipped and need not to be \\ specified. \\ ISID (NCOL, NROW) \\ Soil-type identity (Item 8 ) \\ If, for ILGR $>0$ and IGRID $>1$, ISID $=\mathrm{P}$, then the child model's soil-type identity array is derived \\ automatically from the parent soil-type identity. In this case, soil-type related data lists (see below, item 9) \\ are skipped and need not to be specified. \\ ICID (NCOL, NROW) \\ Crop-type identity (Item 10 if IROTFL $\geq 1$, Item 28 if IROTFL $=-1$ ) \\ If, for ILGR $>0$ and IGRID $>1$, ICID $=\mathrm{P}$, then the child model's crop-type identity array is derived automati- \\ cally from the parent crop-type identity. In this case, crop-type related data lists (see below, Items 11-15, \\ 25-29) are skipped and need not to be specified. \\ ETR(NCOL, NROW) \\ Reference Evapotranspiration (see climate related data) $[\mathrm{L} / \mathrm{T}]$ (Item $30 \mathrm{~b}$ if ICUFL $=1,-1$ ) \\ PFLX (NCOL, NROW) \\ Precipitation flux (see climate related data) $[\mathrm{L} / \mathrm{T}]$ (Item 33)
}

\section{Farm Related Data Lists (Items 7, 19, 21a, 21b, 25, 27, 35, 36, 37a, 37b, 39)}

Farm-ID

OFE(Farm-ID, Crop-ID NCROPS $_{\text {(I) }}$ )

GWcost1,2,3,4 and SWcost1,2,3,4

NRDV, NRDR, and NRDU

Row, Column, Segment, Reach

CALL
Farm identity to which the parameters below are attributed

On-farm Efficiency per farm and per crop (real number, $0,<\mathrm{OFE} \leq 1$ ),

definitions see "Water Cost Coefficients" below

definitions see "Non-Routed Surface-Water Deliveries" below

definitions see "Locations of Diversion for Semi-Routed Surface-Water Deliveries" or "Locations of Return flow for Semi Routed Surface-Water Runoff" below definitions see "Surface-Water Allotment Prior Appropriation"

\section{Soil Type Related Data List (Item 9)}

Soil-ID Soil-type identity to which the parameters below are attributed

CapFringe Capillary Fringe [L]

The following parameters are only needed if ICCFL $=1$ or 3 :

Either:

A-Coeff, B-Coeff, C-Coeff Coefficients $a, b, c$ for function $D R Z=f\left(T_{c-p o t}\right.$, TRZ)

D-Coeff, E-Coeff Coefficients d, e for function $n=f(D R Z)$

Or:

Soil-Type Soil type in words:

3 options are available:

SANDYLOAM, SILT, and SILTYCLAY (not case-sensitive).

(For these three options, the FMP code contains intrinsic soil-type specific coefficients a, b, c and d, e for the functionalities $D R Z=f\left(T_{c-p o t}, T R Z\right)$ and $n=f(D R Z)$. If a soil type is entered as a word, then $a, b, c, d, e$ are not read).

The intrinsic coefficients in the program are as follows (Schmid, 2004):

\begin{tabular}{lccccc}
\hline \multicolumn{1}{c}{ Soil type } & a & b & c & d & e \\
\hline SANDYLOAM & 0.201 & -0.195 & 3.083 & 3.201 & -3.903 \\
SILT & 0.320 & -0.329 & 2.852 & 1.303 & -2.042 \\
SILTYCLAY & 0.348 & -0.327 & 1.731 & 0.530 & -0.377 \\
\hline
\end{tabular}


The parameters DRZ and $\mathrm{n}$ allow the fitting of a vertical pseudo steady-state pressure head distribution over the total root zone:

(3)

(4)
The Depleted Root Zone (DRZ) is a function of the potential Transpiration and the Total Root Zone. It is defined as the lower part of the root zone at which the pressure head increases with depth from the minimum (negative) pressure head (defined as $\psi_{4}$ in stress response function, see below) to zero at the bottom of the root zone.

$D R Z=[\exp (a \times \ln (T R Z \times M L T)+b \times \ln (T P O T \times M L T)+c)]$

The Sinuosity Coefficient (n) expresses the curvature of the vertical pressure head configuration over depth, which increases with increasing DRZ.

$N E X P=d \times \ln (D R Z)+e$

Although the intrinsic parameters a, b, c, d, e were derived on the basis of CENTIMETER length units, multipliers in the program (MLT) can adjust the equations accordingly to length units of METER or FEET, if so chosen as LENUNI $=2$ or $=1$ in the Discretization file (Harbaugh and others, 2000).

\section{Crop-Type-Related Data List (Natural Crop Growth Parameters) (Items 11-15, 29-32)}

Crop-ID
ROOT
CU
NONIRR
FTR
FEP
FEI
FIESWP
FIESWI
PSI1
PSI2
PSI3
PSI4
BaseT
MinCutT
MaxCutT
C0, C1, C2, C3
BegRootD
MaxRootD
RootGC

Crop-type identity, to which the parameters below are attributed.

Depth of root zone [L].

Crop consumptive-use flux [L/T] if ICUFL $=1,2$; crop coefficient if ICUFL $=-1$.

Non-irrigation flag:

$1=$ crop type is not irrigated.

Transpiratory fraction of consumptive use $(0 \leq \mathrm{FTR} \leq 1)$.

Evaporative fraction of consumptive use related to precipitation $(0 \leq \mathrm{FEP} \leq 1)$.

Evaporative fraction of consumptive use related to irrigation $(0 \leq \mathrm{FEI}<1)$.

Fraction of inefficiency losses to surface-water related to precipitation $(0 \leq$ FIESWP $\leq 1)$.

Fraction of inefficiency losses to surface-water related to irrigation $(0 \leq \mathrm{FIESWI} \leq 1)$.

Negative (partially saturated) or positive (saturated or submerged) value of pressure head, at which root uptake becomes zero due to anoxia or high pressure [L].

Negative or positive values of pressure head, at which root uptake is at maximum and from which uptake decreases with rising pressure head due to anoxia [L].

Negative pressure head, at which root uptake is at maximum and from which uptake decreases with falling pressure head due to wilting [L].

Negative pressure head, at which root uptake becomes zero due to wilting [L].

Base temperature.

Minimum cutoff temperature.

Maximum cutoff temperature.

Polynomial coefficients for CGDD - Kc functionality (see Chapter "General Data Requirements").

Beginning root depth [L].

Maximum root depth [L].

Root-growth coefficient.

\section{Climate-Related Data (Items 16, 30b, 33)}

\section{Climate Time Series (Item 16):}

TimeSeriesStep Time-step in climate time series. The length of a time-series time step must consistently be equal to the MODFLOW time unit chosen in the Discretization File (ITMUNI).

For ICUFL $=3$ or IRTFL $=3$, the MODFLOW time unit must be days (ITMUNI $=4$ ). For IPFL $=3$ (while ICUFL $\neq 3$, and IRTFL $\neq 3$ ), all MODFLOW time units are possible (seconds, minutes, hours, days, years; ITMUNI $=1,2,3,4,5)$. However, ITMUNI $=1$ or 2 for units of seconds or minutes should be avoided for very long periods of simulation because of the possibility of insufficient computer memory.
Precip
Precipitation flux [L/T]
MaxT
Maximum temperature
MinT
Minimum temperature
ETref
Reference Evapotranspiration flux [L/T]
LENSIM
Total number of steps in a time series $=$ length of the simulation. 
Reference Evapotranspiration Array (Item 30b):

ETR (NCOL,NROW) Reference Evapotranspiration Array or Constant $[\mathrm{L} / \mathrm{T}]$ if ICUFL $=1,-1$

Precipitation Array (Item 33):

PFLX(NCOL, NROW) Precipitation Flux Array or Constant [L/T]

\section{Crop-Type-Related Data Lists (Agro-Economic Parameters) (Items 17, 18, 34)}

\section{Fallow List (Item 17):}

Crop-ID Crop-type identity to which the parameter below is attributed.

IFallow Fallow-Flag:

$1=$ Crop type fallowed

$0=$ Crop type not fallowed (for example, pecan trees)

\section{Crop Benefits List (Items 18, 34):}

Crop-ID Crop-type identity to which the parameters below are attributed.

WPF-Slope $\quad$ Slope of crop-specific water-production function (yield vs. ET $_{\text {c-act }}$ )

WPF-Int Intercept of crop-specific water-production function (yield vs. $\mathrm{ET}_{\mathrm{c} \text {-act }}$ ) (can be zero).

Crop-Price Market-price per crop [value/weight]

\section{Water Cost Coefficients (Items 19, 35)}

Farm-ID Farm identity to which the cost coefficients below are attributed.

\section{Groundwater Cost Coefficients:}

GWcost 1

GWcost 2

GWcost 3

GWcost 4
Groundwater Base Maintenance Costs per unit volume $\left[\$ / \mathrm{L}^{3}\right]$

Groundwater Costs for Pumping in Well per unit volume, per unit lift [\$/( $\left.\left.\mathrm{L}^{3} \times \mathrm{L}\right)\right]$

Groundwater Costs for Vertical Lift from Well to Cell per unit volume, per unit lift $\left[\$ /\left(\mathrm{L}^{3} \times \mathrm{L}\right)\right]$

Groundwater Delivery Costs per unit volume, per unit distance $\left[\$ /\left(\mathrm{L}^{3} \times \mathrm{L}\right)\right]$

\section{Surface-Water Cost Coefficients:}

SWcost 1

SWcost2

SWcost 3

SWcost4
Fixed Price of (Semi-) Routed Surface-Water per unit volume $\left[\$ / \mathrm{L}^{3}\right]$

Costs for Vertical Lift of (Semi-) Routed Surface-Water from Reach to Cell per unit volume, per unit lift [\$/(L $\left.\left.\mathrm{L}^{3} \times \mathrm{L}\right)\right]$ Delivery Costs of (Semi-)Routed Surface-Water per unit volume, per unit distance $\left[\$ /\left(\mathrm{L}^{3} \times \mathrm{L}\right)\right]$ Fixed Price of Non-Routed Surface-Water per unit volume $\left[\$ / L^{3}\right]$

\section{Non-Routed Surface-Water Deliveries_-Farm-Related Data List (Item 36)}

Farm-ID

NRDV

NRDR

NRDU
Farm identity to which the parameters below are attributed

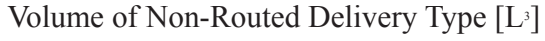

Rank of Non-Routed Delivery Type

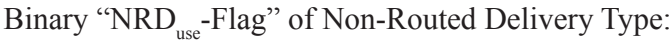

if 0: only the amount sufficient is used to meet the farm's demand.

if 1: the absolute amount available is used; surplus is discharged back into farm's head gate reach.

if 2: the absolute amount available is used; surplus is injected into farm wells attributed to farm ID. 


\title{
Locations of Diversion for Semi-Routed Surface-Water Deliveries (Items 21a, 37a) or Locations of Return Flow for Semi-Routed Surface-Water Runoff (Items 21b, 37b)—Farm-Related Data Lists
}

\author{
Farm-ID \\ Row \\ Column \\ Segment
}

Farm identity to which the parameters below are attributed

Row number of point of diversion (for ISRDFL $>0$ ) or return flow (for ISRRFL $>0$ )

Column number of point of diversion (for ISRDFL $>0$ ) or return flow (for ISRRFL $>0$ )

Number of stream segments in which the diversion reach (for ISRDFL $>0$ ) or return flow reach (for ISRRFL $>0$ )

is located (must be equal to the number of the identical stream reach specified in column four of the data list defined in the SFR2 input file defined for the entire simulation). Segments are defined for SFR2 only and are specified as 0 for SWR delivery locations. A zero segment number automatically indicates that this is an SWR semi-routed delivery location.

Reach

Number of reaches from which diversion (for ISRDFL $>0$ ) or to which the return flow (for ISRRFL $>0$ ) occurs (must be equal to the number of the identical reach specified in column five of the data list in the SFR2 input file defined for the entire simulation). If the reach represents an SWR delivery, then the reach number corresponds to REACH

Four options of data input (marked by "x") are available in order to uniquely identify the point of diversion or return flow within a cell (all four values must be specified):

\begin{tabular}{cccclc}
\hline Row & Column & Segment & Reach & Comments \\
\hline $\mathrm{x}$ & $\mathrm{x}$ & $\mathrm{x}$ & $\mathrm{x}$ & Full set of information is available & Maximum information \\
$\mathrm{x}$ & $\mathrm{x}$ & $\mathrm{x}$ & 0 & If more than one segment passes through the cell & User prefers identification of location by row/ \\
$\mathrm{x}$ & $\mathrm{x}$ & 0 & 0 & If just one segment passes through the cell & column coordinates \\
0 & 0 & $\mathrm{x}$ & $\mathrm{x}$ & If more than one segment pass through the cell & $\begin{array}{c}\text { User prefers identification of location by segment } \\
\text { and reach number }\end{array}$ \\
\hline
\end{tabular}

\section{Surface-Water Allotment (Items 38, 39)}

Equal Appropriation:

ALLOT Surface-water allotment height [L] for a stress period.

Prior Appropriation:

Farm-ID Farm identity to which the parameter below is attributed

CALL Water Rights Call attributed to a farm $\left[\mathrm{L}^{3} / \mathrm{T}\right]$

\section{Output Data for FMP3}

Simulation results from FMP3 can be reported to seven auxiliary data sets in addition to the main MF2005 list and global files. These data sets consist of the following components. Various options to either print these data to the MF2005 list file or to save them to ASCII or binary files are controlled by the associated flags in parentheses:

(1) Farm-well budget (IFWLCB).

(2) Farm net-recharge budget (IFNRCB).

(3) Farm supply and demand budget (ISDPFL).

(4) Farm Budget—Budget of all physical flows into and out of a farm (IFBPFL).

(5) Evapotranspiration (IETPFL).

(6) Routing information for farm deliveries and returnflows (IRTPFL).

(7) Optimized flow rates and optimized acreage of farms that experience a deficiency (IOPFL); only if acreageoptimization is chosen as a deficiency scenario (IDEFFL $>0$ ).

(8) Budget at the point of diversions from the river into diversion segments and a budget at the point of a farm-diversion from the diversion segment (IPAPFL), only if prior appropriation is chosen as surface-water rights option (IALLOT > 1). 
For ILGR $>0$ and IGRID $>1$, that is, for more than one model grid, several farm-ID related budget lists required the addition of a "GRID" number after the "TIME[UNIT]" column. As a new standard, the introduction of this column is not backwards compatible to FMP3, so if LGR is not active and there is only one parent grid, the GRID column will simple show "1." So far, this was implemented for IFWLCB $=1$, IFWLCB $>1$ (if "Compact Budget" is specified in Output Control), ISDPFL $\geq 1$, and IFBPFL $\geq 1$. That is, for any time step, budgets for each model are listed in sequence of the GRID number.

\section{Farm-Well Budget}

The simulated farm-well flow rates can either be printed for each well location identified by layer, row, and column to the list file or saved to an ASCII file named "FWELLS.OUT." In addition, farm-well flow rates can be saved to a binary file for each well location identified by the respective model node or as a 2D-array for each cell.

\section{Farm Net-Recharge Budget}

Simulated farm net recharge flow rates can be printed as a 2D-array for each cell to the list file or to an ASCII file named "FNRCH_ARRAY.OUT." Alternatively, a list of the cumulative farm net recharge for each farm can be saved to either an ASCII file named "FNRCH_LIST.OUT" or to a binary file named "FNRCH_LIST_BIN.OUT." In addition, a list of cumulative farm net-recharge flow rates or a 2D-array of cell-by-cell farm net-recharge flow rates can optionally be saved to binary files on a unit number specified in the Name File.

\section{Farm Supply and Demand Budget}

The simulated components of farm irrigation demand and supply of any current stage of solution during a time step (per iteration) and of the final demand and supply rates at the end of time steps or stress periods may be printed to list file of each grid:

Lists of current (iterative) and final farm demand and supply flow rates consist of the following parameters:

(1) FID, farm ID.

(2) OFE, on-farm efficiency.

(3) TFDR, total farm delivery requirement.

(4) NR-SWD, non-routed surface-water delivery.

(5) R-SWD, (semi-)routed surface-water delivery.

(6) QREQ, groundwater pumping requirement.

(7) (Q-FIN), groundwater pumping (only available for list of final rates).

Notice that the list of "current" rates is iteratively updated within a present time step and does not yet contain a final supply flow rate from groundwater pumping, Q-FIN, which is available the end of a time step and, therefore, included in the list of final rates. For cases of irrigation-water supply insufficiency, a comment is printed at the end of each record, informing about a possible imbalance of the farm demand-and-supply budget. If the final supply exceeds the original or optimized demand by a certain flow rate $\mathrm{X}$, then the following messages will be printed:

For Deficit Irrigation or Zero Scenario (IDEFFL $=-1$ or 0 ):

"QREQ exceeds QMAXF by" X

For Deficit Irrigation with Water-Stacking (IDEFFL $=-2)$ :

"Original QREQ exceeded QMAXF by" X

"QREQ of priority crops still exceeds QMAXF by" $\mathrm{X}$

If, for Acreage-Optimization (IDEFFL > 0), the optimized demand is actually less than the original constrained surface-water or groundwater resource (by a flow rate of $\mathrm{X}$ ), then the following messages will be printed:

"Surface-Water Demand falls behind original Surface-Water Supply by" X

"Groundwater Demand falls behind original QMAXF by" X

Another, more comprehensive form of saving initial and final farm demand and supply budget is to save the estimated flow rates to an ASCII file named "FDS.OUT" for all time steps or, alternatively, to a binary file either for all or for selected time steps. Final rates only differ from initial ones, if either water-stacking or acreage-optimization was applied as deficiency scenario. A list of initial and final farm demand-and-supply flow rates for all time steps consists of the following parameters: 


\begin{tabular}{ll}
\hline General information: & \\
\hline (1) PER: & Stress period \\
(2) STP: & Time step \\
(3) TIME [UNIT]: & Elapsed time (in units chosen in discretization file) \\
(4) GRID: & Grid identification (1=parent grids, >1= child grids) \\
(5) FID: & Farm identification \\
(6) OFE: & Specified or calculated on-farm efficiency \\
\hline Initial flow rates before invoking a deficiency scenario: \\
\hline (1) TFDR-INI: & Initial Total Farm Delivery Requirement \\
(2) NR-SWD-INI: & Initial Non-Routed Surface-Water Delivery \\
(3) R-SWD-INI: & Initial (Semi-) Routed Surface-Water Delivery \\
(4) QREQ-INI: & Initial Pumping Requirement \\
\hline Final flow rates of a solution found by means a deficiency scenario: \\
\hline (1) TFDR-FIN: & Final Total Farm Delivery Requirement \\
(2) NR-SWD-FIN: & Final Non-Routed Surface-Water Delivery \\
(3) R-SWD-FIN: & Final (Semi-) Routed Surface-Water Delivery \\
(4) QREQ-FIN: & Final Pumping Requirement \\
(5) Q-FIN: & Final Pumping Rate \\
(6) DEF-FLAG: & Deficiency Scenario Flag
\end{tabular}

\section{Farm Budget}

\section{Compact}

A list of flow rates, $\mathrm{Q}\left[\mathrm{L}^{3} / \mathrm{T}\right]$, or cumulative volumes, $\mathrm{V}\left[\mathrm{L}^{3}\right]$, of the simulated Compact Farm Budget components is saved for all time steps in ASCII file "FB_COMPACT.OUT" (if IFBPFL = 1) or in a binary file on a unit number specified in the Name File (if IFBPFL $>2$ and odd). The list is saved in a binary file for all time steps if "Compact Budget" is not specified in Output Control or for time steps for which in Output Control "Save Budget" is specified if "Compact Budget" is specified in Output Control.

A list of Compact Farm Budget rates consists of the following parameters:

Headers in Farm Budget Explanation

Model attributes:

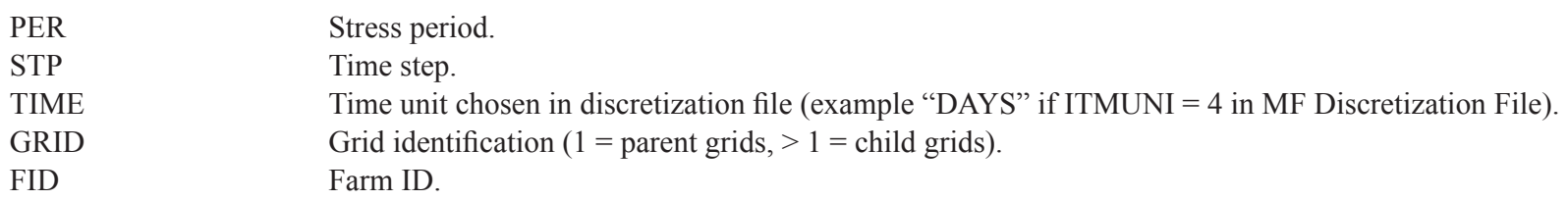

Flow rates into a farm:

$\begin{array}{ll}\text { Q-p-in } & \text { Precipitation. } \\ \text { Q-sw-in } & \text { Surface water inflow. } \\ \text { Q-gw-in } & \text { Groundwater inflow. } \\ \text { Q-ext-in } & \text { External deliveries. } \\ \text { Q-tot-in } & \text { Total inflows. }\end{array}$

Flow rates out of farm:

Q-et-out

Q-ineff-out

Q-sw-out

Q-gw-out

Q-tot-out

Q-in-out

Q-Discrepancy[\%]
Evapotranspiration outflow.

Inefficiency losses.

Surface-water outflow (excess non-routed deliveries back into stream segment).

Groundwater outflow (excess non-routed deliveries injected into farm-wells).

Total outflows.

Inflows minus outflows.

Percent discrepancy. 


\section{Detailed}

A list of flow rates, $\mathrm{Q}\left[\mathrm{L}^{3} / \mathrm{T}\right]$, or cumulative volumes, $\mathrm{V}\left[\mathrm{L}^{3}\right]$, of the simulated Detailed Farm Budget components is saved for all time steps in ASCII file "FB DETAILS.OUT" (if IFBPFL = 2) or in a binary file on a unit number specified in the Name File (if IFBPFL $>2$ and even). The list is saved in a binary file for all time steps if "Compact Budget" is not specified in Output Control or for time steps for which in Output Control "Save Budget" is specified if "Compact Budget" is specified in Output Control.

A list of Detailed Farm Budget rates consist of the following parameters:

Headers in Farm Budget Explanation

Model attributes:

$\begin{array}{ll}\text { PER } & \text { Stress period } \\ \text { STP } & \text { Time step } \\ \text { TIME } & \text { Time unit chosen in discretization file (example "DAYS" if ITMUNI = 4 in MF Discretization File) } \\ \text { GRID } & \text { Grid identification }(1=\text { parent grids, }>1=\text { child grids }) \\ \text { FID } & \text { Farm ID }\end{array}$

Flow rates into a farm:

$\begin{array}{ll}\text { Q-p-in } & \text { Precipitation } \\ \text { Q-nrd-in } & \text { Non-routed deliveries } \\ \text { Q-srd-in } & \text { Semi-routed deliveries } \\ \text { Q-rd-in } & \text { Fully routed deliveries } \\ \text { Q-wells-in } & \text { Groundwater well pumping deliveries } \\ \text { Q-egw-in } & \text { Evaporation from groundwater into the farm } \\ \text { Q-tgw-in } & \text { Transpiration from groundwater into the farm } \\ \text { Q-ext-in } & \text { External deliveries } \\ \text { Q-tot-in } & \text { Total inflows }\end{array}$

Flow rates out of a farm:

$\begin{array}{ll}\text { Q-ei-out } & \text { Evaporation from irrigation out of the farm } \\ \text { Q-ep-out } & \text { Evaporation from precipitation out of the farm } \\ \text { Q-egw-out } & \text { Evaporation from groundwater out of the farm } \\ \text { Q-ti-out } & \text { Transpiration from irrigation out of the farm } \\ \text { Q-tp-out } & \text { Transpiration from precipitation out of the farm } \\ \text { Q-tgw-out } & \text { Transpiration from groundwater out of the farm } \\ \text { Q-run-out } & \text { Overland runoff out of the farm } \\ \text { Q-dp-out } & \text { Deep percolation out of the farm } \\ \text { Q-nrd-out } & \text { Non-routed deliveries from the farm } \\ \text { Q-srd-out } & \text { Semi-routed deliveries out of the farm (in form of excess non-routed deliveries recharged back into 'remote' } \\ & \text { head-gate) } \\ \text { Q-rd-out } & \text { Fully routed deliveries out of the farm (in form of excess non-routed deliveries recharged back into a head-gate } \\ & \text { within the farm) } \\ \text { Q-wells-out } & \text { Injection from farm into farm-wells (excess non-routed deliveries injected into farm-wells) } \\ \text { Q-tot-out } & \text { Total outflows } \\ \text { Q-in-out } & \text { Inflows minus outflows } \\ \text { Q-Discrepancy[\%] } & \text { Percent discrepancy }\end{array}$

For both the compact and the detailed farm budget, cumulative volumes $\left[\mathrm{L}^{3}\right]$ into and out of a farms are printed to the right of the flow rates and are denoted by "V" analogous to "Q" for flow rates (for example, V-p-in = cumulative precipitation into a farm). 


\section{Routing Information for Farm Deliveries and Runoff Returnflows}

The following illustrates the format in which the routing information for a particular farm is written either to the list file or to file ROUT.OUT. Depending on how the user has set flags IRDFL, ISRDFL, IRRFL, and ISRRFL, one statement out of several possible statements (separated by OR) will summarize the routing system of deliveries or runoff return flows. For ILGR $>0$ and IGRID $>1$, that is, for more than one model grid, the routing information is written in sequence of the GRID number to the same ASCII file "ROUT.OUT."

Text highlighted in yellow is text that is written to either the list file or to file ROUT.OUT. Exactly which information is written is explained in text highlighted in light blue:

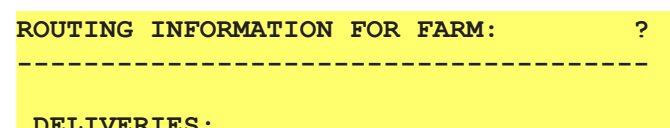

DELIVERIES :

FULLY-ROUTED DELIVERIES :
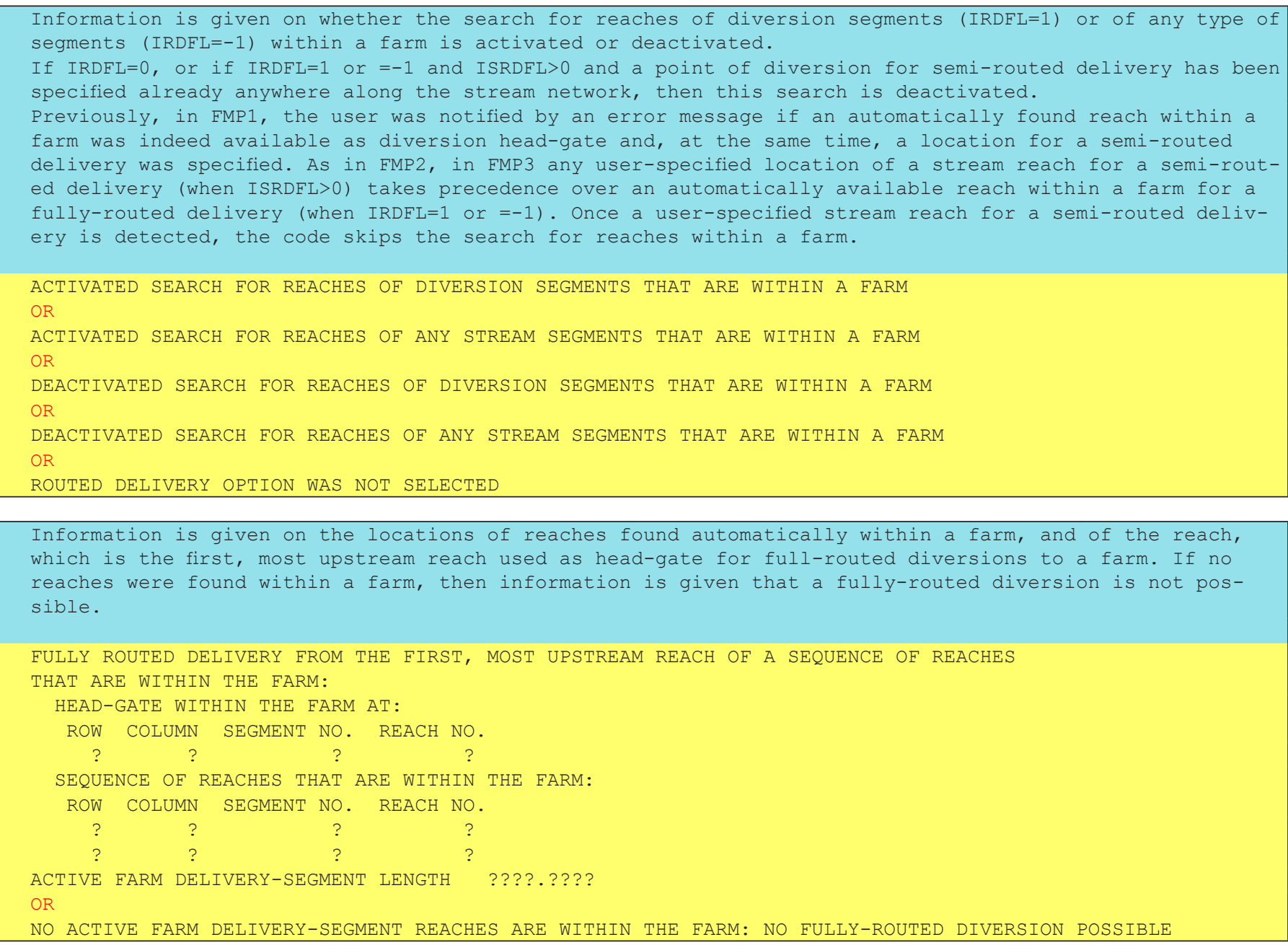

\section{SEMI-ROUTED DELIVERIES :}

Information is given on the location of a stream reach specified for a diversion of a semi-routed delivery. If ISRDFL $=0$ or if ISRDFL $>0$ and no reach was specified for a particular farm, then information is given that a semi-routed diversion is not possible.

SEMI-ROUTED DELIVERY FROM A SPECIFIED STREAM REACH AT:

ROW COLUMN SEGMENT NO. REACH NO.

OR

NO POINT OF DIVERSION FOR SEMI-ROUTED DELIVERY SPECIFIED: NO SEMI-ROUTED DIVERSION POSSIBLE 
RETURNFLOWS :

\section{FULLY-ROUTED RETURNFLOWS :}

Information is given on whether the search for reaches of non-diversion segments (IRREL=1) or of any type of segments (IRRFL=-1) within a farm is activated or deactivated. Unless ISRDFL>0 and a point of semi-routed runoff returnflow has been specified anywhere on the stream network, this search is always activated as FMP attempts to return runoff fully-routed to reaches within a farm. This is attempt based on the assumption, that occurring runoff always has to be returned to the stream network if possible in order to preserve mass. Therefore, the user does not have the option to disable the check for reaches receiving fully-routed returnflow analogous to a check for reaches, which fully-routed deliveries are diverted from.

If ISRRFL>0 and a point of semi-routed runoff-returnflow has been specified anywhere on the stream network, then this search is deactivated.

Previously, in FMP1, the user was notified by an error message if automatically found reaches within a farm were indeed available to receive fully-routed runoff-returnflow and, at the same time, locations for semi-routed runoff-returnflows were specified. As in FMP2, in FMP3 any user-specified location of a stream reach for a semi-routed runoff-returnflow (when ISRRFL>0) takes precedence over automatically available reaches within a farm for fully-routed returnflows. Once a user-specified stream reach for a semi-routed delivery is detected, the code skips the search for delivery-segment reaches adjacent or within a farm.

\section{ACTIVATED SEARCH FOR REACHES OF NON-DIVERSION SEGMENTS THAT WITHIN A FARM}

OR

ACTIVATED SEARCH FOR REACHES OF ANY STREAM SEGMENTS THAT WITHIN A FARM

OR

DEACTIVATED SEARCH FOR REACHES OF NON-DIVERSION SEGMENTS THAT ARE WITHIN A FARM

OR

DEACTIVATED SEARCH FOR REACHES OF ANY STREAM SEGMENTS THAT ARE WITHIN A FARM

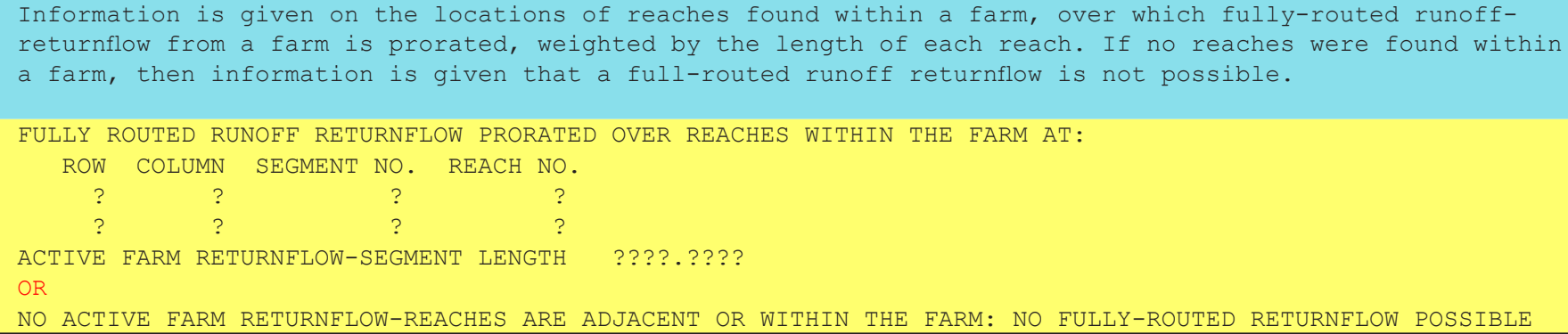

\section{SEMI-ROUTED RETURNFLOWS:}

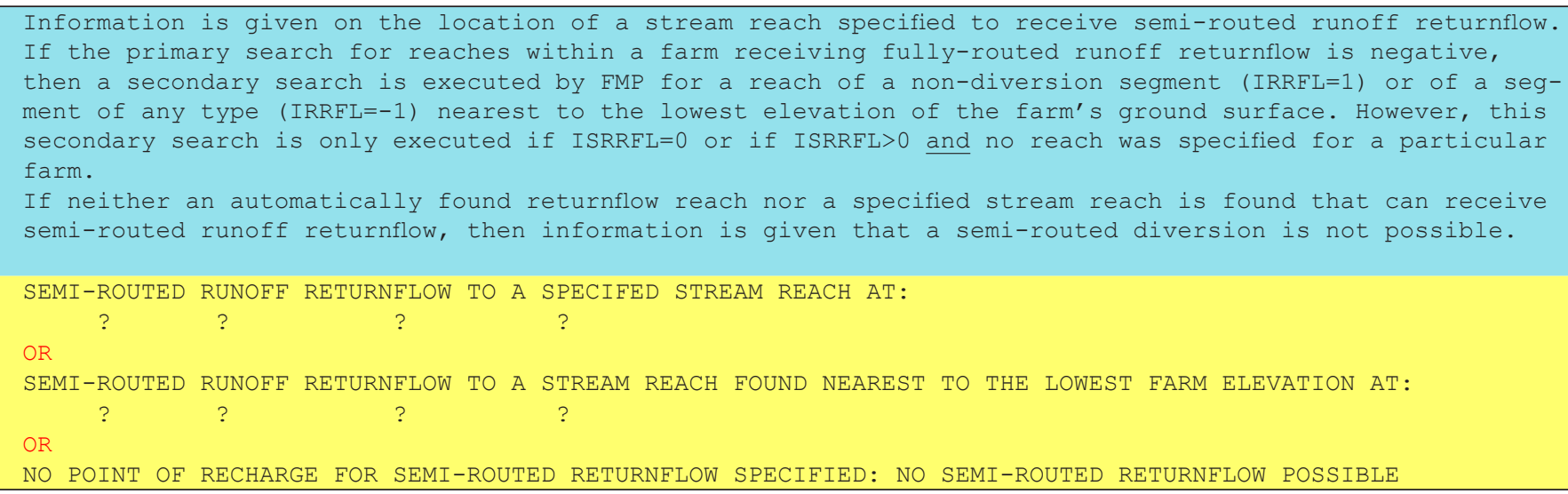

\section{Optimized Flow Rates and Optimized Acreage of Farms}

The user has various options of saving different data of interest if acreage-optimization was chosen as a deficiency scenario (IDEFFL $>0$ ). Fractions of active cell acreage will be printed as a 2D array either to the list file or saved to an ASCII file named "ACR_OPT.OUT" for all time steps. Alternatively, original and optimized flow rates of constrained resources may either be saved for each farm by themselves or in conjunction with a list of fractions of active cell acreage. This option will save the 
resulting reduced cell fractions according to active acreage either to the list file or to an ASCII file named "ACR_OPT.OUT" for any farm and any iteration that are subject to optimization.

For each cell (row, column) within an optimized farm, the list of fractions of cell acreage consists of the following parameters:
A-tot-opt/A-tot-max
fraction of total optimized acreage on total maximum acreage
A-gw-opt/A-tot-opt
fraction of optimized groundwater irrigated acreage on total optimized acreage
A-sw-opt/A-tot-opt
fraction of optimized (semi-)routed surface-water irrigated acreage on total optimized acreage
fraction of optimized non-routed surface-water irrigated acreage on total optimized acreage

Users with specific interest in the definition of the linear optimization tableaux matrix may save this matrix either to the list file or to an ASCII file named "ACR_OPT.OUT." The number of columns in the tableaux matrix equals the number of optimization variables +1 . The number of rows in the matrix equals the number of constraints +1 .

\section{Budgets at Points of Diversion from the River and Farm Diversion}

A budget at the point of diversions from the river into diversion segments and a budget at the point of a farm-diversion from the diversion segment are printed to the list file or to an ASCII file named "PRIOR.OUT" if Prior Appropriation is chosen as surface-water allotment option (IALLOT > 1). The "Prior Appropriation Subroutine" in FMP solves (1) for the delivery to a farm from a diversion segment and (2) for the diversion into the respective diversion segment from a river. Solutions for (1) and (2) are found iteratively. The budgets for both points of diversion are therefore printed for any farm on an iterative basis. However, after having found solutions for (1) and for (2) for a certain farm, those solutions are not iterated anymore within a current time step. The output budgets for both points of diversion also inform whether a "convergence solution" or "exceedance solution" was found. A "convergence solution" is found if the surface-water delivery to the farm "convergences" to the delivery requirement from the farm's head-gate reach. An "exceedance solution" is found if the necessary diversion from the river into the respective diversion segment "exceeds" the river streamflow, and consequently, the diversion from the diversion segment into a junior water rights farm will be insufficient to satisfy the delivery requirement from that farm's head-gate reach. The output data set for each farm consists of three blocks of information:

1. Information about routing system during current iteration:

Farm-ID

Head-gate reach number

Delivery segment number

River segment number

2. Budget at Point of Diversion from River into a Diversion Segment:

Qstr-in Inflow to point of diversion at the end of current stream segment

Qstr-out Outflow from point of diversion past the end of current stream segment

Qstr-min Minimum river-streamflow requirement at point of diversion from stream that is not available for diversion to the current farm (necessary to account for the demand and for related conveyance losses to a downstream farm senior farm located at a downstream diverting segment)

ADIV Actual diversion rate from stream into current delivery segment

PDIV Potential diversion rate from stream into current delivery segment

3. Budget at Point of Farm Diversion from Diversion Segment:

RDEL-req Delivery requirement from current head-gate reach

Qcn-in Inflow to point of diversion from current diversion segment at beginning of current head-gate reach

Qcn-out Outflow from point of diversion from current diversion segment past the beginning of current head-gate reach

Qcn-min Minimum "canal-streamflow requirement" at point of diversion from diversion segment that is not available for farm "f" at its head-gate (necessary to account for senior farm on the same diversion segment)

DELIVERY Surface-water delivery to current farm from current head-gate reach at present iteration

Comments:

\begin{tabular}{|l|l|}
\hline STAGE: & $\begin{array}{l}\text { RESULT: } \\
\text { A record (in quotes) is printed informing about the action taken at a } \\
\text { "prior appropriation" algorithm; three different stages are possible. } \\
\text { certain stage of the algorithm; three different results are possible at } \\
\text { two different stages }\end{array}$ \\
\hline $\begin{array}{l}\text { "INITIAL VALUES" (initial values at beginning of algorithm are printed) } \\
\text { unsatisfied increment [RDELreq. - Qcn-in] ) }\end{array}$ & $\begin{array}{l}\text { "Exit and apply new PDIV rates" (exit MF2005 and solve with incre- } \\
\text { mented PDIV) }\end{array}$ \\
\hline "SOLUTION" (final values are printed once a solution was found) & $\begin{array}{c}\text { "Convergence Solution" } \\
\text { "Exceedance Solution" }\end{array}$ \\
\hline
\end{tabular}




\section{Appendix B. Subsidence Package Linkages and Parameters (SUB)}

The new Subsidence Package optional features include the Subsidence Linkage and the Subsidence parameters. These new features, which allow separation of elastic and inelastic compaction for instantaneous compaction described by Schmid and Hanson (2009), are also included in MF-OWHM, but are not backwardly compatible with the version of the SUB package distributed with other versions of MODFLOW.

\section{Subsidence Linkage}

A new linkage between the Subsidence Package, SUB (Hoffmann and others, 2003; Hanson and others, 2009), and the Streamflow Routing Package, SFR (Niswonger and Prudic, 2005), the Farm Process, FMP (Schmid and Hanson, 2009), and the Layer Property Flow Package, LPF (Harbaugh, 2005), and Upstream-Property Weighting, UPW (Niswonger and others., 2011) was integrated into MF-OWHM. The new capability allows MF-OWHM to adjust elevations of the streambed in SFR, canal elevations in SWR, land surface in FMP, RIP-ET, and DRN, and tops and bottoms of layers in LPF or UPW. These changes also affect secondary calculations, such as the slope of a streambed, slope-related runoff in farms, proximity of the capillary fringe to the root zone in FMP, and changing hydraulic properties of layers in LPF and UPW. The major components of the code integration with MF-FMP are illustrated in figure 4. This appendix is an expansion of the description summarized by Schmid and others (2014). The vertical displacements simulated by the SUB package are passed to the other features that represent the land surface or other subsurface layer boundaries at the end of each time step for use in the subsequent time step (fig. B1).

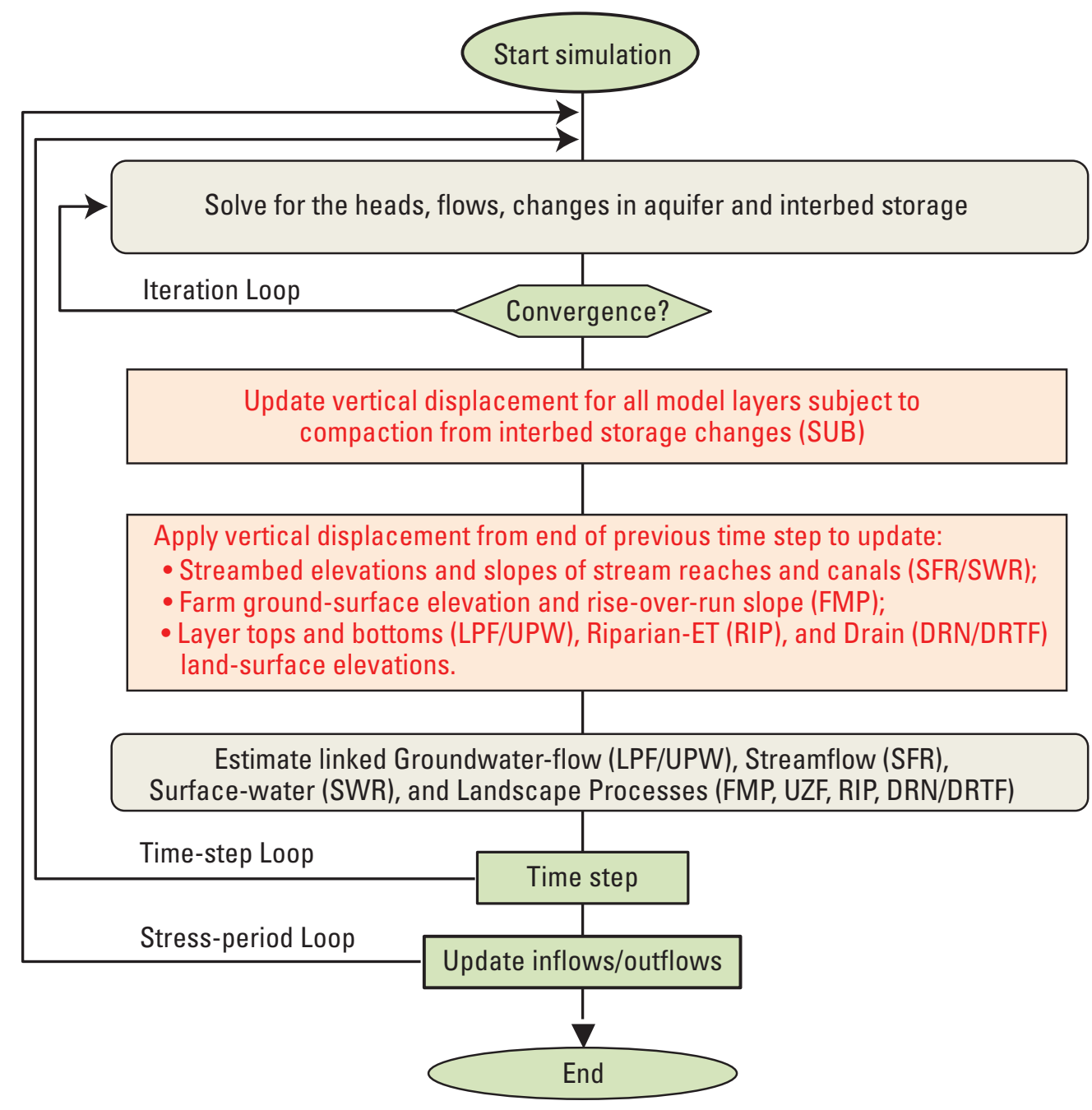

Figure B1. Generalized flow chart illustrating major components of the linkage between SUB, SFR, FMP, RIP, DRN, and LPF/UPW and the integration into MF-OWHM 
The change to SUB Package input is the additional flag to designate activation of the linkage with the deforming mesh. Schmid and others (2014) split the linkages between landscape and surface-water processes with subsidence (SUBLNK) and linkages between aquifer packages (LPF/UPW) with subsidence (LPFLNK) for purposes of analysis of these effects separately. In MF-OWHM these flags are combined as one linkage flag, SUBLNK, and are specified at the end of the first line of flag options of the SUB Package as follows:

\begin{tabular}{|c|c|c|c|c|c|c|c|c|c|c|c|c|}
\hline \multirow[t]{2}{*}{ Line 1: } & ISUBCB & ISUBOC & NNDB & NDB & NMZ & $\mathrm{NN}$ & $\mathrm{AC} 1$ & $\mathrm{AC} 2$ & ITMIN & IDSAVE & IDREST & SUBLNK \\
\hline & 40 & 11 & 3 & 0 & 0 & 0 & 0.0 & 0.2 & 5 & -1 & -1 & 1 \\
\hline SUBLNK & & $\begin{aligned}= & 0 \text { No link } \\
= & 1 \text { linkage } \\
& \text { related p }\end{aligned}$ & $\begin{array}{l}\text { ge with s } \\
\text { with simu } \\
\text { ckages an }\end{array}$ & $\begin{array}{l}\text { ulated } \\
\text { ed def } \\
\text { proces }\end{array}$ & $\begin{array}{l}\text { ormatic } \\
\text { lations }\end{array}$ & rom & abside & $\begin{array}{l}\text { packa } \\
\text { packas }\end{array}$ & and land & ape, surfa & -water, a & aquifer- \\
\hline
\end{tabular}

\section{Subsidence Parameters}

The SUB Package is modified in MF-OWHM to incorporate the MODFLOW-2005 parameter feature to the variables RNB, HC, Sfe, Sfv, ComE, ComV, Dstart, DHC, DCOME, DCOMV, and DZ. The parameterized variables have access to MULT, ZONE, and PVAL for defining their values. The input file is modified such that it is backwards compatible with the previous FMP version of SUB. To declare parameters, the first non-commented line in the SUB input file must contain the flag PARAMETER followed by the number subsidence parameters, NSBP, and the print flag, IPRNTFLG, used by UPARARRSUB1. The parameters are defined after the definition of the interbed storage layer assignments, LN and LDN. If a parameter type (PARTYP) is defined for one interbed, it must be defined for all interbeds. Each variable that is defined by parameter is omitted from its original input location. Changes to the FMP version of the SUB package are delineated as Blue text in the following:

\section{FOR EACH SIMULATION}

\section{0. [\#Text]}

Item 0 is optional, “\#” must be in column 1. Item 0 can be repeated multiple times

1. [PARAMETER NSBP IPRNTFLG]

This optional item must start with the word "PARAMETER"

2. ISUBCB ISUBOC NNDB NDB NMZ NN AC1 AC2 ITMIN IDSAVE IDREST ISUBLINK

(Enter integers for variables other than AC1 and AC2, which are floating-point variables.)

3. $[\mathrm{LN}(\mathrm{NNDB})]$ if $N N D B>0$

(Enter NNDB integers separated by one or more spaces or by commas.)

4. $[\operatorname{LDN}(\mathrm{NDB})]$ if $\mathrm{NDB}>0$

(Enter NDB integers separated by one or more spaces or by commas.)

5. [PARNAM PARTYP Parval NCLU]

Repeat Item 5 combined with the indicated repetitions of Item 6 NCLU times. Item 5 and 6 are not read if

PARAMETER is not declared in Item 1 or NSBP $=0$.

6. [Layer Mltarr Zonarr IZ]

After each Item 5, repeat Item 6 NCLU times.

7. [RNB(NCOL, NROW)] U2DREL if NDB > $\theta$ and NOT defined with PARTYP="SRNB"

(One array for each of the NDB systems of interbeds.)

The following four arrays are needed to describe the initial conditions and properties of each of the NNDB systems of no-delay interbeds. All of the arrays (items 8-12) for system 1 
are read first; then all of the arrays for the remaining systems.

8. $[\mathrm{HC}(\mathrm{NCOL}, \mathrm{NROW})]$ U2DREL read if NNDB >0 and NOT defined with PARTYP="NDHC"

9. [Sfe(NCOL, NROW)] U2DREL read if NNDB > $\theta$ and NOT defined with PARTYP="SFE"

10. $[\mathrm{SFV}(\mathrm{NCOL}, \mathrm{NROW})]$ U2DREL read if NNDB > $\theta$ and NOT defined with PARTYP="SFF"

11. [COmE(NCOL, NROW)] U2DREL read if NNDB > $\theta$ and NOT defined with PARTYP="COME"

12. [COmV(NCOL, NROW)] U2DREL read if NNDB > $\theta$ and NOT defined with PARTYP="COMV”

13. $[\mathrm{DP}(\mathrm{NMZ}, 3)]$ if $\mathrm{NDB}>0$

(Use one record for each material zone. Data item includes NMZ records, each with a value of vertical hydraulic conductivity, elastic skeletal specific storage, and inelastic skeletal specific storage.)

The following five arrays are needed to describe the initial conditions and properties of each of the NDB systems of delay interbeds. All of the arrays (items 14-18) for system 1 are read first, then all of the arrays for the remaining systems.

14. [Dstart(NCOL, NROW)] U2DREL read if NDB > $\theta$ and NOT defined with PARTYP="DSTR"

15. [DHC(NCOL, NROW)] U2DREL read if NDB > $\theta$ and NOT defined with PARTYP="DHC"

16. [DCOME(NCOL, NROW)] U2DREL read if NDB > $\theta$ and NOT defined with PARTYP="DCME"

17. [DCOMV(NCOL, NROW)] U2DREL read if NDB > $\theta$ and NOT defined with PARTYP="DCMV"

18. $[\mathrm{DZ}(\mathrm{NCOL}, \mathrm{NROW})] \quad$ U2DREL read if NDB >0 and NOT defined with PARTYP="SDZ"

19. $[\mathrm{NZ}(\mathrm{NCOL}, \mathrm{NROW})]$ U2DINT read if NDB $>0$

20. [Ifm1 Iun1 Ifm2 Iun2 Ifm3 Iun3 Ifm4 Iun4 Ifm5 Iun5 Ifm6 Iun6 Ifm7 Iun7 Ifm8 Iun8 Ifm9 Iun9 Ifm10 Iun10] if ISUBOC >0

(Data item 20 consists of one record with 20 integers separated by one or more spaces or by commas.)

21. [ISP1 ISP2 ITS1 ITS2 Ifl1 Ifl2 Ifl3 Ifl4 Ifl5 Ifl6 Ifl7 Ifl8 Ifl9 Ifl10 Ifl11 Ifl12 Ifl13 Ifl14 Ifl15 Ifl16 Ifl17 Iff18 Ifl19 Ifl20 Ifl21] if ISUBOC $>\theta$.

(Data item 21 consists of ISUBOC records with xx integers separated by one or more spaces or by commas. Please see the section entitled "Package Output" for a detailed explanation of the use of data item 21.) 


\section{Explanation of Parameter Fields Used in Input Instructions}

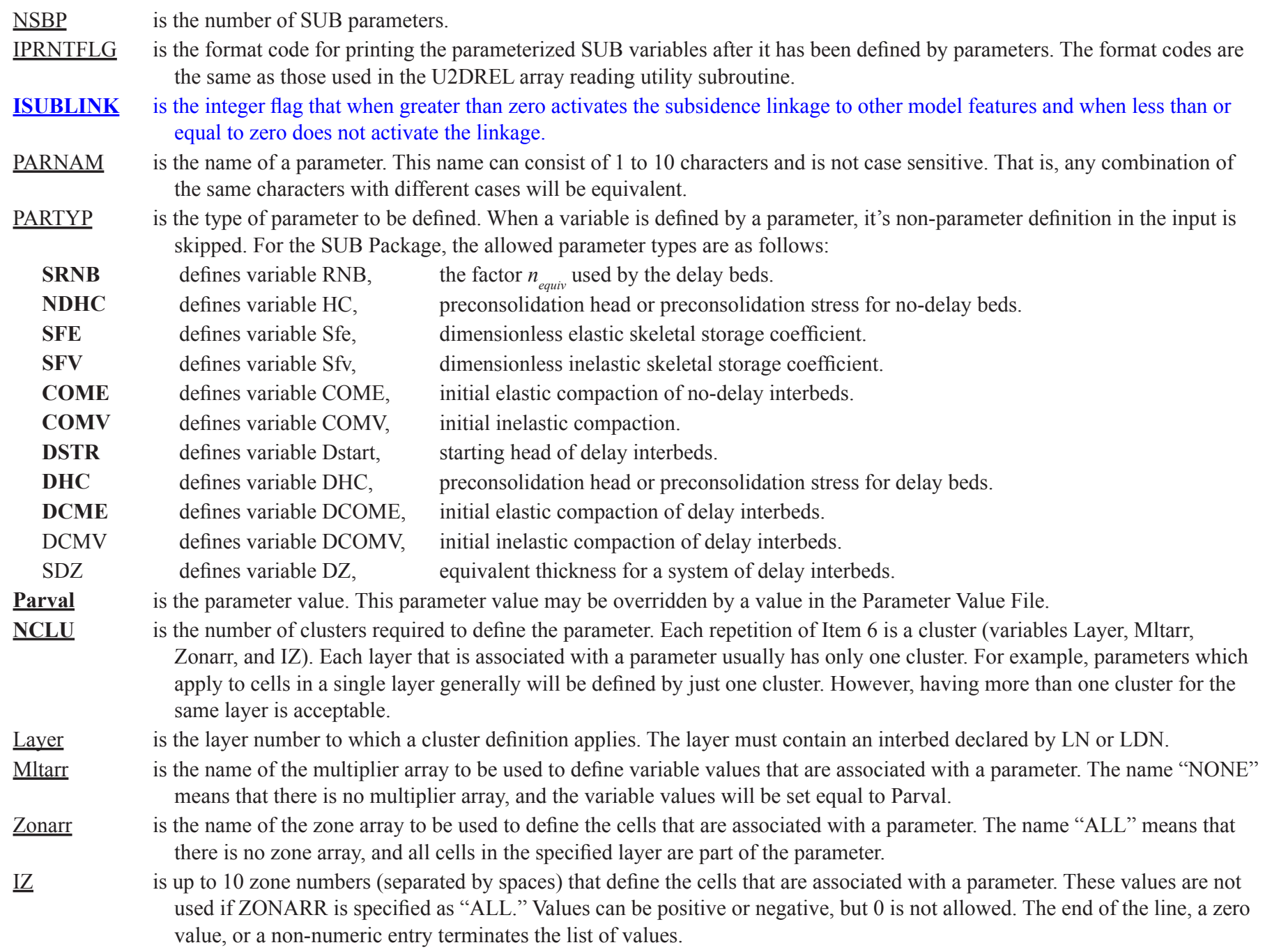




\section{Appendix C. Enhancements to the Horizontal Flow Barrier Package (HFB2)}

HFB has been modified to incorporate two new features and updates to the original code (HFB2). The first feature allows barriers to change with stress periods by adding a new read and prepare subroutine, GWF2HFB7RP. The second feature, which works only with the NWT package, allows a barrier to route flow between two models cells that are not adjacent to each other. The flow chart of subroutines there were added or changed to allow these two features is shown in figure $\mathrm{C} 1$. The boxes in the center column of the flow chart between the Program Start/End are subroutine calls made by the MODFLOW main code. These subroutines make calls to additional subroutines to the left/right of the main column.

\section{Input Instructions for Modified HFB (HFB2)}

Input for the HFB Package is read from the file that has the type "HFB6" in the name file. Optional variables are shown in brackets. The input file is backward compatible with previous versions of HFB, but the input should be viewed as specifying two model cells that contain a barrier between them that flow passes through. These two model cells do not have to be adjacent to each other. New variables in the HFB input file are delineated as Blue text. The input file is broken into three sections. Sections A and B are required, and Section C is optional. Section A sets up array sizes and parameters for the HFB. Section B assigns for the first stress period the location of non-parameter barriers and activates any parameterized barriers. Section $\mathrm{C}$ is optional and specifies the barriers for subsequent stress period. If Section C is not present, then barriers specified in Section B are used for the entire simulation.

\section{(A) FOR EACH SIMULATION}

0 . [\#Text]

Item 0 is optional- “\#” must be in column 1. Item 0 can be repeated multiple times.

1. NPHFB MXFB NHFBNP [MXHFBNP] [NOPRINT]
[NTP

The optional keyword "NOPRINT" specified that lists of flow barriers will not be written to the List File.

2. [ PARNAM PARTYP Parval NLST ]

3. [Layer IROW1 ICOL1 IROW2 ICOL2 Factor [Layer2] ]

Repeat Items 2 and 3 NPHFB times. Items 2 and 3 are not read if NPHFB is negative or zero.

NLST repetitions of Item 3 are required; they are read by subroutine ULSTRD.

(SFAC of the ULSTRD utility subroutine applies to Factor).

(B) FOR FIRST STRESS PERIOD OR ALL STRESS PERIODS

4. Layer IROW1 ICOL1 IROW2 ICOL2 Hydchr [Layer2]

NHFBNP, from item 1, repetitions of Item 4 are read. Item 4 is not read if NHFBNP is negative or zero.

5. NACTHFB

6. Pname

NACTHFB repetitions of Item 6 are read. Item 6 is not read if NACTHFB is negative or zero.

(C) OPTIONAL: FOR EACH SUBSEQUENT STRESS PERIOD

7. NACTHFB NHFBNP

If NACTHFB is set to -1 , then NHFBNP and items 8 and 9 are not read. Instead the barriers defined in the previous

8. Pname

stress period are used. If MXHFBP is 0 , then NHFBNP is not read in since it cannot be larger than 0 .

NACTHFB, from item 7, repetitions of Item 8 are read. Item 8 is not read if NACTHFB is negative or zero.

9. Layer IROW1 ICOL1 IROW2 ICOL2 Hydchr [Layer2]

NHFBNP, from item 7, repetitions of Item 9 are read. Item 9 is not read if NHFBNP or MXHFBP is negative or zero.

\section{Explanation of Fields Used in HFB Package Input Instructions}

$\underline{\text { Text }}$

is a character variable (199 characters) that starts in column 2. Any characters can be included in Text. The "\#” must be in column 1. Lines beginning with \# are restricted to the first lines of the file. Text is written to List File.

$\underline{\text { NPHFB }}$

is the number of horizontal flow barrier parameters to be defined in Items 2 and 3. Note: An HFB parameter must be defined in Items 2 and 3, and made active using Item 6 and 9 to have an effect in the simulation. 


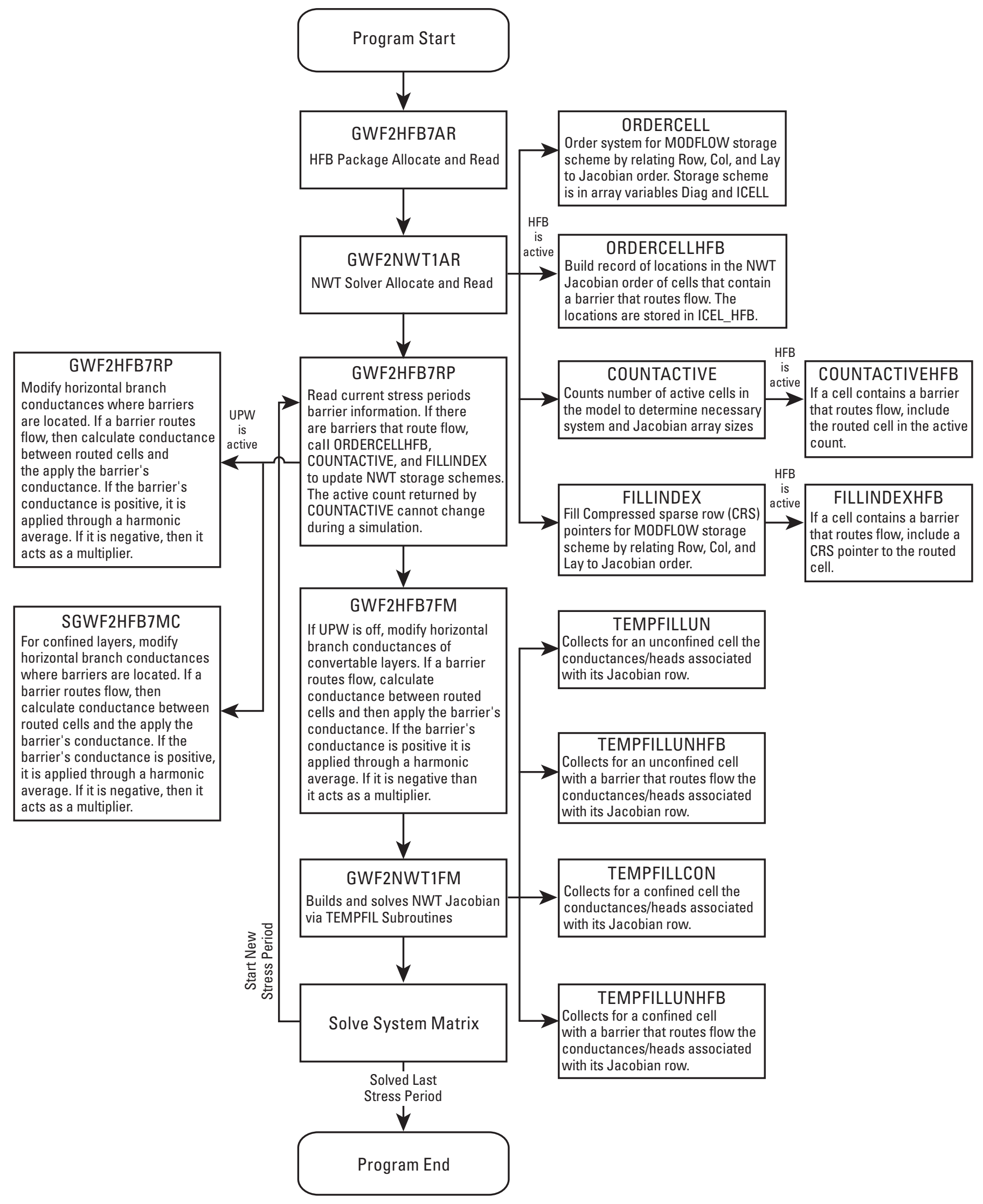

Figure C1. Flowchart of key subroutines in MF-OWHM used when HFB has transient faults and layer routing. Note that the center column includes all routines within the MF-OWHM main file. 
NHFBNP

MXHFBNP

PARNAM

PARTYP

Parval

\section{NLST}

Layer

IROW1

ICOL1

IROW2

ICOL2

Factor

Hydchr is the number of HFB barriers not defined by parameters for current stress period. Item 4 will be read NHFBNP times as specified in item 1. If NHFBNP is set to -1 in item 7, then NACTHFB and items 8 and 9 are not read, and the barriers defined in the previous stress period are used. Item 8 will be read NHFBNP times as specified in item 7 .

is the maximum number of HFB barriers not defined by parameters used during any stress period. If MXHFBNP is not specified, it is set equal to NHFBNP in item 1.

is the name of a parameter. This name can consist of 1 to 10 characters and is not case sensitive. That is, any combination of the same characters with different cases will be equivalent.

is the type of parameter. For the HFB Package, the only allowed parameter type is HFB, which defines values of the hydraulic characteristic of the barrier.

is the parameter value. This parameter value may be overridden by a value in the Parameter Value File. If Parval makes the final hydraulic characteristic negative, then it acts as a multiplier to the conductance between the two model cells specified as containing a barrier. For example, if the final result was -1.5 , it would multiply by 1.5 the conductance between the two cells.

is the number of horizontal flow barrier cells included in the parameter.

is the model layer of the first cell which contains a barrier. This cell is indexed as [IROW1, ICOL1, Layer] .

is the model row of the first cell which contains a barrier. This cell is indexed as [IROW1, ICOL1, Layer].

is the model column of the first cell which contains a barrier. This cell is indexed as [IROW1, ICOL1, Layer].

is the model row of the second cell which contains a barrier. This cell is indexed as [IROW2, ICOL2, Layer2].

is the model column of the second cell which contains a barrier. This cell is indexed as [IROW2, ICOL2, Layer2].

is the factor used to calculate hydraulic characteristic from the parameter value. The hydraulic characteristic is the product of Factor and the parameter value. If final hydraulic characteristic is negative, then it acts as a multiplier to the conductance between the two model cells specified as containing a barrier. For example, if the final result was -1.5 , it would multiply by 1.5 the conductance between the two cells.

is the hydraulic characteristic of the horizontal flow barrier. The hydraulic characteristic is the barrier hydraulic conductivity divided by the width of the horizontal flow barrier. If hydraulic characteristic is negative, then it acts as a multiplier to the conductance between the two model cells specified as containing a barrier. For example, if the final result was -1.5 , it would multiply by 1.5 the conductance between the two cells.

is the model layer of the second cell which contains a barrier. This cell is indexed as [IROW2, ICOL2, Layer2]. This variable is optional and if not present is set equal to Layer. If it is equal to Layer, then no flow routing occurs, and the barrier functions identically to previous versions of HFB.

is the number of active HFB parameters for the current stress period.

is the name of a parameter to be used in the current stress period. NACTHFB parameter names will be read. 


\section{Appendix D: Multiplier Array (MULT) and Zone (ZONE) Enhancements}

The capabilities of the MULT package were extended through the addition of a new Fortran module, called ExpressionParser, that allows the option of constructing a multiplier array, vector, or scalar from an algebraic expression of previously defined multiplier arrays, vectors, or scalars. The expression is read as a single 500-character line and processed using an algorithm called precedence climbing that follows a mathematical order of operations. This new feature allows multiplier arrays, vectors, or scalars to be defined with parentheses in a fashion similar to a five-function calculator. To activate this new feature the key word EXPRESSION is added after a multiplier name is specified. In addition to this hierarchy for individual expressions, multiple expressions can be nested through sequential estimation.

The enhancement to the MULT input file is backward compatible with previous versions. Below is a description of the input file with optional variables are shown in brackets and new variables delineated as Blue text.

\section{FOR EACH SIMULATION}

\section{0. [\#Text]}

Item 0 is optional- “\#” must be in column 1 . Item 0 can be repeated multiple times.

1. NML [MULTPRINT]

2. MLTNAM [FUNCTION] [EXPRESSION]

If Item 2 does not contain the optional FUNCTION key word or optional EXPRESSION keyword, read item 3. Item 2 cannot have both key words FUNCTION and EXPRESSION at the same time.

3. $[R M L T(N C O L, N R O W)]-$ U2DREL

4. [MLTNAM1 [op1 MLtNAM2] [op2 MLtNAM3] [op3 MLtNAM4] ... ]

Item 4 is only read if Item 3 contains the optional FUNCTION key word.

5. [Algebraic_Expression]

Item 5 is only read if Item 3 contains the optional EXPRESSION key word. It is a single mathematical expression composed of previously defined multiplier arrays.

Repeat Item 2 with Items 3 or 4 or 5 until NML multiplier arrays, vectors, or scalars have been defined.

$\underline{\text { Text }}$

$\underline{\mathrm{NML}}$

MULTPRINT

MLTNAM

RMULT

FUNCTION

EXPRESSION

MLTNAM1, MLTNAM2, ... op1, opt2, op $3, \ldots$ is a character variable (199 characters) that starts in column 2. Any characters can be included in Text. The "\#” must be in column 1. Lines beginning with \# are restricted to the first lines of the file. Text is written to List File.

is the number of multiplier arrays, vectors, or scalars to be defined.

is an optional print flag that when set $>0$ writes all multiplier arrays, vectors, or scalars to file called "MULT_Arrays.txt." This will not occur if MULTPRINT is not present or set to $<1$.

is the name of a multiplier array. This name can consist of 1 to 10 characters and is not case sensitive. That is, any combination of the same characters with different cases is equivalent. The name "NONE" is a reserved word and should not be used for a multiplier array.

is a multiplier array.

is an optional keyword, which indicates that the multiplier array will be constructed from other multiplier arrays, vectors, or scalars that have already been defined. Construction is by arithmetic combinations of the multipliers that follow left to right order of operations. See the explanation that follows for variable "op1, op2, op $3, \ldots$ ".

is an optional keyword, which indicates that the multiplier array will be constructed from other multiplier arrays, vectors, or scalars that have already been defined. Construction is different from the FUNCTION keyword in that it follows mathematical order of operations with parenthetic support. See explanation for variable Algebraic_Expression.

are names of multiplier arrays, vectors, or scalars that have already been defined.

are arithmetic operators used to define a multiplier array on the basis of other multiplier arrays. Each operator can be either "+,", “-," “*," " "," or "^." The order of operations is applied from left to right to each array element. The operators must be separated from the multiplier array names by at least one space. 


\section{Algebraic_Expression}

is a single line with a maximum length of 500 characters that contains an algebraic expression composed of multiplier arrays, vectors, or scalars that have already been defined (that is, MLTNAM). The expression is evaluated by following mathematical order of operations (also called operator precedence).

The expression calculates the result using the following algebraic operators “+,, "_,, "“*," " ",, "“^," and parentheses "(“, ")" for multinomial expressions. Decimal (for example, 1.4 and 2.33) and integer (for example, 1 and 2) numbers can be included in the expression, but NOT exponential notation (for example, $1 \mathrm{E}-5$ ).

The expression parser has an additional set of keywords, that CAN NOT appears anywhere in a variable names that is used in the expression (that is, MLTNAM). The keywords operate on what is inside the ( ) and are as follows:

$\begin{array}{ll}\operatorname{ABS}() & \text { for absolute value }(|x|) \\ \operatorname{EXP}() & \text { for solving the natural exponential function }\left(e^{\mathrm{x}}\right) \\ \operatorname{LOG}() & \text { for solving the natural logarithm }\left(\log _{e}\right) \\ \operatorname{L10}() & \text { for solving the base } 10 \operatorname{logarithm}\left(\log _{10}\right) \\ \operatorname{NEG}() & \text { for multiplying the function by negative one }(\mathrm{NEG}(\mathrm{x})=-\mathrm{x}) \\ \operatorname{SQRT}() & \text { for solving the square root }(\sqrt{ }) \text { of positive values only }\end{array}$

The following two example inputs illustrate the use of the FUNCTION and EXPRESSION keywords to construct a multiplier array from other multiplier arrays. In the first example, a model layer that has 5 rows and 4 columns has six multiplier arrays, vectors, or scalars to be defined, and, accordingly, the first line of the file contains "6." The first two arrays (named M1 and M2) are read using the U2DREL utility array reader (Item 3), the third array (named POW) is a multiplier array set to the number 2. The fourth array (named M4) is defined by using the FUNCTION key word, which follows left to right order of operations. This results in calculating M4 as the sum of M1 and M2, which is then raised to power POW (that is, (M1+M2) ${ }^{\mathrm{POW}}$ ). The fifth matrix (named M5) is defined by using the EXPRESSION key word, which follows mathematical order of operations and produces an identical multiplier to M4. The sixth matrix (named M6) is defined by using the EXPRESSION key word that calculations $\mathrm{M} 2^{\mathrm{POW}}$ first and then sums the result with M1.

The second example is a more complex application of the EXPRESSION key word that constructs a multiplier matrix composed of a weighted power mean, $\left(\sum_{k=1}^{n} x_{i}^{l}\right)^{v_{p}}$ and $\sum_{n_{i}=1}^{n}$, of two multiplier matrices $(n=2)$. In this second example there are eight multiplier arrays, vectors, or scalars to be defined, and accordingly the first line of the file contains " 8 ". The first two multiplier arrays, vectors, or scalars (named X1 and X2) define $x_{1}$ and $x_{2}$. The third multiplier array (named POW) defines the power mean power, $p$, which for this case is -1 to represent a harmonic mean. The fourth multiplier matrix is a matrix composed of all ones. The fifth multiplier (named W1) is the first weight, $w_{1}$, read from a free formatted external file. The sixth multiplier (named W2) is the second weight, $w_{2}=1-w_{1}$, which is constructed using the FUNCTION key word (left to right order of operations). The seventh multiplier (named PowerMean1) solves the power mean using W2 with the EXPRESSION key word. The eighth multiplier (named PowerMean2) solves the power mean without using W2 via the EXPRESSION key word.

\section{EXAMPLE 1}

6

M1

INTERNAL $1.0(4 \mathrm{~F} 6.0) 0$

$\begin{array}{llll}1.0 & 1.1 & 1.2 & 1.3\end{array}$

$\begin{array}{llll}1.0 & 1.1 & 1.2 & 1.3\end{array}$

$\begin{array}{llll}2.0 & 2.2 & 2.4 & 2.6\end{array}$

$\begin{array}{llll}2.0 & 2.2 & 2.4 & 2.6\end{array}$

$\begin{array}{llll}1.0 & 1.1 & 1.2 & 1.3\end{array}$

M2

INTERNAL $1.0(4 \mathrm{~F} 6.0) 0$

$\begin{array}{llll}5.0 & 5.1 & 5.2 & 5.3\end{array}$

$\begin{array}{llll}5.0 & 5.1 & 5.2 & 5.3\end{array}$

$\begin{array}{llll}6.0 & 6.1 & 6.2 & 6.3\end{array}$

$\begin{array}{llll}6.0 & 6.1 & 6.2 & 6.3\end{array}$

$\begin{array}{llll}5.0 & 5.1 & 5.2 & 5.3\end{array}$

POW

CONSTANT 2.0 


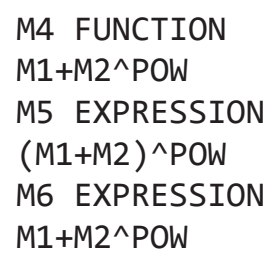

The resulting values for multiplier M5 are:

$\begin{array}{llll}36.00 & 38.44 & 40.96 & 43.56 \\ 36.00 & 38.44 & 40.96 & 43.56 \\ 64.00 & 68.89 & 73.96 & 79.21 \\ 64.00 & 68.89 & 73.96 & 79.21 \\ 36.00 & 38.44 & 40.96 & 43.56\end{array}$

The resulting values for multiplier M4 and M5 are:

$\begin{array}{llll}26.00 & 27.11 & 28.24 & 29.39 \\ 26.00 & 27.11 & 28.24 & 29.39 \\ 38.00 & 39.41 & 40.84 & 42.29 \\ 38.00 & 39.41 & 40.84 & 42.29 \\ 26.00 & 27.11 & 28.24 & 29.39\end{array}$

EXAMPLE 2

8

$\mathrm{X} 1$

\#FIRST NUMBER X1

CONSTANT 25.

$\mathrm{X} 2$

\#SECOND NUMBER X2

CONSTANT 0.01

POW

\#POWER USED IN POWER MEAN, $p$

CONSTANT -1.0

\#MATRIX OF ALL ONES

CONSTANT 1.0

W1

OPEN/CLOSE FIRST_WEIGHT.TXT 1.0 (FREE) -1 W2 FUNCTION

ONES - W1

PowerMean1 EXPRESSION

$\left(\mathrm{W} 1 * X 1^{\wedge} \mathrm{POW}+\mathrm{W} 2 * \mathrm{X} 2^{\wedge} \mathrm{POW}\right)^{\wedge}(\mathrm{ONES} / \mathrm{POW})$

PowerMean2 EXPRESSION

$\left(\mathrm{W} 1 * \mathrm{X} 1^{\wedge} \mathrm{POW}+(\mathrm{ONES}-\mathrm{W} 1) * \mathrm{X} 2^{\wedge} \mathrm{POW}\right)^{\wedge}(\mathrm{ONES} / \mathrm{POW})$

KeywordEx EXPRESSION

\#CALCULATE SECOND WEIGHT AS

\#POWER MEAN

\#POWER MEAN (DOES NOT REQUIRE W2)

$3.14 *$ SQRT $($ EXP(POW $)+\operatorname{LOG}(M 1)-\mathrm{NEG}(M 2)+10^{\wedge}$ POW $)$

\section{Programmer Documentation for ExpressionParser}

The expression parser was written with no dependency on any other MODFLOW packages or global variables. This enables calling a single function that has three required arguments, two optional, and returns the result of an algebraic expression. To get access to this function, the keyword "USE ExpressionParser" must be placed at the beginning of the program, subroutine, or function that will use it. This provides access one generic driver function called EqnEval() and an elemental subroutine, UPPER(). The latter subroutine converts a passed string or an array of strings to upper case. The main function EqnEval return value depends on its input and can be either a scalar, vector, or 2D array. The generic input is as follows:

FUNCTION EqnEval(Ln, NML, NMV) RESULT(RES)

$\operatorname{CHARACTER}(*)$,

$\operatorname{CHARACTER}(*), \quad \operatorname{DIMENSION}(:)$,

INTENT(IN) : :Ln !Expression

INTENT(IN): :NML !Variable Name List 


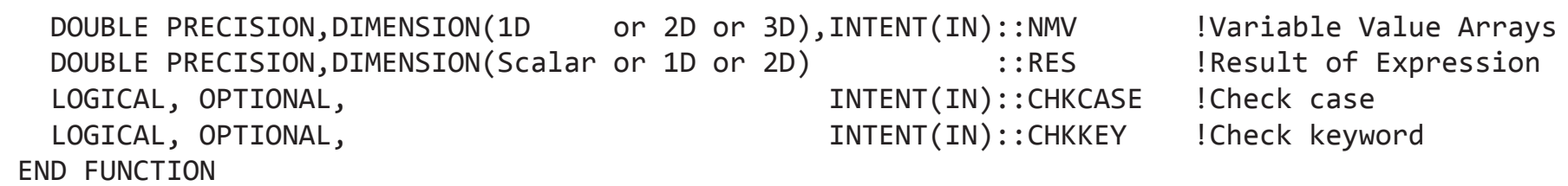

RES is the double precision result of the expression and can be either a scalar, 1D (vector), or 2D array. The result depends on the dimension of NMV (always one dimension less).

Ln $\quad$ is a character variable of any length that contains an expression to be evaluated by EqnEval. Internally, a copy of the string is made, stripped of all blank spaces, and converted to upper case.

NML is a one-dimensional character array (vector) containing the names of all possible variables that could be in Ln. Variables not in Ln will be ignored, but missing variables will stop the program. The length of each variable name can be at most 25 characters.

NMV is a double precision array that is either 1D (vector), 2D, or 3D array, where the right most (outer) dimension has a one to one agreement with NML. For example, if the result, RES, is a scalar, then each row in NML is a variable name that corresponds with each row of NMV, and if the result, RES, is a vector, then each row in NML is a variable name that corresponds with each column of NML.

CHKCASE is an optional logical variable that is FALSE when not present. When set to true, the program will create an internal copy of the NML and convert it to upper case to ensure an exact match with its evaluation in Ln.

CHKKEY is an optional logical variable that is FALSE when not present. When set to true, the program will check to see if a keyword appears in any part of the strings in NML. If there is a keyword present, this would cause the program to crash without warning, so this will notify the user of the bad variable name and the keyword that is found in it.

\section{Zone Array File (ZONE)}

The Zone Array File was modified to include an optional print flag that creates a separate file, ZONE_Array.txt, and writes a transcript of all ZONE arrays. If the print flag is not specified, then the file will not be created. The enhancement to the ZONE input file is backward compatible with previous versions of the model. A description of the input file follows with optional variables are shown in brackets and new variables delineated as Blue text.

\section{FOR EACH SIMULATION}

0 . [\#Text]

Item 0 is optional- “\#” must be in column 1. Item 0 can be repeated multiple times.

1. NZN [ZONEPRINT]

2. ZONNAM

3. $\operatorname{IZON}(\mathrm{NCOL}, \mathrm{NROW})$ - U2DINT

Item 2 and 3 are repeated for each of the NZN zone arrays.

Text is a character variable (199 characters) that starts in column 2. Any characters can be included in Text. The "\#” must be in column 1. Lines beginning with \# are restricted to the first lines of the file. Text is written to List File.

NZN is the number of zone arrays to be defined.

ZONEPRINT is an optional print flag that when set $>0$ writes all zone arrays to file called "ZONE_Arrays.txt." This will not occur if ZONEPRINT is not present or set to $<1$.

ZONNAM is the name of a zone array. This name can consist of 1 to 10 characters and is not case sensitive. That is, any combination of the same characters with different cases are equivalent. The name "ALL" is a reserved word and should not be used for a multiplier array. 


\section{Appendix E. Summary of Upgrades to Other MODFLOW-OWHM Packages}

\section{Output Suppression in List File (UTL7)}

The UTL7 Package was modified to include the option of selected levels of output suppression to the list file. The options for output suppression are specified as part of the name file and extend to all possible features that are active in a user's simulation configuration. These options allow for reduced output that may have advantages for certain applications such as parameter estimation analysis. Note that these options should not be used if the parameter estimation relies on observations that are embedded in the list file. The options for output suppression are activated by specifying a negative Fortran unit number in the name file for the List file. The integer flag options follow the list file name, such as the following:
Keyword
Fortran unit
Number list file name
LSTLVL option
LIST
$-60$
your_model.lst
1

The options for output suppression are variable LSTLVL:

1 - Disable List File Output Completely

2 - Show Error Messages Only

3 - Show Error and Warning Messages

4 - Show Error, Warning, and Informational Messages (Show All)

\section{Groundwater Budget Summary Output (OC)}

The Output Control Package was modified to include the option of writing the groundwater summary budgets to a separate output file. The additional option for water-budget output file is specified as part of the name file. This definition in the Output Control Header records is as follows:

$\begin{array}{ccc}\text { Keyword } & \text { Fortran } & \text { Unit } \\ \text { WBGT } & \text { SAVE } & \text { UNIT } 80\end{array}$

To activate the option for any stress period add the output command option as follows:

Action Keyword

SAVE WBGT

\section{Maximum Number of Parameter, Instance, and Cluster Specification (BAS)}

The Basic package (BAS) was modified to dynamically allocate the required global storage for package parameters. These arrays contain the names of all parameters from all packages, their values, clusters, and instances. This is specified in Data Item 1 (Options) of the BAS package with the Option "MAXPARAM" followed by MXPAR, MXCLST, and MXINST. The minimum allowable size for the three arrays is 1. MXPAR is the maximum size of the parameter names and values used by parameters; MXCLST is the maximum size of the clusters associated with parameters (for example, zone number, multiplier name, layer/row/col); MXINST is the maximum size of the instance parameter names. If MAXPARAM is not specified then the default values are MXPAR $=2000$, MXCLST $=2000000$, MXINST $=50000$.

An important note to prevent problems is that MXCLST should be greater than or equal to MXPAR + MXINST (that is, MXCLTST $\geq$ MXPAR + MXINST). This is advantageous for highly parameterized models that require additional parameter storage space or models that do not use parameters/instances to save memory. For example, to save memory, a model that does not use instances can set MXINST to 1 . If there are any problems with the storage requirements, an error flag is raised printing the current inadequate storage, and the program is stopped.

\section{Parameter Values Output Arrays (PVAL/LPF/UPW)}

For parameter estimation and visualization purposes, the user can now output the actual property arrays that are constructed and used by LPF or UPW. This aids in understanding the final result for input files that contain complex parameter scaling, multiplier arrays, and zone arrays. The arrays are printed as row-column slices to a separate file for each LGR grid and layer. Some of the properties that are printed include lateral hydraulic conductivities $(\mathrm{Kx}, \mathrm{Ky})$, vertical hydraulic conductivities $(\mathrm{Kv})$, specific storage (Ss), and specific yield (Sy). 
To initiate printing of the model parameters to separate files the keyword "PROPPRINT" is specified in the PVAL file after the variable NPVAL. If PVAL is not needed, but parameter printing is desired, then PVAL must appear in the NAM file and NPVAL be set to 0 , followed by the keyword "PROPPRINT" (without quotes).

PROPPRINT is read as part of the PVAL file, which structure would be as follows:

\#URWORD COMMENTS THAT BEGIN WITH “\#”

NPVAL \{OPTIONS\}

Where

OPTIONS is the optional keyword "PROPPRINT" without quotes

When activated, this option will output for each model layer individual files for each hydraulic property used within the model (only model layer 1-L1 shown here), such as the following:

Horizontal hydraulic conductivity: PARAM_HKC_G1_L1.txt

Conductivity Anisotropy Ratio: PARAM_HKR_G1_L 1 .txt

Vertical Hydraulic Conductivity: PARAM_VKA_G1_L1.txt

Specific Storage: PARAM_Ss_G1_L1.txt

Specific Yield: PARAM_Sy_G1_L1.txt

\section{Rate Balance Percent Error Printing (BAS)}

The Basic package (BAS) was modified to calculate the rate mass balance at every time step. A new integer variable, PDIFFPRT, represents the maximum acceptable rate mass balance error before triggering a warning to the command prompt and prints the rate mass balance to the list file. The default value of PDIFFPRT is set to 50 (that is, 50 percent) and can be adjusted on Data Item 1 (Options) of the BAS package with the Option "PERCENTERROR" followed by PDIFFPRT. Acceptable values for PDIFFPRT are any integer greater than 0. If PDIFFPRT is set to zero, then a volumetric budget is printed, without the command prompt warning, for every time step.

\section{Decimal Starting Year (DIS)}

The Discretization package (DIS) was modified to optionally read an initial decimal year that represents the start of the simulation. This starting date is updated and printed along with an estimate of the month based on leap/non-leap year to the list file's Time Summary. To set the starting decimal year, the keyword, "STARTTIME", followed by the year is added to the end of the first read of Data Set 7. The update to the decimal year makes the appropriate conversions based on the time step scale and assumes there are 365.242 days in a year. Below is a DIS example of Data Set 7 with a starting date of 1949.7479 (Oct, 1, 1949). Note that the transient simulation then starts in October of 1950.

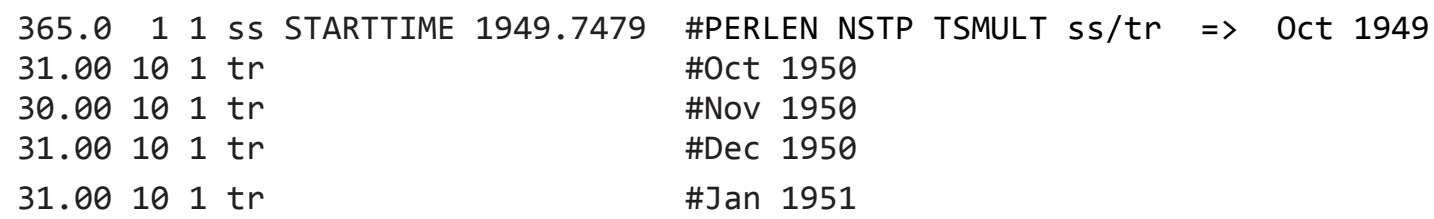

For general reference the following is a reference table for each month's fraction of a year.

\begin{tabular}{lcc}
\hline \multicolumn{1}{c}{ Month } & Non leap year & Leap year \\
\hline January & 0 & 0 \\
February & 0.08493 & 0.08470 \\
March & 0.16164 & 0.16393 \\
April & 0.24658 & 0.24863 \\
May & 0.32877 & 0.33060 \\
June & 0.41370 & 0.41530 \\
July & 0.49589 & 0.49727 \\
August & 0.58082 & 0.58197 \\
September & 0.66575 & 0.66667 \\
October & 0.74795 & 0.74863 \\
November & 0.83288 & 0.83333 \\
December & 0.91507 & 0.91530
\end{tabular}




\section{Internal Coordinate System (DIS)}

The Discretization package (DIS) was modified to calculate every model cell center's X, Y Cartesian coordinate. The default coordinate system assumes that the lower left corner (outer most corner of row NROW and column 1) of the model domain has a $(\mathrm{X}, \mathrm{Y})$ coordinate of $(0,0)$ and a polar angle of $0^{\circ}$. To override the default values, the DIS can optionally read in a reference Cartesian coordinate and Polar angle and calculate the corresponding model cell centers. The X, Y Cartesian coordinate's reference location has a different meaning dependent on the flags that are used. It is important to note that with NO flags specified the X, Y Cartesian coordinate's reference location is the cell center at Row 1 and Column 1 (fig. E1). Additional flags can be added to move the reference point from the cell center to the outer most corner or to row NROW and column 1 (model's lower left cell). With this information, the Cartesian coordinates of the cell centers for the entire model are calculated and optionally printed to the List file. The coordinates are read in on Data Item/Set 1 of the DIS file as presented below with \{\} indicating optional variables:

NLAY NROW NCOL NPER ITMUNI LENUNI \{XFIRSTCORD YFIRSTCORD GRIDROTATION \{COORD_OPTIONS\}\}

Where

XFIRSTCORD

YFIRSTCORD

GRIDROTATION

COORD_OPTIONS is the X Cartesian coordinate the model cell center at Row 1, Column 1

is the Y Cartesian coordinate the model cell center at Row 1, Column 1

is the Polar angle of the model grid

is a character variable that is scanned for keywords (separated by one or more spaces) that specify coordinate options. Unrecognized words are ignored, and a word may be specified in either uppercase or lowercase. A blank record is acceptable and indicates no options. The following are recognized keywords.

"CORNERCOORD" is an optional coordinate keyword, without quotes, that when present indicates that XFIRSTCORD, and YFIRSTCORD refer to the model cell's outer most corner (that is, NOT the cell center).

"LLCOODRINATE" is an optional coordinate keyword, without quotes, that when present indicates that XFIRSTCORD, and YFIRSTCORD refer to the cell center or outer most cell corner of Row NROW and Column 1 (that is, the model's lower left corner)

"PRINTCOORD" is an optional coordinate keyword, without quotes, that when present signifies that the coordinate arrays are to be printed to the list file.

\section{Drains with Return Flow Connections (DRT)}

Both FMP3 and SWR are now optionally connected to DRT to keep water simulated the Drain Package within the model simulation. The Drains with Return Flow package was enhanced by including two additional options for where the return flow is sent and a new output file that prints the flow results at each timestep. The original DRT package has the user specify a model cell where the drain flow is returned to the groundwater system in a manner similar to the recharge package. The DRT package now has the option to send drain water to a user specified farm (FMP) or to a user-specified reach of the Surface-Water Routing Process (SWR). Drain water that is sent to a FMP farm is treated as runoff and is handled on the basis of the farm's specified fully routed or semi-routed return flow of FMP. Drain water that is sent to SWR is delivered to a user-specified reach through the SWR external flow accumulator subroutine. An additional indirect link of DRT can be made to SFR by sending drain water to a farm that has its semi-routed return flow sent to a SFR segment and reach. The input file is the same to preserve backwards compatibility and relies on a redefinition of the input variables LayR, RowR and ColR, as described later. (Note that only the changed items are presented. For the entire input format, please see the DRT documentation or the online user's guide at http:// water.usgs.gov/ogw/modflow-owhm/Guide/index.html.

To facilitate parameter estimation, a new output file was added to the DRT to create observations for drain return flows. This output file prints to either a binary file or text (ASCII) file, a header and then all the drain cells' locations, where drain water was sent to, and the flow rate. This option is activated by adding the option keyword PRINTFILE on Item 1, followed by a unit number of the file to which data will be written. For binary files, a set of static information is written for each drain location to be consistent. Below is an example written to a binary file where the variables are those previously defined in the DRT documentation or in the next section.

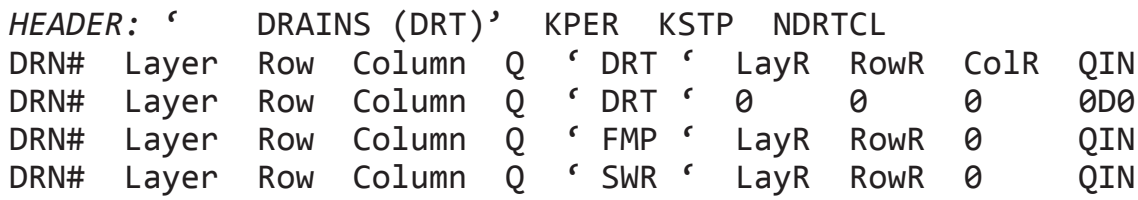

The first record is a header that contains a string, the current stress period, time step, and the number of drains that will be printed. The subsequent records contain the current drain count, DRN\#, the flow rate out of the drain cell, Q, a four-character string that indicates the package that the drain flow is sent to, and the flow rate into that package, QIN. Note that if Rfprop=1.0, then $\mathrm{Q}=\mathrm{QIN}$. The second entry represents when DRT functions like DRN and is specified with a zero layer, row, and column, and the type at the end of the line is set to zero because this drain flow is not returned within the model. 
GRID ROTATION $0^{\circ}$
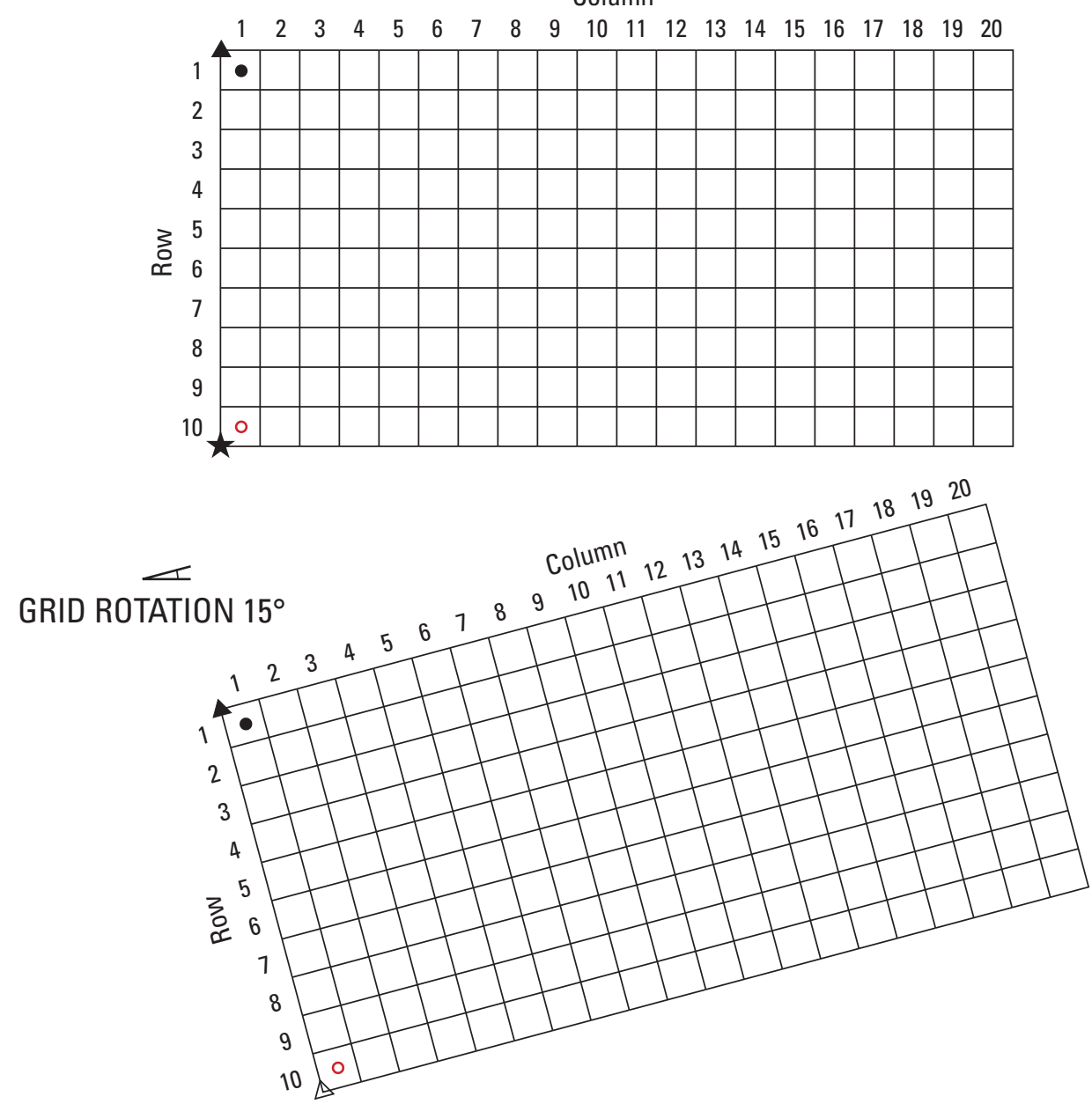

EXPLANATION

Default when not specified

- XFIRSTCORD and YFIRSTCORD

- XFIRSTCORD and YFIRSTCORD with "LLCOORDINATE" flag

- XFIRSTCORD and YFIRSTCORD with "CORNERCOORD" flag

$\triangle$ XFIRSTCORD and YFIRSTCORD with "LLCOORDINATE" and “CORNERCOORD” flags

\section{GRID ROTATION $165^{\circ}$}

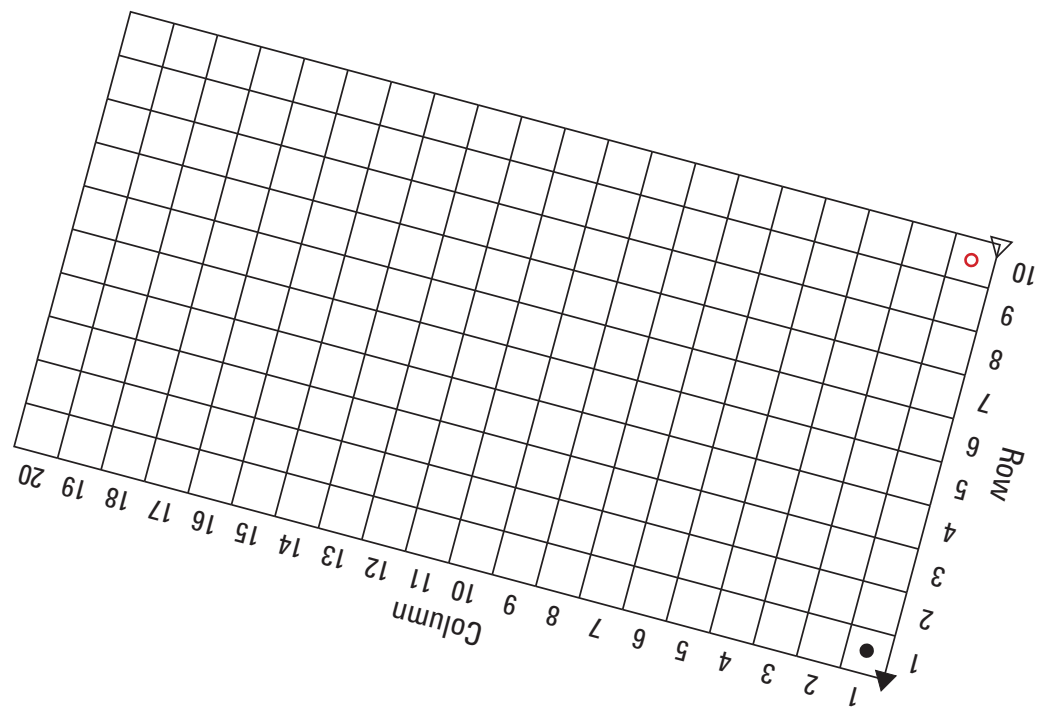

Figure E1. Potential rotation representations of a 10 row, 20 column model grid in the DIS file. (Note that each representation is an independent coordinate system with different sets of XFIRSTCOORD, YFIRSTCORD to accommodate the presented grids within a single image.) 


\title{
INPUT FILE WITH REDEFINED VARIABLES
}

1. MXADRT IDRTCB NPDRT MXL [Option] [xyz]

\author{
3. Layer Row Column Elevation Condfact [LayR RowR ColR Rfprop] [xyz] \\ 5. Layer Row Column Elevation Cond [LayR RowR ColR Rfprop] [xyz]
}
Option is an optional list of character values.
“PRINTFILE" PRTFIL, The keyword is PRINTFILE (without quotes) followed by a unit number, PRTFIL, that is specified in the NAM. The unit number is where the DRT flow data is written.
LayR is a flag and, if $L a y R>0$, a layer number. If $\operatorname{Lay} R<0$, its value defines where drain water is sent. If auxiliary variables are being read, LayR must be nonzero, so that RowR, ColR, and Rfprop are read. LayR is not read if "RETURNFLOW" is not listed as an option in item 1 .
If LayR > $>, \quad$ it is the layer number of the recipient cell that will receive the drain water as recharge (this is the normal operation of the DRT package).
If LayR $=0, \quad$ there is no return flow for the drain cell, and RowR, ColR, and Rfprop are NOT read. DRT will operate the same as the DRN package.
If LayR = -1, $\quad$ signifies that drain water will be sent to a FMP farm whose farm ID is specified. RowR, ColR, and Rfprop and any aux variables are read.
If LayR = -2, $\quad$ signifies that drain water will be sent to a SWR reach. RowR, ColR, and Rfprop and any auxiliary variables are read.
RowR is defined by the value of LayR that is read.
If LayR > $>, \quad$ RowR is the row number of the recipient cell that will receive the drain water as recharge.
If LayR $=0, \quad$ RowR is NOT read, and there is no return flow for the drain cell, and the water leaves the model.
If LayR = -1, $\quad$ RowR is the farm ID of the farm that will receive the drain water, and the water stays in the model. If RowR $=0$, then the farm located at the drain's Row and Column is used.
If LayR = -2, RowR is the SWR reach that will receive the drain water, and the water stays in the model.
ColR is defined by the value of LayR that is read.
If LayR $>\theta, \quad$ ColR is the column number of the recipient cell that will receive the drain water as recharge.
If LayR $=0, \quad$ ColR is NOT read, and there is no return flow for the drain cell.
If LayR $=-1, \quad$ ColR is read, but is not used. It can be any integer number to serve as a place holder before reading Rfprop and any auxiliary variables.
If LayR = -2, $\quad$ ColR is read, but is not used. It can be any integer number to serve as a place holder before reading Rfprop and any auxiliary variables.

\section{Enhanced TABFILE (GHB, WEL, MNW2, and SFR2)}

To facilitate simple updates of temporal data needed for self-updating models, the GHB, WEL, MNW2, and SFR2 packages have the same input file and make use of key words to trigger the use of tabfiles. The SFR package can utilize the new tabfile code through the use of a different keyword and maintain support to the original implementation. In SFR, if both keywords are used, both forms of tabfiles are used, but if the same segment is referenced, the newer version will supersede the legacy. A tabfile replaces the need for instances to describe a time varying property. It is a separate file that contains a list of simulation times and numerical values. The numerical values that are replaced for SFR, GHB, WEL and MNW2 are flow rate into a segment, BHEAD, Q (pump rate), and Qdes (desired pumping rate), respectively.

The advantage of the new tabfiles is that each individual tabfile has a unique name to enable it to link to multiple features. In this section, a feature refers to the part of a package that is linked to a tabfile (that is, a SFR segment that will be linked to a tabfile). This is beneficial for multiple GHB cells that refer to the same tabfile. Another advantage is that a tab scale factor is included for each of the features that are linked to a tabfile. The scale factor scales the numerical value stored in the tabfile, making its value unique to each time series specified.

The tabfile structure is a list of two columns of data. The first column contains simulation times, and the second column contains numerical values used in the model. The information is read using URWORD, which accepts tab, space, and comma delimited data. The following is an example tabfile that would be used for a model with 30 day stress periods (SP) and 5 day time steps: 


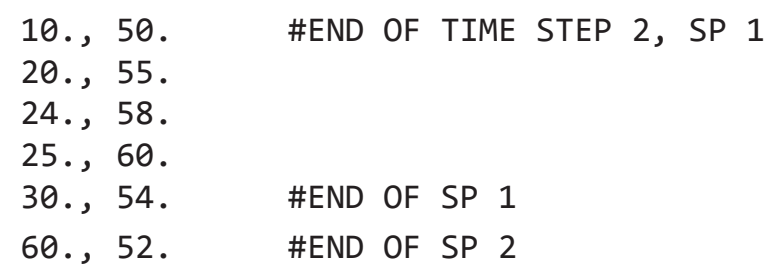

The data in the tabfile is interpreted in one of three ways based on the availability of data within the current time step (that is, TOTIM-DELT $<$ DATA $\leq$ TOTIM). If the current simulation time is before the first tabfile time, after the last tabfile time, or has a single value within the time step, then the appropriate single value in the tabfile is applied. For example, the first time step ( 0 to 5 days) would use a value of 50, and any time step after 60 will have a value of 52 . If there are no values within a time step, then a value is linearly interpolated to TOTIM. For example, the time step from 35 to 40 days would linearly interpolate to 40 days using the values $(30,54)$ and $(60,52)$. If there are multiple tabfile values within a time step, they are time-weight averaged. For example, the time from 20 to 25 days would time average $(20,55)$ and $(24,58)$. A note of caution is that these data are applied on a time-step basis, not by a stress period. The following is another example with a 30 day stress period (SP) and 10 day time steps (TS).

$$
\begin{array}{ll}
\text { 10.0, 52. } & \text { \# SP } 1, \text { TS } 1 \text { (52 is applied to interval }(0,10]) \\
20.0,54 . & \text { \# SP } 1, \text { TS } 2 \text { (54 is applied to interval }(10,20]) \\
30.0,56 . & \text { \# SP } 1, \text { TS } 3 \text { (56 is applied to interval }(20,30]) \\
60.0,99 . & \text { \# SP } 2 \text { time steps are interpolated between } 30 \text { and } 60 .
\end{array}
$$

The SFR, GHB, WEL and MNW2 input files are backwards compatible with the previous input format and make use of the keyword "TABFILE" to trigger the use of tabfiles. Described after this is the input structure for SFR, WEL, MNW2, and then GHB. Features from SFR and MNW2 may only be linked once to a tabfile (for example, A MNW2 well may only be linked to one tabfile, but multiple wells may be linked to a single tabfile). In contrast, the WEL and GHB may have the same model cell with the feature linked to multiple tabfiles. For GHB, this is clearly done by specifying a tabfile name during the layer, row, and column input of each cell (see GHB input format). Because of limitations in the code structure of the WEL package, it is more ambiguous to have multiple identical features linked to tabfiles (for example, 2 wells at the same row, column, and layer are linked to two tabfiles). For the WEL package, if there are repeated identical features (same row, column and layer) linked to tabfiles, then the selected tabfiles will be applied in the order they are read (if there are three identical features and only two are present for a stress period, only the first two tabfiles read will be applied).

For SFR, the key word is TABFILE and not TABFILES (original keyword). The latter is the key word that triggers the original tabfile code only in SFR. For SFR, the code supports simultaneous use of both TABILES and TABFILE with any conflicting segment references using the latter. [] indicates an optional input, italic/bold words are keywords that are input as is, and blue indicates a new feature.

\section{SFR INPUT FILE WITH TABFILE SUPPORT}

0 [\#TEXT]

0a. [PARAMETER NPSFR MXL]

1a. [REACHINPUT TRANSROUTE]

1b. [TABFILES NUMTAB MAXVAL]

1bb. [TABFILE NTAB FILEIO TIMEOPTION]

[TABNAM TABLOCATION] READ NTAB TIMES IF NTAB $>0$

[Printoption NLNK] READ IF NTAB $>0$

[ISEG TABNAM TSFAC] READ NLNK TIMES IF NLNK $>0$

1C. NSTRM NSS NSFRPAR NPARSEG CONST DLEAK ISTCB1 ISTCB2 [ISFROPT]

[NSTRAIL ] [ISUZN] [NSFRSETS ] [IRTFLG] [NUMTIM] [WEIGHT] [FLWTOL] 


\section{WEL INPUT FILE WITH TABFILE SUPPORT}

0. [\#TEXT]

1. [PARAMETER NPWEL MXL]

1a. [TABFILE NTAB FILEIO TIMEOPTION]

[TABNAM TABLOCATION]

READ NTAB TIMES IF NTAB>0

[PrintOption NLNK]

READ IF NTAB $>0$

[LAYER ROW COIUmn TABNAM TSFAC]

READ NLNK TIMES IF NLNK>0

2. MAXACTW IWELCB [OPTION]

MNW2 INPUT FILE WITH TABFILE SUPPORT

๑. [\#TEXT]

0a. [TABFILE NTAB FILEIO TIMEOPTION]

[TABNAM TABLOCATION] READ NTAB TIMES IF NTAB>0

[Printoption NLNK] READ IF NTAB>0

[WELLID TABNAM TSFAC] READ NLNK TIMES IF NLNK>0

1. MNWMAX [NODTOT] IWL2CB MNWPRNT [OPTION]

2. WELLID NNODES

\section{GHB INPUT FILE WITH TABFILE SUPPORT}

0 . [\#TEXT]

1a. [PARAMETER NPGHB MXL]

1b. [TABFILE NTAB FILEIO TIMEOPTION]

[TABNAM TABLOCATION] READ NTAB TIMES IF NTAB>0

2. MXACTB IGHBCB [Option]

3. [PARNAM PARTYP Parval NLST [INSTANCES NUMINST]]

4a. [INSTNAM]

4b. [Layer Row Column Bhead Condfact [xyz] [TABNAM TSFAC]]

5. ITMP NP

6. Layer Row Column Bhead Cond [xyz] [TABNAM TSFAC]

7. [Pname [Iname]]

\section{EXPLANATION OF NEW INPUT VARIABLES}

TABFILE is a keyword that triggers reading subsequent tabfile information.

NTAB is the number of tabfiles that will be read.

FILIO is a flag that determines if the tabfile is loaded entirely into memory or if only the portion that pertains to the current timestep is read in. If FILEIO is set to 0 , then the entire tabfile is loaded into memory. If it is set to a nonzero value, then only the portion of the tabfile that pertains to the current time step is loaded into memory.

TIMEOPTION is a required flag that must be one of the two following keywords.

"SIMTIME", The keyword "SIMTIME" (without quotes) specifies that tabfile times use the model simulated time with time units specified by the DIS and a starting point of 0 . This is the default operation and will occur if TIMEOPTION is not specified.

"REALTIME", The keyword "REALTIME" (without quotes) specifies that tabfile times use decimal years that begin with the date specified in the DIS with the keyword "STARTTIME." IF STARTTIME is not specified in the DIS, then MODFLOW will raise an error message and stop the program. tabfile. 
Printoption is a required flag that must be one of the two following keywords.

"TABPRINT", The keyword "TABPRINT" (without quotes) will produce a detailed output of the tabfile information that is applied at each time step to the list file.

"TABNOPRINT", The keyword "TABNOPRINT" will not produce tabfile output to the list file.

NLNK is the number features that will be linked to a tabfile.

TSFAC is a feature's scale factor. This factor is multiplied with the tabfile value before it is applied to a feature.

Option is an optional list of character values.

"TABPRINT", The keyword "TABPRINT" (without quotes) will produce a detailed output of the tabfile information that is applied at each time step to the list file.

ISEG is the segment number that will have its flow overwritten with the tabfile TABNAM.

Layer is the layer number of the model cell that contains a feature linked to the tabfile TABNAM.

Row is the row number of the model cell that contains a feature linked to the tabfile TABNAM.

Column is the column number of the model cell that contains a feature linked to the tabfile TABNAM.

WELLID is the name of the MNW2 well that is linked to the tabfile TABNAM. 


\section{Appendix F. Selected Input and Output Files for Hypothetical Example}

The test problem illustrates basic and some of the new features of the selected processes and packages. Details of the test problem and results are discussed in the section titled "Example Problem." The entire example input problem is available with the model at the USGS web site (http://water.usgs.gov/software/lists/groundwater). The following data sets show the input data sets to help understand the discussion of the example problem structure, and selected results show how the new features allow the more detailed analysis of the hydrologic system. The explanation of files and input data variables are shown in a blue text after the each data entry. The example problem is distributed in two versions. The first is the example using the LPF/ PCG and MNW1 packages (OWHM_EX1a.nam), and the second uses NWT/UPW and MNW2 packages (OWHM_EX1b.nam). The following is the latter example, which also includes the use of tabfiles for GHB and SFR.

\section{Name File (NAM) Input Data Set}

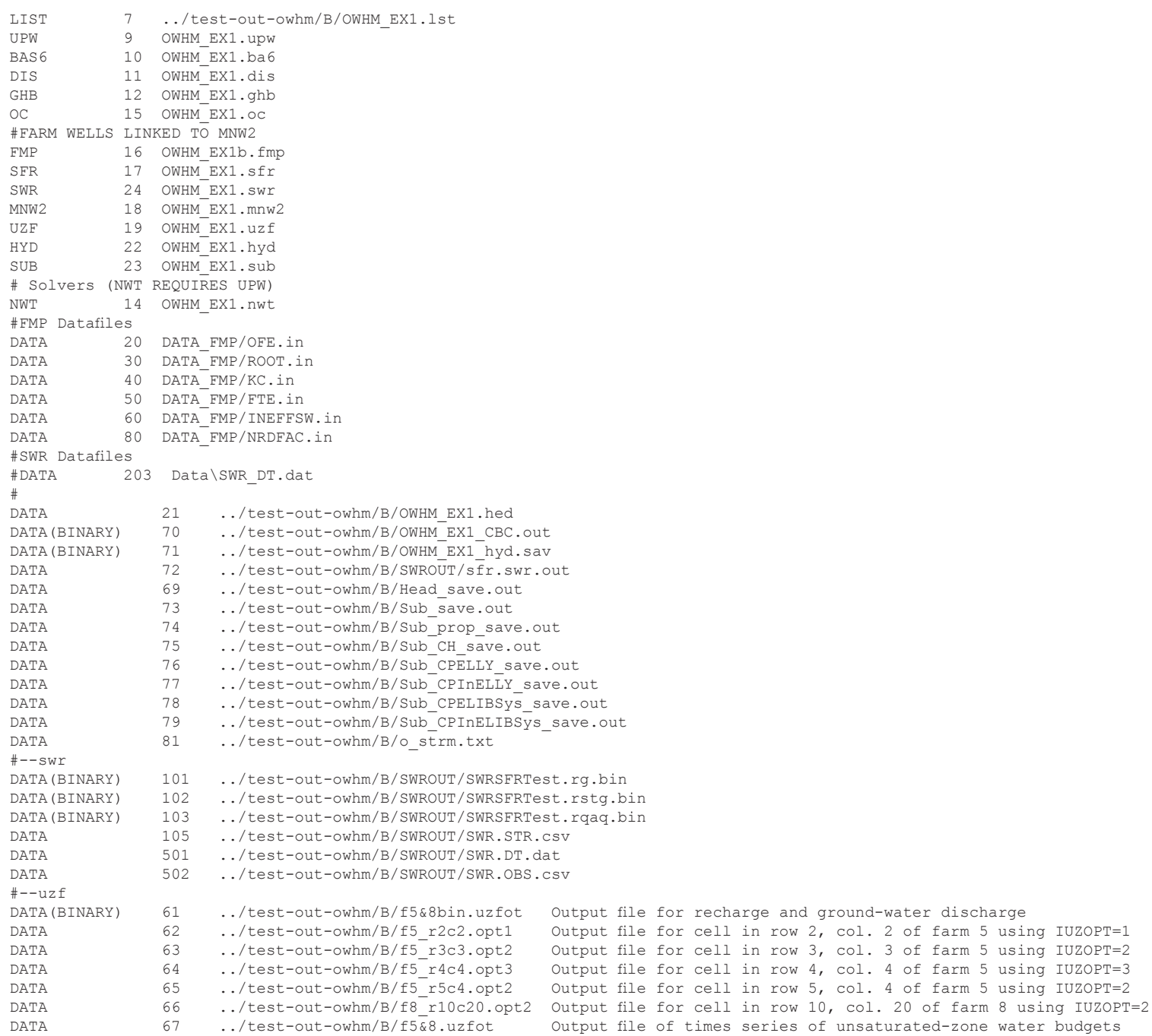

Basic (BAS) Package Input Data Set

\# example model 1

free MAXPARAM $1020 \quad 1$ PERCENTERROR 5

constant 1

constant 1

constant

constant 1

constant 1

constant 1

constant

$-999$ 


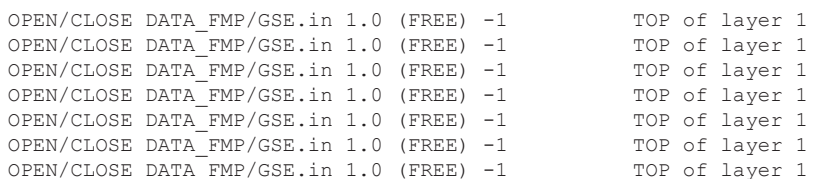

TOP of layer 1

TOP of layer 1

TOP of layer 1

TOP of layer 1

TOP of layer 1

TOP of layer 1

Discretization File (DIS) Input Data Set

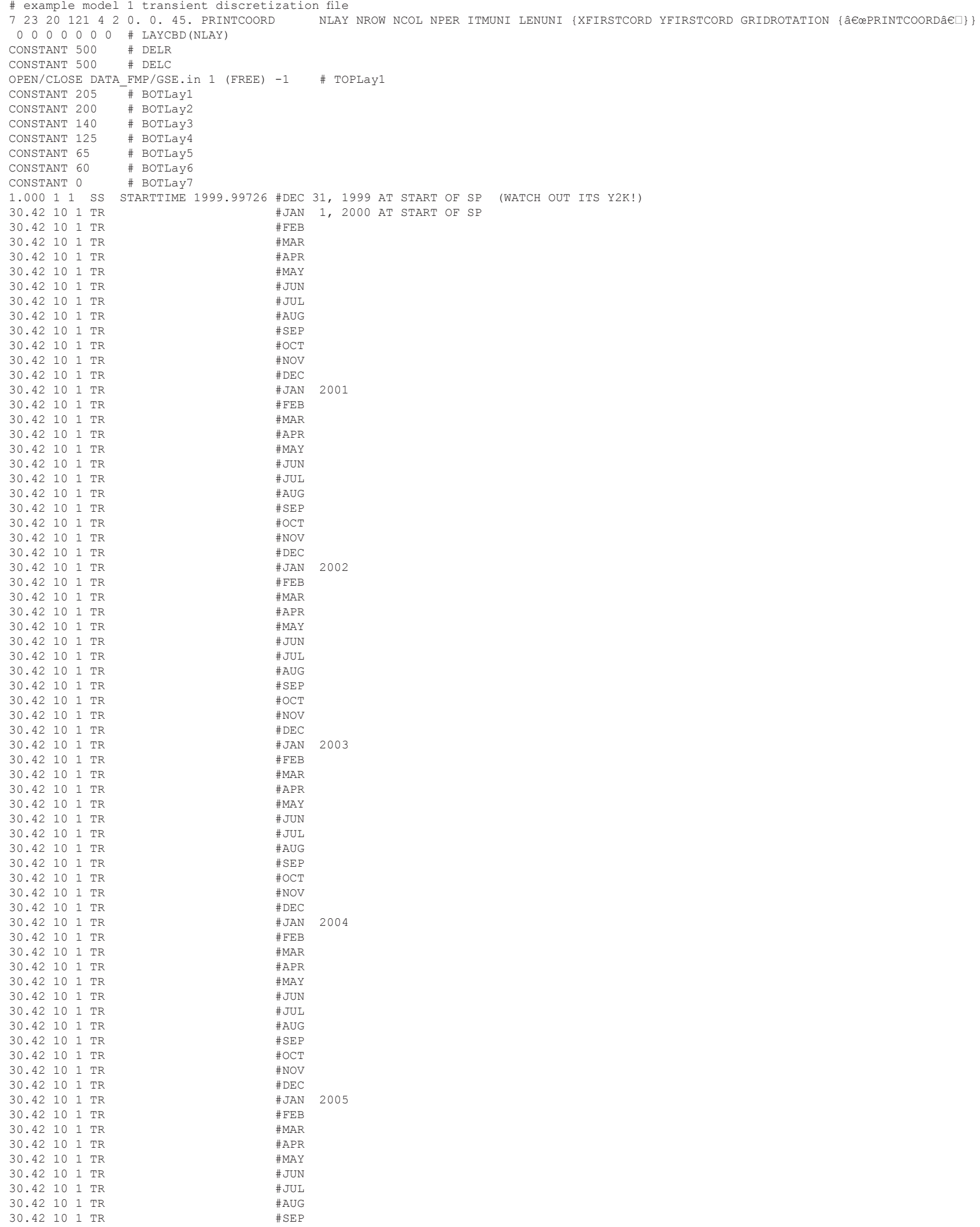

CONSTANT 125 \# BOTLaY4

$0.42101 \mathrm{TR}$

30.42101 TR

$30.42 \quad 101 \mathrm{TR}$
\#JAN 1,2000 AT START OF SP

\#UUN

$\#$ AUG

SEP

NOV

DEC

\# JUI

\#OCT

\#DEC

JAN 200

MAR

JUI

\#AUG

FEB

MAR

$\#$ SEP

$\#$ NOV 


\begin{tabular}{|c|c|c|c|c|}
\hline 30.42 & 101 & TR & $\# \mathrm{OCT}$ & \\
\hline 30.42 & 101 & $T R$ & \#NOV & \\
\hline 30.42 & 101 & TR & $\# \mathrm{DEC}$ & \\
\hline 30.42 & 101 & $T R$ & \# JAN & 2006 \\
\hline 30.42 & 101 & $\mathrm{TR}$ & $\# F E B$ & \\
\hline 30.42 & 101 & $T R$ & \#MAR & \\
\hline 30.42 & 101 & $T R$ & \#APR & \\
\hline 30.42 & 101 & $T R$ & \#MAY & \\
\hline 30.42 & 101 & $T R$ & \# JUN & \\
\hline 30.42 & 101 & $T R$ & \# JUL & \\
\hline 30.42 & 101 & $\mathrm{TR}$ & \#AUG & \\
\hline 30.42 & 101 & $T R$ & \#SEP & \\
\hline 30.42 & 101 & TR & \#OCT & \\
\hline 30.42 & 101 & $T R$ & \#NOV & \\
\hline 30.42 & 101 & $T R$ & \#DEC & \\
\hline 30.42 & 101 & TR & \# JAN & 2007 \\
\hline 30.42 & 101 & $T R$ & $\# \mathrm{FEB}$ & \\
\hline 30.42 & 101 & TR & \#MAR & \\
\hline 30.42 & 101 & $T R$ & $\# A P R$ & \\
\hline 30.42 & 101 & $T R$ & \#MAY & \\
\hline 30.42 & 101 & $\mathrm{TR}$ & \# JUN & \\
\hline 30.42 & 101 & TR & \#JUL & \\
\hline 30.42 & 101 & $\mathrm{TR}$ & \#AUG & \\
\hline 30.42 & 101 & $T R$ & \#SEP & \\
\hline 30.42 & 101 & $T R$ & $\# \mathrm{OCT}$ & \\
\hline 30.42 & 101 & $\mathrm{TR}$ & \#NOV & \\
\hline 30.42 & 101 & $T R$ & \#DEC & \\
\hline 30.42 & 101 & $T R$ & \# JAN & 2008 \\
\hline 30.42 & 101 & TR & $\# F E B$ & \\
\hline 30.42 & 101 & TR & \#MAR & \\
\hline 30.42 & 101 & $T R$ & \#APR & \\
\hline 30.42 & 101 & TR & \#MAY & \\
\hline 30.42 & 101 & TR & \# JUN & \\
\hline 30.42 & 101 & TR & \# JUL & \\
\hline 30.42 & 101 & TR & \#AUG & \\
\hline 30.42 & 101 & $T R$ & \#SEP & \\
\hline 30.42 & 101 & $\mathrm{TR}$ & \#OCT & \\
\hline 30.42 & 101 & $\mathrm{TR}$ & \#NOV & \\
\hline 30.42 & 101 & $\mathrm{TR}$ & \#DEC & \\
\hline 30.42 & 101 & TR & \# JAN & 2009 \\
\hline 30.42 & 101 & $T R$ & $\# \mathrm{FEB}$ & \\
\hline 30.42 & 101 & TR & \#MAR & \\
\hline 30.42 & 101 & $\mathrm{TR}$ & \#APR & \\
\hline 30.42 & 101 & TR & \#MAY & \\
\hline 30.42 & 101 & $\mathrm{TR}$ & \# JUN & \\
\hline 30.42 & 101 & TR & \#JUL & \\
\hline 30.42 & 101 & $\mathrm{TR}$ & \#AUG & \\
\hline 30.42 & 101 & TR & \#SEP & \\
\hline 30.42 & 101 & $T R$ & \#OCT & \\
\hline 30.42 & 101 & $\mathrm{TR}$ & \#NOV & \\
\hline 30.42 & 101 & קח & $\# D E C$ & 2009 \\
\hline
\end{tabular}

\section{Upstream Weighted Flow (UPW) Input Data Set}

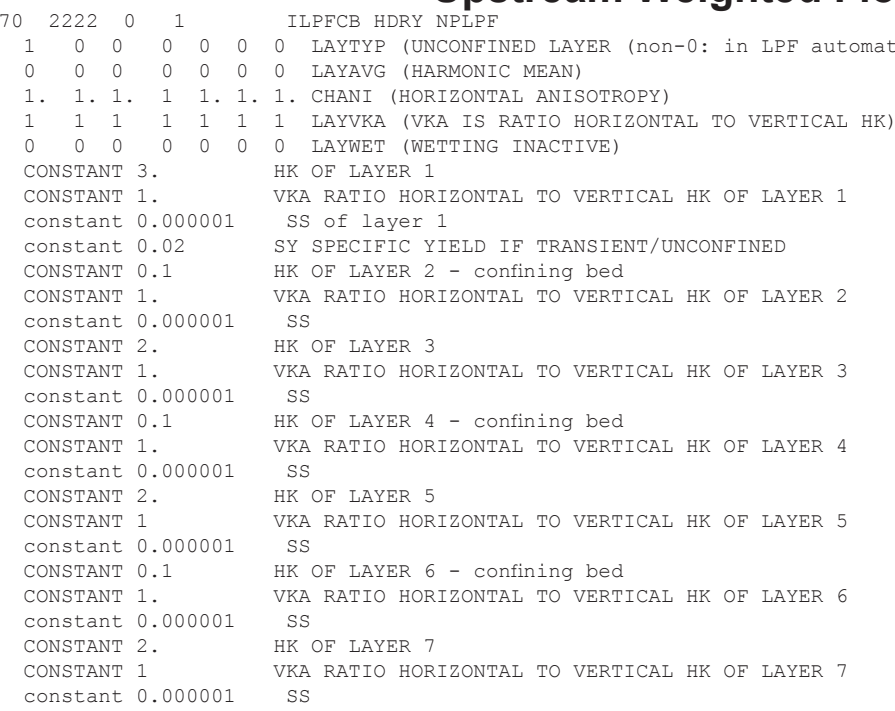

Newton-Raphson Package (NWT) Package Input Data Set 


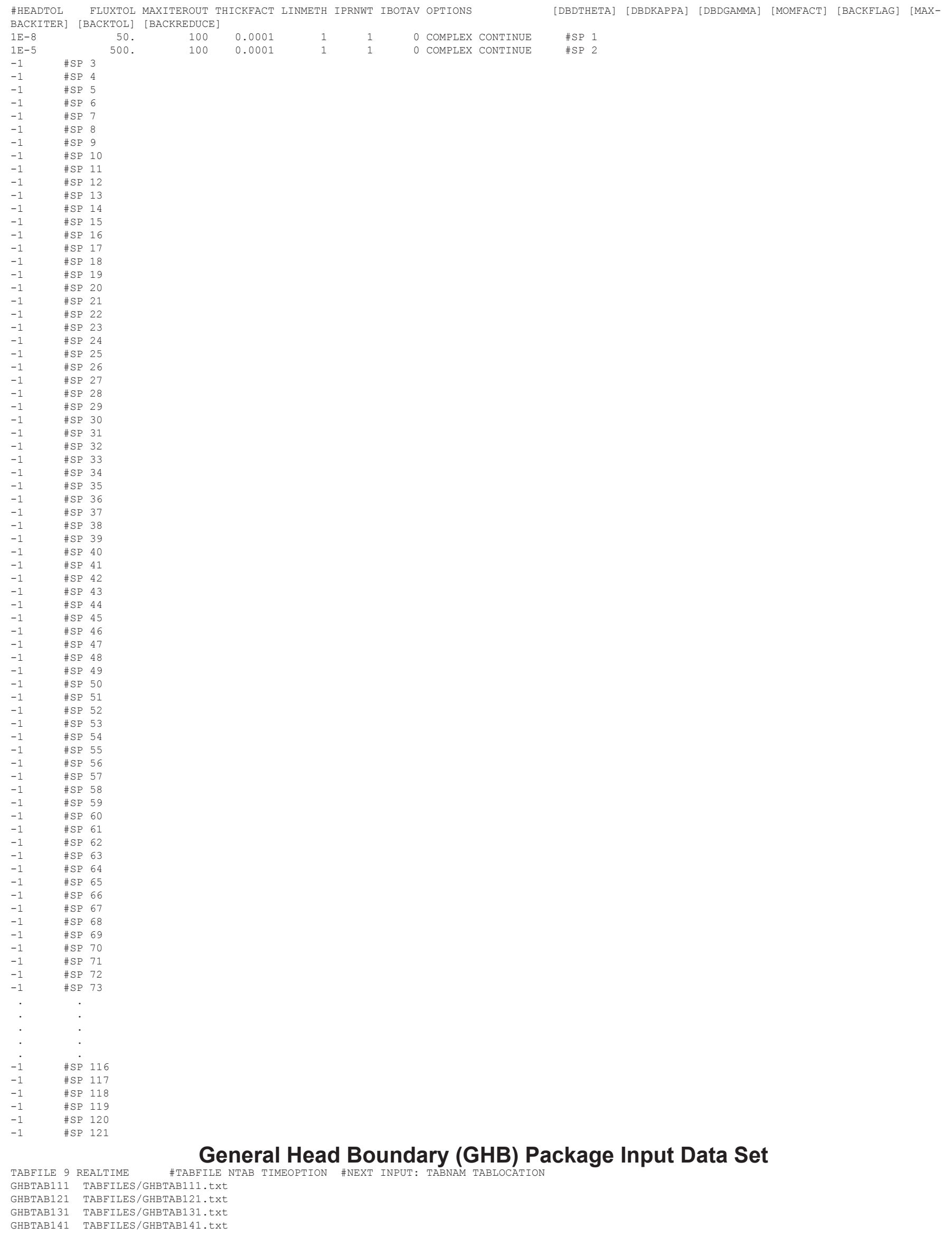




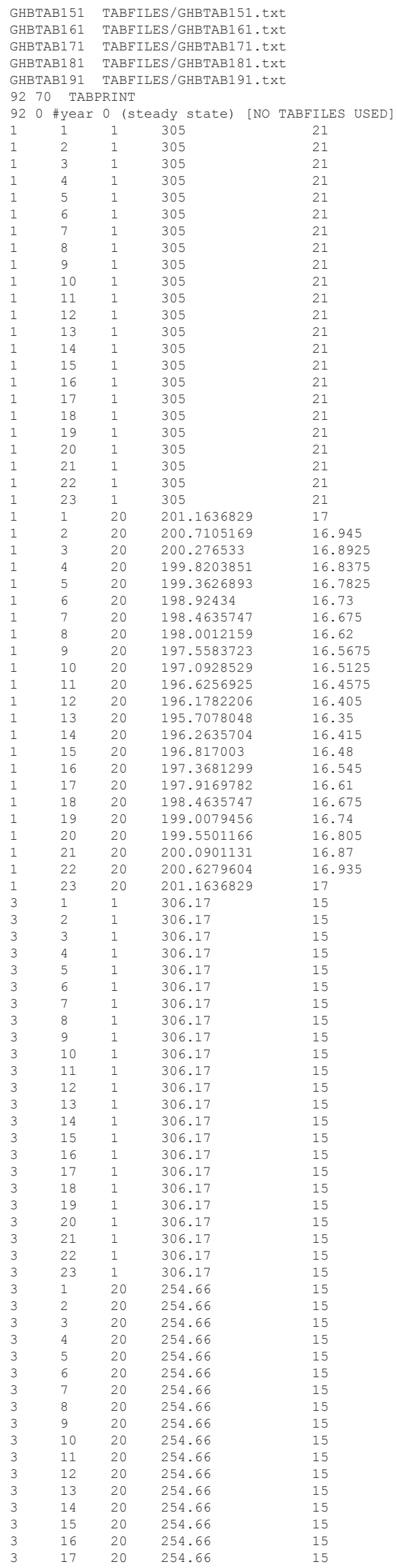




$\begin{array}{llll}3 & 18 & 20 & 254.66 \\ 3 & 19 & 20 & 254.66 \\ 3 & 20 & 20 & 254.66 \\ 3 & 21 & 20 & 254.66 \\ 3 & 22 & 20 & 254.66 \\ 3 & 23 & 20 & 254.66 \\ 92 & 0 \text { \#year 1 }\end{array}$

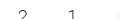

0.000000000

0.000000000

0.000000000

0.000000000

0.000000000

0.000000000

0.000000000

0.000000000

0.000000000

0.000000000

0.000000000

0.000000000

0.000000000

0.000000000

0.000000000

0.000000000

0.000000000

304.3952758

304.3992519

304.4019657

304.4033596

205.167688

204.9582686

$20 \quad 204.7638395$

204.5487402

204.3257061

204.0873661

203.8286009

203.6015144

$20 \quad 203.3076441$

$10 \quad 20 \quad 202.9939686$

$\begin{array}{lll}11 & 20 & 202.6377489\end{array}$

$\begin{array}{lll}11 & 20 & 202.2702928\end{array}$

$\begin{array}{lll}13 & 20 & 201.807234\end{array}$

$\begin{array}{lll}14 & 20 & 202.2677102\end{array}$

$\begin{array}{lll}15 & 20 & 202.6642159\end{array}$

$\begin{array}{lll}16 & 20 & 203.0038291\end{array}$

$\begin{array}{lll}17 & 20 & 203.3213229\end{array}$

$\begin{array}{lll}18 & 20 & 203.6415677\end{array}$

$\begin{array}{lll}19 & 20 & 203.8952134\end{array}$

$20 \quad 20 \quad 204.1821924$

$2120 \quad 204.4348358$

$\begin{array}{lll}22 & 20 & 204.69791\end{array}$

$23 \quad 20$

$1-1302.2657361$

$\begin{array}{ll}1 & 302.2657361 \\ 3 & 302.2784994\end{array}$

302.28567

302.2848847

302.2877949

302.2744833

302.2754238

302.2874815

302.2994306

302.3169208

302.3424724

302.3942571

302.4538365

302.3756783

302.3162486

302.266946

302.2281257

302.1961886

302.1747598

302.1567981

302.1431184

302.1340636

302.1295917

258.3704168

258.363224

258.3604795

258.3511039

258.3394437

258.3276315

258.2982173

258.2800906

258.2336985

258.1882693

258.1214402

258.0587532

257.9724078

0.000000000

0.000000000

$\begin{array}{lll}15 & 20 & 0.000000000 \\ 16 & 20 & 0.000000000\end{array}$

$1720 \quad 0.000000000$
15

15

15
15

15

22.3225

22.3325

22.34

22.3425
22.3425

.3425

2.335

22.335
22.34

22.3525

22.375

22.405

22.5425

22.4375

22.3725

22.3225

22.2825

22.25

22.225

22.205

22.19
22.18

22.175

17.95

17.9475

17.945

17.94

17.9325

17.92

17.905

17.895

17.87

17.84

17.8025

17.76

17.6975

17.7525

17.79

17.8175

17.84

17.86

17.8675

17.88

17.8875

17.895

17.9

22.315

22.325

22.3325

22.335

22.335

22.3275

22.3275

22.335

22.3475

22.3675

22.3975

22.445

22.5075

22.4275

22.365

22.315

22.275

22.2425

22.2175

22.1975

22.1825

22.1725

22.1675

17.9925

17.99

17.9875

17.9825

17.975

17.965

17.95

17.9375

17.9125

17.8825

17.845

17.805

17.755

17.7975

17.8325

17.86

17.8825

GHBTAB131

GHBTAB131

GHBTAB1 31

GHBTAB131
1.000000000 \#GHB CELL $\{1,1,1\}$ LINKED TO TABFILE GHBTAB111 AND BHEAD VALUE IS IGNORED

1.000000000

1.000000000

1.000000000

1.000000000

1.000000000

1.000000000

1.000000000

1.000000000

0.999972211747

0.999932746435

0.999928462777

0.999878836015

0.999931544921

0.999974761677

1.000005808458

1.000030422205

1.000076157857

\#SUBSEQUENT FILES NOT USING A TABFILE 


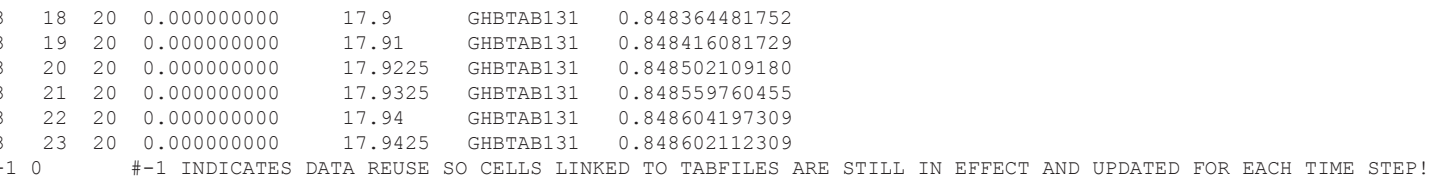


$\begin{array}{ll}-1 & 0 \\ -1 & 0\end{array}$

$\begin{array}{ll}-1 & 0 \\ -1 & 0\end{array}$

$\begin{array}{ll}-1 & 0 \\ -1 & 0\end{array}$

$\begin{array}{cc}-1 & 0 \\ -1 & 0\end{array}$

$\begin{array}{ll}-1 & 0 \\ -1 & 0\end{array}$

-10 \#year 9

$\begin{array}{lll}-1 & 0 \\ -1 & 0\end{array}$

$\begin{array}{cc}-1 & 0 \\ -1 & 0\end{array}$

$\begin{array}{ll}-1 & 0 \\ -1 & 0\end{array}$

$\begin{array}{llll}-1 & 0\end{array}$

$\begin{array}{ll}-1 & 0 \\ -1 & 0\end{array}$

$-110$

$\begin{array}{lll}-1 & 0 \\ -1 & 0 & 0\end{array}$

$\begin{array}{lll}-1 & 0 \\ -1 & 0\end{array}$

$\begin{array}{lll}-1 & 0 & \\ -1 & 0 & \text { \#year } 10\end{array}$

$\begin{array}{lll}-1 & 0 \\ -1 & 0\end{array}$

$-10$

$-1$

$-10$

$\begin{array}{cc}-1 & 0 \\ -1 & 0\end{array}$

$\begin{array}{lll}-1 & 0 \\ -1 & 0 & -1 \\ -1 & -1\end{array}$

$\begin{array}{ll}-1 & 0 \\ -1 & 0\end{array}$

$-10$

$\begin{array}{ll}-1 & 0 \\ -1 & 0\end{array}$

Streamflow Routing (SFR2) Package Input Data Set

\# Project 1 New Stream Aquifer Package TABFILE 4 SIMTIME

SFR_SEG_01 TABFILES/SFR_SEG_01.txt

SER_SEG_02 TABFILES/SFR_SEG_02.txt

SFR SEG ${ }^{-} 06$ TABFILES/SFR SEG ${ }^{-}$06.txt

SFR_SEG_12 TABFILES/SFR_SEG_12.txt

TABPRINT 7

SFR_SEG_01 10.0E0

\#Printoption NLNK

\#Printoption NLNK \$NEXTLINE: ISEG TABNAM TSFAC

SFR_SEG 02 1.0E0

SFR_SEG_06 1.0E0

SER SEG $12 \quad 0.0 \mathrm{E} 0$

10 SFR ${ }^{-}{ }^{-1}-12 \quad 0.0 E^{-12}$

SEG TABNAM TSFAC - TABFILE MULTIPLIED BY 1

SFR_SEG_-12 0.0E0

12 SER_SEG_12 $1.0 \mathrm{E} 0$

$104 \quad 15 \overline{0} \quad 0 \quad \overline{8} 6400 \quad 0.0001 \quad 708$

USED TO DEMONSTRATE SCALE, VALUE IS ALWAYS ZERO

\#USED TO DEMONSTRATE SCALE, VALUE IS ALWAYS ZERO

AUSED TO DEMONSTRATE SCALE, VALUE IS ALWAYS ZERO

$\begin{array}{lll}13 & 1 & 1 \\ 13 & 2 & 1 \\ 13 & 3 & 1 \\ 13 & 3 & 2 \\ 12 & 3 & 2 \\ 11 & 3 & 2 \\ 10 & 3 & 2 \\ 9 & 3 & 2 \\ 8 & 3 & 2 \\ 7 & 3 & 2 \\ 6 & 3 & 2 \\ 5 & 3 & 2 \\ 4 & 3 & 2 \\ 3 & 3 & 2 \\ 3 & 4 & 2 \\ 3 & 5 & 2 \\ 3 & 6 & 2 \\ 3 & 7 & 2 \\ 3 & 8 & 2 \\ 3 & 9 & 2 \\ 3 & 10 & 2 \\ 3 & 11 & 2 \\ 3 & 12 & 2 \\ 4 & 12 & 2 \\ 5 & 12 & 2 \\ 6 & 12 & 2 \\ 7 & 12 & 2 \\ 8 & 12 & 2 \\ 9 & 12 & 2 \\ 10 & 12 & 2 \\ 10 & 7 & 3 \\ 10 & 8 & 3 \\ 10 & 9 & 3 \\ 10 & 10 & 3 \\ 10 & 11 & 3 \\ 10 & 12 & 3 \\ 10 & 12 & 4 \\ 11 & 12 & 4 \\ 12 & 12 & 4 \\ 13 & 12 & 4 \\ 13 & 3 & 5 \\ 13 & 4 & 5 \\ 13 & 5 & 5 \\ 13 & 5 & 6 \\ & 5 & \end{array}$

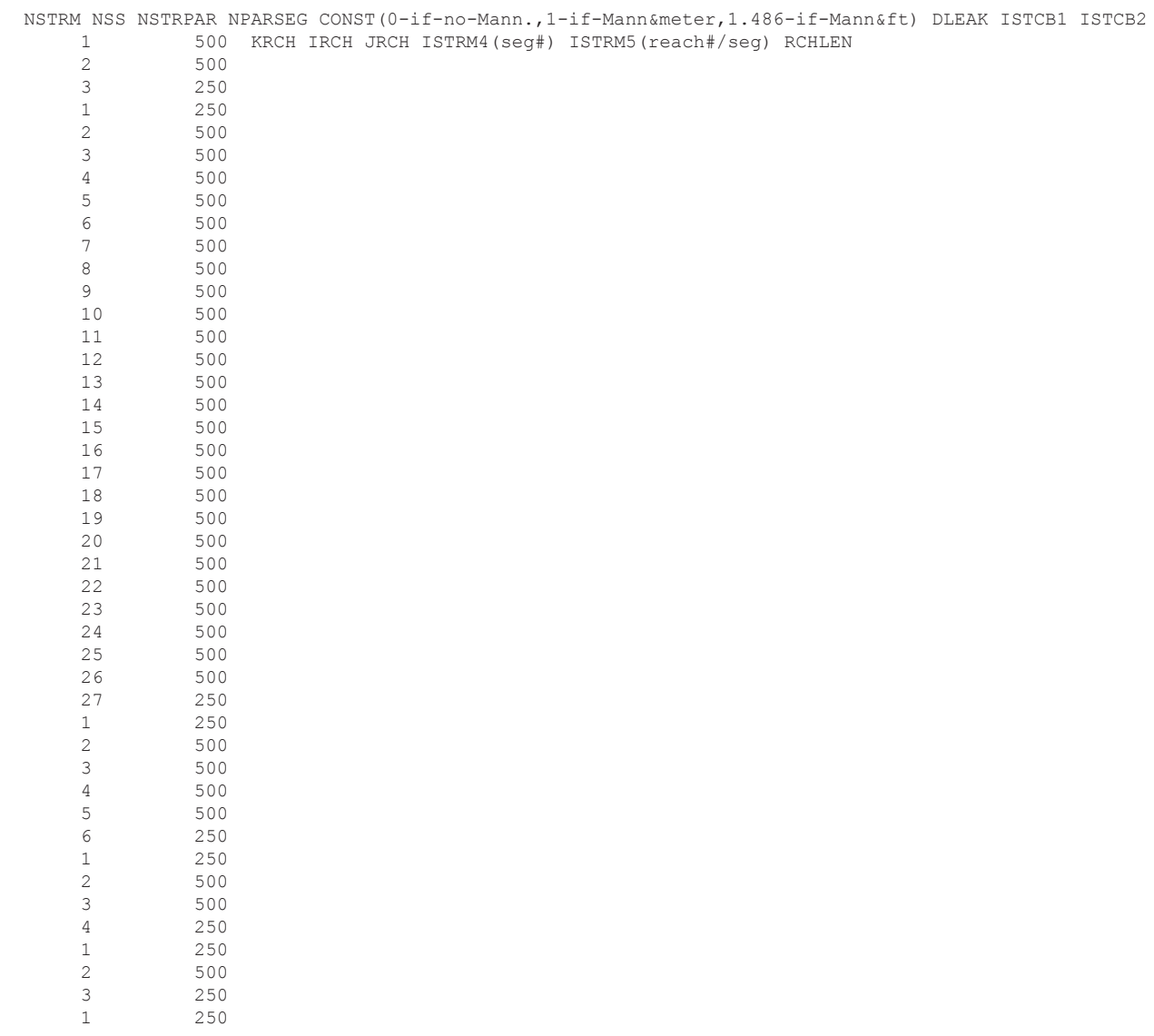



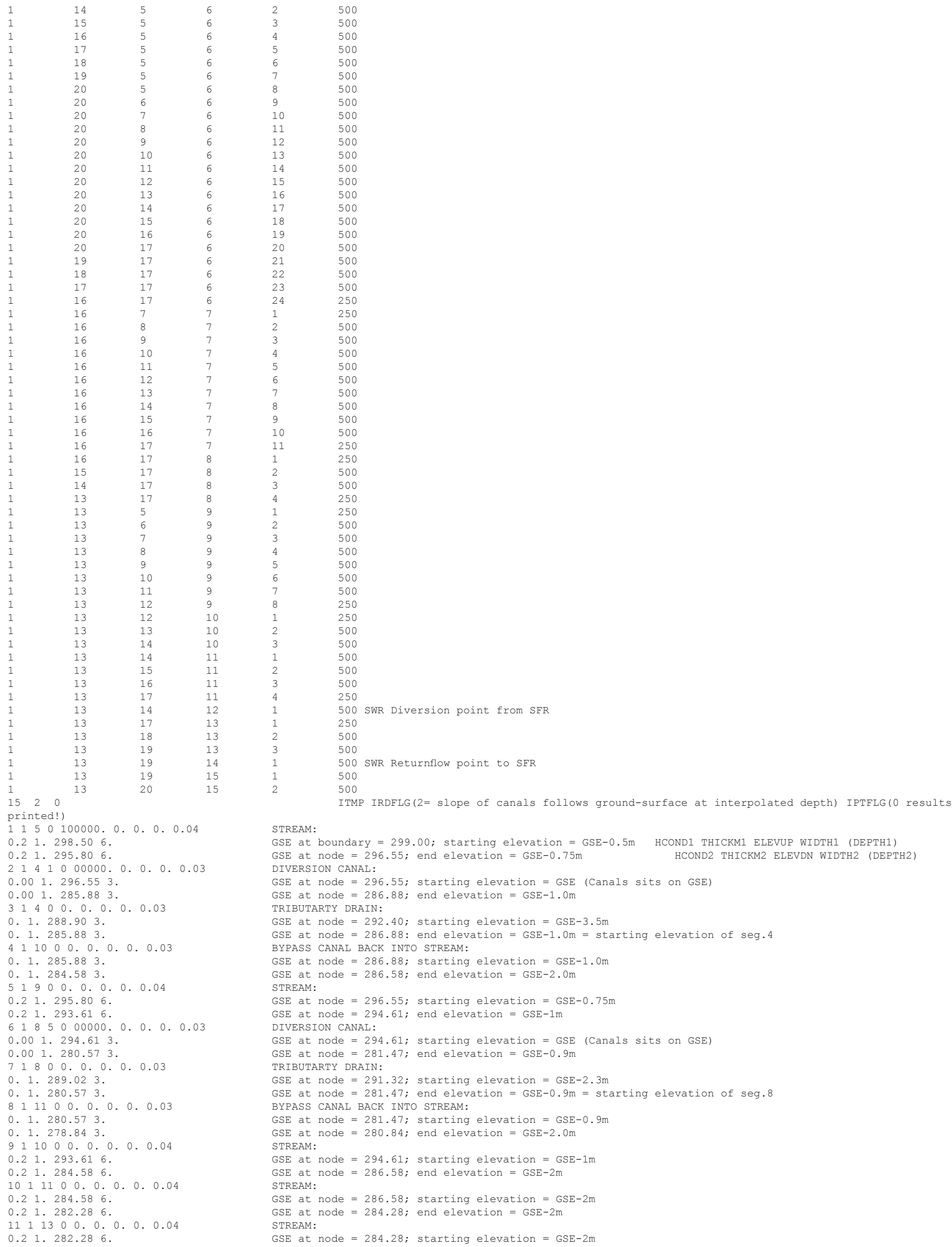


\section{$98 \quad$ One-Water Hydrologic Flow Model}

$0.21 .278 .846 .0 .0 .04 \quad$ GSE at boundary $=280.84$; end elevation $=$ GSE- $2 \mathrm{~m}$

12113110100000.0 .0 .0 .0 .04 DIVERSION Connection to SWR Inflow: (Part 6a) NSEG, ICALC, OUTSEG, IUPSEG, IPRIOR, FLOW, RUNOFF, ETSW, PPTSW **diversion(Part 6a) NSEG, ICALC, OUTSEG, IUPSEG, IPRIOR, FLOW, RUNOFF, ETSW, PPTSW **diversion(Part 6a) NSEG, ICALC, OUTSEG, IUPSEG, IPRIOR, FLOW, RUNOFF, ETSW, PPTSW **diversion

0.21 .282 .286 .

GSE at node $=284.28$; starting elevation $=$ GSE- $2 \mathrm{~m}$

.21 .281 .28 6. GSE at node $=284.28$; end elevation $=$ GSE $-3.0 \mathrm{~m}$ 1311500.0 .0 .0 .0 .04 STREAM:

0.21 .278 .846$.

0.21 .276 .556$.

$\begin{array}{llllllll}14 & 15 & 0 & 0.0 .0 .0 .0 & 0.04\end{array}$

0.21 .277 .556$.

0.21 .276 .556

$\begin{array}{lllllllllll}15 & 1 & 0 & 0 & 0.0 .0 .0 .0 .04\end{array}$

0.21 .276 .556$.

0.21 .275 .406$.

$\begin{array}{lll}15 & 2 & 0\end{array}$

printed!)

1150100000 . 0. 0. 0.0.04

0.21 .298 .506$.

0.21 .295 .806 .

2141010000.0 .0 .0 .0 .03

0.011 .296 .553$.

0.011 .285 .883$.

31400.0 .0 .0 .0 .03

1. 1. 288.903.

1. 1. 285.883 .

$\begin{array}{lllllllll}4 & 1 & 10 & 0 & 0.0 .0 .0 .0 .03\end{array}$

1. 1. 285.883.

0.21 .284 .583$.

$\begin{array}{lllllll}5 & 1 & 9 & 0 & 0.0 .0 .0 .0 .0 .04\end{array}$

0.21 .295 .806$.

0.21 .293 .616 .

6185010000.0 .0 .0 .0 .03

0.011 .294 .613$.

0.011 .280 .573$.

$\begin{array}{llllllll}7 & 1 & 8 & 0 & 0.0 .0 .0 .0 & 0.03\end{array}$

1. 1. 289.023.

1. 11100.0 .0 .0 .0 .03

1. 1. 280.573.

0.21 .278 .843

911000.0 .0 .0 .0 .04

0.21 .293 .616

0.21 .284 .586$.

$\begin{array}{llllllllll}10111 & 0 & 0.0 .0 .0 .0 .04\end{array}$

0.21 .284 .586

0.21 .282 .286$.

$\begin{array}{llllll}11 & 1 & 13 & 0 & 0.0 .0 .0 .0 .0 .04\end{array}$

0.21 .282 .286$.

0.21 .278 .846

12113110100000.0 .0 .0 .0 .04

GSE at node $=280.84 ;$ starting elevation $=$ GSE $-2 \mathrm{~m}$

GSE at boundary $=278.55$; end elevation $=$ GSE- $2 \mathrm{~m}$

DIVERSION Connection from SWR Outflow:

GSE at node $=278.55$; starting elevation $=$ GSE-1.0m

GSE at node $=278.55$; end elevation $=$ GSE-2.0m

STREAM:

GSE at node $=278.55 ;$ starting elevation $=$ GSE- $2 \mathrm{~m}$

GSE at boundary $=277.4$; end elevation $=$ GSE- $2 \mathrm{~m}$

ITMP IRDFLG $(2=$ slope of canals follows ground-surface at interpolated depth) IPTFLG $(0$ results

STREAM:

GSE at boundary $=299.00$; starting elevation $=$ GSE-0.5m HCOND1 THICKM1 ELEVUP WIDTH1 (DEPTH1)

GSE at node $=296.55$; end elevation $=$ GSE-0.75m

DIVERSION CANAI:

GSE at node $=296.55 ;$ starting elevation $=$ GSE (Canals sits on GSE)

GSE at node $=286.88$; end elevation $=$ GSE-1.0m

TRIBUTARTY DRAIN:

GSE at node $=292.40$; starting elevation $=$ GSE-3.5m

$\mathrm{GSE}$ at node $=286.88$ : end elevation $=\mathrm{GSE}-1.0 \mathrm{~m}=$ starting elevation of seg. 4

BYPASS CANAL BACK INTO STREAM:

GSE at node $=286.88$; starting elevation $=$ GSE-1.0

GSE at node $=286.58$; end elevation $=$ GSE-2.0m

STREAM:

GSE at node $=296.55 ;$ starting elevation $=$ GSE $-0.75 \mathrm{~m}$

GSE at node $=294.61$; end elevation $=$ GSE-1m

DIVERSION CANAL:

GSE at node $=294.61$; starting elevation $=$ GSE (Canals sits on GSE)

GSE at node $=281.47$; end elevation $=$ GSE-0.9m

TRIBUTARTY DRAIN:

GSE at node $=291.32$; starting elevation $=\mathrm{GSE}-2.3 \mathrm{~m}$

GSE at node $=281.47$; end elevation $=$ GSE-0.9m $=$ starting elevation of seg. 8

BYPASS CANAL BACK INTO STREAM:

GSE at node $=281.47$; starting elevation $=$ GSE-0.9m

GSE at node $=280.84$; end elevation $=$ GSE-2.0m

STREAM:

GSE at node $=294.61 ;$ starting elevation $=$ GSE-1m

GSE at node $=286.58$; end elevation $=\mathrm{GSE}-2 \mathrm{~m}$

STREAM:

GSE at node $=286.58$; starting elevation $=$ GSE- $2 \mathrm{~m}$

GSE at node $=284.28$; end elevation $=$ GSE $-2 \mathrm{~m}$

STREAM:

GSE at node $=284.28$; starting elevation $=$ GSE- $2 \mathrm{~m}$

GSE at boundary $=280.84$; end elevation $=\mathrm{GSE}-2 \mathrm{~m}$

DIVERSION Connection to SWR Inflow:

GSE at node $=284.28$; starting elevation $=$ GSE $-2 \mathrm{~m}$

GSE at node $=284.28$; end elevation $=$ GSE $-3.0 \mathrm{~m}$

STREAM:

GSE at node $=280.84 ;$ starting elevation $=$ GSE $-2 \mathrm{~m}$

GSE at boundary $=278.55$; end elevation $=$ GSE- $2 \mathrm{~m}$

DIVERSION Connection from SWR Outflow:

GSE at node $=278.55$; starting elevation $=$ GSE $-1.0 \mathrm{~m}$

GSE at node $=278.55$; end elevation $=$ GSE-2.0

STREAM:

GSE at node $=278.55$; starting elevation $=$ GSE $-2 \mathrm{~m}$

GSE at boundary $=277.4$; end elevation $=$ GSE- $2 \mathrm{~m}$

0.21 .276 .556

0.21 .275 .406$.

$\begin{array}{lll}-1 & 2 & 0\end{array}$

$\begin{array}{lll}-1 & 2 & 0\end{array}$

$\begin{array}{ccc}-1 & 2 & 0 \\ -1 & 2 & 0\end{array}$

$\begin{array}{lll}-1 & 2 & 0 \\ -1 & 2 & 0\end{array}$

$\begin{array}{lll}-1 & 2 & 0\end{array}$

$\begin{array}{llllll}-1 & 2 & 0\end{array}$

$\begin{array}{lll}-1 & 2 & 0\end{array}$

$\begin{array}{lll}-1 & 2 & 0\end{array}$

$\begin{array}{lllll}-1 & 2 & 0 & -1 & -1\end{array}$

$-1122$

$\begin{array}{ccc}-1 & 2 & 0 \\ 15 & 2 & 0\end{array}$

printed!)

$115050000 \cdot 0 \cdot 0.0 .0 .04$

0.21 .298 .506$.

0.21 .295 .806 .

2144108000.0 .0 .0 .0 .03

0.011 .296 .553$.

0.01 1. 285.883.

$\begin{array}{lllllll}3 & 1 & 4 & 0 & 0.0 .0 .0 .0 & 0.03\end{array}$

1. 1. 288.903 .

1.1 .285 .883$.

$\begin{array}{llllll}4 & 10 & 0 & 0.0 .0 .0 .0 .0 .03\end{array}$

1. 1. 285.883.

0.21 .284 .583$.

$\begin{array}{lllllll}5 & 1 & 9 & 0 & 0.00 & 0.0 .0 .04\end{array}$

0.21 .295 .806$.

0.21 .293 .616$.

618508000.0 .0 .0 .0 .03

0.011 .294 .613$.

0.01 1. 280.573.

ITMP IRDFLG( $2=$ slope of canals follows ground-surface at interpolated depth) IPTFLG(0 results

STREAM:

GSE at boundary $=299.00$; starting elevation $=$ GSE-0.5m HCOND1 THICKM1 ELEVUP WIDTH1 (DEPTH1)

GSE at node $=296.55$, end elevation $=$ GSE $-0.75 \mathrm{~m}$

HCOND2 THICKM2 EITEVN WTITH2 (DEPTH2)

DIVERSION CANAL:

GSE at node $=296.55$; starting elevation $=$ GSE (Canals sits on GSE)

GSE at node $=286.88$; end elevation $=$ GSE-1.0m

TRIBUTARTY DRAIN:

GSE at node $=292.40$; starting elevation $=$ GSE-3.5m

GSE at node $=286.88$ : end elevation $=$ GSE-1.0m $=$ starting elevation of seg. 4

BYPASS CANAL BACK INTO STREAM:

GSE at node $=286.88 ;$ starting elevation $=$ GSE $-1.0 \mathrm{~m}$

GSE at node $=286.58$; end elevation $=\mathrm{GSE}-2.0 \mathrm{~m}$

STREAM:

GSE at node $=296.55$; starting elevation $=$ GSE $-0.75 \mathrm{~m}$

GSE at node $=294.61$; end elevation $=$ GSE-1m

DIVERSION CANAL:

GSE at node $=294.61$; starting elevation $=$ GSE (Canals sits on GSE)

GSE at node $=281.47$; end elevation $=$ GSE-0.9m 


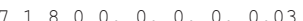

1. 1.289 .023

1. 1.280 .573 .

811100.0 .0 .0 .0 .03

1. 1. 280.573.

0.21 .278 .843

91110000.0 .0 .0 .0 .04

0.21 .293 .616$.

0.21 .284 .586 .

$\begin{array}{llllllllll}0 & 1 & 11 & 0 & 0.0 .0 .0 .0 .04\end{array}$

0.21 .284 .586$.

0.21 .282 .286$.

$\begin{array}{lllllllllll}11 & 1 & 13 & 0 & 0.0 .0 .0 .0 .04\end{array}$

0.21 .282 .286$.

0.21 .278 .846$.

121131100100000.0 .0 .0 .0 .04

0.21 .282 .286$.

0.21 .281 .286$.

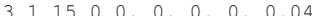

0.21 .278 .846$.

0.21 .276 .556$.

$\begin{array}{lllllllll}14 & 1 & 15 & 0 & 0.0 & 0.0 .0 .0 .04\end{array}$

0.21 .277 .556$.

0.21 .276 .556$.

$\begin{array}{llllllllll}5 & 1 & 0 & 0 & 0 & 0 & 0 & 0.0 & 0.04\end{array}$

0.21 .276 .556$.

$0.21,275.406$

$\begin{array}{llll}-1 & 2 & 0\end{array}$

$-12$

$\begin{array}{lll}-1 & 2 & 0 \\ -1 & 2 & 0\end{array}$

$\begin{array}{lll}-1 & 2 & 0\end{array}$

$\begin{array}{llll}-1 & 2 & 0\end{array}$

122

$\begin{array}{lll}-1 & 2 & 0\end{array}$

$\begin{array}{lll}-1 & 2 & 0\end{array}$

$\begin{array}{lll}-1 & 2 & 0\end{array}$

\section{Surface-Water Routing (SWR1) Process Input Data Set}

SURFACE WATER ROUTING (SWR1)

TITIE -

\# DATASET 1 - DIMENSIONS AND PRELIMINARIES

NREACHES ISWRONLY ILPRCBC ILPRPFL ILPRSTG ILPRBFL ISWRPOM ISWRPSTR ISWRERN OptiOn

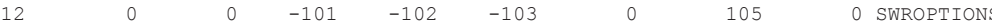

\# DATASET 1B - SWR1 OPTIONS

RINT SWR TO SCREEN

SAVE_SWRDT $5 \overline{0} 1$

SAVE AVERAGE RESULTS

SAVE SWROBSERVATIONS 502

USE NONCONVERGENCE CONTINUE

USE UPSTREAM_WEIGHTING

END

\# DATASET 2 - SOLUtion CONTROLS

\#DLENCONV TIMECONV RTINI RTMIN RTMAX

$3.042 e-4=3.042 e-1$

$.0 .86400 \cdot 0.015120$

0.090900

\# dataset 3 - solver parameters

\# SOLVER NOUTER NINNER IBT TOLS TOLR

$\begin{array}{rrrrrr}1 & 100 & 50 & 10 & 1.0 \mathrm{E}-03 & 5000.000 \\ 2 & 50 & 100 & 10 & 1.0 \mathrm{E}-03 & 86400.000\end{array}$

\# DATASET 4A - REACH LOCATIONS * LAY ROW IREACH IEQN IRGNUM LAY ROW COL

$\begin{array}{lllll}\text { \#IREACH } & \text { IEQN } & \text { IRGNUM } & \text { KRCH } & \text { IRCH } \\ 1 & 3 & 1 & 1 & 12 \\ 2 & 3 & 2 & 1 & 11 \\ 3 & 3 & 3 & 1 & 10 \\ 4 & 3 & 4 & 1 & 09 \\ 5 & 3 & 5 & 1 & 08 \\ 6 & 3 & 6 & 1 & 08 \\ 7 & 3 & 7 & 1 & 08 \\ 8 & 3 & 8 & 1 & 08 \\ 9 & 3 & 9 & 1 & 09 \\ 10 & 3 & 10 & 1 & 10 \\ 11 & 3 & 11 & 1 & 11 \\ 12 & 3 & 12 & 1 & 12\end{array}$

\# DATASET 4B - REACH CONNECTIVITY

IREACH NCONN ICONN1 ICONN2

$\begin{array}{llll}1 & 1 & 2 & \\ 2 & 2 & 1 & 3 \\ 3 & 2 & 2 & 4 \\ 4 & 2 & 3 & 5 \\ 5 & 2 & 4 & 6 \\ 6 & 2 & 5 & 7 \\ 7 & 2 & 6 & 8 \\ 8 & 2 & 7 & 9 \\ 9 & 2 & 8 & 10\end{array}$

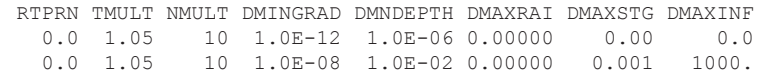

PTOLR TOLA DAMPSS DAMPTR IPRSWR MUTSWR IPC NLEVELS DROPTOL IBTPRT $\begin{array}{lllll}0.00 & 1.00 & 1.00 & 0 & 3 \\ 0.00 & 1.00 & 1.00 & 0 & 3\end{array}$
500.0000

500.0000

500.0000

603.5534

603.5534

500.0000

500.0000

603.5534

603.5534

500.0000

500.0000

500.0000
TY DRATN

GSE at node $=281.47$; end elevation $=$ GSE-0.9m $=$ starting elevation of seg. 8

$=281.47$; starting elevation $=\mathrm{GSE}-0.9 \mathrm{~m}$

at node $=294.61 ;$ starting elevation $=\mathrm{GSE}-1 \mathrm{n}$

at node $=286.58 ;$ starting elevation $=$ GSE $-2 \mathrm{~m}$

te $284.28 ;$ starting elevation $=\mathrm{GSE}-2 \mathrm{~m}$

at node $=278.55 ;$ starting elevation $=$ GSE $-2 \mathrm{n}$ 


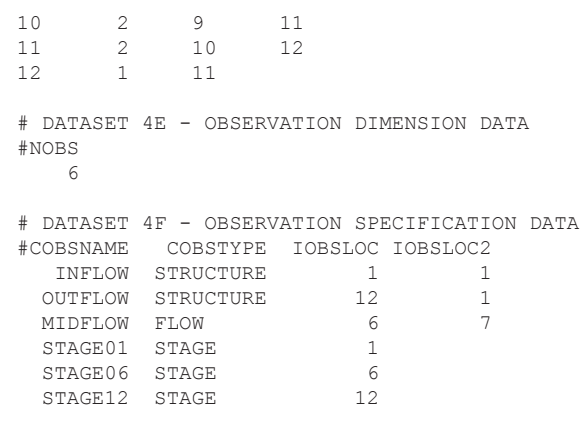

\# DATASET 5 - STRESS PERIOD 1 - STEADY STATE

\# ITMP IRDBND IRDRAI IRDEVP IRDLIN IRDGEO IRDSTR IRDSTG IPTELG

\# DATASET 6 - boundary DAtA

\# IBNDRCH ISWRBND

$1-1$

$2-1$

$-1$

$-1$

$-1$

-1
-1

-1
-1

$-1$

$-1$

$-1$

\# DATASET 7A - RAINFALL DATA

\# DATASET 8B - EVAPORATION DATA

\# dataset 9A - LAteral InfLOW DAta

\# DATASET 10 - GEOMETRY ASSIGNMENT DATA

\# DATASET 8A

\#IGMODRCH IGEONUM GZSHIFT

$\begin{array}{lll}1 & 1 & -0.1955\end{array}$

$\begin{array}{lll}2 & 1 & -0.5866\end{array}$

$\begin{array}{lll}5 & 1 & -1.4093 \\ 6 & 1 & -1.8814\end{array}$

$6 \quad 1$

$\begin{array}{lll}7 & 1 & -2.7041\end{array}$

$\begin{array}{lll}8 & 1 & -3.1357\end{array}$

$10-1$

$\begin{array}{lll}10 & 1 & -4.0394 \\ 11 & 1 & -4.4305\end{array}$

$\begin{array}{lll}12 & 1 & -4.8216\end{array}$

\# DATASET 11A - GEOMETRY DATA

\begin{tabular}{|c|c|c|c|c|c|c|c|c|c|}
\hline $\begin{array}{l}\text { IGEONUM I } \\
1\end{array}$ & $\begin{array}{rr}\text { IGEOTYPE } & \text { IGLKOPT } \\
1 & 1\end{array}$ & $\begin{array}{r}\text { GMANNING } \\
0.040\end{array}$ & NGEOPTS & $\begin{array}{r}\text { GWIDTH } \\
6.000000\end{array}$ & $\begin{array}{r}\text { GBELEV } \\
281.7100\end{array}$ & GSSLOPE & GCOND & $\begin{array}{r}\text { GLK } \\
0.001\end{array}$ & GLKLEN GLKFACT GETEXTD \\
\hline
\end{tabular}

\# DATASET 12 - STRUCtURE ASSignMent DATA

\#ISMODRCH NSTRUCT

$01 \quad 1 \quad$ \#SWR INFLOW FROM SFR

\# DATASET 13A

\#ISTRRCH ISTRNUM ISTRCONN ISTRTYPE NSTRPTS STRCD STRCD2 STRCD3 STRINV STRINV2 STRWID STRWID2 STRLEN STRLEN2 STRMAN STRVAL ISTRDIR ISFRSEG ISFRRCH

$\begin{array}{llll}01 & 1 & 0\end{array}$

\#SFR inflow structure

\# $\begin{array}{cccc}\text { \#fixed-crest weir } & & & \\ & 12 & 1 & 0\end{array}$

1 \#fixed-crest weir

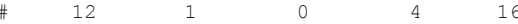

1 \#stage-discharge structure

\#open/close stage-discharge.dat

\# $12 \quad 1000-2$

1 \#zero-depth gradient boundary

\# DATASET 14A - REACH StAge DATA

INTERNAL

\# REACH

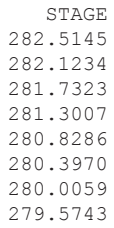

$\begin{array}{ll}0.5276 .889 & 4.572\end{array}$

0.5276 .889

5.5

0.1524

12

0.61

0.5276 .889

0.10

14

276.6929

500.0 


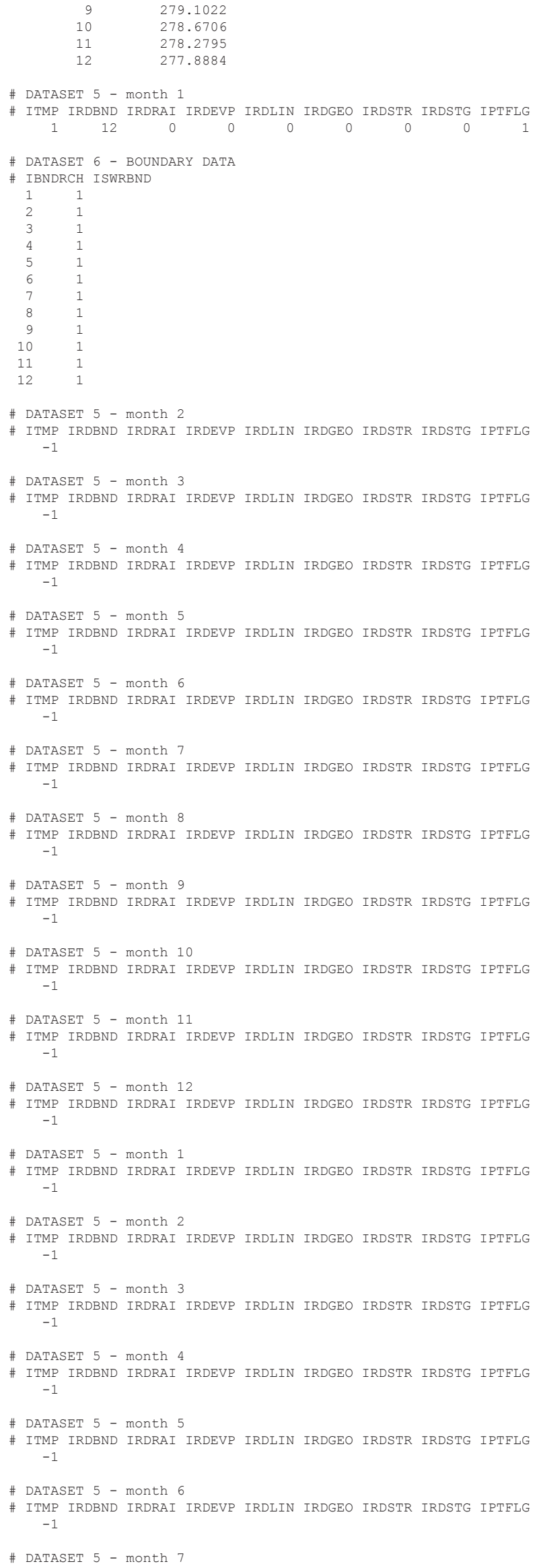


\# ITMP IRDBND IRDRAI IRDEVP IRDLIN IRDGEO IRDSTR IRDSTG IPTFLG $-1$

\# DATASET 5 - month 8

\# ITMP IRDBND IRDRAI IRDEVP IRDLIN IRDGEO IRDSTR IRDSTG IPTFLG

\# DATASET 5 - month 9

\# ITMP IRDBND IRDRAI IRDEVP IRDLIN IRDGEO IRDSTR IRDSTG IPTELG

* DATASET 5 - month 10

\# ITMP IRDBND IRDRAI IRDEVP IRDLIN IRDGEO IRDSTR IRDSTG IPTFLG $-1$

\# DATASET 5 - month 11

\# ITMP IRDBND IRDRAI IRDEVP IRDLIN IRDGEO IRDSTR IRDSTG IPTELG

\# DATASET 5 - month 12

\# ITMP IRDBND IRDRAI IRDEVP IRDLIN IRDGEO IRDSTR IRDSTG IPTFLG $-1$

\# DATASET 5 - month 1

\# ITMP IRDBND IRDRAI IRDEVP IRDLIN IRDGEO IRDSTR IRDSTG IPTFLG

\# DATASET 5 - month 2

\# ITMP IRDBND IRDRAI IRDEVP IRDLIN IRDGEO IRDSTR IRDSTG IPTELG

\# DATASET 5 - month 3

\# ITMP IRDBND IRDRAI IRDEVP IRDLIN IRDGEO IRDSTR IRDSTG IPTFLG $-1$

\# DATASET 5 - month 4

\# ITMP IRDBND IRDRAI IRDEVP IRDLIN IRDGEO IRDSTR IRDSTG IPTFLG

\# DATASET 5 - month 5

\# ITMP IRDBND IRDRAI IRDEVP IRDLIN IRDGEO IRDSTR IRDSTG IPTFLG $-1$

\# DATASET 5 - month 6

\# ITMP IRDBND IRDRAI IRDEVP IRDLIN IRDGEO IRDSTR IRDSTG IPTFLG

\# DATASET 5 - month 7

\# ITMP IRDBND IRDRAI IRDEVP IRDLIN IRDGEO IRDSTR IRDSTG IPTELG

\# DATASET 5 - month 8

\# ITMP IRDBND IRDRAI IRDEVP IRDLIN IRDGEO IRDSTR IRDSTG IPTFLG $-1$

\# DATASET 5 - month 9

\# ITMP IRDBND IRDRAI IRDEVP IRDLIN IRDGEO IRDSTR IRDSTG IPTFLG

\# DATASET 5 - month 10

\# ITMP IRDBND IRDRAI IRDEVP IRDLIN IRDGEO IRDSTR IRDSTG IPTELG

* DATASET 5 - month 11

\# ITMP IRDBND IRDRAI IRDEVP IRDLIN IRDGEO IRDSTR IRDSTG IPTFLG

\# DATASET 5 - month 12

\# ITMP IRDBND IRDRAI IRDEVP IRDLIN IRDGEO IRDSTR IRDSTG IPTFLG

\# DATASET 5 - month 1

\# ITMP IRDBND IRDRAI IRDEVP IRDLIN IRDGEO IRDSTR IRDSTG IPTFLG $-1$

\# DATASET 5 - month 2

\# ITMP IRDBND IRDRAI IRDEVP IRDLIN IRDGEO IRDSTR IRDSTG IPTFLG

\# DATASET 5 - month 3

\# ITMP IRDBND IRDRAI IRDEVP IRDLIN IRDGEO IRDSTR IRDSTG IPTELG

\# DATASET 5 - month 4

\# ITMP IRDBND IRDRAI IRDEVP IRDLIN IRDGEO IRDSTR IRDSTG IPTFLG $-1$

\# DATASET 5 - month 5

\# ITMP IRDBND IRDRAI IRDEVP IRDLIN IRDGEO IRDSTR IRDSTG IPTFLG

\# DATASET 5 - month 6 
\# ITMP IRDBND IRDRAI IRDEVP IRDLIN IRDGEO IRDSTR IRDSTG IPTFLG $-1$

\# DATASET 5 - month 7

\# ITMP IRDBND IRDRAI IRDEVP IRDLIN IRDGEO IRDSTR IRDSTG IPTFLG

\# DATASET 5 - month 8

\# ITMP IRDBND IRDRAI IRDEVP IRDLIN IRDGEO IRDSTR IRDSTG IPTFLG $-1$

\# DATASET 5 - month 9

\# ITMP IRDBND IRDRAI IRDEVP IRDLIN IRDGEO IRDSTR IRDSTG IPTFLG

\# DATASET 5 - month 10

\# ITMP IRDBND IRDRAI IRDEVP IRDLIN IRDGEO IRDSTR IRDSTG IPTFLG

\# DATASET 5 - month 11

\# ITMP IRDBND IRDRAI IRDEVP IRDLIN IRDGEO IRDSTR IRDSTG IPTFLG $-1$

\# DATASET 5 - month 12

\# ITMP IRDBND IRDRAI IRDEVP IRDLIN IRDGEO IRDSTR IRDSTG IPTFLG

\# DATASET 5 - month 1

\# ITMP IRDBND IRDRAI IRDEVP IRDLIN IRDGEO IRDSTR IRDSTG IPTFLG

\# DATASET 5 - month 2

\# ITMP IRDBND IRDRAI IRDEVP IRDLIN IRDGEO IRDSTR IRDSTG IPTFLG $-1$

\# DATASET 5 - month 3

\# ITMP IRDBND IRDRAI IRDEVP IRDLIN IRDGEO IRDSTR IRDSTG IPTFLG

\# DATASET 5 - month 4

\# ITMP IRDBND IRDRAI IRDEVP IRDLIN IRDGEO IRDSTR IRDSTG IPTFLG $-1$

\# DATASET 5 - month 5

* ITMP IRDBND IRDRAI IRDEVP IRDLIN IRDGEO IRDSTR IRDSTG IPTFLG

\# DATASET 5 - month 6

\# ITMP IRDBND IRDRAI IRDEVP IRDLIN IRDGEO IRDSTR IRDSTG IPTFLG

\# DATASET 5 - month 7

* ITMP IRDBND IRDRAI IRDEVP IRDLIN IRDGEO IRDSTR IRDSTG IPTFLG $-1$

\# DATASET 5 - month 8

\# ITMP IRDBND IRDRAI IRDEVP IRDLIN IRDGEO IRDSTR IRDSTG IPTFLG

\# DATASET 5 - month 9

\# ITMP IRDBND IRDRAI IRDEVP IRDLIN IRDGEO IRDSTR IRDSTG IPTFLG $-1$

\# DATASET 5 - month 10

\# ITMP IRDBND IRDRAI IRDEVP IRDLIN IRDGEO IRDSTR IRDSTG IPTFLG

\# DATASET 5 - month 1

\# ITMP IRDBND IRDRAI IRDEVP IRDLIN IRDGEO IRDSTR IRDSTG IPTFLG

\# DATASET 5 - month 12

\# ITMP IRDBND IRDRAI IRDEVP IRDLIN IRDGEO IRDSTR IRDSTG IPTELG $-1$

\# DATASET 5 - month 1

\# ITMP IRDBND IRDRAI IRDEVP IRDLIN IRDGEO IRDSTR IRDSTG IPTFLG

\# DATASET 5 - month 2

\# ITMP IRDBND IRDRAI IRDEVP IRDLIN IRDGEO IRDSTR IRDSTG IPTFLG

\# DATASET 5 - month 3

\# ITMP IRDBND IRDRAI IRDEVP IRDLIN IRDGEO IRDSTR IRDSTG IPTFLG $-1$

\# DATASET 5 - month 4

\# ITMP IRDBND IRDRAI IRDEVP IRDLIN IRDGEO IRDSTR IRDSTG IPTFLG

\# DATASET 5 - month 5

\# ITMP IRDBND IRDRAI IRDEVP IRDLIN IRDGEO IRDSTR IRDSTG IPTFLG 
$-1$

\# DATASET 5 - month 6

\# ITMP IRDBND IRDRAI IRDEVP IRDLIN IRDGEO IRDSTR IRDSTG IPTFLG

$-1$

\# DATASET 5 - month 7

\# ITMP IRDBND IRDRAI IRDEVP IRDLIN IRDGEO IRDSTR IRDSTG IPTFLG $-1$

\# DATASET 5 - month 8

\# ITMP IRDBND IRDRAI IRDEVP IRDLIN IRDGEO IRDSTR IRDSTG IPTFLG

\# DATASET 5 - month 9

\# ITMP IRDBND IRDRAI IRDEVP IRDLIN IRDGEO IRDSTR IRDSTG IPTFLG

\# DATASET 5 - month 10

\# ITMP IRDBND IRDRAI IRDEVP IRDLIN IRDGEO IRDSTR IRDSTG IPTFLG $-1$

\# DATASET 5 - month 11

\# ITMP IRDBND IRDRAI IRDEVP IRDLIN IRDGEO IRDSTR IRDSTG IPTFLG

\# DATASET 5 - month 12

\# ITMP IRDBND IRDRAI IRDEVP IRDLIN IRDGEO IRDSTR IRDSTG IPTFLG $-1$

\# DATASET 5 - month 1

\# ITMP IRDBND IRDRAI IRDEVP IRDLIN IRDGEO IRDSTR IRDSTG IPTFLG

\# DATASET 5 - month 2

\# ITMP IRDBND IRDRAI IRDEVP IRDLIN IRDGEO IRDSTR IRDSTG IPTFLG

\# DATASET 5 - month 3

\# ITMP IRDBND IRDRAI IRDEVP IRDLIN IRDGEO IRDSTR IRDSTG IPTFLG $-1$

\# DATASET 5 - month 4

\# ITMP IRDBND IRDRAI IRDEVP IRDLIN IRDGEO IRDSTR IRDSTG IPTFLG

\# DATASET 5 - month 5

\# ITMP IRDBND IRDRAI IRDEVP IRDLIN IRDGEO IRDSTR IRDSTG IPTFLG

DATASET 5 - mOnth 6

\# ITMP IRDBND IRDRAI IRDEVP IRDLIN IRDGEO IRDSTR IRDSTG IPTFLG

\# DATASET 5 - month 7

\# ITMP IRDBND IRDRAI IRDEVP IRDLIN IRDGEO IRDSTR IRDSTG IPTELG

\# DATASET 5 - month 8

\# ITMP IRDBND IRDRAI IRDEVP IRDLIN IRDGEO IRDSTR IRDSTG IPTELG $-1$

\# DATASET 5 - month 9

* ITMP IRDBND IRDRAI IRDEVP IRDLIN IRDGEO IRDSTR IRDSTG IPTFLG

\# DATASET 5 - month 10

\# ITMP IRDBND IRDRAI IRDEVP IRDLIN IRDGEO IRDSTR IRDSTG IPTFLG

\# DATASET 5 - month 11

\# ITMP IRDBND IRDRAI IRDEVP IRDLIN IRDGEO IRDSTR IRDSTG IPTFLG

\# DATASET 5 - month 12

\# ITMP IRDBND IRDRAI IRDEVP IRDLIN IRDGEO IRDSTR IRDSTG IPTFLG

\# DATASET 5 - month 1

\# ITMP IRDBND IRDRAI IRDEVP IRDLIN IRDGEO IRDSTR IRDSTG IPTFLG $-1$

\# DATASET 5 - month 2

\# ITMP IRDBND IRDRAI IRDEVP IRDLIN IRDGEO IRDSTR IRDSTG IPTFLG

\# DATASET 5 - month 3

\# ITMP IRDBND IRDRAI IRDEVP IRDLIN IRDGEO IRDSTR IRDSTG IPTELG

\# DATASET 5 - month 4

\# ITMP IRDBND IRDRAI IRDEVP IRDLIN IRDGEO IRDSTR IRDSTG IPTFLG $-1$ 
\# DATASET 5 - month 5

\# ITMP IRDBND IRDRAI IRDEVP IRDLIN IRDGEO IRDSTR IRDSTG IPTFLG

\# DATASET 5 - month 6

\# ITMP IRDBND IRDRAI IRDEVP IRDLIN IRDGEO IRDSTR IRDSTG IPTFLG $-1$

\# DATASET 5 - month 7

\# ITMP IRDBND IRDRAI IRDEVP IRDLIN IRDGEO IRDSTR IRDSTG IPTFLG

\# DATASET 5 - month 8

\# ITMP IRDBND IRDRAI IRDEVP IRDLIN IRDGEO IRDSTR IRDSTG IPTFLG $-1$

DATASET 5 - month 9

* ITMP IRDBND IRDRAI IRDEVP IRDLIN IRDGEO IRDSTR IRDSTG IPTFLG

\# DATASET 5 - month 10

\# ITMP IRDBND IRDRAI IRDEVP IRDLIN IRDGEO IRDSTR IRDSTG IPTFLG

\# DATASET 5 - month 11

* ITMP IRDBND IRDRAI IRDEVP IRDLIN IRDGEO IRDSTR IRDSTG IPTFLG $-1$

\# DATASET 5 - month 12

\# ITMP IRDBND IRDRAI IRDEVP IRDLIN IRDGEO IRDSTR IRDSTG IPTFLG

\# DATASET 5 - month 1

\# ITMP IRDBND IRDRAI IRDEVP IRDLIN IRDGEO IRDSTR IRDSTG IPTFLG

DATASET 5 - month 2

\# ITMP IRDBND IRDRAI IRDEVP IRDLIN IRDGEO IRDSTR IRDSTG IPTFLG

\# DATASET 5 - month 3

\# ITMP IRDBND IRDRAI IRDEVP IRDLIN IRDGEO IRDSTR IRDSTG IPTELG

\# DATASET 5 - month 4

\# ITMP IRDBND IRDRAI IRDEVP IRDLIN IRDGEO IRDSTR IRDSTG IPTFLG $-1$

\# DATASET 5 - month 5

\# ITMP IRDBND IRDRAI IRDEVP IRDLIN IRDGEO IRDSTR IRDSTG IPTFLG

\# DATASET 5 - month 6

\# ITMP IRDBND IRDRAI IRDEVP IRDLIN IRDGEO IRDSTR IRDSTG IPTFLG

\# DATASET 5 - month 7

\# ITMP IRDBND IRDRAI IRDEVP IRDLIN IRDGEO IRDSTR IRDSTG IPTFLG

\# DATASET 5 - month 8

\# ITMP IRDBND IRDRAI IRDEVP IRDLIN IRDGEO IRDSTR IRDSTG IPTFLG

\# DATASET 5 - month 9

\# ITMP IRDBND IRDRAI IRDEVP IRDLIN IRDGEO IRDSTR IRDSTG IPTFLG $-1$

\# DATASET 5 - month 10

\# ITMP IRDBND IRDRAI IRDEVP IRDLIN IRDGEO IRDSTR IRDSTG IPTFLG

\# DATASET 5 - month 11

\# ITMP IRDBND IRDRAI IRDEVP IRDLIN IRDGEO IRDSTR IRDSTG IPTFLG

\# DATASET 5 - month 12

* ITMP IRDBND IRDRAI IRDEVP IRDLIN IRDGEO IRDSTR IRDSTG IPTFLG $-1$

\# DATASET 5 - month 1

\# ITMP IRDBND IRDRAI IRDEVP IRDLIN IRDGEO IRDSTR IRDSTG IPTFLG

\# DATASET 5 - month 2

\# ITMP IRDBND IRDRAI IRDEVP IRDLIN IRDGEO IRDSTR IRDSTG IPTFLG

\# DATASET 5 - month 3

\# ITMP IRDBND IRDRAI IRDEVP IRDLIN IRDGEO IRDSTR IRDSTG IPTELG 


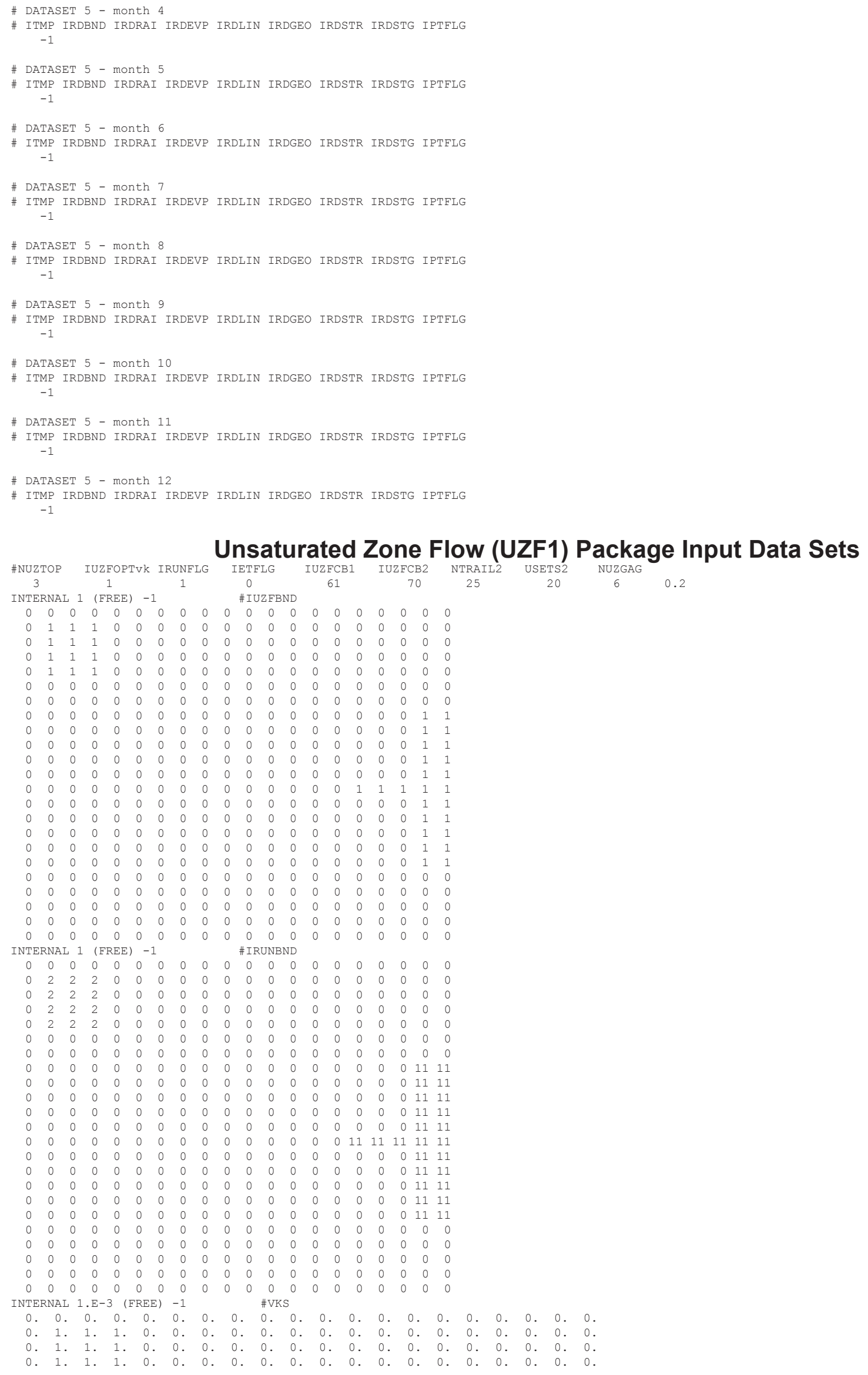

Unsaturated Zone Flow (UZF1) Package Input Data Sets

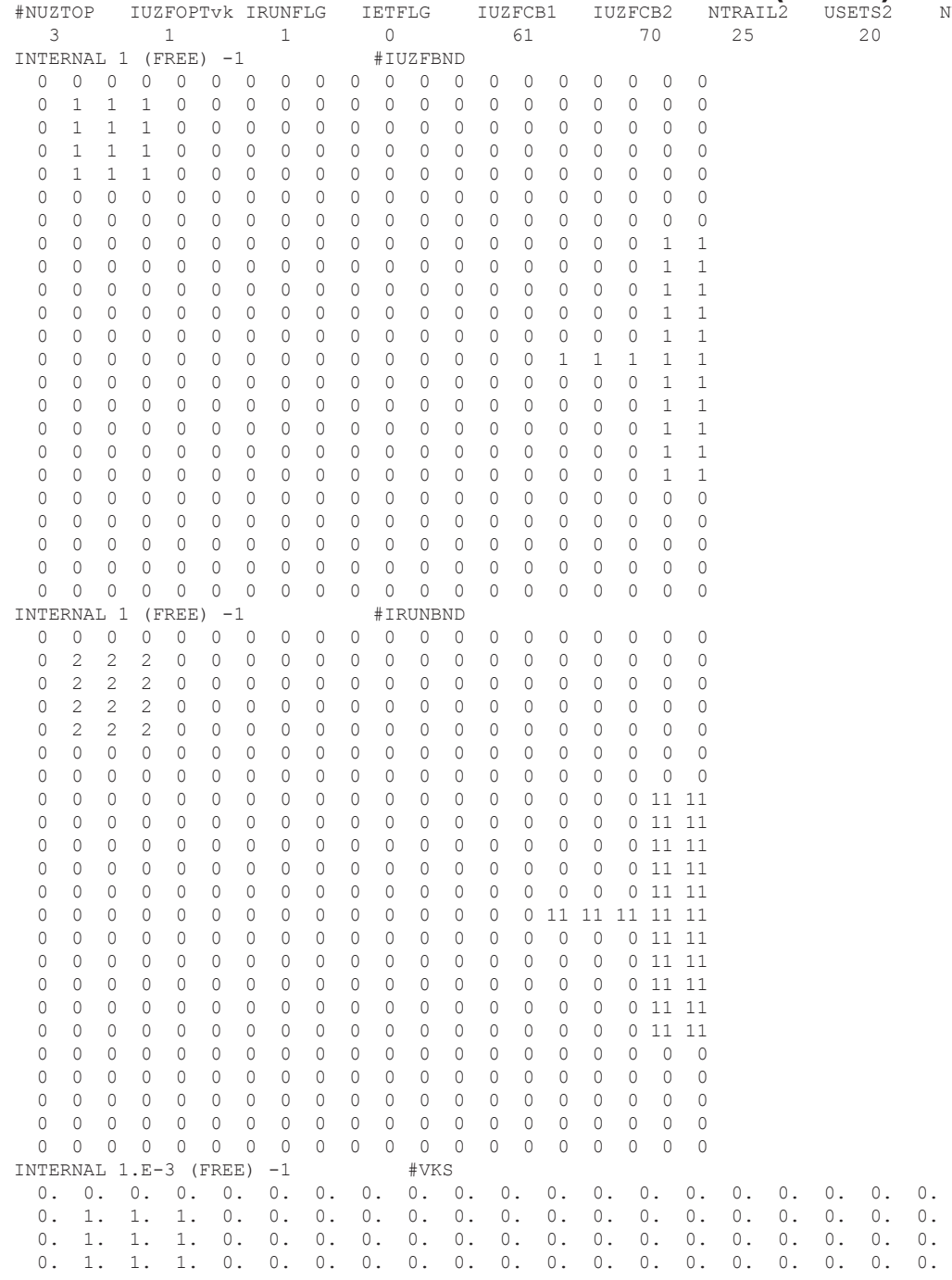




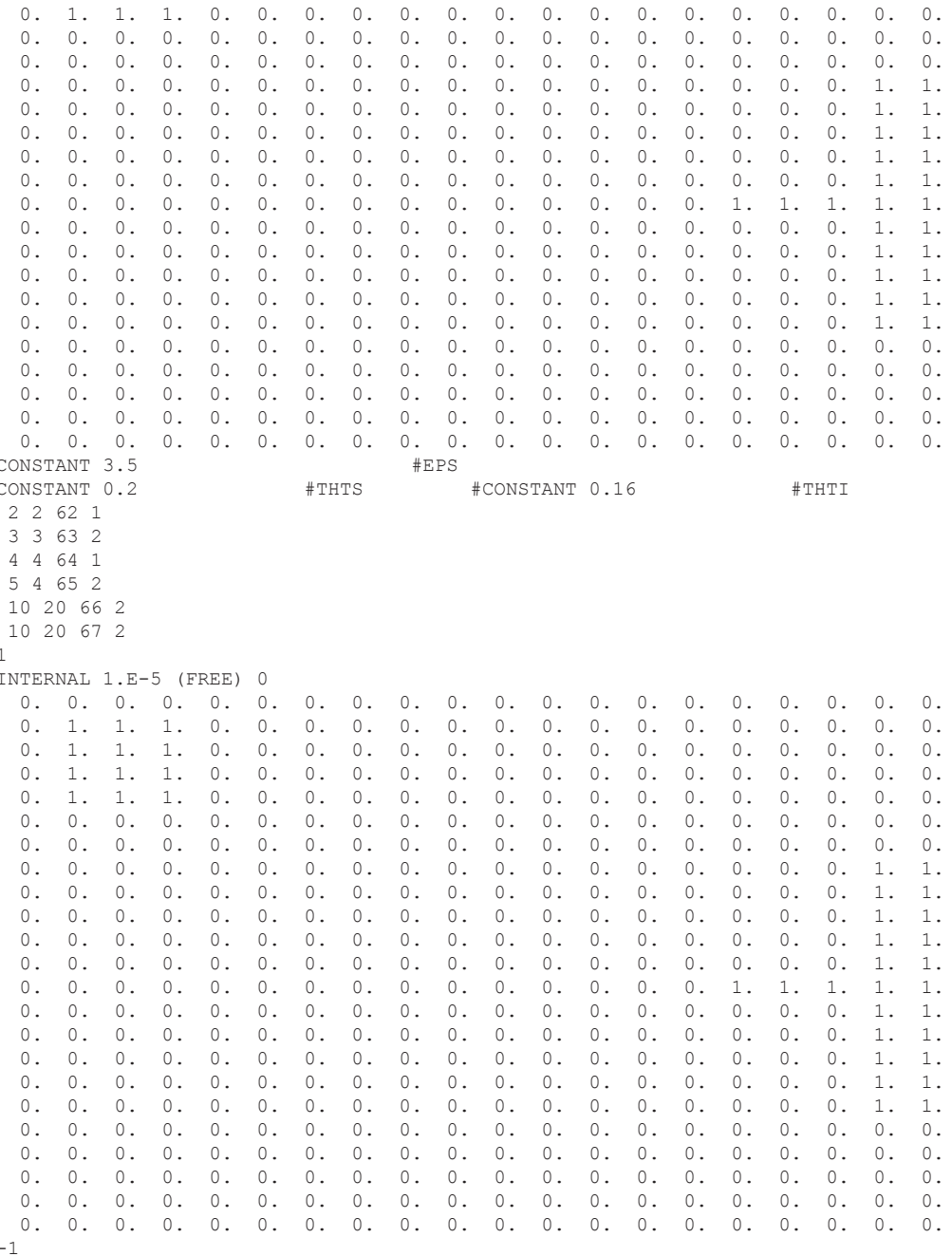




\section{Multi-Node Well (MNW2) Input Data Sets}

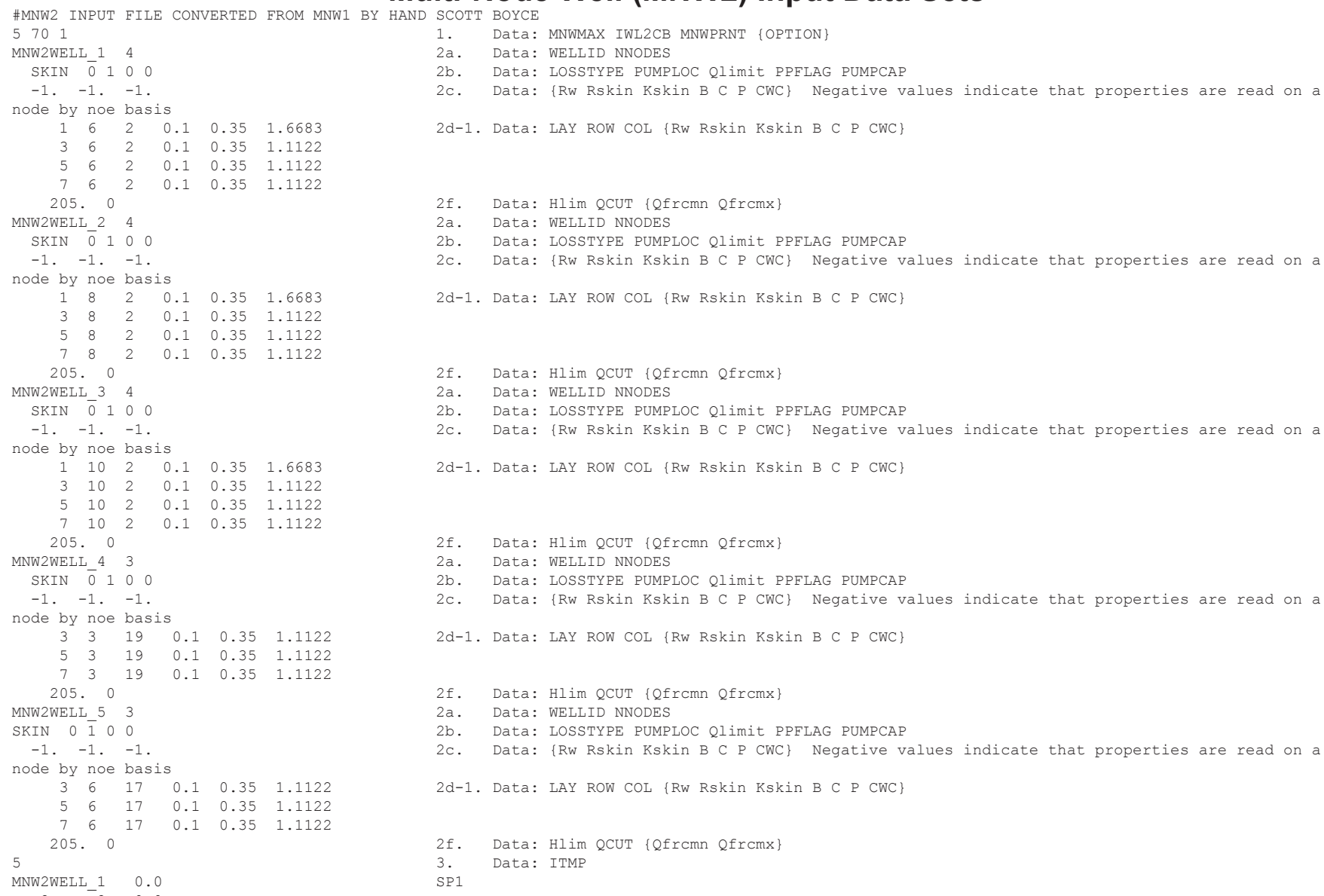




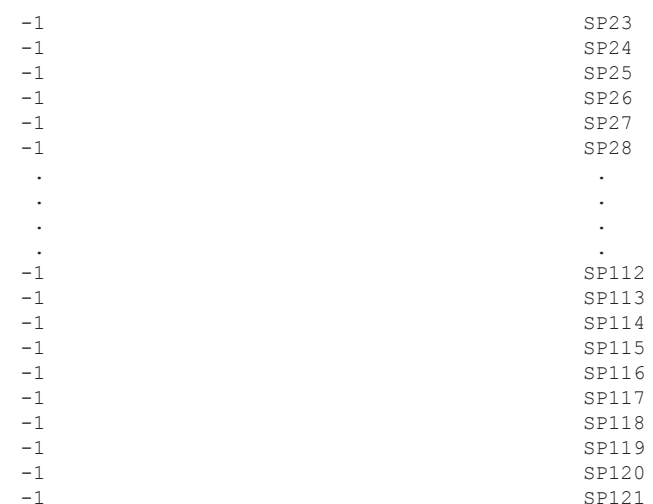

Farm Process (FMP3) Input Data Sets

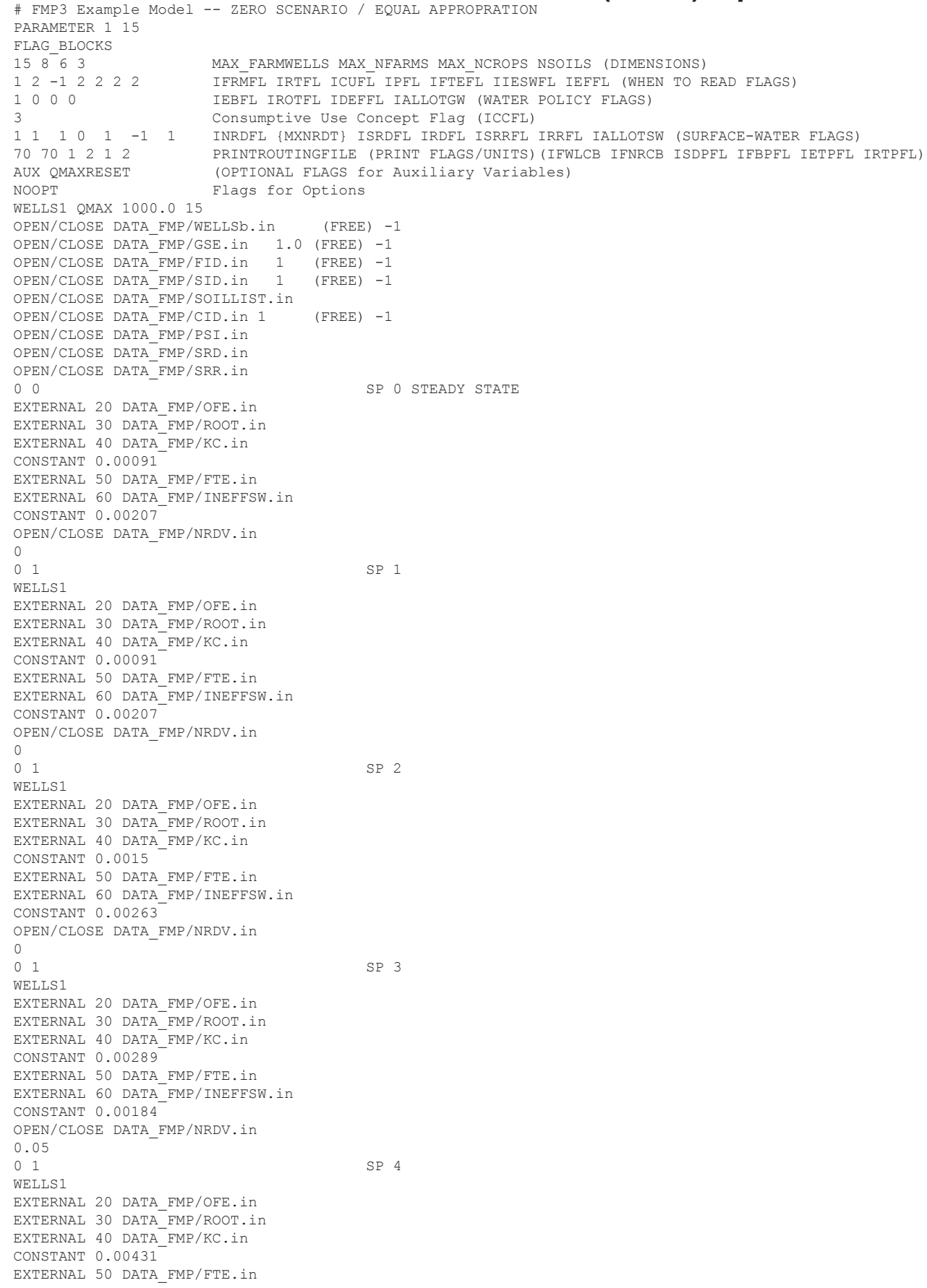


EXTERNAL 60 DATA_FMP/INEFFSW.in

CONSTANT 0.00061

OPEN/CLOSE DATA_FMP/NRDV. in

0.05

WEILS1

SP 5

EXTERNAL 20 DATA FMP/OFE. in

EXTERNAL 30 DATA_FMP/ROOT.in

EXTERNAL 40 DATA_FMP/KC.in

CONSTANT 0.00592

EXTERNAL 50 DATA FMP/FTE. in

EXTERNAL 60 DATA FMP/INEFFSW. in

CONSTANT 0.00029

OPEN/CLOSE DATA_FMP/NRDV.in

0.05

$\begin{array}{ll}0 & 1 \\ \text { WELLS1 }\end{array}$

EXTERNAL 20 DATA FMP/OFE. in

EXTERNAL 30 DATA FMP/ROOT. in

EXTERNAL 40 DATA FMP/KC. in

CONSTANT 0.00688

EXTERNAL 50 DATA_FMP/FTE.in

EXTERNAL 60 DATA FMP/INEFFSW.in

CONSTANT 0.00013

OPEN/CLOSE DATA FMP/NRDV. in

0.2

01

WELLS1

EXTERNAL 20 DATA_FMP/OFE. in EXTERNAL 30 DATA FMP/ROOT. in

EXTERNAL 40 DATA_FMP/KC.in

CONSTANT 0.00692

EXTERNAL 50 DATA FMP/FTE. in

EXTERNAL 60 DATA FMP/INEFFSW. in

CONSTANT 0.00003

OPEN/CLOSE DATA_FMP/NRDV. in

0.2

1

SP 8

EXTERNAL 20 DATA_FMP/OFE. in

EXTERNAL 30 DATA_FMP/ROOT.in

EXTERNAL 40 DATA_FMP/KC.in

CONSTANT 0.00617

EXTERNAL 50 DATA FMP/FTE. in

EXTERNAL 60 DATA FMP/INEFFSW. in

CONSTANT 0.00003

OPEN/CLOSE DATA_FMP/NRDV. in

0.2

$\begin{array}{ll}0 & 1 \\ \text { WELLS1 }\end{array}$

EXTERNAL 20 DATA FMP/OFE. in

EXTERNAL 30 DATA FMP/ROOT. in

EXTERNAL 40 DATA_FMP/KC. in

EXTERNAL 50 DATA_FMP/FTE. in

EXTERNAL 60 DATA FMP/INEFFSW.in

CONSTANT 0.00008

OPEN/CLOSE DATA FMP/NRDV. in

0.075

01

WELLS1

EXTERNAL 20 DATA_FMP/OFE. in

EXTERNAL 30 DATA FMP/ROOT. in

EXTERNAL 40 DATA FMP/KC. in

CONSTANT 0.00349

EXTERNAL 50 DATA_FMP/FTE.in

EXTERNAL 60 DATA_FMP/INEFFSW.in

CONSTANT 0.00039

OPEN/CLOSE DATA FMP/NRDV. in

0.075

0.075
01
WELLS

SP 6

EXTERNAL 20 DATA_FMP/OFE. in

EXTERNAL 30 DATA_FMP/ROOT.in

EXTERNAL 40 DATA FMP/KC. in

CONSTANT 0.00154

EXTERNAL 50 DATA FMP/FTE. in

EXTERNAL 60 DATA FMP/INEFFSW.in

CONSTANT 0.00149

OPEN/CLOSE DATA_FMP/NRDV. in

0

01

WELLS1

EXTERNAL 20 DATA FMP/OFE. in

EXTERNAL 30 DATA FMP/ROOT. in

EXTERNAL 40 DATA_FMP/KC.in

CONSTANT 0.00096

EXTERNAL 50 DATA_FMP/FTE. in

EXTERNAL 60 DATA FMP/INEFFSW. in

CONSTANT 0.0021

OPEN/CLOSE DATA_FMP/NRDV. in

0 
WELLS1

EXTERNAL 20 DATA FMP/OFE. in

EXTERNAL 30 DATA_FMP/ROOT.in

EXTERNAL 40 DATA FMP/KC. in

CONSTANT 0.00091

EXTERNAL 50 DATA FMP/FTE. in

EXTERNAL 60 DATA FMP/INEFFSW. in

CONSTANT 0.00207

OPEN/CLOSE DATA_FMP/NRDV.in

0

$\begin{array}{ll}0 & 1 \\ \text { WELLS } & 0\end{array}$

SP 14

EXTERNAL 20 DATA FMP/OFE. in

EXTERNAL 30 DATA FMP/ROOT. In

EXTERNAL 40 DATA_FMP/KC. in

CONSTANT 0.0015

EXTERNAL 50 DATA FMP/FTE. in

EXTERNAL 60 DATA FMP/INEFFSW.in

CONSTANT 0.00263

OPEN/CLOSE DATA FMP/NRDV. in 0

01

EXTERNAL 20 DATA FMP/OFE. in

EXTERNAL 30 DATA FMP/ROOT. in

EXTERNAL 40 DATA FMP/KC. in

CONSTANT 0.00289

EXTERNAL 50 DATA FMP/FTE. in

EXTERNAL 60 DATA_FMP/INEFFSW.in

CONSTANT 0.00184

OPEN/CLOSE DATA FMP/NRDV. in

0.0125

01

WELLS1

EXTERNAL 20 DATA_FMP/OFE. in

EXTERNAL 30 DATA FMP/ROOT. In

EXTERNAL 40 DATA FMP/KC. in

CONSTANT 0.00431

EXTERNAL 50 DATA FMP/FTE. in

EXTERNAL 60 DATA FMP/INEFFSW. in

CONSTANT 0.00061

OPEN/CLOSE DATA_FMP/NRDV. in

0.0125

1

EXTERNAL 20 DATA FMP/OFE. in

EXTERNAL 30 DATA FMP/ROOT.in

EXTERNAL 40 DATA_FMP/KC. in

CONSTANT 0.00592

EXTERNAL 50 DATA FMP/FTE. in

EXTERNAL 60 DATA FMP/INEFFSW. in

CONSTANT 0.00029

OPEN/CLOSE DATA FMP/NRDV. in

0.0125

01

WELLS1

EXTERNAL 20 DATA FMP/OFE. in

EXTERNAL 30 DATA FMP/ROOT. in

EXTERNAL 40 DATA FMP/KC in

CONSTANT 0.00688

EXTERNAL 50 DATA_FMP/FTE.in

EXTERNAL 60 DATA_FMP/INEFFSW.in

CONSTANT 0.00013

OPEN/CLOSE DATA_FMP/NRDV.in

0.05

01

EXTERNAL 20 DATA_FMP/OFE. in

EXTERNAL 30 DATA FMP/ROOT.in

EXTERNAL 40 DATA FMP/KC. in

CONSTANT 0.00692

EXTERNAL 50 DATA FMP/FTE. in

EXTERNAL 60 DATA FMP/INEFFSW. in

CONSTANT 0.00003

OPEN/CLOSE DATA_EMP/NRDV. in

0.05

1

WELLS1

EXTERNAL 20 DATA FMP/OFE. in

EXTERNAL 30 DATA FMP/ROOT. in

EXTERNAL 40 DATA_FMP/KC. in

CONSTANT 0.00617

EXTERNAL 50 DATA FMP/FTE. in

EXTERNAL 60 DATA FMP/INEFFSW. in

CONSTANT 0.00003

OPEN/CLOSE DATA_FMP/NRDV.in

0.05

01

WELLS1

EXTERNAL 20 DATA FMP/OFE. in

EXTERNAL 30 DATA FMP/ROOT. in

EXTERNAL 40 DATA FMP/KC. in

CONSTANT 0.00484 
EXTERNAL 50 DATA_FMP/FTE. in

EXTERNAL 60 DATA_FMP/INEFFSW.in

CONSTANT 0.00008

OPEN/CLOSE DATA_FMP/NRDV. in

0.01875

01

SP 22

WELLS1

EXTERNAL 20 DATA_FMP/OFE. in

EXTERNAL 30 DATA_FMP/ROOT. in

EXTERNAL 40 DATA_FMP/KC. in

CONSTANT 0.00349

EXTERNAL 50 DATA FMP/FTE. in

EXTERNAL 60 DATA FMP/INEFFSW. in

CONSTANT 0.00039

OPEN/CLOSE DATA_FMP/NRDV.in

0.01875

01

WELLS1

EXTERNAL 20 DATA FMP/OFE. in

EXTERNAL 30 DATA FMP/ROOT. In

EXTERNAL 40 DATA_FMP/KC.in

CONSTANT 0.00154

EXTERNAL 50 DATA_FMP/FTE. in

EXTERNAL 60 DATA FMP/INEFFSW. in

CONSTANT 0.00149

OPEN/CLOSE DATA FMP/NRDV. in

0

$\begin{array}{ll}0 & 1 \\ \text { WELLS } 1\end{array}$

EXTERNAL 20 DATA_FMP/OFE. in

EXTERNAL 30 DATA FMP/ROOT. in

EXTERNAL 40 DATA FMP/KC. in

CONSTANT 0.00096

EXTERNAL 50 DATA_FMP/FTE. in

EXTERNAL 60 DATA_FMP/INEFFSW.in

CONSTANT 0.0021

OPEN/CLOSE DATA FMP/NRDV. in

(1)

1

WELLS1

EXTERNAL 20 DATA_FMP/OFE. in
EXTERNAL 30 DATA_FMP/ROOT. in

EXTERNAL 40 DATA FMP/KC. in

CONSTANT 0.00091

EXTERNAL 50 DATA FMP/FTE. in

EXTERNAL 60 DATA FMP/INEFFSW. in

CONSTANT 0.00207

OPEN/CLOSE DATA_FMP/NRDV.in

01

WELLS1

EXTERNAL 20 DATA FMP/OFE. in

EXTERNAL 30 DATA_FMP/ROOT.in

EXTERNAL 40 DATA_FMP/KC. in

CONSTANT 0.0015

EXTERNAL 50 DATA FMP/FTE. in

EXTERNAL 60 DATA_FMP/INEFFSW.in

CONSTANT 0.00263

OPEN/CLOSE DATA FMP/NRDV. in 0

01

WELLS1

EXTERNAL 20 DATA FMP/OFE. in

EXTERNAL 30 DATA FMP/ROOT in

EXTERNAL 40 DATA FMP/KC. in

CONSTANT 0.00289

EXTERNAL 50 DATA_FMP/FTE. in

EXTERNAL 60 DATA_FMP/INEFFSW.in

CONSTANT 0.00184

OPEN/CLOSE DATA FMP/NRDV.in

0.05

01

WELLS 1

EXTERNAL 20 DATA_FMP/OFE. in

EXTERNAL 30 DATA_FMP/ROOT. in

EXTERNAL 40 DATA FMP/KC. in

CONSTANT 0.00431

EXTERNAL 50 DATA FMP/FTE. in

EXTERNAL 60 DATA FMP/INEFFSW. in

CONSTANT 0.00061

DPEN/CLOSE DATA_FMP/NRDV.in

0.05

01

WEIS1

EXTERNAL 20 DATA FMP/OFE. in

EXTERNAL 30 DATA_FMP/ROOT.in

EXTERNAL 40 DATA_FMP/KC. in

CONSTANT 0.00592

EXTERNAL 50 DATA FMP/FTE. in

EXTERNAL 60 DATA FMP/INEFFSW. in

CONSTANT 0.00029

OPEN/CLOSE DATA FMP/NRDV. in

0.05 
01

WELLS

EXTERNAL 20 DATA FMP/OFE. i EXTERNAL 30 DATA FMP/ROOT. in

EXTERNAL 40 DATA FMP/KC. in

CONSTANT 0.00688

EXTERNAL 50 DATA FMP/FTE. in

EXTERNAL 60 DATA FMP/INEFFSW. in

CONSTANT 0.00013

OPEN/CLOSE DATA FMP/NRDV. in

1

EXTERNAL 20 DATA FMP/OFE. in

EXTERNAL 30 DATA FMP/ROOT. in

EXTERNAL 40 DATA_FMP/KC.in

CONSTANT 0.00692

EXTERNAL 50 DATA FMP/FTE. In

EXTERNAL 60 DATA FMP/INEFFSW. in

CONSTANT 0.00003

OPEN/CLOSE DATA_FMP/NRDV.in

0.2

1

WELLS1

EXTERNAL 20 DATA FMP/OFE. in

EXTERNAL 30 DATA FMP/ROOT. in

EXTERNAL 40 DATA FMP/KC. in

CONSTANT 0.00617

EXTERNAL 50 DATA FMP/FTE. In

EXTERNAL 60 DATA_FMP/INEFFSW. in

CONSTANT 0.00003

OPEN/CLOSE DATA FMP/NRDV. in

0.2

01

ELLS1

EXTERNAL 20 DATA_FMP/OFE. in

EXTERNAL 30 DATA FMP/ROOT. in

EXTERNAL 40 DATA FMP/KC. in

CONSTANT 0.00484

EXTERNAL 50 DATA_FMP/FTE.in

EXTERNAL 60 DATA FMP/INEFFSW. in

CONSTANT 0.00008

PEN/CLOSE DATA FMP/NRDV. in

0.075

01

TELIS

EXTERNAL 20 DATA_FMP/OFE.in

EXTERNAL 30 DATA_FMP/ROOT.in

EXTERNAL 40 DATA_FMP/KC. in

CONSTANT 0.00349

EXTERNAL 50 DATA FMP/FTE. in

EXTERNAL 60 DATA FMP/INEFFSW. in

CONSTANT 0.00039

PEN/CLOSE DATA FMP/NRDV. i

0.075

1

WELLS1

EXTERNAL 20 DATA FMP/OFE. in

XXTERNAL 30 DATA FMP/ROOT, in

EXTERNAL 40 DATA FMP/KC. in

CONSTANT 0.00154

EXTERNAL 50 DATA_FMP/FTE. in

EXTERNAL 60 DATA FMP/INEFFSW. in

CONSTANT 0.00149

OPEN/CLOSE DATA FMP/NRDV. in

1

WELLS

EXTERNAL 20 DATA_FMP/OFE. in

EXTERNAL 30 DATA FMP/ROOT. in

EXTERNAL 40 DATA FMP/KC. in

CONSTANT 0.00096

EXTERNAL 50 DATA FMP/FTE. in

EXTERNAL 60 DATA_FMP/INEFFSW.i

CONSTANT 0.002

OPEN/CLOSE DATA FMP/NRDV. in

1

WELLS1

EXTERNAL 20 DATA_FMP/OFE.in

EXTERNAL 30 DATA_FMP/ROOT.in

EXTERNAL 40 DATA_FMP/KC.in

CONSTANT 0.00091

EXTERNAL 50 DATA FMP/FTE. in

EXTERNAL 60 DATA FMP/INEFFSW. in

CONSTANT 0.00207

PEN/CLOSE DATA_FMP/NRDV.in

01

EXTERNAL 20 DATA FMP/OFE. in

EXTERNAL $30 \mathrm{DATA}^{-} \mathrm{FMP} / \mathrm{ROOT}$. in

EXTERNAL 40 DATA_FMP/KC. in
SP 6

SP

SP 8

SP 9

SP 10

SP 11 
CONSTANT 0.0015

EXTERNAL 50 DATA FMP/FTE. in

EXTERNAL 60 DATA_FMP/INEFFSW.in

CONSTANT 0.00263

OPEN/CLOSE DATA_FMP/NRDV. in

0

$\begin{array}{ll}0 & 1 \\ \text { WELLS1 }\end{array}$

WELLS1

SP 15

EXTERNAL 30 DATA FMP/ROOT. in

EXTERNAL 40 DATA FMP/KC. in

CONSTANT 0.00289

EXTERNAL 50 DATA FMP/FTE. in

EXTERNAL 60 DATA FMP/INEFFSW. in

CONSTANT 0.00184

OPEN/CLOSE DATA_FMP/NRDV. in

0.0125

01

WEI S1

EXTERNAL 20 DATA FMP/OFE. In

EXTERNAL 30 DATA_FMP/ROOT.in

EXTERNAL 40 DATA_FMP/KC. in

CONSTANT 0.00431

EXTERNAL 50 DATA FMP/FTE. in

EXTERNAL 60 DATA FMP/INEFFSW. in

CONSTANT 0.00061

OPEN/CLOSE DATA_FMP/NRDV. in

0.0125

01

WELLS1

EXTERNAL 20 DATA FMP/OFE. in

EXTERNAL 30 DATA FMP/ROOT. in

EXTERNAL 40 DATA FMP/KC. in

CONSTANT 0.00592

EXTERNAL 50 DATA_FMP/FTE.in

EXTERNAL 60 DATA_FMP/INEFFSW. in

CONSTANT 0.00029

OPEN/CLOSE DATA FMP/NRDV. in

0.0125

01

WELLS1

EXTERNAL 20 DATA_FMP/OFE. in

EXTERNAL 30 DATA FMP/ROOT. in

EXTERNAL 40 DATA FMP/KC. in

CONSTANT 0.00688

EXTERNAL 50 DATA FMP/FTE. in

EXTERNAL 60 DATA FMP/INEFFSW. in

CONSTANT 0.00013

OPEN/CLOSE DATA_FMP/NRDV. in

0.05

1

SP 19

EXTERNAL 20 DATA_FMP/OFE. in

EXTERNAL 30 DATA_FMP/ROOT.in

EXTERNAL 40 DATA_FMP/KC.in

CONSTANT 0.00692

EXTERNAL 50 DATA FMP/FTE. in

EXTERNAL 60 DATA FMP/INEFFSW. in

CONSTANT 0.00003

OPEN/CLOSE DATA_FMP/NRDV.in

0.05

01

WELLS1

EXTERNAL 20 DATA FMP/OFE. in

EXTERNAL 30 DATA FMP/ROOT. in

EXTERNAL 40 DATA FMP/KC. in

CONSTANT 0.00617

EXTERNAL 50 DATA_FMP/FTE. in

EXTERNAL 60 DATA FMP/INEFFSW.in

CONSTANT 0.00003

OPEN/CLOSE DATA FMP/NRDV. in

0.05

01

WELLS1

EXTERNAL 20 DATA_FMP/OFE. in

EXTERNAL 30 DATA FMP/ROOT. in

EXTERNAL 40 DATA FMP/KC. in

CONSTANT 0.00484

EXTERNAL 50 DATA_FMP/FTE.in

EXTERNAL 60 DATA_FMP/INEFFSW.in

CONSTANT 0.00008

OPEN/CLOSE DATA FMP/NRDV. in

0.01875

01

WELLS1

EXTERNAL 20 DATA_FMP/OFE.in

EXTERNAL 30 DATA_FMP/ROOT. in

EXTERNAL 40 DATA_EMP/KC. in

CONSTANT 0.00349

EXTERNAL 50 DATA FMP/FTE. in

EXTERNAL 60 DATA FMP/INEFFSW. in

CONSTANT 0.00039

OPEN/CLOSE DATA_FMP/NRDV.in 
0.01875

01

WELLS1

EXTERNAL 20 DATA_FMP/OFE. in

EXTERNAL 30 DATA FMP/ROOT. in

EXTERNAL 40 DATA FMP/KC. in

CONSTANT 0.00154

EXTERNAL 50 DATA_FMP/FTE.in

EXTERNAL 60 DATA_FMP/INEFFSW. in

CONSTANT 0.00149

OPEN/CLOSE DATA FMP/NRDV. in

0

01

SP 24

WELLS1

EXTERNAL 30 DATA FMP/ROOT. in

EXTERNAL 40 DATA FMP/KC. in

CONSTANT 0.00096

EXTERNAL 50 DATA FMP/FTE in

EXTERNAL 60 DATA FMP/INEFFSW. in

CONSTANT 0.0021

OPEN/CLOSE DATA_FMP/NRDV.in

FMP Time blocks for stress periods 1-24 (2 years of months) repeated 5 more times to yield 10 years of months

Farm Process (FMP3) Ancillary Input Data Sets

DATA 20 DATA_FMP/OFE.in

DATA 30 DATA_FMP/ROOT.in

DATA 40 DATA_FMP/KC. in

DATA 60 DATA FMP/INEFFSW. in

DATA 80 DATA FMP/NRDFAC.in

$\begin{array}{llllll}\text { BAS } & \text { HD } & \text { I } & 1 & 3750 & 8750 \text { insideF2 L1 } \\ \text { BAS } & \text { HD } & \text { I } & 2 & 3750 & 8750 \text { insideF2 L2 }\end{array}$

BAS HD $\quad$ I $\quad 2 \quad 3750 \quad 8750$ insideF2_L2

BAS HD I $\quad 2 \quad 6750 \quad 4250$ northofF 4 L2

BAS HD $\quad$ I $\quad 115750 \quad 5250$ confluence $\overline{1}$

$\begin{array}{llllll}\text { BAS } & \text { HD } & \text { I } & 1 & 8250 & 5250 \text { confluence } 2\end{array}$

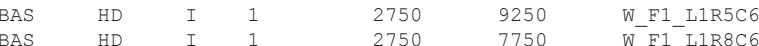

BAS HD I $1-4250-7750-151-51809$

BAS HD I T 110250

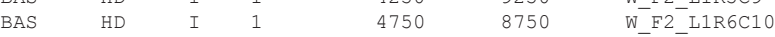

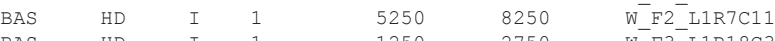

$\begin{array}{lllllll}\text { BAS } & \text { HD } & \text { I } & 1 & 1250 & 2750 & \text { W_F3-L1R18C3 } \\ \text { BAS } & \text { HD } & \text { I } & 1 & 1250 & 1250 & \text { W F3 }\end{array}$

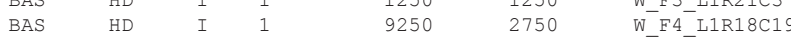

BAS HD I $119250 \quad 1250$ W

BAS HD I $112750 \quad 8750 \quad$ W F5 L1R6C2

$\begin{array}{llllll}\text { BAS HD } & \text { I } & 2 & 750 & 8750 & \text { W_F5_L2R6C2 }\end{array}$

BAS HD I $3 \quad 750 \quad 8750$ W_F5_L3R6C2

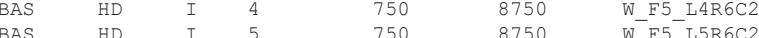

BAS 1 HD 150750

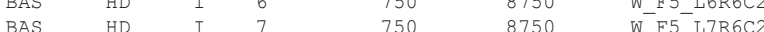

BAS HD $\quad$ I $11750 \quad 750$ W_F5_L1R8C2

$\begin{array}{llllll}\text { BAS HD } & \text { I } & 2 & 750 & 7750 & \text { W_F5_L2R8C2 }\end{array}$

$\begin{array}{llllll}\text { BAS HD } & \text { I } & 3 & 750 & 7750 & \text { W F5 L } 5 \text { 3R8C2 }\end{array}$

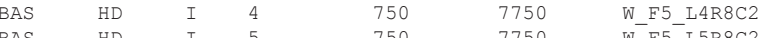

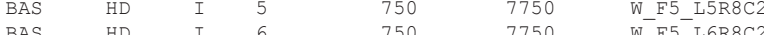

BAS HD $\mathrm{I} \quad 7 \quad 750 \quad 7750 \quad$ WEF5_L7R8C2

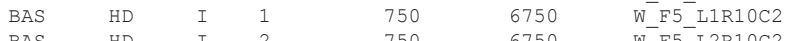

BAS HD I $20750 \quad 6750$ W_F5_L2R10C2

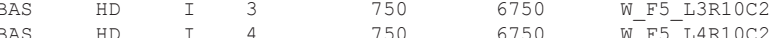

BAS HD I 5 - $750 \quad 6750-6750$

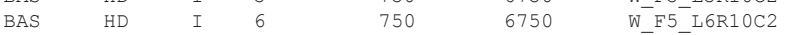

BAS HD I 7 r $750 \quad 6750$ W_F5_L7R10C2

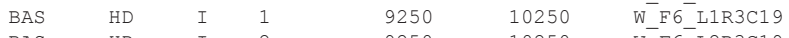

BAS HD I 20250 W_E6_L2R3C19

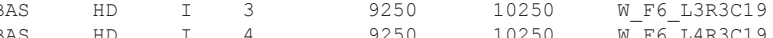

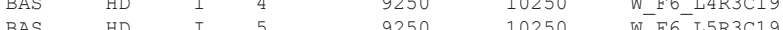

BAS HD I $6 \quad 10250$ W_F6_L6R3C19

BAS HD I 7 T $9250 \quad 10250$ W_F6_L7R3C19

$\begin{array}{llllll}\text { BAS HD } & \text { I } & 1 & 8250 & 8750 & \text { W_F6_L1R6C17 }\end{array}$

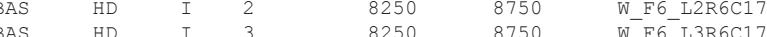

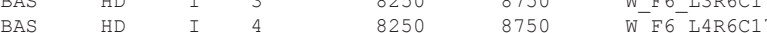

BAS HD I $6 \quad 1250 \quad 8750$ W_F6_L6R6C17 


\begin{tabular}{|c|c|c|c|c|c|}
\hline BAS & HD & I & 7 & & 8250 \\
\hline SUB & $\mathrm{HC}$ & I & & 1 & 3750 \\
\hline SUB & $\mathrm{HC}$ & I & & 2 & 3750 \\
\hline SUB & $\mathrm{HC}$ & I & & 1 & 6750 \\
\hline SUB & $\mathrm{HC}$ & I & & 2 & 6750 \\
\hline SUB & $\mathrm{HC}$ & I & & 1 & 5750 \\
\hline SUB & $\mathrm{HC}$ & I & & 1 & 8250 \\
\hline SUB & $\mathrm{HC}$ & I & 1 & & 2750 \\
\hline SUB & $\mathrm{HC}$ & I & 1 & & 2750 \\
\hline SUB & $\mathrm{HC}$ & I & 1 & & 4250 \\
\hline SUB & $\mathrm{HC}$ & I & 1 & & 4250 \\
\hline SUB & $\mathrm{HC}$ & I & 1 & & 4750 \\
\hline SUB & $\mathrm{HC}$ & I & 1 & & 5250 \\
\hline SUB & $\mathrm{HC}$ & I & 1 & & 1250 \\
\hline SUB & $\mathrm{HC}$ & I & 1 & & 1250 \\
\hline SUB & $\mathrm{HC}$ & I & 1 & & 9250 \\
\hline SUB & $\mathrm{HC}$ & I & 1 & & 9250 \\
\hline SUB & $\mathrm{HC}$ & I & 1 & & 750 \\
\hline SUB & $\mathrm{HC}$ & I & 2 & & 750 \\
\hline SUB & $\mathrm{HC}$ & I & 3 & & 750 \\
\hline SUB & $\mathrm{HC}$ & I & 4 & & 750 \\
\hline SUB & $\mathrm{HC}$ & I & 5 & & 750 \\
\hline SUB & $\mathrm{HC}$ & I & 6 & & 750 \\
\hline SUB & $\mathrm{HC}$ & I & 7 & & 750 \\
\hline SUB & $\mathrm{HC}$ & I & 1 & & 750 \\
\hline SUB & $\mathrm{HC}$ & I & 2 & & 750 \\
\hline SUB & $\mathrm{HC}$ & I & 3 & & 750 \\
\hline SUB & $\mathrm{HC}$ & I & 4 & & 750 \\
\hline SUB & $\mathrm{HC}$ & I & 5 & & 750 \\
\hline SUB & $\mathrm{HC}$ & I & 6 & & 750 \\
\hline SUB & $\mathrm{HC}$ & I & 7 & & 750 \\
\hline SUB & $\mathrm{HC}$ & I & 1 & & 750 \\
\hline SUB & $\mathrm{HC}$ & I & 2 & & 750 \\
\hline SUB & $\mathrm{HC}$ & I & 3 & & 750 \\
\hline SUB & $\mathrm{HC}$ & I & 4 & & 750 \\
\hline SUB & $\mathrm{HC}$ & I & 5 & & 750 \\
\hline SUB & $\mathrm{HC}$ & I & 6 & & 750 \\
\hline SUB & $\mathrm{HC}$ & I & 7 & & 750 \\
\hline SUB & $\mathrm{HC}$ & I & 1 & & 9250 \\
\hline SUB & $\mathrm{HC}$ & I & 2 & & 9250 \\
\hline SUB & $\mathrm{HC}$ & I & 3 & & 9250 \\
\hline SUB & $\mathrm{HC}$ & I & 4 & & 9250 \\
\hline SUB & $\mathrm{HC}$ & I & 5 & & 9250 \\
\hline SUB & $\mathrm{HC}$ & I & 6 & & 9250 \\
\hline SUB & $\mathrm{HC}$ & I & 7 & & 9250 \\
\hline SUB & $\mathrm{HC}$ & I & 1 & & 8250 \\
\hline SUB & $\mathrm{HC}$ & I & 2 & & 8250 \\
\hline SUB & $\mathrm{HC}$ & I & 3 & & 8250 \\
\hline SUB & $\mathrm{HC}$ & I & 4 & & 8250 \\
\hline SUB & $\mathrm{HC}$ & I & 5 & & 8250 \\
\hline SUB & $\mathrm{HC}$ & I & 6 & & 8250 \\
\hline SUB & $\mathrm{HC}$ & I & 7 & & 8250 \\
\hline SUB & $\mathrm{SE}$ & I & & 1 & 3750 \\
\hline SUB & $\mathrm{SE}$ & I & & 2 & 3750 \\
\hline SUB & $\mathrm{SE}$ & I & & 1 & 6750 \\
\hline SUB & $\mathrm{SE}$ & I & & 2 & 6750 \\
\hline SUB & $\mathrm{SE}$ & I & & 1 & 5750 \\
\hline SUB & $\mathrm{SE}$ & I & & 1 & 8250 \\
\hline SUB & $\mathrm{SE}$ & I & 1 & & 2750 \\
\hline SUB & $\mathrm{SE}$ & I & 1 & & 2750 \\
\hline SUB & $\mathrm{SE}$ & I & 1 & & 4250 \\
\hline SUB & $\mathrm{SE}$ & I & 1 & & 4250 \\
\hline SUB & $\mathrm{SE}$ & I & 1 & & 4750 \\
\hline SUB & $\mathrm{SE}$ & I & 1 & & 5250 \\
\hline SUB & $\mathrm{SE}$ & I & 1 & & 1250 \\
\hline SUB & $\mathrm{SE}$ & I & 1 & & 1250 \\
\hline SUB & $\mathrm{SE}$ & I & 1 & & 9250 \\
\hline SUB & $\mathrm{SE}$ & I & 1 & & 9250 \\
\hline SUB & $\mathrm{SE}$ & I & 1 & & 750 \\
\hline SUB & $\mathrm{SE}$ & I & 2 & & 750 \\
\hline SUB & $\mathrm{SE}$ & I & 3 & & 750 \\
\hline SUB & $\mathrm{SE}$ & I & 4 & & 750 \\
\hline SUB & $\mathrm{SE}$ & I & 5 & & 750 \\
\hline SUB & $\mathrm{SE}$ & I & 6 & & 750 \\
\hline SUB & $\mathrm{SE}$ & I & 7 & & 750 \\
\hline SUB & $\mathrm{SE}$ & I & 1 & & 750 \\
\hline SUB & SE & I & 2 & & 750 \\
\hline SUB & $\mathrm{SE}$ & I & 3 & & 750 \\
\hline SUB & $\mathrm{SE}$ & I & 4 & & 750 \\
\hline SUB & $\mathrm{SE}$ & I & 5 & & 750 \\
\hline SUB & $\mathrm{SE}$ & I & 6 & & 750 \\
\hline SUB & $\mathrm{SE}$ & I & 7 & & 750 \\
\hline SUB & $\mathrm{SE}$ & I & 1 & & 750 \\
\hline SUB & $\mathrm{SE}$ & I & 2 & & 750 \\
\hline SUB & $\mathrm{SE}$ & I & 3 & & 750 \\
\hline SUB & $\mathrm{SE}$ & I & 4 & & 750 \\
\hline SUB & $\mathrm{SE}$ & I & 5 & & 750 \\
\hline SUB & SE & I & 6 & & 750 \\
\hline SUB & SE & I & 7 & & 750 \\
\hline SUB & $\mathrm{SE}$ & I & 1 & & 9250 \\
\hline SUB & $\mathrm{SE}$ & I & 2 & & 9250 \\
\hline SUB & $\mathrm{SE}$ & I & 3 & & 9250 \\
\hline SUB & $\mathrm{SE}$ & I & 4 & & 9250 \\
\hline
\end{tabular}




\begin{tabular}{|c|c|c|c|c|c|}
\hline SUB & $\mathrm{SE}$ & I & 5 & & 9250 \\
\hline SUB & $\mathrm{SE}$ & I & 6 & & 9250 \\
\hline SUB & SE & I & 7 & & 9250 \\
\hline SUB & $\mathrm{SE}$ & I & 1 & & 8250 \\
\hline SUB & SE & I & 2 & & 8250 \\
\hline SUB & SE & I & 3 & & 8250 \\
\hline SUB & SE & I & 4 & & 8250 \\
\hline SUB & $\mathrm{SE}$ & I & 5 & & 8250 \\
\hline SUB & $\mathrm{SE}$ & I & 6 & & 8250 \\
\hline SUB & SE & I & 7 & & 8250 \\
\hline SUB & $\mathrm{SE}$ & I & 1 & & \\
\hline SUB & SV & I & & 1 & 3750 \\
\hline SUB & SV & I & & 2 & 3750 \\
\hline SUB & SV & I & & 1 & 6750 \\
\hline SUB & SV & I & & 2 & 6750 \\
\hline SUB & SV & I & & 1 & 5750 \\
\hline SUB & SV & I & & 1 & 8250 \\
\hline SUB & SV & I & 1 & & 2750 \\
\hline SUB & SV & I & 1 & & 2750 \\
\hline SUB & SV & I & 1 & & 4250 \\
\hline SUB & SV & I & 1 & & 4250 \\
\hline SUB & SV & I & 1 & & 4750 \\
\hline SUB & SV & I & 1 & & 5250 \\
\hline SUB & SV & I & 1 & & 1250 \\
\hline SUB & SV & I & 1 & & 1250 \\
\hline SUB & SV & I & 1 & & 9250 \\
\hline SUB & SV & I & 1 & & 9250 \\
\hline SUB & SV & I & 1 & & 750 \\
\hline SUB & SV & I & 2 & & 750 \\
\hline SUB & SV & I & 3 & & 750 \\
\hline SUB & SV & I & 4 & & 750 \\
\hline SUB & SV & I & 5 & & 750 \\
\hline SUB & SV & I & 6 & & 750 \\
\hline SUB & SV & I & 7 & & 750 \\
\hline SUB & SV & I & 1 & & 750 \\
\hline SUB & SV & I & 2 & & 750 \\
\hline SUB & SV & I & 3 & & 750 \\
\hline SUB & SV & I & 4 & & 750 \\
\hline SUB & SV & I & 5 & & 750 \\
\hline SUB & SV & I & 6 & & 750 \\
\hline SUB & SV & I & 7 & & 750 \\
\hline SUB & SV & I & 1 & & 750 \\
\hline SUB & SV & I & 2 & & 750 \\
\hline SUB & SV & I & 3 & & 750 \\
\hline SUB & SV & I & 4 & & 750 \\
\hline SUB & SV & I & 5 & & 750 \\
\hline SUB & SV & I & 6 & & 750 \\
\hline SUB & SV & I & 7 & & 750 \\
\hline SUB & SV & I & 1 & & 9250 \\
\hline SUB & SV & I & 2 & & 9250 \\
\hline SUB & SV & I & 3 & & 9250 \\
\hline SUB & SV & I & 4 & & 9250 \\
\hline SUB & SV & I & 5 & & 9250 \\
\hline SUB & SV & I & 6 & & 9250 \\
\hline SUB & SV & I & 7 & & 9250 \\
\hline SUB & SV & I & 1 & & 8250 \\
\hline SUB & SV & I & 2 & & 8250 \\
\hline SUB & SV & I & 3 & & 8250 \\
\hline SUB & SV & I & 4 & & 8250 \\
\hline SUB & SV & I & 5 & & 8250 \\
\hline SUB & SV & I & 6 & & 8250 \\
\hline SUB & SV & I & 7 & & 8250 \\
\hline SUB & SV & I & 1 & & 750 \\
\hline SUB & $\mathrm{SB}$ & I & 1 & & 750 \\
\hline SFR & so & C & & 1 & 15 \\
\hline SER & SI & C & & 1 & 2 \\
\hline SER & So & C & & 1 & 2 \\
\hline SFR & SI & C & & 1 & 2 \\
\hline SER & so & C & & 1 & 2 \\
\hline SER & SI & C & & 1 & 6 \\
\hline SFR & so & C & & 1 & 6 \\
\hline SFR & SI & C & & 1 & 6 \\
\hline SFR & so & C & & 1 & 6 \\
\hline SFR & SI & C & & 1 & 11 \\
\hline SFR & so & C & & 1 & 11 \\
\hline SFR & SI & C & & 1 & 3 \\
\hline SFR & so & C & & 1 & 3 \\
\hline SFR & SI & C & & 1 & 2 \\
\hline SFR & so & C & & 1 & 2 \\
\hline SFR & SI & C & & 1 & 7 \\
\hline $\mathrm{SFR}$ & so & C & & 1 & 7 \\
\hline SFR & SI & C & & 1 & 6 \\
\hline SER & so & C & & 1 & 6 \\
\hline $\mathrm{SFR}$ & SI & C & & 1 & 13 \\
\hline SFR & so & C & & 1 & 13 \\
\hline SFR & so & C & & 1 & 9 \\
\hline SER & SI & C & & 1 & 10 \\
\hline SFR & so & C & & 1 & 11 \\
\hline SFR & SI & C & & 1 & 11 \\
\hline SFR & so & C & & 1 & 12 \\
\hline SFR & SI & C & & 1 & 12 \\
\hline SFR & so & C & & 1 & 14 \\
\hline & SI & C & & 1 & 14 \\
\hline
\end{tabular}




\section{Zonebudget Input File}

FMP waterbalance.out csv2

OWHM EXI CBC.out

Watêr Balance Regions -- 8 Farms

$\dot{\mathrm{A}}$

Zonebudget (ZON) Input Data Sets - FMPzone.zon

72320

EXTERNAL () -10

../postprocessor_input/FID1. IN

../postprocessor_input/FID2.IN

EXTERNAL () -10

../postprocessor_input/FID3.IN

EXTERNAL () -10

../postprocessor_input/FID4.IN

$\begin{array}{ll}\text { EXTERNAL () } & -10 \\ \text {../postprocessor_input/FID5. IN }\end{array}$

EXTERNAL () -10

../postprocessor_input/FID6.IN

EXTERNAL

$\begin{array}{llllllll}1 & 2 & 3 & 4 & 5 & 6 & 7 & 8\end{array}$

OWHM EX1 HYD.Sav

HYDFMT17 Input Data Sets - hydfmt_bat.in

OWHM_EXI_HYDMOD_OUT

$\mathrm{D}$
$\mathrm{Y}$

$\mathrm{Y}$
0

I

$2000.0 \quad 304.366022$

$2003.2 \quad 304.366022$

$2003.4 \quad 304.366022$

$2003.5 \quad 304.366022$

$2003.6 \quad 304.366022$

2003.6304 .366022

2003.8304 .366022

$2003.9-304.366022$

$2005.0 \quad 304.36602$

$2007.0 \quad 304.366022$

$2010.0 \quad 304.366022$

EXAMPLE TABFILE FOR GHB [GHBTAB111.txt] \#TIME, BHEAD

0.900000

1.100000
31.320000

31.320000

31.520000

61.740000

61.940000

92.160000

92.360000

122.580000

122.780000

153.000000

153.200000

183.420000

183.620000

213.840000

214.040000

244.260000

244.460000

274.680000

274.880000

305.100000

305.30000

335.520000

335.720000

365.940000

366.140000

396.360000

396.560000

426.780000

426.980000

457.200000

457.400000

487.620000

487.820000

518.040000

518.240000

548.46000

548.66000

578.880000

579.080000

609.300000

609.500000

639.720000

639.920000

670.140000

670.340000

700.560000

700.760000

10000.

10000 .

10000 .

10000 .

10000 .

10000 .

10000 .

10000

10000 .

10000

10000

.

10000

10000

10000 .

10000

10000

10000 .

10000 .

10000.

10000

10000

10000

10000 .

10000 .

10000

5000 .

5000 .

5000 .

5000 .

5000 .

5000 .

5000.

5000 .

5000 .

5000 .

5000 .

5000 .

5000 .

5000 .

5000.

5000 .

5000 .

5000 .

5000 .

EXAMPLE TABFILE FOR SFR [SFR_SEG_01.txt] 


\begin{tabular}{|c|c|}
\hline 730.980000 & 5000 . \\
\hline 731.180000 & 10000 \\
\hline 761.400000 & 10000 \\
\hline 761.600000 & 10000 \\
\hline 791.820000 & 10000 \\
\hline 792.020000 & 10000 \\
\hline 822.240000 & 10000 \\
\hline 822.440000 & \\
\hline 852.660000 & 10000 \\
\hline 852.860000 & 10000 \\
\hline 883.080000 & \\
\hline 883.280000 & 10000 \\
\hline 913.500000 & 10000 \\
\hline 913.700000 & 10000 \\
\hline 943.920000 & 10000 \\
\hline 944.120000 & 10000 \\
\hline 974.340000 & \\
\hline 974.540000 & 10000 \\
\hline 1004.760000 & 10000 \\
\hline 1004.960000 & \\
\hline 1035.180000 & 10000 \\
\hline 1035.380000 & 10000 \\
\hline 1065.600000 & \\
\hline 1065.800000 & 10000 \\
\hline 1096.020000 & 10000 \\
\hline 1096.220000 & 5000 . \\
\hline 1126.440000 & 5000 . \\
\hline 1126.640000 & 5000 . \\
\hline 1156.860000 & 5000. \\
\hline 1157.060000 & 5000 . \\
\hline 1187.280000 & 5000. \\
\hline 1187.480000 & 5000. \\
\hline 1217.700000 & 5000 . \\
\hline 1217.900000 & 5000. \\
\hline 1248.120000 & 5000 . \\
\hline 1248.320000 & 5000 . \\
\hline 1278.540000 & 5000 . \\
\hline 1278.740000 & 5000. \\
\hline 1308.960000 & 5000 . \\
\hline 1309.160000 & 5000 . \\
\hline 1339.380000 & 5000 . \\
\hline 1339.580000 & 5000 . \\
\hline 1369.800000 & 5000 . \\
\hline 1370.000000 & 5000 . \\
\hline 1400.220000 & 5000 . \\
\hline 1400.420000 & 5000 . \\
\hline 1430.640000 & 5000 . \\
\hline 1430.840000 & 5000 . \\
\hline 1461.060000 & 5000 . \\
\hline 1461.260000 & 10000 \\
\hline 1491.480000 & 10000 \\
\hline 1491.680000 & 10000 \\
\hline 1521.900000 & 10000 \\
\hline 1522.100000 & 10000 \\
\hline 1552.320000 & 10000 \\
\hline 1552.520000 & 10000 \\
\hline 1582.740000 & 10000 \\
\hline 1582.940000 & 10000 \\
\hline 1613.160000 & 10000 \\
\hline 1613.360000 & 10000 \\
\hline 1643.580000 & 10000 \\
\hline 1643.780000 & 10000 \\
\hline 1674.000000 & 10000 \\
\hline 1674.200000 & 10000 \\
\hline 1704.420000 & 10000 \\
\hline 1704.620000 & 10000 \\
\hline 1734.840000 & 10000 \\
\hline 1735.040000 & 10000 \\
\hline 1765.260000 & 10000 \\
\hline 1765.460000 & 10000 \\
\hline 1795.680000 & 10000 \\
\hline 1795.880000 & 10000 \\
\hline 1826.100000 & 10000 \\
\hline 1826.300000 & 5000. \\
\hline 1856.520000 & 5000 . \\
\hline 1856.720000 & 5000 . \\
\hline 1886.940000 & 5000 . \\
\hline 1887.140000 & 5000 . \\
\hline 1917.360000 & 5000 . \\
\hline 1917.560000 & 5000. \\
\hline 1947.780000 & 5000 . \\
\hline 1947.980000 & 5000 . \\
\hline 1978.200000 & 5000 . \\
\hline 1978.400000 & 5000. \\
\hline 2008.620000 & 5000 . \\
\hline 2008.820000 & 5000. \\
\hline 2039.040000 & 5000 . \\
\hline 2039.240000 & 5000 . \\
\hline 2069.460000 & 5000 . \\
\hline 2069.660000 & 5000 . \\
\hline 2099.880000 & 5000. \\
\hline 2100.080000 & 5000 . \\
\hline 2130.300000 & 5000. \\
\hline 2130.500000 & 5000. \\
\hline 2160.720000 & \\
\hline & \\
\hline
\end{tabular}




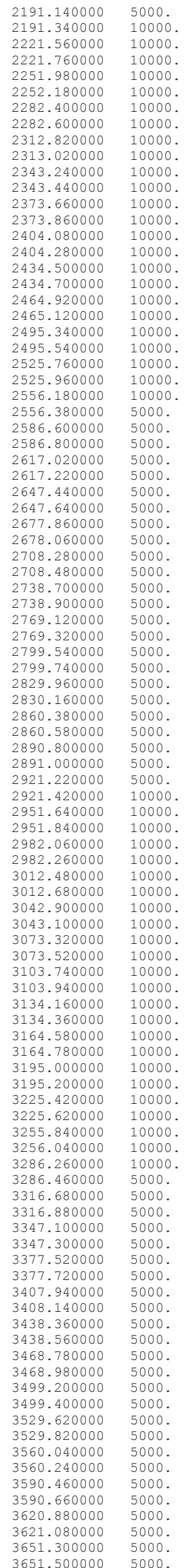


Prepared by the Sacramento Publishing Service Center.

For more information concerning this report, contact:

Director

U.S. Geological Survey

California Water Science Center

6000 J Street, Placer Hall

Sacramento, CA 95819

dc_ca@usgs.gov

or visit our Web site at:

http://ca.water.usgs.gov 


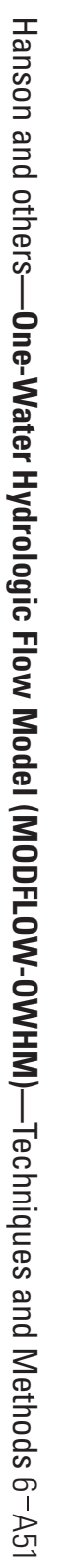

